\title{
Widespread polytypic species or complexes of local species? Revising bumblebees of the subgenus Melanobombus world-wide (Hymenoptera, Apidae, Bombus)
}

\author{
Paul H. WILLIAMS ${ }^{1, *}$, Dorjsuren ALTANCHIMEG ${ }^{2}$, Alexandr BYVALTSEV ${ }^{3}$, \\ Roland DE JONGHE ${ }^{4}$, Saleem JAFFAR ${ }^{5}$, George JAPOSHVILI ${ }^{6}$, Sih KAHONO ${ }^{7}$, \\ Huan LIANG ${ }^{8}$, Maurizio MEI ${ }^{9}$, Alireza MONFARED ${ }^{10}$, Tshering NIDUP ${ }^{11}$, Rifat RAINA ${ }^{12}$, \\ Zongxin REN ${ }^{13}$, Chawatat THANOOSING ${ }^{14}$, Yanhui ZHAO $^{15}$ \& Michael C. ORR ${ }^{16}$ \\ ${ }^{1,14}$ Natural History Museum, Cromwell Road, London SW7 5BD, UK. \\ ${ }^{2}$ Institute of General and Experimental Biology, Peace Avenue 54b, Ulaanbaatar 13330, Mongolia. \\ ${ }^{3}$ Novosibirsk State University, ul. Pirogova 2, Novosibirsk, 630090 Russia. \\ ${ }^{4}$ Langstraat 105, B-2260 Westerlo, Belgium. \\ ${ }^{5}$ South China Agricultural University, Guangzhou 510642, China. \\ ${ }^{6}$ Agricultural University of Georgia, 240 Agmashenebli Alley, Tbilisi, Georgia. \\ ${ }^{7}$ Indonesian Institute of Sciences (LIPI), Jakarta, Indonesia. \\ ${ }^{8,13,15}$ Kunming Institute of Botany (Chinese Academy of Sciences), 132 Lanhei Road, Kunming, \\ Yunnan 650201, China. \\ ${ }^{9}$ Università di Roma 'Sapienza', Piazzale Valerio Massimo 6, Roma 00162, Italy. \\ ${ }^{10}$ Yasouj University, Zirtol, Yasouj, Iran. \\ ${ }^{11}$ Sherubtse College, Royal University of Bhutan, Trashigang, Bhutan. \\ ${ }^{12}$ Zoological Survey of India, Pali Road, Jodhpur 342005, Rajasthan, India. \\ ${ }^{16}$ Institute of Zoology (Chinese Academy of Sciences), 1 Beichen West Road, Chaoyang, \\ Beijing 100101, China.

\footnotetext{
*Corresponding author: paw@nhm.ac.uk

${ }^{2}$ Email: altanchimegd@mas.ac.mn

${ }^{3}$ Email: byvam@yandex.ru

${ }^{4}$ Email: roland.de.jonghe@telenet.be

${ }^{5}$ Email: saleemjaffar@stu.scau.edu.cn

${ }^{6}$ Email: g.japoshvili@agruni.edu.ge

${ }^{7}$ Email: sihkahono@gmail.com

${ }^{8}$ Email: lianghuan@mail.kib.ac.cn

${ }^{9}$ Email: maurizio.mei@uniroma1.it

${ }^{10}$ Email: alirezamonfared1@yahoo.com

${ }^{11}$ Email: tsheringnidup@sherubtse.edu.bt

${ }^{12}$ Email: rifat72001@rediffmail.com

${ }^{13}$ Email: renzongxin@mail.kib.ac.cn

${ }^{14}$ Email: c.thanoosing@nhm.ac.uk

${ }^{15}$ Email: zhaoyanhui@mail.kib.ac.cn

${ }^{16}$ Email: michael.christopher.orr@gmail.com
} 


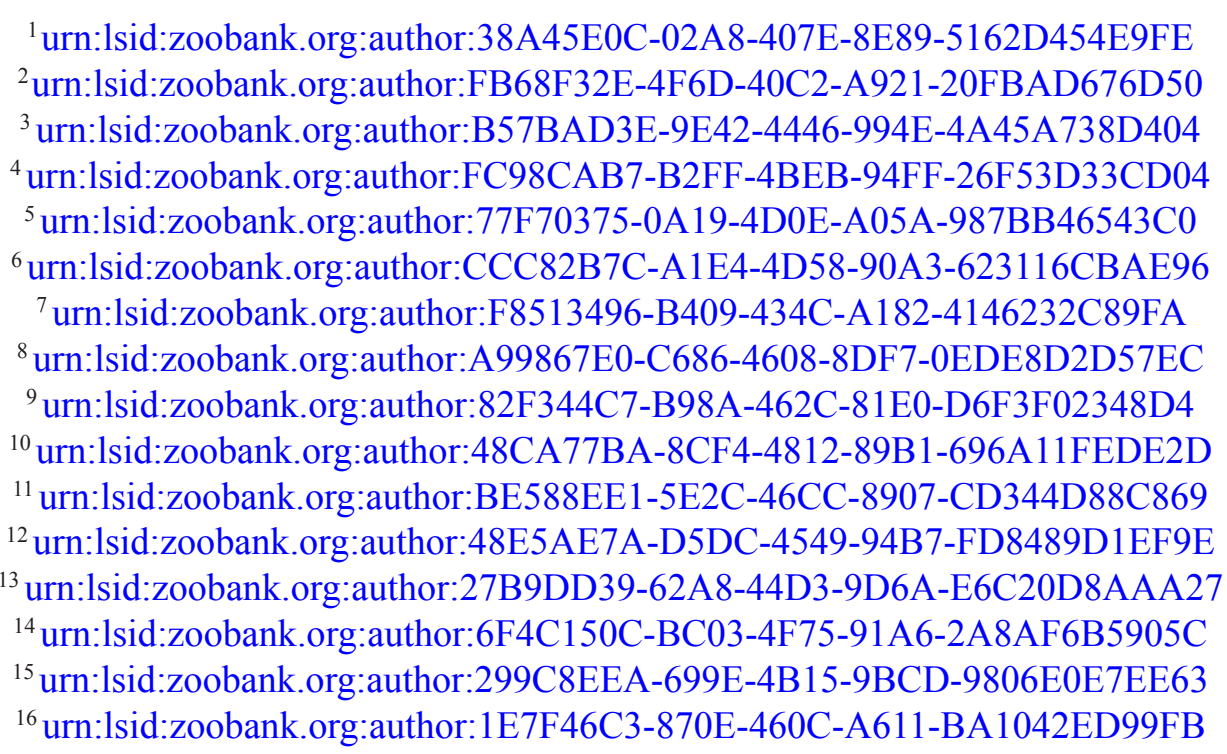

Abstract. Species are often presumed to be apparent in nature, but in practice they may be difficult to recognise, especially when viewed across continents rather than within a single site. Coalescent-based Poisson-tree-process (PTP) models applied to fast-evolving genes promise one quantitative criterion for recognising species, complete with the estimates of uncertainty that are required of a scientific method. Such methods face challenges especially in discerning between widespread polytypic species and complexes of closely related, restricted-range species. In particular, 'over-sampling' of many closely related individuals within one species could risk causing groups of less closely-related individuals within other species appearing relatively more distinct and consequently could risk them being interpreted falsely as separate species. Some of the most persistent taxonomic problems among bumblebees (genus Bombus Latreille, 1802) are within the subgenus Melanobombus von Dalla Torre, 1880. For a global revision of Melanobombus species, we use COI barcodes and seek to reduce the risk from localised over-sampling by filtering the data to include only unique haplotypes. Unique haplotypes give more conservative results than unfiltered data, but still increase the number of species in comparison with recent morphological treatments. After integrative assessment of COI coalescents in comparison with morphological groups, the number of accepted species shows a non-linear increase with sample size that plateaus to an increase of $47 \%$ (to 25 species) compared with a previous estimate (of 17) based on morphology alone. For the most widespread and variable species-complexes, our revised species improve the match to the patterns expected of species, both for genetic divergence-with-distance and for sympatry, leading to three main inferences. (1) The particularly widespread polytypic Bombus sichelii Radoszkowski, 1859, is a single species. (2) We detect two candidates for species within previous broad concepts of each of the former B. lapidarius (Linnaeus, 1758), B. miniatus Bingham, 1897, and B. rufofasciatus Smith, 1852. Within B. lapidarius s. lat. we find insufficient evidence to corroborate the candidate species, with no coalescent or morphological support for a recent claim for a separate species, B. bisiculus Lecocq, Biella, Martinet \& Rasmont, 2019 described from southern Italy, but rather we find a weak and uncorroborated coalescent for a different and much broader group of samples from across southeastern Europe but excluding Turkey. Within the former broad concepts of B. miniatus s. lat. and $B$. rufofasciatus s. lat. the coalescent evidence is stronger and subtle evidence from morphology corroborates recognising $B$. miniatus s. str. and B. eurythorax Wang, 1892 stat. rev. as separate species as well as $B$. rufofasciatus s. str. and B. prshewalskyi Morawitz, 1880 stat. rev. as separate species. (3) Our coalescent and morphological results 'split' more clearly what has long been interpreted as a single polytypic $B$. keriensis Morawitz, 1887, s. lat., by supporting novel concepts of the restrictedrange species: B. alagesianus Reinig, 1930 stat. rev., B. incertoides Vogt, 1911 stat. rev., B. keriensis s. str., B. qilianensis sp. nov., B. separandus Vogt, 1909 stat. rev., and B. tibeticus sp. nov. A lectotype 
is designated for the name $B$. keriensis and a neotype is designated for the name B. alagesianus. We estimate the phylogeny of Melanobombus species by including three slower-evolving genes to provide more evidence for deeper relationships, to estimate the time calibration of this phylogeny, and to estimate ancestral distributions, all within a Bayesian framework. We provide the first keys for identifying all of the species of Melanobombus.

Keywords. Barcode, bumblebee, coalescent, distribution, species.

Williams P.H., Altanchimeg D., Byvaltsev A., De Jonghe R., Jaffar S., Japoshvili G., Kahono S., Liang H., Mei M., Monfared, A., Nidup T., Raina R., Ren Z., Thanoosing C., Zhao Y. \& Orr M.C. 2020. Widespread polytypic species or complexes of local species? Revising bumblebees of the subgenus Melanobombus world-wide (Hymenoptera, Apidae, Bombus). European Journal of Taxonomy 719: 1-120. https://doi.org/10.5852/ejt.2020.719.1107

\section{Introduction}

It may be the current paradigm that biological diversity is divided into separate species (Mallet 2013; Schluter \& Pennell 2017), but the 'species problem' is an admission that it can be difficult both in theory and in practice to recognise the separations among species (Cracraft 1989). If there is sometimes a lack of clarity in agreed ideas of what species are, there is often a much more severe lack of the observational data needed to apply those ideas. Our study reviews in outline the variety and history of different species concepts that have been applied to bumblebees, genus Bombus Latreille, 1802. We then examine the application of one of the currently most popular species concepts to a group of bumblebees that are distributed especially broadly across the largest continent, Eurasia, and which encompass substantial but poorly understood variation: the subgenus Melanobombus von Dalla Torre, 1880 . We are concerned particularly with how to discriminate between (1) widespread polytypic species and (2) widespread complexes of narrowly distributed monotypic species.

\section{Bumblebees as a model group for studying the nature of species}

Bumblebees have long been claimed as a model group of organisms for the study of what species are and how to recognise them (Vogt 1909, 1911; Reinig 1939). Reasons for this include that these insects are large, common, and very obviously variable in their colour patterns, while being very well represented in collections. Bumblebees are a valuable example for biodiversity and conservation studies because they are unusual for having their greatest diversity in subarctic and subalpine biomes rather than in the tropics (see global richness maps with the underlying information on species enumerated in Williams 1998). Bumblebees are also economically some of the most important pollinators of crops in temperate regions, worth billions of dollars annually for their agricultural pollination services, and among the few bees that are relatively easily managed for pollination (Dias et al. 1999; Winter et al. 2006; Goulson 2010). The present study seeks to clarify the species in one group of bumblebees, the subgenus Melanobombus, in an effort to contribute towards a better foundation for other areas of investigation, including conservation. We choose to focus on bumblebees of Melanobombus because this group includes several species complexes that are each widely distributed and to some extent vary in parallel. Species of Melanobombus in its recently expanded broad sense (Williams et al. 2008) have long been known to be widespread throughout Europe and Asia as well as occurring in the Atlas mountains of North Africa (Skorikov 1923; Reinig 1935). Monophyly of Melanobombus in this sense is supported by an estimate of phylogeny including nearly all bumblebee species (Cameron et al. 2007) that is based on five genes (nuclear opsin, EF-1 $\alpha$, arginine kinase, PEPCK, and the mitochondrial 16S ribosomal RNA gene).

\section{Outline history of species concepts as applied to Melanobombus}

The history of bumblebee taxonomy can be considered to have shown three principal phases, each characterised by an emphasis on a different species concept and a different character set. 
In the first phase, from Linnaeus (1758) up until the late nineteenth century, bumblebee species were usually viewed as typological classes, which were described with an emphasis on differences in the colour patterns of the 'hair'. These colour patterns are often especially bright and with strongly contrasting bands in the subgenus Melanobombus (Figs 1-6). An early example of the use of colour pattern to describe a bumblebee species is Linnaeus (1758) short description of Apis lapidaria as: 'A.[pis] hirfuta atra, ano fulvo' (hairy black bee with an orange tail). This species was subsequently designated as the type-species of the subgenus Melanobombus by Sandhouse (1943) (the later subgeneric names Lapidariobombus Vogt, 1911, Kozlovibombus Skorikov, 1923, Rufipedibombus Skorikov, 1923, Atrocinctobombus Skorikov, 1933, Tanguticobombus Pittioni, 1939, and Festivobombus Tkalců, 1972, are now considered junior synonyms: Williams et al. 2008). Over the next century, descriptions of other Melanobombus species, including Bombus sichelii Radoszkowski, 1859, and B. keriensis Morawitz, 1887 , continued to follow a typological approach in that they consisted of descriptions of a single colour pattern of the hair, usually without reference to any variation (Klug 1807; Smith 1852a, 1852b, 1861; Morawitz 1880, 1881, 1887, 1890; Bingham 1897; e.g., Table 1).

By the twentieth century, during a second phase, the polytypic species concept was beginning to be adopted for bumblebees. This concept emphasised an increasing significance for morphological character states of exoskeleton shape and surface sculpturing as indicating species, combined with a recognition that colour-pattern characters could vary within species. Across biology a more nuanced morphological concept of species had been developing during the nineteenth century (e.g., Darwin 1859) because it had become apparent that in some characters there can be much variation within species. For butterflies this observation had become encapsulated in the idea of polytypic species (Wallace 1865). Consequently, in the second phase of bumblebee taxonomy, the idea of species of similar exoskeleton shape that can at the same time be polytypic for colour pattern both locally and between different geographical regions began to be applied by authors such as Radoszkowski $(1883)$ and $\operatorname{Vogt}(1909,1911)$. An important factor in this development was the realisation that although bumblebees may be relatively 'morphologically monotonous' in many female shape characters (Michener 2000, at least compared with the bee tribes Euglossini Latreille, 1802 and Meliponini Lepeletier, 1836), it was recognised (Radoszkowski 1883) that bumblebee male genitalia can often show evidence of more discrete morphological species. Unfortunately, the polytypic species concept was not applied uniformly by all authors. Some authors continued to describe bumblebee species primarily from differences in colour pattern alone, although often in comparisons that included only those other species that (implicitly) had the most similar morphology. For the subgenus Melanobombus, many publications now accepted that colour-pattern variation occurred within species (Skorikov 1910a, 1914a, 1914b, 1931, 1933b; Richards 1928b, 1930; Frison 1934). The most substantial re-assessment for Melanobombus in this period came with Reinig's detailed studies of colour pattern and morphology (Reinig 1930, 1935, 1939), which were based in part on his experience from collecting during the 1928 Alai-Pamir expedition. Reinig's studies of Melanobombus subsumed many earlier taxa (some originally described as separate species) within broader concepts of species, for example within what were considered by him to be three widespread polytypic species: B. lapidarius s. lat., B. sichelii s. lat., and $B$. keriensis s. lat. (Table 1). Reinig's supporting evidence came from what he interpreted as morphological similarity in combination with often continuous clines of variation in colour pattern within each of these complexes, together with a lack of hybrids or intermediates between the three complexes where they occur in proximity in the region of the Caucasus mountains. From a morphological re-examination of some of these bees from Europe and from in and around Kashmir (Williams 1991), Reinig's arguments continued to appear convincing and this explicitly influenced a later interpretation of these species (Williams 1998: 91). A concept that species in general should be recognised from their interbreeding populations had been developing during the twentieth century (Mayr 1963). However, despite its apparently simple appeal, the translation of this 'biological' species concept into operational criteria for taxonomy was severely problematic (Mallet 2013). One attempt to solve this was by examining evidence for 'specific-mate-recognition systems' (Paterson 1985). This approach has 


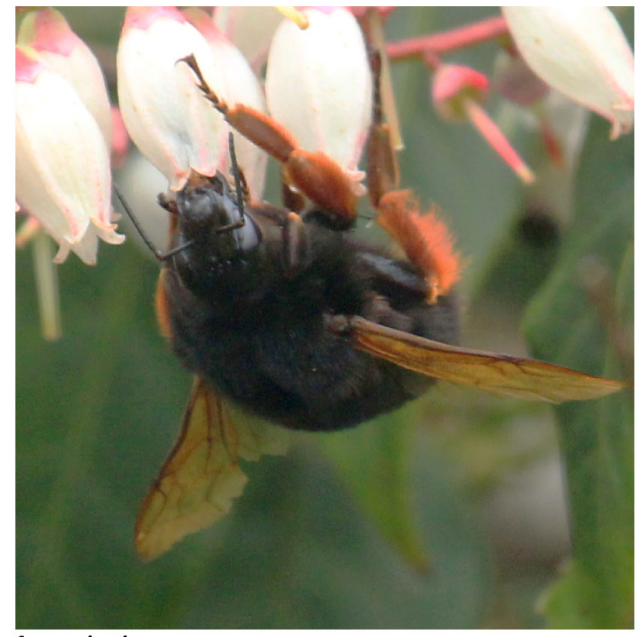

1 eximius

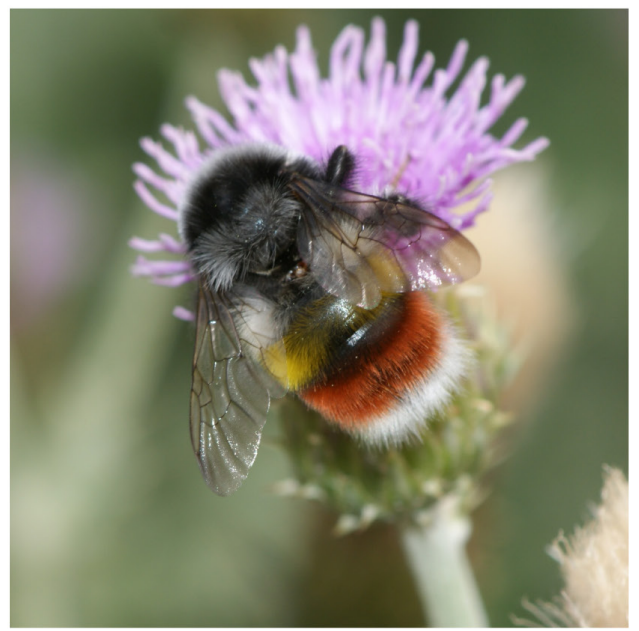

3 prshewalskyi

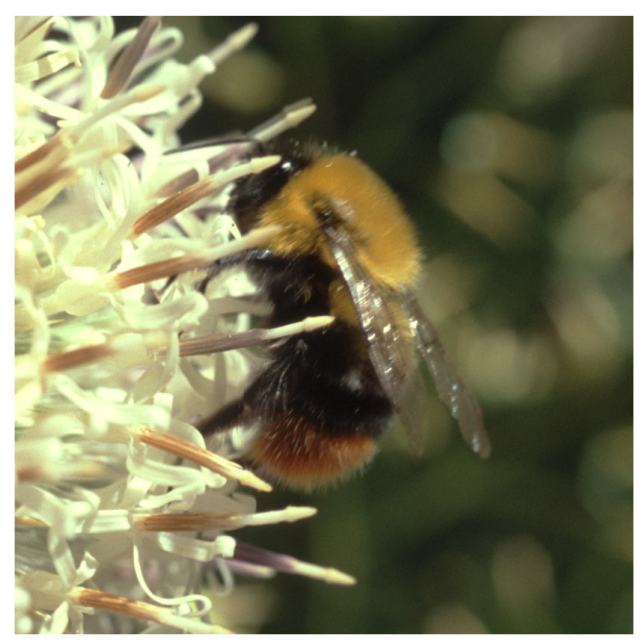

5 semenovianus

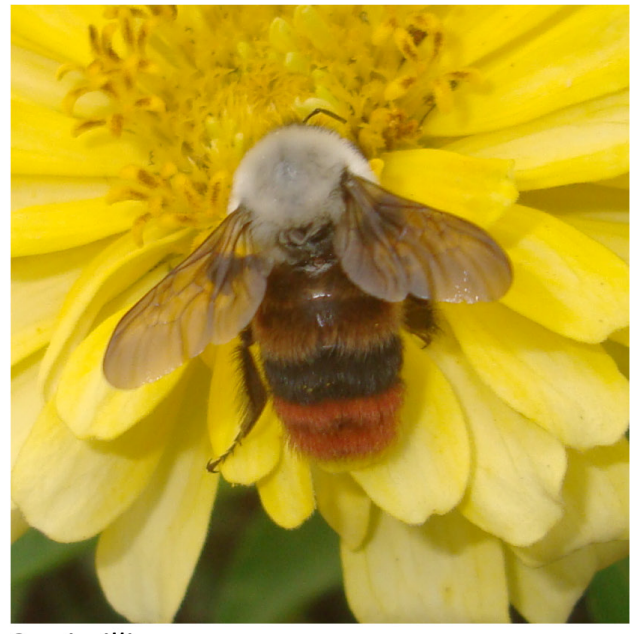

2 simillimus

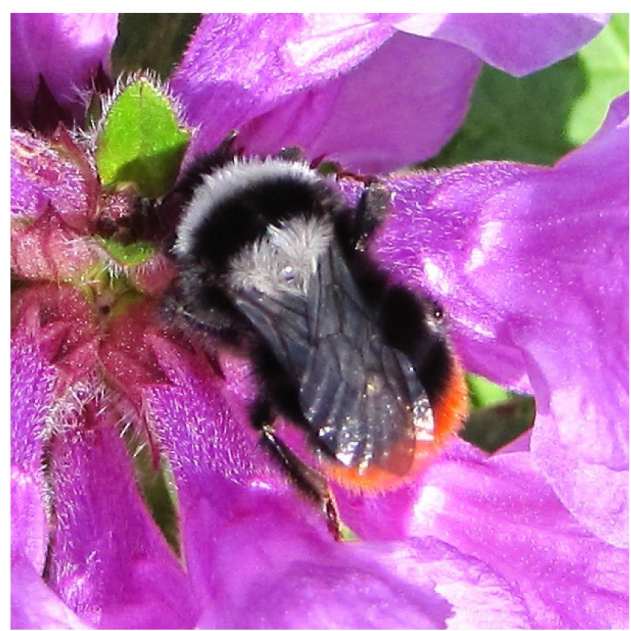

4 eriophorus

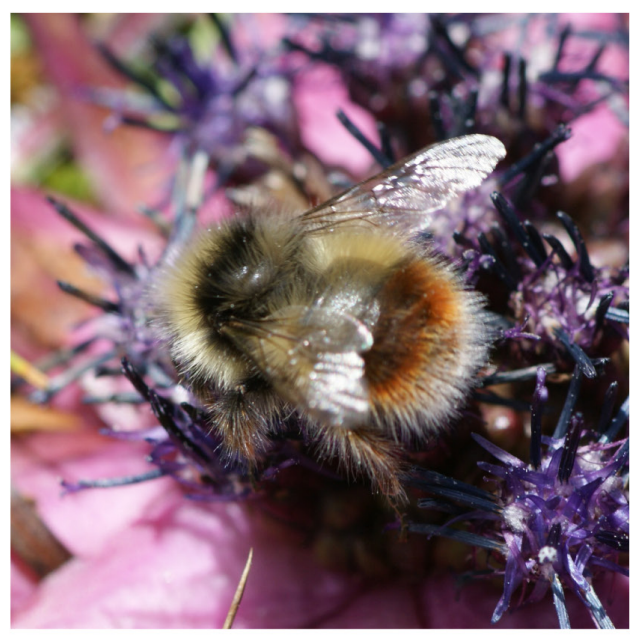

6 ladakhensis

Figs 1-6. Individuals of the subgenus Melanobombus von Dalla Torre, 1880 (with photo credits). 1. Bombus eximius Smith, 1852, queen, Thailand (CT). 2. B. simillimus Smith, 1852, worker, IndiaKashmir (RR). 3. B. prshewalskyi Morawitz, 1880, worker, China-Gansu (PW). 4. B. eriophorus Klug, 1807, queen, Georgia (I. Popov). 5. B. semenovianus (Skorikov, 1914), male, India-Kashmir (PW). 6. B. ladakhensis Richards, 1928, male, China-Gansu (PW). Some images reversed. 
Table 1. Taxa interpreted as species for three species-complexes (left) before Reinig (1935), by Reinig (1935), and from the integrated assessment here. (Note that the taxa qilianensis and tibeticus are not equivalent to the taxa kozlovi and tenellus.)

\begin{tabular}{llll}
\hline Species complex & $\begin{array}{l}\text { Taxa accepted as separate } \\
\text { species prior to Reinig (1935)* }\end{array}$ & $\begin{array}{l}\text { Species according to } \\
\text { Reinig (1935) }\end{array}$ & Species recognized here \\
\hline lapidarius-complex & $\begin{array}{l}\text { caucasicus } \\
\text { eriophorus } \\
\text { lapidarius }\end{array}$ & lapidarius & $\begin{array}{l}\text { eriophorus } \\
\text { lapidarius }\end{array}$ \\
sichelii-complex & alticola & sichelii & sichelii \\
& cazurroi & & \\
& sichelii & & \\
& verticiflavus & keriensis & alagesianus \\
keriensis-complex & alagesianus & & incertoides \\
& incertoides & & keriensis \\
& keriensis & qilianensis sp. nov. \\
& kozlovi & & separandus \\
& separandus & & tibeticus sp. nov. \\
\hline
\end{tabular}

* By their original authors or by Skorikov (1923), Richards (1930). For details of authors and dates of description see the lists of names in the text.

been applied to bumblebees, either by comparing contrasting male mate-searching behaviours (Williams 1991) or by comparing the composition of male cephalic labial gland secretions (CLGS), components of which are believed to function as sex pheromones (Bertsch et al. 2005; Lecocq et al. 2015; Brasero et al. 2017). However, interpreting a lack of difference in CLGS composition as indicating that bees are conspecific may be unreliable, either if species were prevented from co-occurring after divergence so that there can be no selection for divergence in CLGS, or if there were some other divergent component to mate-searching behaviour that prevented them from interbreeding (discussed in De Meulemeester 2012; Williams et al. 2015b, 2019; Brasero et al. 2017).

In the present century, bumblebee taxonomy has entered a third phase, in which species are often viewed as evolutionarily independent lineages in the sense of de Queiroz (2007). This has coincided with an increasing emphasis on support from molecular evidence. Here, we focus on DNA evidence, because this is the most widely used and most thoroughly understood (Woodard et al. 2015). DNA can provide many data that are easily gathered and which can relate to all levels of variation. Applying genetic methods has led to a new wave of 'splitting' of bumblebee species, as genetically distinct (but sometimes morphologically cryptic or near-cryptic) populations within the broader morphologicallydiagnosed taxon complexes have become interpreted as separate species (e.g., Bertsch et al. 2005; Williams et al. 2011, 2012a, 2015b, 2016; Ratnasingham \& Hebert 2013; Lecocq et al. 2014; Potapov et al. 2017; Martinet et al. 2018b). This has recently included proposing one new species within the subgenus Melanobombus (Lecocq et al. 2013, 2015, 2019).

\section{Bumblebee species recognised from DNA}

DNA sequence data were used initially to identify prospective species as groups with reciprocal monophyly and strong genetic divergence, which is represented in tree diagrams by long branches (Bertsch et al. 2005, 2010; Bertsch 2010; Williams et al. 2011, 2012b). However, simple quantitative 
thresholds for genetic divergence were found to be insufficient for assessing bumblebee species, because the genetic divergence is sometimes greater within species than it is between species (Williams et al. 2012a), as had been found previously in other groups of organisms (Meyer \& Paulay 2005; Meier et al. 2006; B.C. Schmidt \& Sperling 2008).

Speciation may be associated most directly with gene coalescents when they can be identified at the transitions from recombinant lineages to evolutionarily-independent lineages, because these coalescents are then direct evidence of the beginnings of evolutionary independence between lineages. Such transitions can be discovered de novo from the changing branching rates within phylogenetic trees for fast-evolving genes by using either general mixed Yule-coalescent models (GMYC: Monaghan et al. 2005) or Poisson-tree-process models (PTP: Zhang et al. 2013). Under ideal conditions with sufficient sampling, species are expected to appear in trees as groups with short internal branches but with longer external branches between them. Coalescent species have been found to show a $77 \%$ correspondence to interbreeding species for Drosophila fruit flies, one of the groups studied most intensively in speciation studies (Campillo et al. 2020).

The most important assumptions required to be able to use GMYC and PTP methods for identifying species coalescents (Papadopoulou et al. 2008, 2009; Lohse 2009; Fujisawa \& Barraclough 2013) are matched well by bumblebees, which should place bumblebees among the more suitable subjects for their application, i.e.: (1) most bumblebees have a short (annual) generation time (Goulson 2010) relative to the ages of all of their species (estimates in Hines 2008); (2) effective genetic population sizes may be low despite the abundance of the foraging individuals that can be sampled, because bumblebees are social and it is the colonies that are the 'genetic individuals' (Zayed \& Packer 2005), so that these genetic individuals are rarer by 1-3 orders of magnitude than the foragers; and yet (3) bumblebee foragers tend to be relatively well sampled in all continents where they occur because they are large, slowflying, and brightly coloured, which has attracted attention and collecting by many biologists (Williams 1998). Problems such as paralogy and incomplete lineage sorting can be tested by comparing among trees obtained for multiple genes (Maddison \& Knowles 2006; Knowles \& Carstens 2007). Crucially, sampling must be representative to estimate with precision the pattern of relationships among samples in these trees.

Both GMYC and PTP methods have so far been applied to bumblebees for just two entire subgenera (Alpinobombus Skorikov, 1914, Mendacibombus Skorikov, 1914: by Williams et al. 2015b, 2016, 2019). GMYC has been used without PTP in studies of other entire bumblebee subgenera (Bombus Latreille, 1802 s. str.: Williams et al. 2012a), and in studies of restricted species' groups within several other bumblebee subgenera (Lecocq et al. 2014; Duennes et al. 2017; Potapov et al. 2017; Martinet et al. 2018b). What is striking is the degree to which the results from these methods agree with the earlier morphological taxonomy for the same bumblebees in many cases (with similar findings also from comparisons using other bees: S. Schmidt et al. 2015). GMYC has been applied previously to the subgenus Melanobombus, but only in studies of the small and polyphyletic European fauna (Lecocq et al. 2013, 2015; see the Discussion), even though the majority of Melanobombus species is restricted to Asia (Williams 1998).

\section{Integrative assessment of species}

With the rise in popularity of the interbreeding concept of species in the second half of the twentieth century, it became increasingly common practice in taxonomic revisions to examine multiple sources of independent characters to assess whether or not there are multiple fixed character states within populations as evidence that the populations do not interbreed (Williams 1991). Since the turn of the century, the idea has been developed further under the term integrative assessment, to form a framework for assessing corroboration in meeting criteria for species status from multiple different sources of evidence (Schlick- 
Steiner et al. 2010). It was encouraged particularly because studies focussing on genetic evidence have tended to recognise more species than those considering morphology alone, so that some form of check on a single approach or resolution among multiple approaches was desired. Integrative assessment has been applied increasingly in studies revising bumblebee species (Bertsch et al. 2004, 2005; Williams et al. 2011, 2012a, 2015b, 2016; Lecocq et al. 2013, 2014, 2015, 2019; Potapov et al. 2017; Martinet et al. 2018b).

Disagreements on the meaning of integrative taxonomy have focussed on the kind of corroboration among different character sources that is required for two groups of individuals to be accepted as separate species (Padial et al. 2010: 2): (1) for 'integration by congruence' it was suggested that it is necessary that there be congruence between molecular and morphological characters; whereas (2) for 'integration by cumulation' it was suggested that any a priori selection of particular character sources should be avoided. For agreement by congruence, agreement will necessarily be constrained by the most conservative character source (often in practice morphology) and this could substantially reduce the contribution of integration. Consequently, integration by congruence may under-estimate the numbers of species if different characters diverge at different rates, especially if species have diverged only recently (Schlick-Steiner et al. 2010). In contrast, for integration by cumulation, character sources may be permitted to conflict, but only if there is a reasonable evolutionary explanation for why this might be so (Schlick-Steiner et al. 2010). Accepting this conflict may make it more likely that recently-diverged species are recognised, although without care this approach could over-estimate the numbers of species (Padial et al. 2010). The pros and cons of the application of the different forms of integrative assessment to bumblebees continue to be discussed (Martinet et al. 2018a; Lecocq et al. 2019; Williams et al. 2019).

What may be most important for the integrative approach is not so much having evidence from particular character sources, or indeed having the largest number of different character sources, but rather having evidence from the most appropriate and most nearly independent sources, with each source satisfying as far as possible the assumptions needed for assessing species status. These assumptions include that the characters should: (1) be reliably homologous among samples; (2) evolve sufficiently rapidly for there to be a realistic expectation that they might show fixed divergence between sister species (but not so fast as to over-write any indication of species), whether by drift or by selection; and (3) be not highly homoplastic. Here, our choice of characters is constrained by these principles, by budget, and by access to fresh material.

\section{The approach to recognising species in this revision}

We accept the current unified theoretical concept that considers species as evolutionarily independent lineages (de Queiroz 2007). There are then a variety of properties that can be used operationally for the practice of species discovery, recognition, or 'delimitation' (de Queiroz 2007). The term delimitation has become popular but has also been understood by some to imply that species are mere classes defined by entirely human constructs that are imposed on reality for pragmatic purposes (Ghiselin 1974; Hull 1980). We prefer the terms 'discovered' or 'recognised' because we view species as individuals that have an independent reality in nature.

One of the properties that may be most directly and closely related to the idea of evolutionarily independent lineages and which can be used operationally to discover or recognise species is gene coalescents (for the reasons described above). Gene coalescents associated with speciation are identified here de novo using PTP (Zhang et al. 2013). For relatively recent species, coalescent methods depend on data from fast-evolving DNA, most often from the barcode fragment of the COI gene, by comparing different haplotypes (= amplicon-sequence variants, or zero-distance operational taxonomic units). Initially in the development of coalescent methods they were applied to recognise species within samples from a single collecting site or narrow geographical region, without a priori knowledge of the number of 
species involved. However, here we are more interested in applying PTP to a more difficult problem: for recognising species in a revision of an entire monophyletic group of multiple species world-wide. Early in the application of the coalescent approach to the latter problem in other groups it was realised that a particular challenge might be posed by geographically isolated subpopulations showing varying (and sometimes small) degrees of divergence (Lohse 2009; Fujisawa \& Barraclough 2013; Mason et al. 2020). This is a problem that we investigate empirically.

Species are recognised here within an integrative framework, by assessing the corroboration for putative or 'candidate species' starting from one initial source of evidence (Vieites et al. 2009). We assess support for species from evidence of divergence in: (1) gene coalescents (in the case of COI fast evolving); (2) colour patterns of the hair (potentially fast evolving); and (3) in skeletal morphology (tending to be slow evolving).

\section{Aims of this revision}

Our study aims to apply DNA-, colour-pattern-, and morphology-based criteria consistently to all of the bumblebees of the subgenus Melanobombus world-wide as part of a continuing integrated (sensu Schlick-Steiner et al. 2010; Carstens et al. 2013) assessment of the species, which will then be used for future more detailed work on historical biogeography and on conservation.

A potential problem for revisionary taxonomy identified by Zhang et al. (2013) is that local 'oversampling' of some haplotypes in one subgroup could bias the PTP analysis causing the number of species recognised to be falsely inflated in other subgroups. We seek to mitigate this bias by restricting the analysis to include only unique haplotypes. This filtering aims to improve the discrimination between cases of: (1) widespread invariant species; (2) widespread polytypic species; and (3) complexes of restricted-range monotypic species. We examine the effect of this filtering and the resulting patterns of genetic-divergence-by-distance and the patterns of sympatry against our expectations for species. The interpretation draws on field experience of most of the species over the period 1980-2019 by PW in Europe and especially in Asia, extending to higher elevations ( $>5000 \mathrm{~m}$ a.s.1.) not only in the Himalaya (Williams 1991) but also in the mountains at the northern and eastern edges of the Qinghai-Tibetan Plateau ('QTP') (Williams et al. 2009, 2017a). These are the mountains from which many taxa of the subgenus Melanobombus have been described.

\section{Material and methods}

As far as possible, best practice for revisionary taxonomy should include: (1) an explicit statement of the species concept and the appropriate practical criteria that need to be met for recognising species; (2) representation of all species and taxa world-wide from the entire monophyletic group under revision; (3) representation of variation from across the entire geographical ranges of all of those species, covering all constituent taxa and representing all apparent gradients and clines; (4) iterative tree estimation as sampling develops until convergence on robust trees is attained; (5) integrative assessment of species; and (6) examination and comparison of type specimens for all of the named taxa in order to apply names (Bolton 2007; Williams et al. 2016). Relaxing any of these principles should be expected to reduce the value of the results. But on the other hand, the drive to satisfy these principles may encourage more collaboration among people from different countries and continents. It is supremely important that the entire process should be transparent and reproducible. We do not recognise subspecies as consistent biological entities (Wilson \& Brown 1953; Barrowclough 1982; Zink 2004; Williams et al. 2015b).

\section{Initial sampling}

The area of geographical distribution of the subgenus Melanobombus extends across most of the large Palaearctic Region of Europe and Asia, as well as across much of the Oriental Region of 
Asia (Skorikov 1931; Reinig 1935; Williams 1998). Some species are restricted to areas in remote mountain ranges of Asia, where access can be difficult (Williams 2018). Studies need sample sizes that are sufficiently large to detect species while keeping costs within reasonable bounds (Phillips et al. 2018). To reduce sampling costs and to facilitate access permissions, we use a global coalition of collaborators to contribute samples from a network of sites that are spaced deliberately widely across taxon distributions (following the practice of Williams et al. 2012a). We also use many specimens from older collections, demonstrating again the value of museum collections. Although other revisionary projects have had comprehensive central databases for the material examined, this was not possible for this project because access to data and permission to publish data was limited by local policies. Nonetheless, during the project substantially more than 14000 Melanobombus preserved specimens (plus many more field observations) have been examined by PW from the mountains of Central Asia, the Himalaya, and China alone (Williams 1991; Williams et al. 2009, 2010, 2015a; Williams 2011; An et al. 2014), many through a ten-year project to enumerate the bumblebee species of China (Williams et al. 2017a). Also examined are voucher specimens from ZR's plant-pollinator interaction projects at KIB and from other collections made in North Africa. Specimens were identified or confirmed by PW. A small ACCESS (ver. 14.0.7; https://www.microsoft.com) database (619 individuals) was compiled to track the sequenced Melanobombus specimens. Unique identifiers for specimens in this database are given in the text in the form 'MLn' (all of these specimens were given green labels with database numbers, except for a few from Lecocq et al. (2015) that had sequences downloaded from GenBank and for a few small collections in China). Decimal latitude and longitude coordinates are given in the Material Sequenced. The holotype specimens of the two new species from China have been deposited in the national collection at the Chinese Academy of Sciences, Institute of Zoology, Beijing, China.

\section{Abbreviations for depositories}

The material upon which this study is based is located in the following institutions (some grouped within national academies: CAS $=$ Chinese Academy of Sciences; CAAS $=$ Chinese Academy of Agricultural Sciences; RAS = Russian Academy of Science):

$\begin{array}{ll}\text { AMNH } & =\text { American Museum of Natural History, New York, USA } \\ \text { AUG } & \text { Agricultural University of Georgia, Tbilisi, Georgia } \\ \text { CSPU } & =\text { Chuvash State Pedagogical University, Cheboksary, Russia } \\ \text { DA } & \text { D. Altanchimeg research collection, Ulaanbaatar, Mongolia } \\ \text { DY } & =\text { Y. Dong, Nanjing University, Nanjing, China } \\ \text { FSCV } & \text { RAS Federal Scientific Center of East Asia Terrestrial Biodiversity, Vladivostok, Russia } \\ \text { IAR } & =\text { Institute for Apicultural Research, CAAS, Beijing, China } \\ \text { INHS } & \text { Illinois Natural History Survey, Champaign, USA } \\ \text { IOZ } & =\text { Institute of Zoology, CAS, Beijing, China } \\ \text { KIB } & =\text { Kunming Institute of Botany, CAS, Kunming, China } \\ \text { KIZ } & =\text { Kunming Institute of Zoology, CAS, Kunming, China } \\ \text { NHMUK } & =\text { Natural History Museum, London, UK } \\ \text { NHMW } & =\text { Natural History Museum, Vienna, Austria } \\ \text { NME } & =\text { Naturkundemuseum Erfurt, Erfurt, Germany } \\ \text { NMS } & =\text { Natur-Museum Senckenberg, Frankfurt, Germany } \\ \text { NSUN } & \text { Novosibirsk State University, Novosibirsk, Russia } \\ \text { OLML } & \text { Oberösterreichisches Landesmuseum, Linz, Austria } \\ \text { OUMNH } & =\text { University Museum of Natural History, Oxford, UK } \\ \text { PCYU } & =\text { L. Packer research collection, University of York, Toronto, Canada } \\ \text { PW } & =\text { P. Williams research collection, London, UK } \\ \text { RMNH } & \text { National Museum of Natural History, Leiden, Netherlands } \\ \text { SC } & =\text { S. Cameron research collection, Urbana, USA }\end{array}$




$\begin{array}{ll}\text { SDM } & =\text { State Darwin Museum, Moscow, Russia } \\ \text { SEHU } & =\text { Hokkaido University Museum, Sapporo, Japan } \\ \text { SEMC } & =\text { University of Kansas Biodiversity Institute and Natural History Museum, Lawrence, USA } \\ \text { SK } & =\text { S. Kahono research collection, Bogor, Indonesia } \\ \text { SMNS } & =\text { Staatliches Museum für Naturkunde, Stuttgart, Germany } \\ \text { TFRI } & =\text { Taiwan Forestry Research Institute, Taipei, Taiwan } \\ \text { UAP } & =\text { University of Agriculture, Peshawar, Pakistan } \\ \text { UMONS } & \text { Laboratoire de Zoologie, Université de Mons, Mons, Belgium } \\ \text { USNM } & =\text { US National Museum of Natural History, Washington DC, USA } \\ \text { YUY } & \text { Yasouj University, Yasouj, Iran } \\ \text { ZIN } & =\text { RAS Zoological Institute, St Petersburg, Russia } \\ \text { ZMHB } & \text { Museum für Naturkunde an der Humboldt-Universität, Berlin, Germany } \\ \text { ZMUM } & =\text { Zoological Museum of the Moscow State University, Moscow, Russia } \\ \text { ZSM } & =\text { Zoologische Staatssammlung, Munich, Germany }\end{array}$

\section{Candidate species from coalescents in fast genes}

Evidence for initial candidate species in the form of gene coalescents is obtained using the PTP technique as implemented in the online bPTP server (https://species.h-its.org/ accessed 2019; Zhang et al. 2013). This technique models rare (Poisson-distributed) branching events directly from the numbers of DNAnucleotide substitutions by using the branch lengths from a metric gene tree. It does this separately for (1) among-species branching events and (2) within-species branching events. It then uses maximum likelihood to seek the local transition points between these two models that are expected to be associated with speciation. The newer multi-rate PTP (mPTP) method fits a different model for branching rates within each species and is claimed to perform better in recognising candidate species that are more similar to the species recognised from morphology (Kapli et al. 2017). However, although mPTP has been applied to bumblebees (Potapov et al. 2019), it is not used here because it has been found to fail to discriminate between some bumblebee species that can be distinguished by morphology and behaviour as well as by COI coalescents using the original PTP (Williams et al. 2019; Williams submitted). We estimate a metric gene tree for the subgenus Melanobombus using MrBayes (ver. 3.1.2; Ronquist \& Huelsenbeck 2003), which is preferred for estimating phylogeny because it uses a Bayesian approach to uncertainty (Baum \& Smith 2012).

In order to meet as closely as possible the assumptions of the gene-coalescent technique for identifying species, we deliberately select a fast-evolving gene (in order to find sufficient variation among samples to discover divergence among even recently diverged species). For this we choose the standard barcode fragment of the mitochondrial gene that codes for cytochrome $c$ oxidase subunit 1 (COI or cox-1), which is well known as an especially fast-evolving gene sufficiently conserved to provide a strong signal for recent relationships in bumblebees and other bees (Williams et al. 2016; Almeida et al. 2018). It is also a haploid gene with simple maternal inheritance (no recombination) and the barcode fragment can be aligned easily by inspection because of its lack of insertions and deletions. Although there are many copies among mitochondria which facilitates extraction, paralogous divergence is uncommon. Ideally we would also use nuclear genes to assess corroboration for the patterns found, but most nuclear genes evolve too slowly so that they are insufficiently variable (Monaghan et al. 2009) and consequently differ little if at all among closely related bumblebee species (Cameron et al. 2007; Hines \& Williams 2012; Lecocq et al. 2015), even within introns (unpublished). Fast-evolving nuclear genes are known, but in these cases interpretation of the results is obscured by complex paralogy among the multiple copies ('pseudogenes') (Cardoso et al. 2009).

COI-barcode sequences are obtained using standard protocols (https://www.boldsystems.org/; Table 2) in the labs of: (1) the Canadian Centre for DNA Barcoding (CCDB) at Guelph (sequences now in the 
BOLD database, boldsystems.org, project folder BBML); (2) the NHMUK; and (3) the KIB. To further reduce costs, for the European taxa of the widespread lapidarius-complex and the sichelii-complex, a subset of published sequences (from Lecocq et al. 2015) are selected for sites dispersed widely across Europe and downloaded from GenBank for re-analysis here. Some Melanobombus sequences in GenBank appear from comparison with the sequences in BOLD and with sequences obtained for this study to have been attributed incorrect taxon names (Appendix 1), so these sequences are excluded from this analysis.

Metric phylogenetic gene trees for the COI-barcode region among samples are estimated with MrBayes. The best nucleotide-substitution model available in MrBayes for this gene fragment is selected using the Bayesian information criterion (BIC) from MEGA (ver. 6.06; Tamura et al. 2013) as the general timereversible model with a gamma-frequency distribution of changes among sites $(\mathrm{GTR}+\Gamma)$. For MrBayes we use four Markov-chain Monte-Carlo (MCMC) chains with the 'temperature' set to 0.2 for 10 million generations.

Methods for recognising species from gene coalescents necessarily depend on obtaining a representative gene tree for at least five genuine species (Reid \& Carstens 2012; Fujisawa \& Barraclough 2013; Talavera et al. 2013; Zhang et al. 2013; Leliaert et al. 2014; Dellicour \& Flot 2015) and on the correct rooting of the tree (Zhang et al. 2013). This also requires accounting for any: (1) 'numts' (nuclear paralogous copies of mitochondrial genes); (2) heteroplasmy; (3) other forms of incomplete lineage sorting; and (4) introgression (e.g., Williams et al. 2019).

\section{'Over-sampling' and widespread species}

When analysing widespread candidate species, obtaining a representative gene tree could face another more insidious challenge. If even one species were relatively 'over-sampled' in the sense that especially many closely similar sequences within the species gave rise to many short branches between them on the gene tree, then this could lead to groups of sequences separated by slightly longer branches within other less well-sampled species being interpreted falsely as separate species (Zhang et al. 2013). This could be a particular problem when it arises from relatively invariant species that are widespread and abundant (e.g., one of the most widespread, abundant, and accessible species of the subgenus Melanobombus is the European B. lapidarius). The solution was suggested to be a "need [for] a criterion for removing over-sampled sequences' (Zhang et al. 2013). To begin to mitigate this effect we move from the unfiltered ('UF') data to filtering the data to include only one sequence for each apparently different haplotype, as represented by the longest available sequence (the unique-haplotype filter or 'UHF'). This procedure has been used previously to filter data prior to GMYC analysis, where the justification was closely related - to reduce exaggerated terminal branching rates within dichotomous trees when no real divergence exists (Monaghan et al. 2009; Reid \& Carstens 2012; Fujisawa \& Barraclough 2013; Talavera et al. 2013). The same filter has also been suggested simply for reducing computation time (Kapli et al. 2017). Haplotypes that are unique for the sequenced fragment are identified here using the COLLAPSE software (ver. 1.2), after ranking sequences from longest to shortest. This ranking avoids matching longer to shorter sequences, which could reject longer sequences that might otherwise obscure real differences (short sequences could hide un-sequenced differences but this cannot be known).

\section{Divergence and geographical distance}

One of the simplest patterns expected of genetic variation is that genetic divergence will increase with geographic distance within species (Dillon 1984; Jackson et al. 2018; Mason et al. 2020). There is no reason to expect that this pattern should persist among species without gene flow for long after speciation, so observing the pattern may be evidence that populations are conspecific. A relationship between geographical and genetic distances is tested with Mantel tests, which assess the correlation between the pairwise distance matrices (Mantel 1967). This is implemented using the ADE4 package on 
Table 2. Primer sequences for the sequenced regions of the four genes.

\begin{tabular}{llll}
\hline Gene & Primer name & Primer sequence & Reference \\
\hline COI & LepF & 5'- ATTCAACCAATCATAAAGATATTGG -3' & Hebert et al. 2004 \\
& LepR & 5'- TAAACTTCTGGATGTCCAAAAAATCA -3' & Hebert et al. 2004 \\
$16 \mathrm{~S}$ & 16SWb & 5'- CACCTGTTTATCACCTGTTTATCAAAAACAT -3' & Dowton \& Austin 1994 \\
& 874-16SIR & 5'- TATAGATAGAAACCAAYCTG -3' & Cameron et al. 1992 \\
\multirow{2}{*}{ Opsin } & LWRhF & 5'-AATTGCTATTAYGARACNTGGGT -3' & Mardulyn \& Cameron 1999 \\
& LWRhR & 5'-ATATGGAGTCCANGCCATRAACCA -3' & Mardulyn \& Cameron 1999 \\
PEPCK & FHv4 & 5'- TGTATRATAATTCGCAAYTTCAC -3' & Cameron et al. 2007 \\
& RHv4 & 5'-CTGCTGGRGTYCTAGATCC -3' & Cameron et al. 2007 \\
\hline
\end{tabular}

the R software platform (Dray \& Dufour 2007) and by drawing scatter plots using the GGPLOT2 package (Wickham 2011). Genetic divergence is measured here using the maximum composite-likelihood model in MEGA, including all three codon positions of the sequence. Geographic (Great Circle) distances are approximated using an estimated mean radius of the Earth of $6371 \mathrm{~km}$ for the WGS84 ellipsoid (Appendix 2).

\section{Divergence and sympatry}

Consistent with a model of speciation in allopatry, the degree of sympatry (overlap) between species' areas of occurrence has been reported to be greater for the more distantly-related species within a group (Barraclough \& Vogler 2000). Measurements of overlap depend strongly on the spatial grain size of the analysis, because no two individuals can occupy exactly the same point. Therefore a very coarse grain size is deliberately used here, with equal-area grid cells of $611000 \mathrm{~km}^{2}$ (Williams 1998), in order to increase measurements of sympatry, as a deliberately conservative approach. The measure of sympatry used is: (area of overlap)/(area occupied by the taxon with the smaller range) (Chesser \& Zink 1994).

\section{Morphology}

We scored morphological characters using a light microscope (Wild model M5A). Morphological terms follow Michener (2000) and Williams et al. (2009), with terms for the components of the male genitalia following homologies identified by Williams $(1985,1991)$. Setae, pile or pubescence is referred to as 'hair' for simplicity, following Michener (2000). Several terms are used as shorthand when describing components of the colour pattern that do not correspond precisely with particular segments or sclerites. On the head, the 'face' is used for the patch of hair around the antennal bases between the eyes, dorsal to the clypeus and ventral to the ocelli (frons + supraclypeal area + paraocular area). The 'side' of the thorax refers to the hair covering the lateral parts of the thorax ventral to the wing bases (on the lateral pronotum + mesepisternum + metepisternum + lateral propodeum). On the metasoma (abdomen posterior to the 'waist'), the term 'tail' is used more flexibly, referring to the contrasting palest long hair covering all or parts of metasomal terga 4-6 (e.g., 'red-tail' or 'white-tail' colour patterns). Terga 1-7 and sterna $1-6$ are abbreviated to $\mathrm{T} 1-7$ and $\mathrm{S} 1-6$ respectively.

\section{Assigning names to species}

We seek to represent the major formally named taxa of the subgenus Melanobombus in our analysis with COI sequences in order to assign these names to the species we recognise and then to identify the oldest available (valid) names for those species (ICZN 1999). However, because data for long gene sequences are usually unavailable from type specimens, we follow a pragmatic procedure (Williams et al. 2012a, 2016) of associating the original name-bearing type specimens with gene sequences via 
the identification of more recently collected informal proxy type specimens for which we do have gene sequences (Table 3). Informal proxy specimens for the types should ideally be identical with the primary type specimen and are chosen here where possible by: (1) matching morphology and colour pattern of the hair; (2) proximity of the proxy locality to the type locality; (3) long COI sequences; and (4), for some taxa, it is desirable to match the sex and caste of the proxies with the original type specimens, because of occasional difficulties in associating sexes and castes among species from morphology alone. Our proxies are not intended to have any formal or persistent nomenclatural status and are not recognised by the ICZN (1999). Aside from the lack of formal status and persistence, our process is otherwise similar to some of the 'epitypification' procedures used by botanists when primary types cannot be sequenced for genes (Hyde \& Zhang 2008). Although still subjective, our process at least provides explicit accountability in applying names, because the proxies can be examined, re-interpreted, and if necessary the application of the names corrected in future studies. It has long been common practice for taxonomists revising the taxonomy of a group to re-examine material in museum collections that had been identified by previous specialists in order to understand their earlier concepts of particular taxa. Our process differs from this traditional practice only in emphasising a particular specimen. This process is especially important when revising the subgenus Melanobombus because species are often closely similar in morphology and in colour pattern. New proxy types are likely to be needed in future studies that require fresh material for more demanding genetic sampling.

\section{Phylogeny among species}

The phylogeny of species of the subgenus Melanobombus is estimated using the *BEAST procedure (Species Tree Ancestral Reconstruction using BEAST, ver. 2.5.2; Drummond \& Bouckaert 2015), which allows for incomplete lineage sorting in individual gene trees among species. COI may be effective for resolving recent (shallow) divergences, but for deeper divergences slower-evolving nuclear genes show more consistent patterns (Cameron et al. 2007; Williams et al. 2016; Almeida et al. 2018). Consequently we use a combination of the mitochondrial genes COI and 16S (coding for 16S ribosomal RNA; the two mitochondrial genes are set as linked) together with the commonly-used nuclear autosomal genes PEPCK (coding for phosphoenolpyruvate carboxykinase) and opsin (long-wavelength rhodopsin copy 1). Where possible, we use available gene sequences from Cameron et al. (2007) with corrected identifications and additional sequences obtained using standard primers and protocols (Table 1). According to the BIC statistic from MEGA, the best nucleotide-substitution model available in *BEAST for the COI is TN93 with a gamma-frequency distribution of changes among sites and a proportion of invariant sites (TN93 $+\Gamma+\mathrm{I}$, Tamura \& Nei 1993); for $16 \mathrm{~S}$ it is GTR $+\Gamma$; and for PEPCK and opsin it is HKY (Hasegawa et al. 1985). The tree prior is set to the calibrated Yule model, and the birth-rate and clock-rate priors are set to gamma distributions with parameters $\alpha$ (shape) $=0.001$ and $\beta$ (scale) $=1000$ (Drummond et al. 2013). A monophyletic ingroup prior is set to identify B. (Alpigenobombus) nobilis Friese, 1905, as the outgroup to root the tree.

Few fossils of species of the subgenus Melanobombus are known that might help with dating parts of the tree (Dehon et al. 2019), so the phylogeny is calibrated with a date from a molecular study. Hines (2008: fig. 2) inferred from models of DNA evolution that the best estimate for the age of crown divergence within the subgenus Melanobombus is that it occurred at ca 16.5 Ma. We use this for the mean and initial age estimate of the most recent common ancestor prior, assuming a normal distribution with a standard deviation of $1 \mathrm{Ma}$, which gives $5 \%$ tails of the prior distribution at 18.5-14.5 Ma. The MCMC algorithm is run for 100 million generations in order to achieve higher effective sample-size (ESS) values with these data (assessed using Tracer software: ver. 1.6.0, accessed 2013: beast.bio.ed.ac.uk/Tracer; Drummond \& Rambaut 2007). The sample of 10000 trees is drawn with Densitree (ver. 2.2.6, accessed 2018; Drummond \& Bouckaert 2015). A maximum clade-credibility tree is obtained after examining a sample of 10000 trees and rejecting the first $1 \%$ of sampled trees. 
Table 3. List of selected available formal names in the species group for taxa of the subgenus Melanobombus von Dalla Torre, 1880 (for details of the references, see the text). These names are associated informally with barcoded specimens as proxies for types. 'Tail' colour refers to the predominant colour of the pale hair on metasomal terga 4-6 (T4-6); project ID refers to the specimen number (MLn) of the proxy type in the Melanobombus project database.

\begin{tabular}{|c|c|c|c|c|c|c|}
\hline Taxon name & Species name & Pale banding & Tail colour & $\begin{array}{l}\text { Original type } \\
\text { locality }\end{array}$ & $\begin{array}{l}\text { Barcode proxy } \\
\text { locality }\end{array}$ & Project ID \\
\hline alagesianus & alagesianus & yellow & orange & Armenia & Armenia & ML190 \\
\hline alticola & sichelii & yellow & orange & Alps & Germany & ML327 \\
\hline atlanticus & lapidarius & cream & orange & Morocco & Morocco & ML193 \\
\hline bisiculus & lapidarius & yellow & orange & Italy & Italy & ML194 \\
\hline cancasicus & eriophorus & white & orange & [Caucasus] & Georgia & ML175 \\
\hline cazurroi & sichelii & white & orange & [Caucasus] & Turkey & ML287 \\
\hline decipiens & lapidarius & yellow & orange & Spain & Spain & ML276 \\
\hline erzurumensis & sichelii & white & orange & Turkey & Iran & ML015 \\
\hline eurythorax & eurythorax & yellow & orange + white & Xizang, China & Himachal, India & ML415 \\
\hline eximius & eximius & - & orange & Bangladesh & Chongqing, China & ML179 \\
\hline festivus & festivus & brown & white & 'N.W.' India & Sichuan, China & ML254 \\
\hline flavissimus & sichelii & yellow & orange & Pyrenees & France & ML289 \\
\hline formosellus & formosellus & white & orange & Taiwan, China & Taiwan, China & ML318 \\
\hline friseanus & friseanus & yellow & orange & Sichuan, China & Sichuan, China & ML007 \\
\hline incertoides & incertoides & white & orange & Mongolia & Mongolia & ML148 \\
\hline incertus & incertus & white & orange & [Caucasus] & Turkey & ML239 \\
\hline keriensis & keriensis & white & orange & Xinjiang, China & Kashmir, India & ML244 \\
\hline kozlovi & separandus & yellow & orange & Mongolia & Mongolia & ML489 \\
\hline ladakhensis & ladakhensis & yellow & orange + white & Kashmir, India & Xizang, China & ML300 \\
\hline lapidarius & lapidarius & - & orange & Sweden & Finland & ML277 \\
\hline latissimus & eximius & - & orange & Taiwan, China & Taiwan, China & ML177 \\
\hline miniatus & miniatus & yellow & orange + white & Sikkim, India & Bhutan & ML512 \\
\hline phariensis & ladakhensis & white & orange + white & Xizang, China & Qinghai, China & ML233 \\
\hline prshewalskyi & prshewalskyi & white & orange + white & Qinghai, China & Gansu, China & ML001 \\
\hline pyrosoma & pyrosoma & white & orange & Shanxi, China & Neimenggu, China & ML234 \\
\hline qilianensis & qilianensis & yellow & orange & Qinghai, China & Qinghai, China & ML307 \\
\hline richardsiellus & richardsiellus & white & white & Burma & Xizang, China & ML002 \\
\hline rufipes & rufipes & - & black & Java, Indonesia & Java, Indonesia & ML250 \\
\hline rufofasciatus & rufofasciatus & white & orange+white & 'N.' India & Pakistan & ML257 \\
\hline semenovianus & semenovianus & yellow & orange & Kashmir, India & Pakistan & ML422 \\
\hline separandus & separandus & white & orange & Xinjiang, China & Kyrgyzstan & ML336 \\
\hline sichelii & sichelii & yellow & orange & Kamchatka, Russia & Kamchatka, Russia & ML217 \\
\hline simillimus & simillimus & white & orange & 'N.' India & Kashmir, India & ML315 \\
\hline tanguticus & tanguticus & yellow & orange & Qinghai, China & Qinghai, China & ML009 \\
\hline tenellus & separandus & yellow & orange & Mongolia & Tuva, Russia & ML269 \\
\hline tibeticus & tibeticus & yellow & orange & Qinghai, China & Qinghai, China & ML252 \\
\hline uniens & sichelii & cream & ?orange & Mongolia & Mongolia & ML218 \\
\hline
\end{tabular}




\section{Biogeographic history}

To assess explanations of current distributions from phylogeny, dispersal, and extinction, we use the BioGeoBEARS methods (Matzke 2013) run from within the RASP package (ver. 4.2, accessed 2020: Yu et al. 2019) in combination with an explicit corridor model for dispersal (Williams et al. 2017b). A version of divergence-vicariance analysis (DIVA) implemented with likelihood includes the broadlysupported founder-event speciation model (DIVALIKE+J: Yu et al. 2019). DIVA assumes that all distribution changes happen at nodes (associated with speciation), which has been found to perform better with other bumblebee data than assuming changes occur along branches (using S-DEC: Williams et al. 2017b). As an estimate of phylogeny we use the maximum clade-credibility tree from the fourgene *BEAST analysis above. Area units are chosen by agglomerating distribution data into a few large areas with shared, often nested, faunas with unique endemics. The number of areas recognised within a species' range is kept low because this biogeographic analysis does not have mechanisms by which two daughter species can both inherit ranges consisting of multiple areas (Lamm \& Redelings 2009; Ree \& Sanmartín 2009). Ancestral ranges are constrained to be a maximum of three contiguous areas in order: (1) to exclude long-distance-dispersal jumps between non-contiguous areas (see below); (2) to not exceed the size (as number of area units) coded for current ranges of species; (3) to offset the bias of analyses towards combining all areas from daughter species into widespread ancestral ranges; and (4) to prevent reconstructed ranges from being highly disjunct (Ronquist 1996; Ree \& Smith 2008; Lamm \& Redelings 2009; Ree \& Sanmartín 2009).

Bumblebees may be able to spread through suitable habitat by short-distance dispersal, but the weight of evidence is that they are unable to disperse long distances over broad barriers before starting colonies and successfully founding new populations (Williams et al. 2017b). To seek the most likely explanation for current distributions using only short-distance dispersal, a simple model of potential corridors for dispersal (assuming suitable climates and habitats in appropriate periods) is defined. The dispersalcorridor model summarises a set of short-distance-dispersal events (excluding long-distance dispersal 'jumps') permitted between neighbouring areas (in either direction) assuming that suitable habitat is present. The sister group is selected as the subgenus Alpigenobombus Skorikov, 1914, with ancestors most likely to have been distributed near the Hengduan region.

\section{Results}

\section{Recognising candidate species from gene coalescents}

Sampling effort deliberately became focussed towards sites in the mountains of eastern Asia progressively from 2011-2019 in order to increase the representation of the rarer taxa (Fig. 7). By 2019, the total (UF) COI-barcode dataset included 374 sequences and the UHF dataset included 161 sequences.

Between 2011-2019, 41 successive versions of the sequence-data set were analysed, often with multiple analyses with different data filters, outgroups, and model settings, until more stable results were obtained (only a sample of analytical results is shown in Table 4, Fig. 8). The best estimate from UF-PTP analysis (Fig. 9) of the number of putative species from the total sequence data is 33 (95\% confidence-interval estimate 30-49 species). When the UHF is applied, the best estimate from PTP analysis (Fig. 10) of the number of putative species is 26 ( $95 \%$ confidence-interval estimate $24-47$ species). The number of final species represented in the data at each stage is shown in Table 4.

The difference between the results in Figs 9-10 lies in groups of sequences with high PTP probability as separate species in Fig. 9 that tend to be basal within the broader putative species in Fig. 10. These differences are interpreted as the consequence of the over-splitting caused by over-sampling of duplicate sequences in Fig. 9. The groups with high probability as candidate species in Fig. 10 are accepted as the 
less biased PTP estimate of species' gene coalescents and hence the best estimate of species, resulting in 26 candidate species.

Six of the candidate species in Fig. 10 have fewer than five sample sequences in Fig. 9 (Table 5): the taxa rufipes Lepeletier, 1835, tanguticus Morawitz, 1887, eurythorax Wang, 1982, richardsiellus (Tkalců, 1968), miniatus Bingham, 1897, and eriophorus Klug, 1807. Ideally more samples would have been included for these taxa, but they are either very rare or are restricted to areas that are especially difficult to access for political reasons. Some of these taxa (rufipes and tanguticus) as well as another (eximius

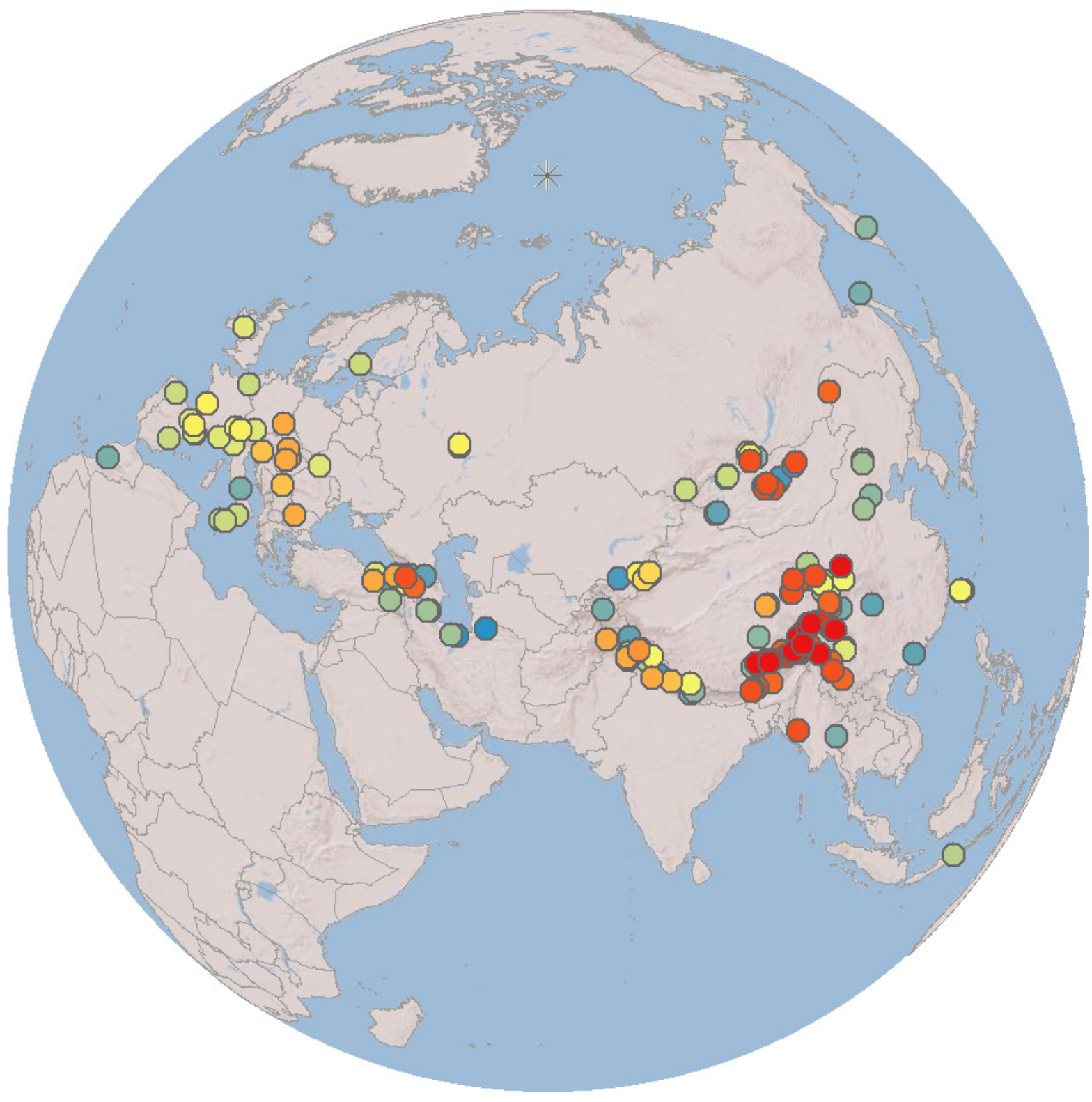

Fig. 7. Sample sites for barcodes for the subgenus Melanobombus von Dalla Torre, 1880, colour-coded for the order in which the samples of selected barcoded individuals were added to the analyses, from blue (2011) to red (2019) (specimens may be much older). Spherical projection with the North Pole shown as a star, international boundaries as recognized by the UN shown as grey lines. Map projected in ArcGIS using the World_Shaded_Relief basemap ${ }^{\circledR} 2014$ ESRI. 
Table 4. Numbers of candidate species from Poisson-tree-process (PTP) analyses (with or without unique haplotype filtering, UHF/UF) of COI barcodes as sampling progressed. All analyses were rerun retrospectively with the same outgroup and model settings. PTP analyses using highest Bayesian support values to fit the models (95\% confidence intervals from PTP analyses in parentheses).

\begin{tabular}{lccccc}
\hline Date of dataset & April 2011 & March 2014 & August 2018 & April 2019 & October 2019 \\
\hline Sequences & 45 & 139 & 233 & 314 & 374 \\
Unique haplotypes & 26 & 71 & 104 & 153 & 161 \\
UF-PTP candidate species $^{1}$ & $17(16-20)$ & $22(20-30)$ & $27(25-39)$ & $33(27-47)$ & $33(30-49)$ \\
UHF-PTP candidate species $^{1}$ & $\mathbf{1 6}(13-19)$ & $\mathbf{2 1}(18-27)$ & $\mathbf{2 6}(22-41)$ & $\mathbf{2 6}(24-44)$ & $\mathbf{2 6}(24-47)$ \\
Final species represented & 14 & 19 & 24 & 25 & 25 \\
Mean haplotypes / final species & 1.0 & 2.8 & 4.1 & 6.1 & 6.4 \\
CV haplotypes/final species & 1.3 & 1.2 & 1.0 & 1.2 & 1.2 \\
\hline
\end{tabular}

1 The number of candidate species recognised by PTP analysis (to go forward to integrative assessment). In some cases this includes candidate species that represent multiple split groups from within what are currently considered genuine species.

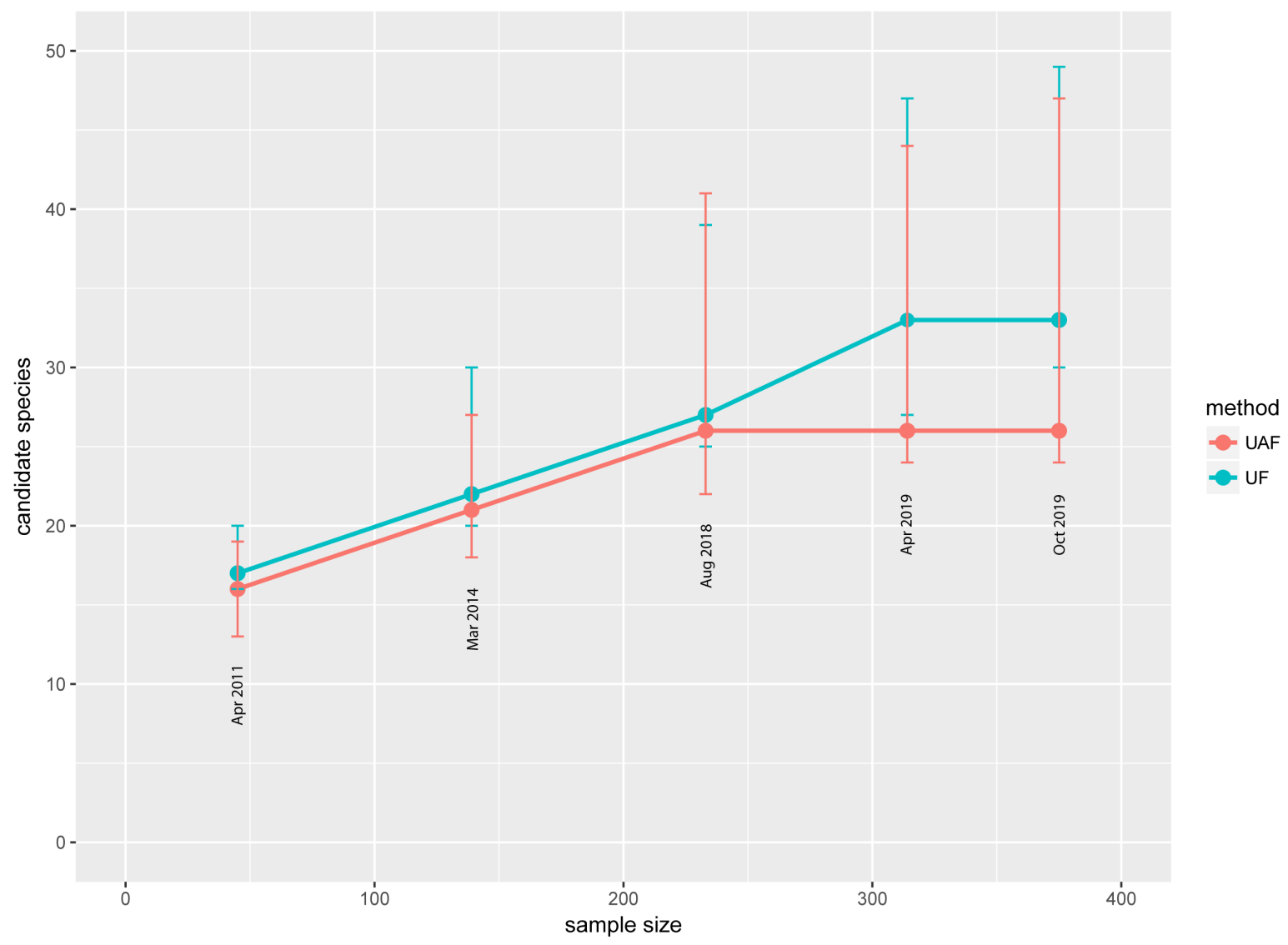

Fig. 8. Numbers of candidate species from example Poisson-tree-process (PTP) analyses using either unfiltered (UF) or with unique haplotype filtering (UHF) from MrBayes trees from COI barcodes ( $y$-axis) as sample sizes of selected barcoded individuals increased through time ( $x$-axis). All analyses were rerun retrospectively with the same outgroup and model settings (see text). PTP analyses using highest Bayesian support values to fit the models (error bars for $95 \%$ confidence intervals from PTP analyses). 
Smith, 1852) are represented among the available sample sequences by only one haplotype. This could indicate either very little genetic variation within these taxa, or more likely it indicates an under-sampling of the possibly greater variation within them (but see the comments below). The numbers of different haplotypes represented per species does not scale simply with species' range sizes in these data (Fig. 11: Spearman correlation $\rho=0.35, p=0.85$; although note that samples are not taken at random but are highly selected from distant sites to increase the genetic diversity represented within species, Fig. 7).

\section{Integrative assessment of candidate species}

Of the 26 candidate species identified from gene coalescents in the UHF dataset in Fig. 10, only one is unsupported as a separate species by any other diagnostic characters. While there is PTP support for two coalescents within B. lapidarius s. lat., it is not strong (Fig. 10: probabilities of $0.5,0.72$ ) and there is as yet no known support for these two groups from any other character source. The first of the two groups includes the taxa lapidarius s. str., decipiens Pérez, 1890, and atlanticus Benoist, 1928 (Fig. 9), whereas the second includes the taxon bisiculus Lecocq et al., 2019. However, the second coalescent group also includes bees that are typical lapidarius s. str. in their morphology and CLGS from south-eastern Europe (Lecocq et al. 2019) and so does not correspond to Lecocq et al.'s taxon bisiculus, which forms just a part of this group.

In contrast, of the 7 candidate species represented in Fig. 10 by a few samples or by only one haplotype (listed above), all appear to be supported by morphological characters, so that under-sampling of genetic variation is not preventing them from being recognised here as species (although uneven sampling remains a potential problem for the PTP analysis). Morphological support for speciation between miniatus / eurythorax Wang, 1982 and between rufofasciatus Smith, 1852 / prshewalskyi Morawitz, 1880 is weak and further work is needed to examine morphology of these species. Consequently 25 candidate species are supported by more than one source of evidence and are accepted here as valid species (Figs 12-16) as described in the comments on each species.

In cases where the status of taxa as separate species remains especially uncertain, these sets of taxa are referred to here as species complexes, e.g., the lapidarius-complex (which is part of the lapidariusgroup, although the lapidarius-group includes in addition the well characterised species B. eriophorus Klug, 1807).

\section{Additional criteria: divergence and geographical distance}

The sichelii-complex is represented by 44 COI barcode sequences (Fig. 9) with 31 variable sites. This complex shows weakly positive relationships in divergence with distance both within and among the

Fig. 9 (see pp. 20-21). October 2019 estimate (Fig. 8) of the metric gene tree for all databased COIbarcode sequences of the subgenus Melanobombus von Dalla Torre, 1880 from MrBayes combined with the Bayesian Poisson-tree-process (PTP) solution with the highest support with spots showing the nodes with the strongest support as coalescents for candidate species (outgroup B. nobilis not shown). Values above the nodes are Bayesian posterior probabilities showing branch support for groups; values below the nodes are PTP Bayesian support values that all daughter haplotypes are parts of a single species. The scale bar is calibrated in substitutions per nucleotide site. Each sample sequence is labelled with: the sequence length in number of nucleotides; a taxon name, often referring to a particular colour pattern; a code that consists of a specimen identifier from the project database and (after the hyphen) a sample identifier; followed with its geographic origin. Lineages with high probabilities of representing one or more candidate species in the Poisson-tree-process (PTP) results are shown with thick lines and the most recent common ancestor of each candidate species (the species' coalescent) is shown with a black spot. The branches within the candidate species are shown with thin lines. Asterisks mark sequences used as informal proxies for the type specimens of each of the taxon names in Table 3. 


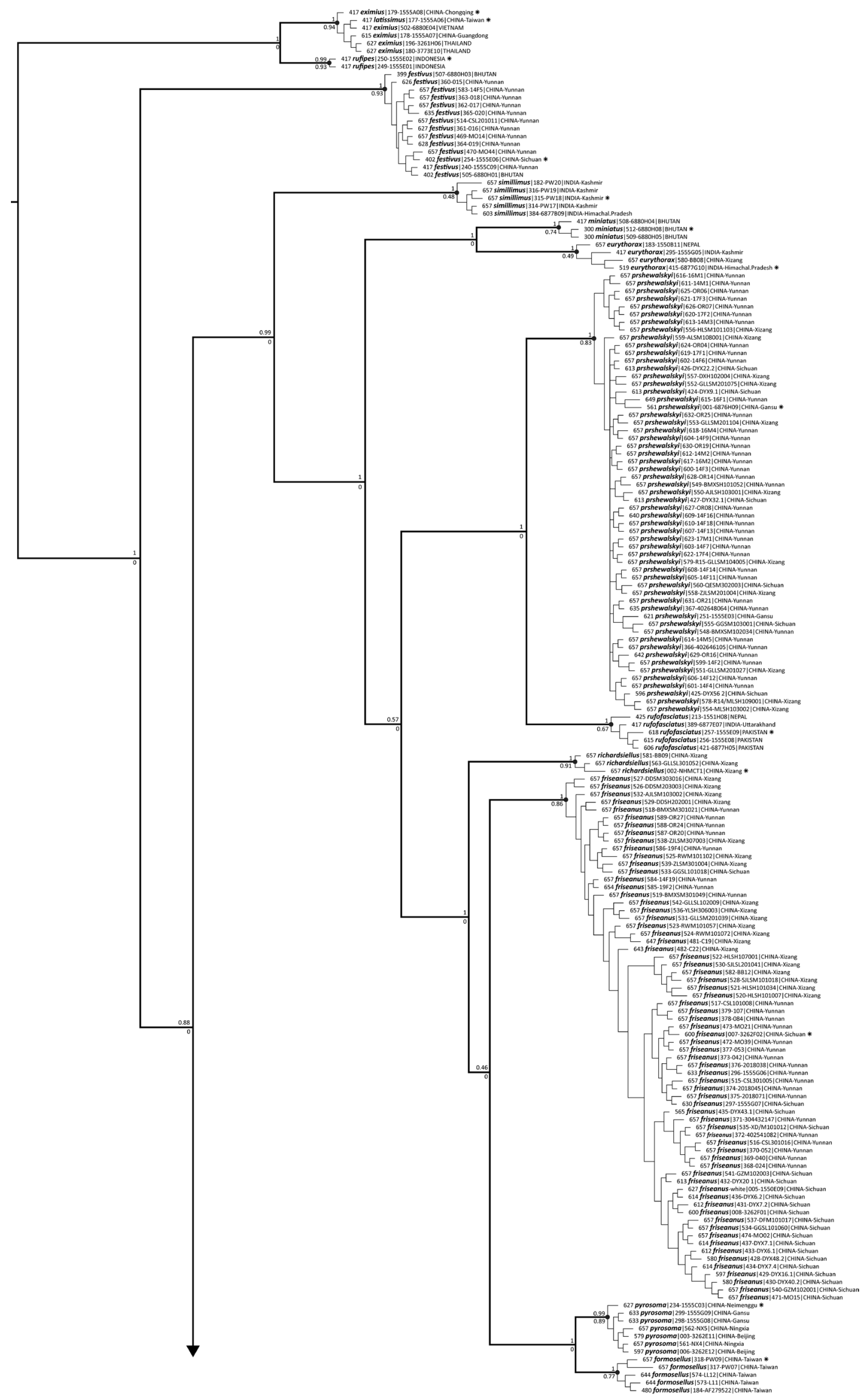




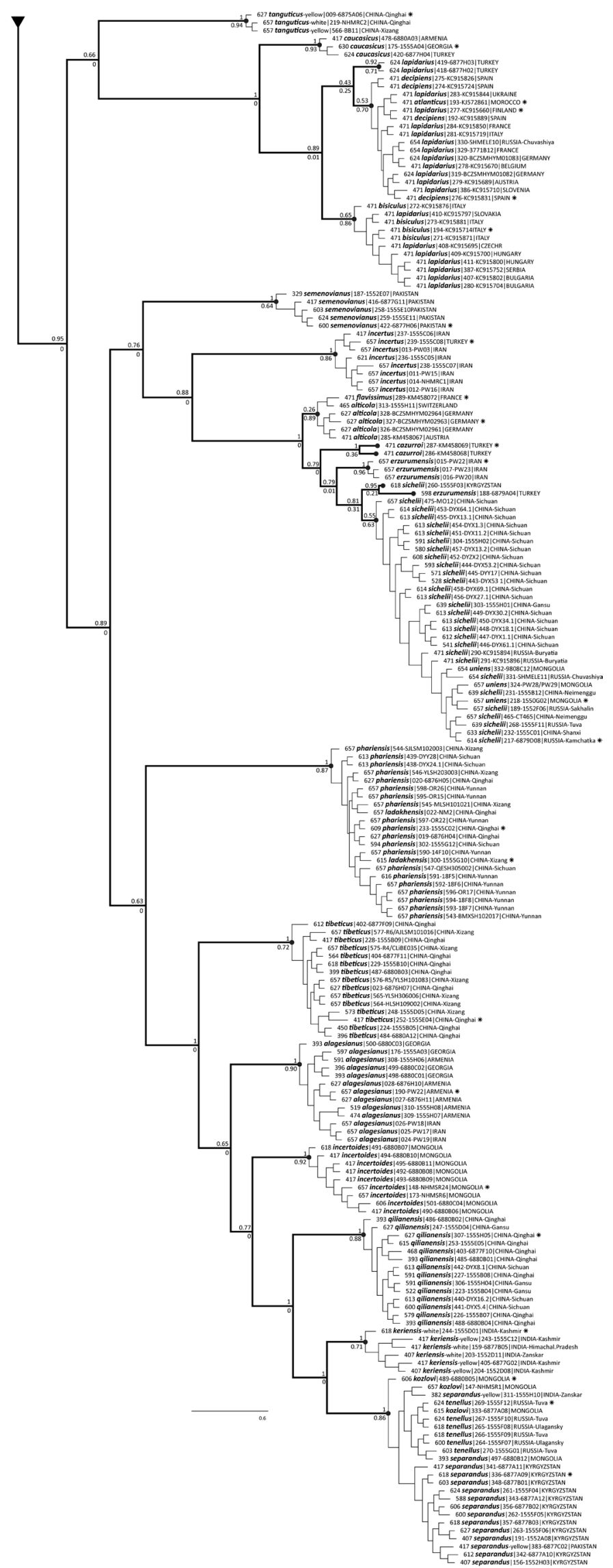




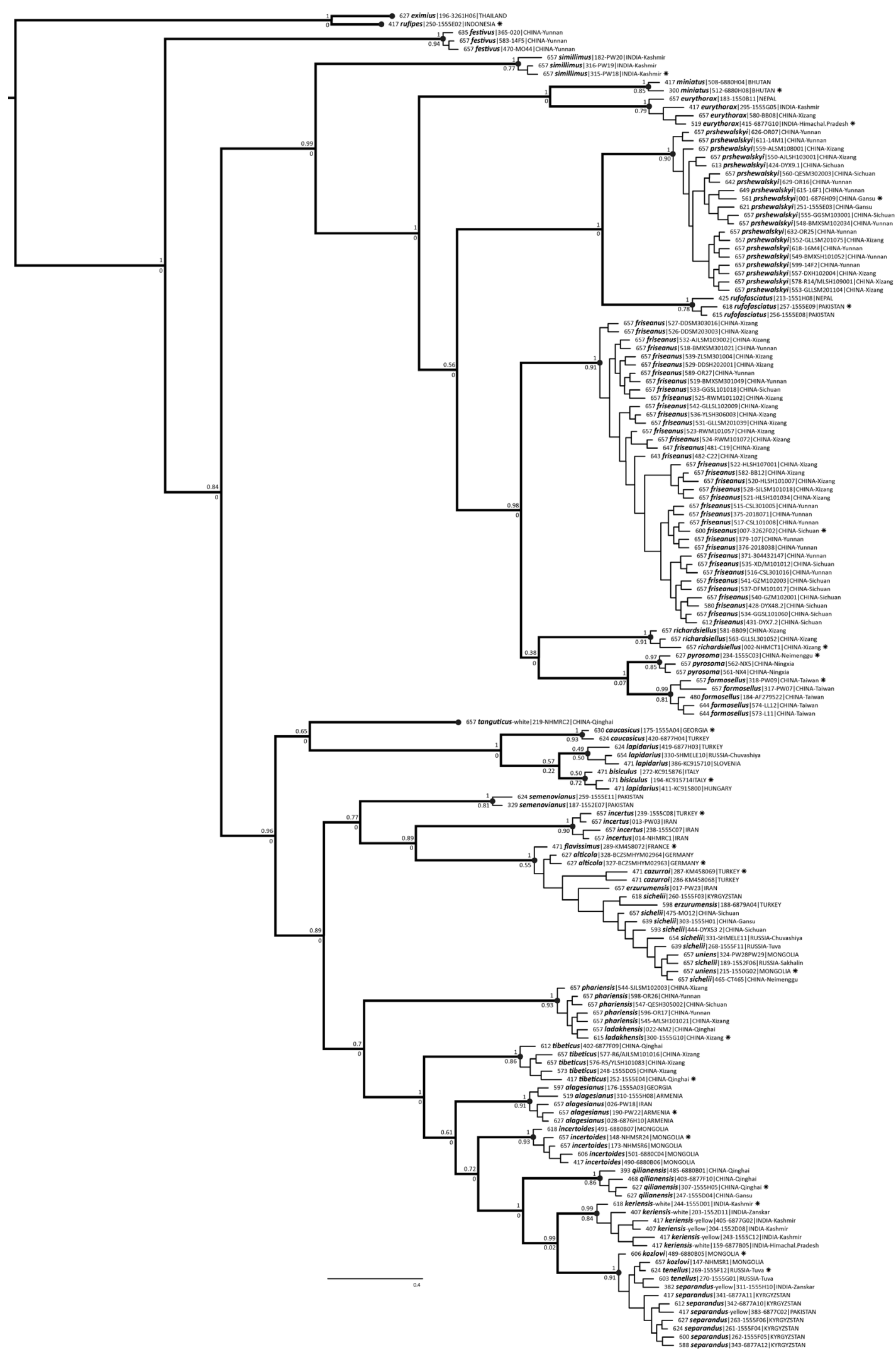

Fig. 10. October 2019 (Fig. 8) Bayesian PTP analysis of MrBayes tree of unique COI barcodes (UHFPTP). Symbols as in Fig. 9. 
Table 5. Principal areas of endemic distribution identified for their combinations of bumblebee species of the subgenus Melanobombus von Dalla Torre, 1880.

\begin{tabular}{|c|c|c|}
\hline Area & Principal ranges included & Species recorded \\
\hline A & Indonesia & rufipes \\
\hline B & Hengduan - SE Asia - S China & $\begin{array}{l}\text { (centre of diversity for the outgroup Alpigenobombus) } \\
\text { eximius festivus prshewalskyi friseanus richardsiellus } \\
\text { ladakhensis }\end{array}$ \\
\hline $\mathrm{C}$ & N China & pyrosoma sichelii \\
\hline $\mathrm{D}$ & Taiwan & eximius formosellus \\
\hline $\mathrm{E}$ & Qinghai - Tibet & $\begin{array}{l}\text { prshewalskyi friseanus tanguticus sichelii ladakhensis } \\
\text { tibeticus qilianensis }\end{array}$ \\
\hline $\mathrm{F}$ & E Himalaya & eximius festivus miniatus prshewalskyi tanguticus \\
\hline G & W Himalaya & $\begin{array}{l}\text { festivus simillimus eurythorax rufofasciatus tanguticus } \\
\text { semenovianus ladakhensis keriensis separandus }\end{array}$ \\
\hline $\mathrm{H}$ & Khangai - Sayan - Altai - Tian Shan & sichelii incertoides separandus \\
\hline I & N Asia - Alborz - Caucasus - Alps & eriophorus lapidarius incertus sichelii alagesianus \\
\hline
\end{tabular}

seven candidate species from the Bayesian UF-PTP analysis (Fig. 17: Mantel $r=0.52, p<0.001$; Fig. 18: Mantel $r=0.21, p<0.001$ ), so that even among these candidate species the relationship is consistent with a single population model. Therefore the sichelii-complex shows a pattern consistent with just one species being present. This result corroborates the UHF-PTP results in Fig. 10 that there is a single species in the sichelii-complex.

The keriensis-complex is represented by 79 COI barcode sequences (Fig. 9) with 90 variable sites. For this complex, divergences within the six candidate species also appear to show a weakly positive relationship between divergence and distance from the Bayesian UF-PTP analysis (Fig. 19: Mantel $r=0.16, p<0.001)$, so this pattern is consistent with a single population model for each of the six candidate species. However, divergences among the six candidate species show no significant relationship between divergence and distance (Fig. 20: Mantel $r=-0.06, p>0.5$ ). Therefore, for the keriensis-complex, it is likely that there are multiple species present. This result corroborates the UHFPTP results in Fig. 10 that there are multiple species in the keriensis-complex.

The lapidarius-complex is represented by 29 COI barcode sequences (Fig. 9) with 13 variable sites. This is too little COI-barcode sequence variation within these data for an analysis of divergence with distance to be informative, with only two sites showing any variation within the three candidate species as they are inferred from the unfiltered PTP analysis in Fig. 9. This pattern is consistent with just one species being present.

\section{Additional criteria: divergence and sympatry}

There is no sympatry at all among the PTP-candidate species of the sichelii-complex even when measured at the very coarse scale of the $611000 \mathrm{~km}^{2}$ grid cells used here. Within the keriensis-complex, there is no overall significant relationship between COI divergence and sympatry among PTP-candidate species (Mantel $r=0.32, p=0.23$ ). These results corroborate the UHF-PTP results in Fig. 10 that there is a single species within the sichelii-complex but that there are multiple species within the keriensis-complex. 


\section{Assigning names to species}

The 25 species of the subgenus Melanobombus recognised from the integrative assessment are named by adopting as the valid name for each species the oldest available name by referring to our sequenced proxy types (from Table 3) in Figs 9-10 and the primary types. In only one case, that of B. eriophorus, have we been unable to obtain a sequence from the taxon with the oldest available name in its narrowest sense. The nomenclature for species is summarised in outline in the Synopsis section below.

\section{Phylogeny among species}

Our data for the mitochondrial gene COI show that $35 \%$ of base-pair sites are variable and $28 \%$ are phylogenetically informative (from MEGA6); for mitochondrial $16 \mathrm{~S}, 22 \%$ of sites are variable and $14 \%$ are phylogenetically informative. In contrast, the data for the nuclear sequences for opsin show $6 \%$ sites are variable and $1 \%$ phylogenetically informative, whereas for PEPCK $8 \%$ are variable and $1 \%$

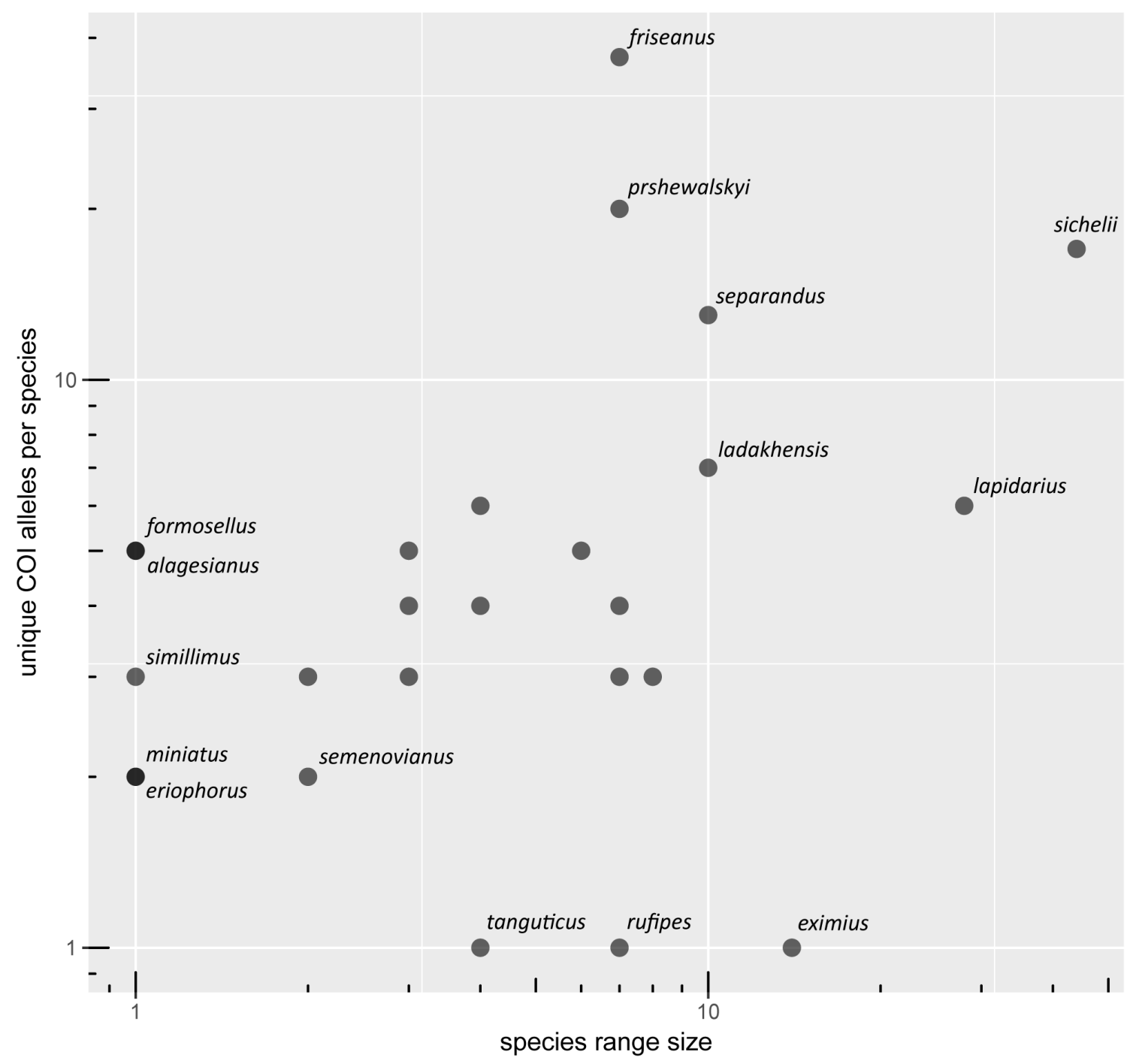

Fig. 11. Numbers of unique COI haplotypes represented per species ( $y$-axis, log scale) plotted against range size per species ( $x$-axis, log scale). Unique COI haplotypes are listed in Fig. 10 and range size is measured as the number of large equal-area grid cells $\left(611000 \mathrm{~km}^{2}\right)$ with records (Williams 1998). 
phylogenetically informative. Consequently the mitochondrial genes are faster-evolving whereas there is little phylogenetic information at this taxonomic rank in the nuclear genes.

After one hundred million MCMC generations with *BEAST, a sample of 10000 trees with a $1 \%$ burn-in shows ESS values from Tracer that are $>100$ for $44 / 51$ of the trace statistics. Some wandering in the trace files shows that there are likely to be multiple 'islands' of different tree topologies, arising from conflicts in the data. These topologies can be seen in the scatter of the sample of *BEAST trees

B. rufipes
B. eximius

- B. festivus

- B. simillimus

- B. eurythorax

B. miniatus

- B. rufofasciatus

O B. prshewalskyi

- B. richardsiellus

- B. friseanus

- B. pyrosoma

- B. formosellus

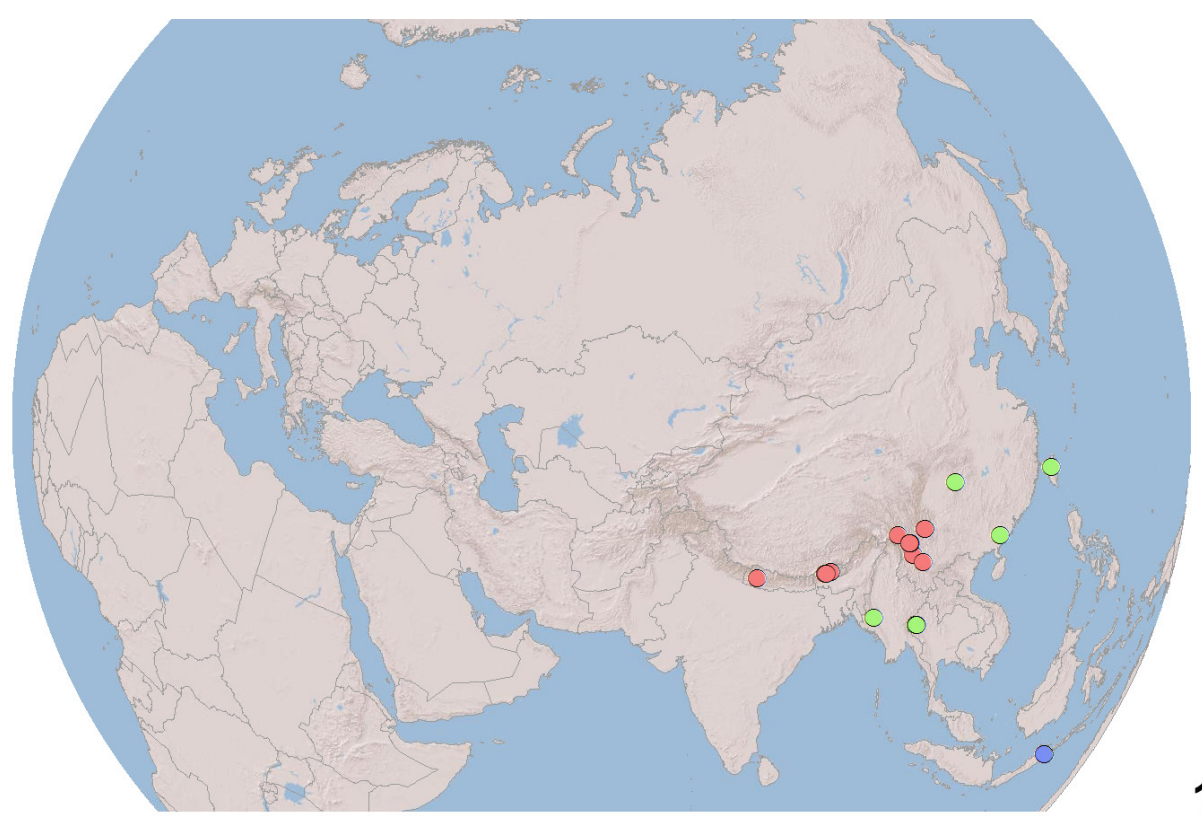

12

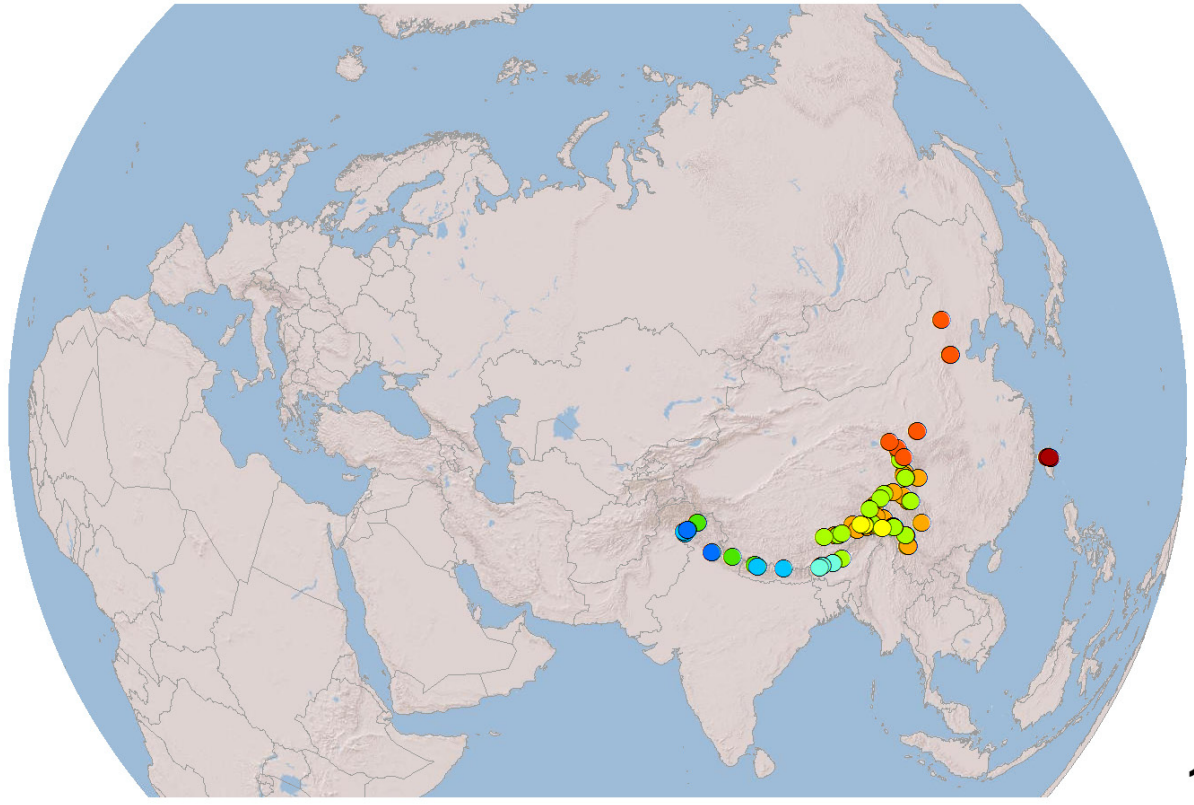

13

Figs 12-13. Maps of sequenced samples. 12. The rufipes-group and festivus-group. 13. The rufofasciatusgroup as recognised as species from the UHF-PTP analysis in Fig. 10. Keys to the coloured symbols are shown on the left (in some cases symbols on the map for one species may overlie symbols for another). Maps projected onto a sphere in ArcGIS using World_Shaded_Relief basemap ${ }^{\circledR} 2014$ ESRI and showing boundaries between countries as recognised by the UN. 


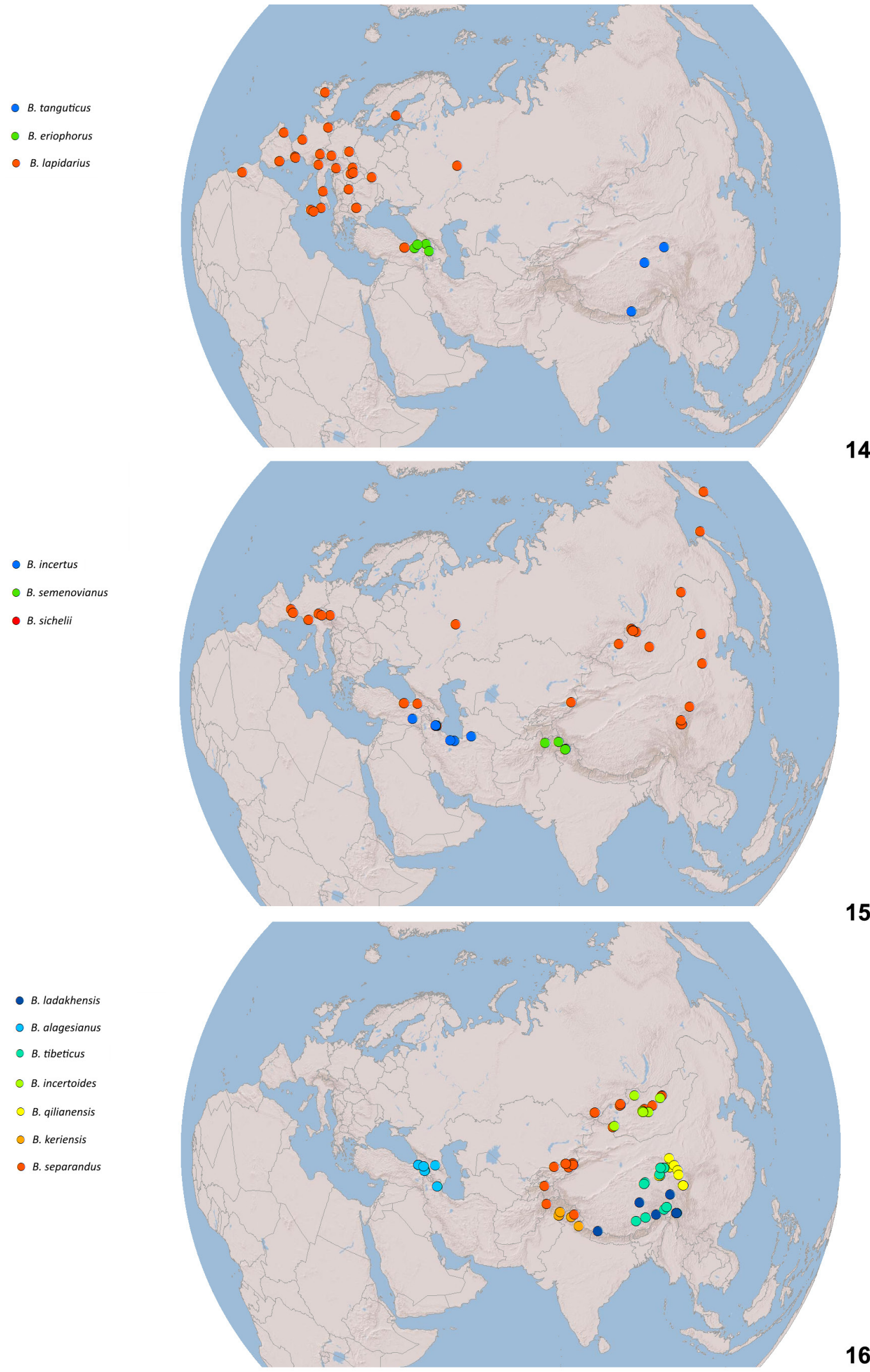

Figs 14-16. Maps of sequenced samples as in Figs 12-13. 14. The tanguticus-group and the lapidariusgroup. 15. The sichelii-group. 16. The keriensis-group. 
from the Densitree plot (Fig. 21), with particular uncertainty in the relationships of B. prshewalskyi + $B$. rufofasciatus, $B$. incertus, and $B$. semenovianus. The date-calibrated phylogeny for the species of the subgenus Melanobombus estimated in the maximum-clade-credibility tree based on the four genes is shown in Fig. 22.

From the estimate of the species tree in Fig. 22 we recognise: (1) a rufipes-group of two species that is the sister group to all of the other species of the subgenus Melanobombus; (2) a festivus-group of one species; (3) a rufofasciatus-group of nine species; (4) a tanguticus-group of one species; (5) a lapidariusgroup of two species; (6) a sichelii-group of three species; and (7) a keriensis-group of seven species.

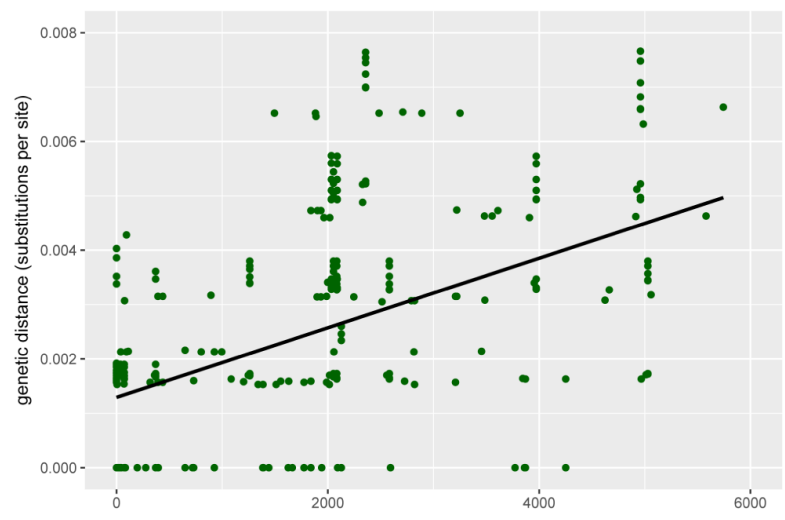

17 sichelii within candidates

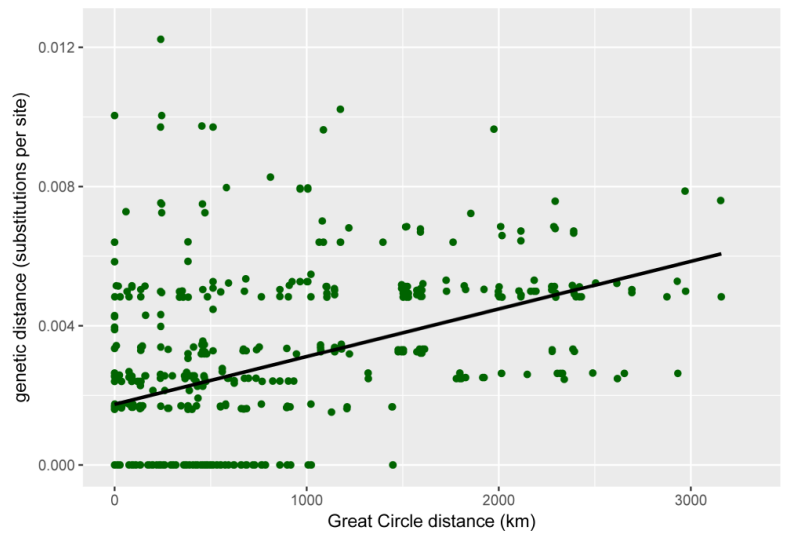

19 keriensis within candidates

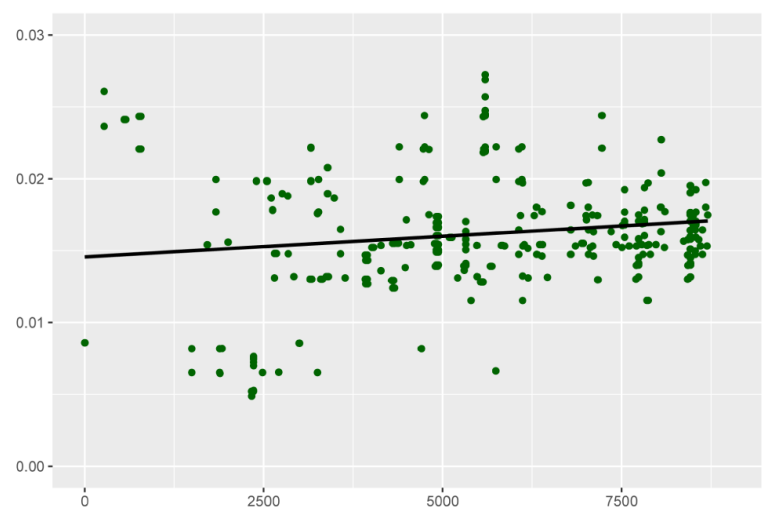

18 sichelii among candidates

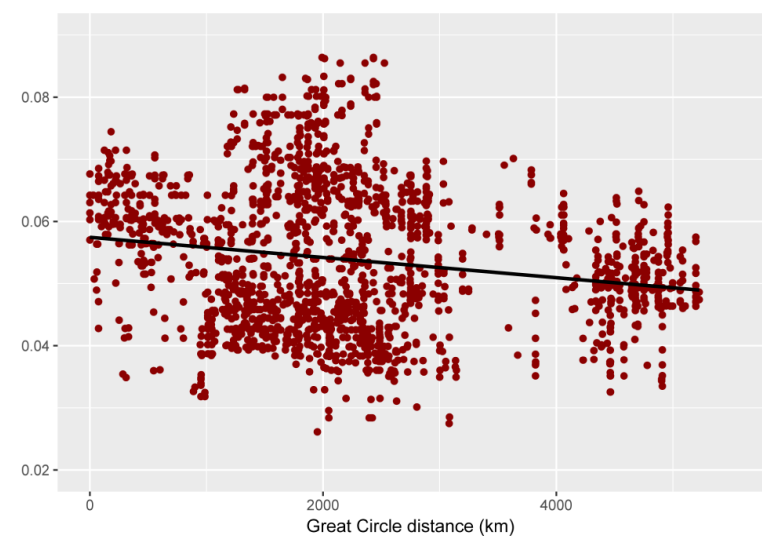

20 keriensis among candidates

Figs 17-20. Plots of (y-axis) pairwise proportion of genetic divergence between COI barcode region sequences against ( $x$-axis) pairwise Great Circle geographical distance in $\mathrm{km}$ between sample sites with linear trend lines (black). 17. Genetic divergences within the candidate species for the sichelii-complex identified using Bayesian UF-PTP (Mantel $r=0.52$ ). 18. Genetic divergences among the candidate species for the sichelii-complex identified using Bayesian UF-PTP (Mantel $r=0.21$ ). 19. Genetic divergences within the candidate species for the keriensis-complex identified using Bayesian UF-PTP (Mantel $r=0.16$ ). 20. Genetic divergences among the candidate species for the keriensis-complex identified using Bayesian UF-PTP (relationship not positive). For details of the measurements see the text. 


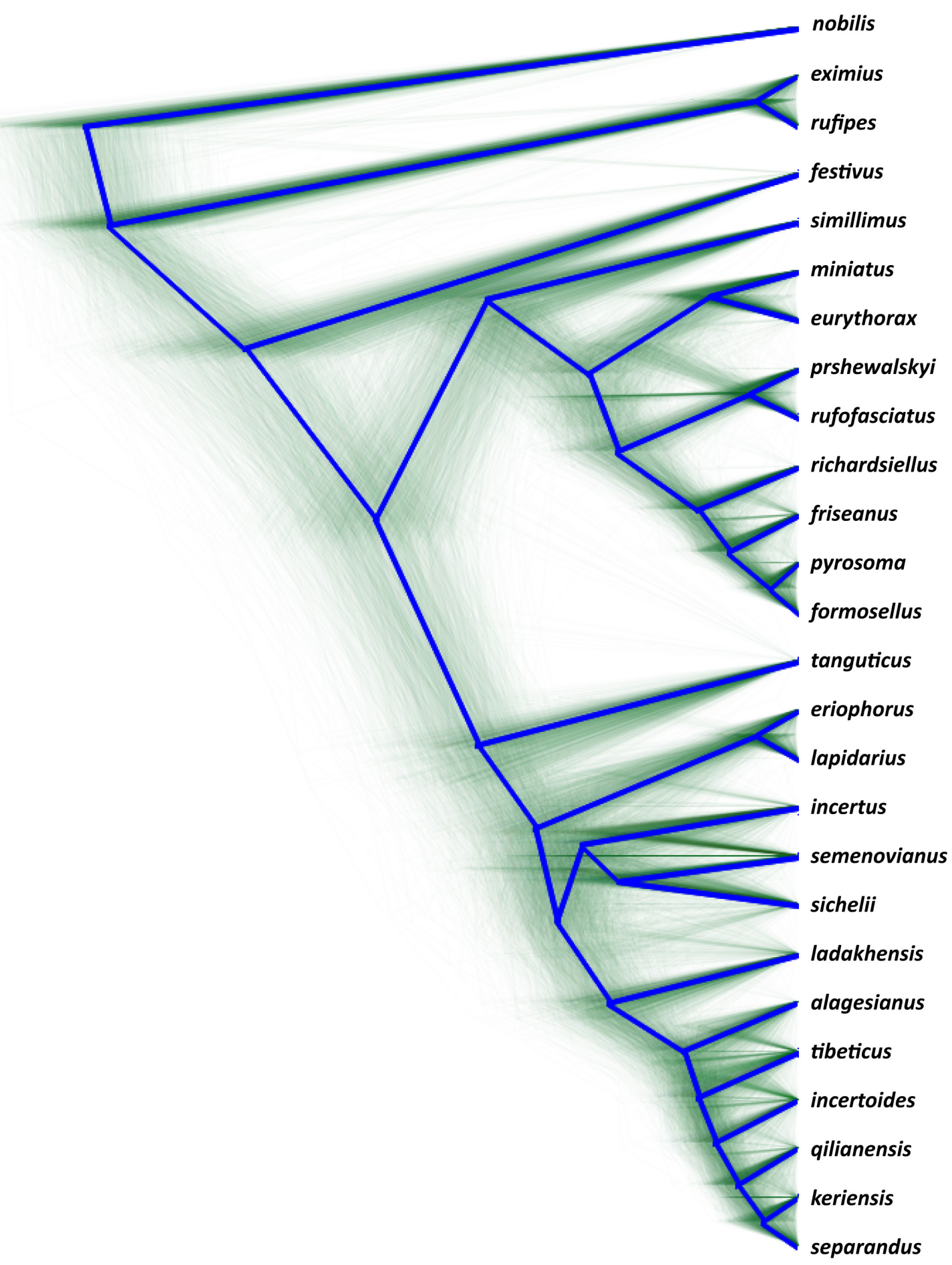

Fig. 21. A sample of 10000 species trees from among 100 million trees for species of the subgenus Melanobombus von Dalla Torre, 1880 reconstructed with *BEAST from gene trees for the COI, 16S, opsin and PEPCK genes, displayed in green using Densitree, with the summary 'root canal' superimposed as a thick blue line. The outgroup B. nobilis Friese, 1905 is shown. 


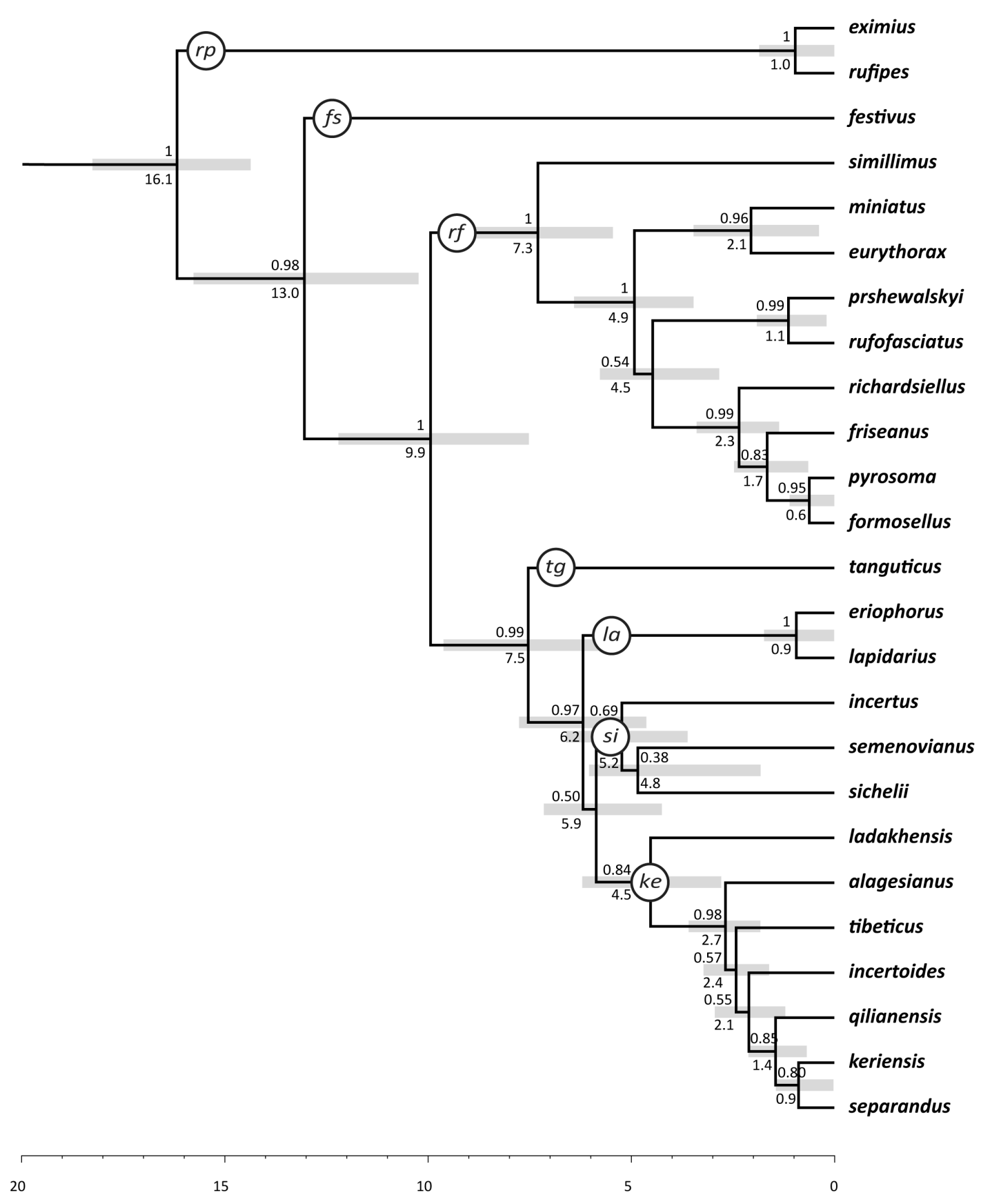

Time before the present ( $\mathrm{Ma}$ )

Fig. 22. Most likely dated phylogenetic (ultrametric) tree for the species of the subgenus Melanobombus reconstructed von Dalla Torre, 1880 with *BEAST from trees for four genes (COI, 16S, PEPCK, opsin) with $B$. nobilis Friese, 1905 as the outgroup (not shown), estimated as the maximum-clade-credibility tree among a sample of 10000 species trees with a $1 \%$ burn-in out of 100 million MCMC trees. Values above the nodes are Bayesian posterior probabilities showing support for groups. Values below the nodes are estimated dates of divergence in Ma (millions of years before the present) calibrated from a molecular estimate for the date of crown divergence within the subgenus Melanobombus. Grey bars show the $95 \%$ confidence limits on the estimated dates of divergence. Species groups discussed in the text are labelled in circles: $r p=$ rufipes-group; $f_{s}=$ festivus-group; $r f=$ rufofasciatus-group; $t g=$ tanguticus-group; la =lapidarius-group; $s i=$ sichelii-group; and $k e=k e r i e n s i$-group. 


\section{Biogeographic history}

The uncertainty in the phylogenetic tree (Fig. 21) involves mainly the positions of terminal species, so it is unlikely to have a strong effect on the broader pattern of biogeographic history.

The dispersal-corridor model is implemented within the analysis by constraining the set of permitted contiguous area distributions for each lineage that allows the area combinations: $\mathrm{AB} B \mathrm{BC} \mathrm{BE} \mathrm{BF} \mathrm{CD} \mathrm{CE}$ CH CI EF EG EH FG GH GI ABC ABE ABF BCD BCE BCF BCH BCI BDF BEF BEG BEH BFG CDE CDH CDI CEF CEG CEH CGH CGI CHI EFG EFH EGH EGI EHI FGH FGI GHI, based on Table 5 and Fig. 23. The most likely solution for ancestral distributions of lineages for the subgenus Melanobombus from the DIVALIKE+J analysis is shown in Fig. 24. All of these events can be resolved requiring only the short-distance dispersal as proposed in Fig. 23, if suitable habitat were available at the appropriate times in all of the corridors.

The earliest most recent common ancestor of the subgenus Melanobombus is most likely to have been distributed in the east Himalayan area. Many early descendent lineage distributions are estimated to include the west Himalayan area (dispersal event 1). This is where most of the extant species of the rufipesgroup, festivus-group, rufofasciatus-group, and tanguticus-group persist (Fig. 24). Later divergences within the rufofasciatus-group are centred on the Hengduan area and, most recently, the north China area. The common ancestors of the lapidarius-group and sichelii-group are likely to have dispersed westwards through the Iranian and Armenian highlands and into Europe (dispersal event 2) and eastwards into north-eastern Asia (dispersal event 3). More recently the common ancestors of the keriensis-group have dispersed back to (dispersal event 4) and then diverged around the QTP area, with the most recent divergence around the west Himalayan area, dispersing back into Central Asia (B. separandus).

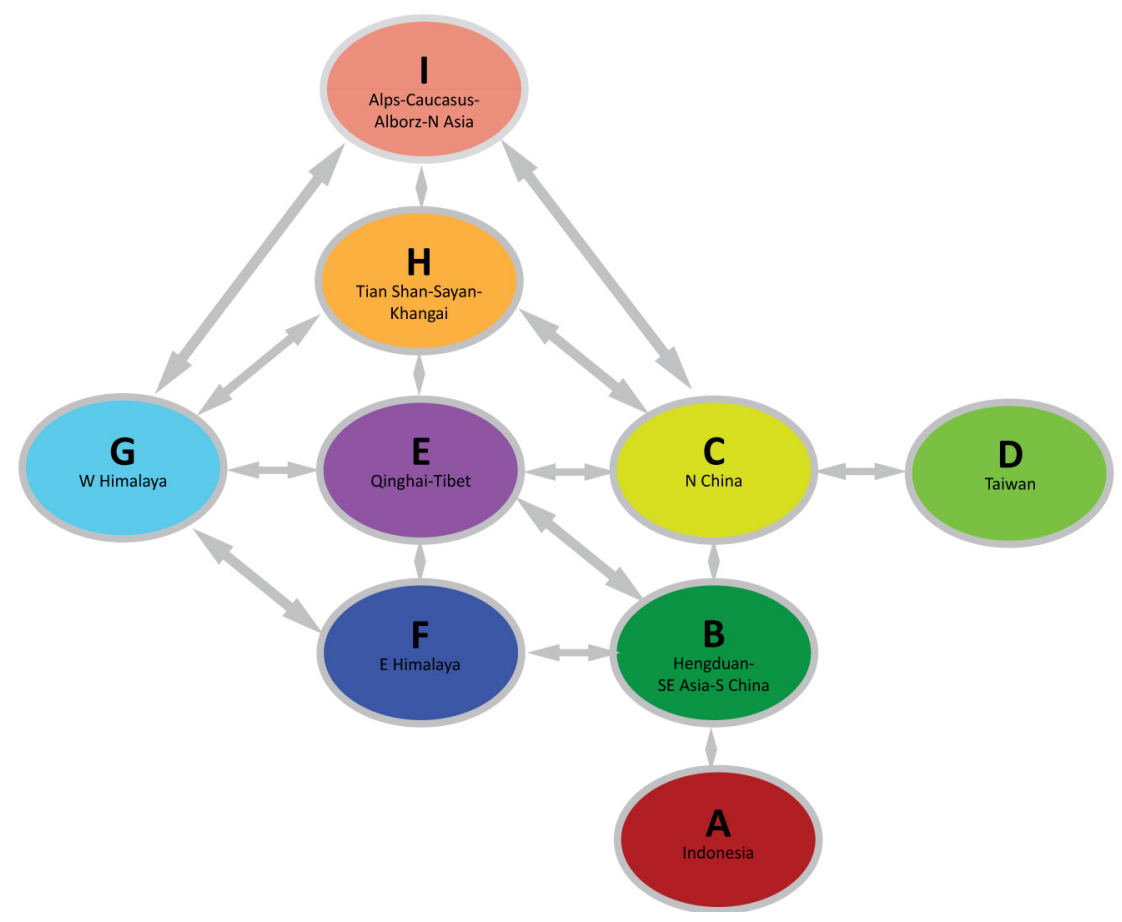

Fig. 23. Diagram representing a corridor-dispersal model, encompassing a set of the short-distance dispersal events permitted (in either direction) between the areas defined in Table 5, based on their geographical proximity and the likely disposition of corridors with suitable habitat and favourable climates in the past. 


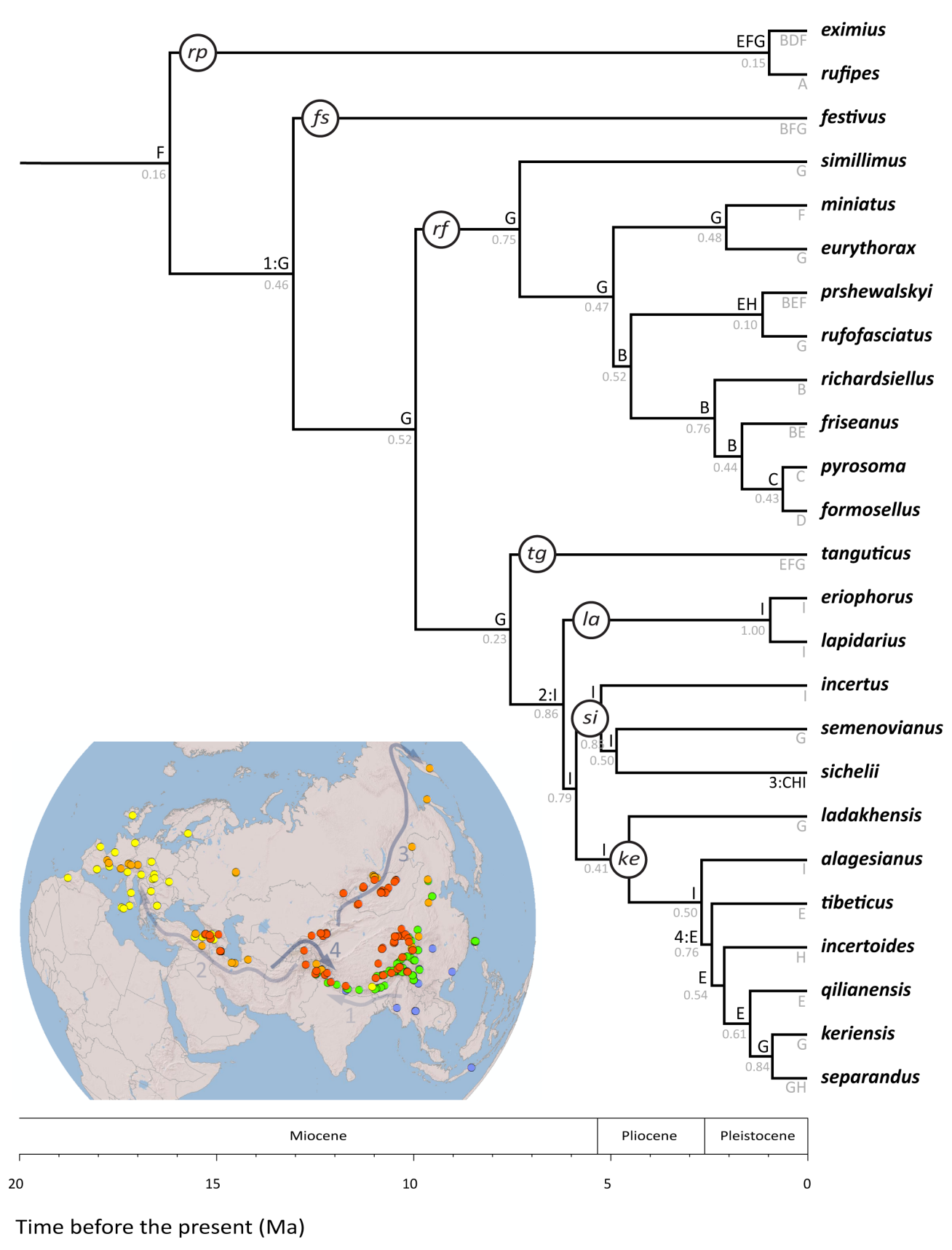

Fig. 24. (Most likely ancestral ranges for lineages of the subgenus Melanobombus von Dalla Torre, 1880. reconstructed with DIVALIKE $+\mathrm{J}$ (BioGeoBEARS) using the short-distance dispersal (no jumps) model in Fig. 23, the estimate of species phylogeny in Fig. 22, and with B. nobilis representing the outgroup (not shown). Letters represent the area units defined in Table 5 and in Fig. 23: letter combinations in grey below terminals show species' current distributions; letter combinations above the nodes show the most likely reconstructions for ancestral distributions (with four selected dispersal events numbered), with the probabilities of these solutions for these ancestors shown below the nodes. Species groups discussed in the text are labelled in circles: $r p=$ rufipes-group; $f s=$ festivus-group; $r f=$ rufofasciatusgroup; $t g$ = tanguticus-group; la = lapidarius-group; $s i=$ sichelii-group; and ke=keriensis-group. Inset map shows sequenced samples for the species groups (blue = the rufipes-group and festivus-group; green $=$ the rufofasciatus-group; yellow $=$ the tanguticus-group and lapidarius -group; orange $=$ the sichelii-group; and red = the keriensis-group) with arrows showing the four numbered dispersal events. 


\title{
Synopsis of world species
}

\author{
Order Hymenoptera Linnaeus, 1758 \\ Family Apidae Linnaeus, 1758 \\ Genus Bombus Latreille, 1802
}

Subgenus Melanobombus von Dalla Torre, 1880

We associate a total of 186 published formal names with species of the subgenus Melanobombus (including misspellings and infrasubspecific names). Applying the ICZN (1999) rules for an assessment of the status of these names under Article 45.6, just 115 names are considered to be available (unavailable names are not listed here). Below is a list of the 25 species recognised from the integrative analysis together with the major taxonomic and nomenclatural changes since the checklist by Williams (1998).

The subgenera Rufipedibombus and Festivobombus (Richards 1968) were included within the subgenus Melanobombus by Williams et al. (2008), based on evidence from the five genes obtained by Cameron et al. (2007). These groups are recognised here as the rufipes-group of species and the festivus-group of species. Within the remaining species of Melanobombus, two species groups had been recognised by Reinig (1935) and by Williams (1991): the rufofasciatus-group and the lapidarius-group of species. Using the pattern of relationships supported here (Fig. 22), we recognise and label a tanguticus-group, a sichelii-group, and a keriensis-group from our estimate of phylogeny in order to facilitate discussion:

rufipes-group

Bombus eximius Smith, 1852

Bombus rufipes Lepeletier, 1835

festivus-group

Bombus festivus Smith, 1861

rufofasciatus-group

Bombus simillimus Smith, 1852

Bombus miniatus Bingham, 1897

Bombus eurythorax Wang, 1982 stat. rev.

Bombus prshewalskyi Morawitz, 1880 stat. rev.

= Bombus rufocinctus Morawitz, 1880 (non Cresson, 1863) syn. nov.

= Bombus chinensis von Dalla Torre, 1890 (non Morawitz, 1890) syn. nov.

Bombus rufofasciatus Smith, 1852

Bombus richardsiellus (Tkalců, 1968)

Bombus friseanus Skorikov, 1933

Bombus pyrosoma Morawitz, 1890

Bombus formosellus (Frison, 1934)

tanguticus-group

Bombus tanguticus Morawitz, 1887

lapidarius-group

Bombus eriophorus Klug, 1807

= Bombus caucasicus Radoszkowski, 1859

Bombus lapidarius (Linnaeus, 1758)

= Bombus bisiculus Lecocq, Biella, Martinet \& Rasmont, 2019 syn. nov. 
sichelii-group

Bombus incertus Morawitz, 1881

Bombus semenovianus (Skorikov, 1914)

Bombus sichelii Radoszkowski, 1859

keriensis-group

Bombus ladakhensis Richards, 1928

Bombus alagesianus Reinig, 1930 stat. rev.

Bombus tibeticus Williams sp. nov.

Bombus incertoides Vogt, 1911 stat. rev.

Bombus qilianensis Williams sp. nov.

Bombus keriensis Morawitz, 1887

Bombus separandus Vogt, 1909 stat. rev.

= Bombus lapidarius [subsp.] kohli Vogt, 1909 (non Cockerell, 1906) syn. nov.

= Bombus kozlovi Skorikov, 1910 syn. nov.

= Bombus lapidarius var. tenellus Friese, 1913 syn. nov.

= Bombus tenellus var. alpivagus Richards, 1930 syn. nov.

= Lapidariobombus alagesianus subsp. pamirus Skorikov, 1931 syn. nov.

= Lapidariobombus alagesianus subsp. mongolicus Skorikov, 1931 (non (Friese, 1916) syn. nov.

= Bombus keriensis f.g. [subsp.] bucharicus Reinig, 1935 syn. nov.

= Bombus keriensis f.g. [subsp.] richardsi Reinig, 1935 (non Frison, 1930) syn. nov.

= Bombus tenellus subsp. tibetensis S.-F. Wang, 1982 syn. nov.

\section{Key to the species of the subgenus Melanobombus}

Future identification of species of the subgenus Melanobombus will be most reliable for specimens from which COI-barcode data are available for comparison of nucleotide differences with the reference data set from this project deposited on www.boldsystems.org, project BBML. Keys using morphological shape, surface sculpturing, and hair-colour-pattern characters follow below, with the most reliable characters placed at the beginning of each couplet. Variation within species necessitates having several terminal couplets for some species. Our results imply that in some cases we should be able to assign most reliably specimens with locality labels to groups or species on the basis of their collection locality alone. All identifications of species from the key or from the figures should be checked against the species' diagnoses within the accounts of each species.

Diagrams showing the major aspects of variation in the colour-patterns of the dorsal hair are presented in Figs 25-180. These diagrams summarise only the major differences (Williams 2007) rather than the details (Williams 1991: figs 394-439). This is a simplification to aid quantitative comparisons and inevitably requires compromises (Williams 2007). Colour-pattern variation within species is established with reference to particular individuals identified from COI barcodes. Morphology of the male genitalia is illustrated in Figs 181-204.

\section{Key to species for females of the subgenus Melanobombus}

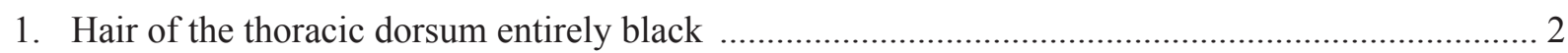

- Hair of the thoracic dorsum with some pale hair that is either white or yellow or brown ............... 6

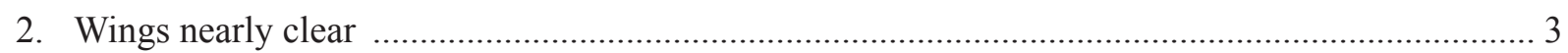

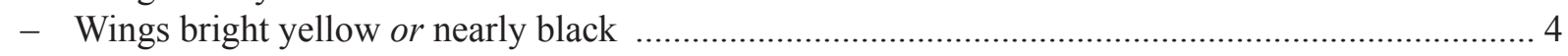

3. Hair of T3 black (Europe)

B. lapidarius (Linnaeus, 1758) (part)

- Hair of T3 orange-red (China) B. pyrosoma Morawitz, 1890 (part) 
4. Wings bright yellow with wing veins orange

B. eximius Smith, 1852

- Wings nearly black with wing veins black

5. Hair of mid and hind tibiae black and T4 -5 red, hind tibia outer surface with many decumbent short branched black hairs (western Himalaya)

B. simillimus Smith, 1852 (part)

- Hair of mid and hind tibiae orange or black, but if black then T4-5 black, hind tibia outer surface without decumbent short branched black hairs (Sumatra, Java)

B. rufipes Lepeletier, 1835

6. Hair of the thoracic dorsum between the wing bases in the centre either white or yellow or brown

- Hair of the thoracic dorsum between the wing bases in the centre black, sometimes with some pale hair intermixed, with paler anterior and often posterior bands of pale hair that is either white or yellow

7. Hair of T5 white

B. festivus Smith, 1861

- Hair of T5 red 8

8. Hair of the thoracic dorsum uniformly yellow B. semenovianus (Skorikov, 1914)

- Hair of the thoracic dorsum white

9. Hair of $\mathrm{T} 2$ chocolate brown, side of thorax white, wings dark (western Himalaya)

B. simillimus (part)

- Hair of T2 black, side of thorax black, wings nearly clear (Caucasus)

B. eriophorus Klug, 1807 (part)

10. Long hair of the face at the antennal base with an obvious patch dominated by long pale grey or pale yellow hair, which in its centre often has few or no black hairs intermixed

- Long hair of the face mostly black, sometimes with a minority of long yellow or grey hair intermixed

11. Hair of $\mathrm{T} 2$ anteriorly brown, $\mathrm{T} 3-5$ bright orange-red

B. friseanus Skorikov, 1933 (part)

- Hair of T2 anteriorly grey or yellow, T3 anterior half at least black, T4-5 orange-red or pale orange or cream

12. Hair of $\mathrm{T} 2$ posteriorly with at least a very narrow fringe of black hair, T3 predominantly black, T4-5 uniformly pale orange-red or pale orange or cream or white

B. sichelii Radoszkowski, 1859 (part)

- Hair of T2 entirely pale, posteriorly without any black hair, T3 black anteriorly but posteriorly usually with a broad pale fringe, T4-5 orange-red sometimes with paler posterior fringes

B. keriensis Morawitz, 1887 (part)

13. Hair of the tail entirely orange-red, although sometimes pale, especially in posterior fringes ...... 14

- Hair of the tail with at least some bright white hair posteriorly on T5 ........................................ 30

14. Hair of $\mathrm{T} 3$ predominantly red 15

- Hair of T3 predominantly or at least anteriorly broadly black sometimes with a narrow posterior fringe of red or white or cream or yellow

15. Hair of the pale thoracic bands golden yellow B. friseanus (part)

- Hair of the pale thoracic bands grey-white 16 
16. From mainland China

- From Taiwan

B. formosellus (Frison, 1934)

17. Hair of face entirely black, thorax anterior and posterior white bands with many black hairs intermixed

B. pyrosoma (part)

- Hair of face with short grey hairs intermixed, thorax anterior and posterior white bands with few black hairs intermixed

B. friseanus (part)

18. Hair of $\mathrm{T} 2$ posteriorly with some black

- Hair of T2 posteriorly entirely either white or cream or yellow

19. Hair of T1 with at least a few cream or yellow hairs, pale bands of thoracic dorsum either cream or yellow

B. lapidarius (part)

- Hair of T1 entirely black, pale bands of thoracic dorsum white

B. eriophorus (part)

20. Hindleg basitarsus broad (length $3 \times$ greatest breadth) with the distal posterior corner broadly angled (nearly $90^{\circ}$ ), outer surface with the short hairs golden, hair of the scutellum with few or no black hairs intermixed

- Hindleg basitarsus narrow (length $4 \times$ greatest breadth) with the distal posterior corner sharply angled (nearly $45^{\circ}$ ), outer surface with the short hairs predominantly black, hair of the scutellum often with many black hairs intermixed

B. tanguticus Morawitz, 1887

21. From Iran westwards to Turkey

- From Afghanistan eastwards to Central Asia, Mongolia, Qinghai-Tibetan Plateau

22. Hair of the corbicular fringes black, at most with a few pale tips, pale bands bright white, scutellum anterior margin with few black hairs, leg bases with black hair, T4-5 deep red

B. incertus Morawitz, 1881

- Hair of the distal posterior corbicular fringes often predominantly orange, pale bands either white or cream or yellow, scutellum anterior margin with a narrow band of many black hairs, leg bases with a few pale hairs, T4-5 either red or orange-red

23. Hair of the pale bands bright white, T4-5 red, often the face with a very few white hairs intermixed and $\mathrm{T} 2$ posteriorly with a very few black hairs intermixed (Iran)

B. sichelii (part)

- Hair of the pale bands white or cream or yellow, T4-5 orange-red, the face entirely black and T2 posteriorly entirely pale

B. alagesianus Reinig, 1930

24. [NB couplets 24-29 may be reliable only for queens and not for workers] Hair of the pale bands white or grey or cream

- Hair of the pale bands light yellow

25. Hair of the side of the thorax in its lower half with some pale hair and T3 laterally with a few pale hairs, scutellum with a narrow anterior band entirely black but usually covering less than half of the length of the scutellum (Central Asia, Mongolia)

- Hair of the side of the thorax in its lower half entirely black and T3 entirely black, scutellum with the anterior half entirely black (Mongolia)

B. incertoides Vogt, 1911

26. Hair of face entirely black, T3 more often with a few pale hairs usually only laterally, leg bases more often with many black hairs, T4-5 uniformly orange-red (Central Asia, northwest Qinghai-Tibetan Plateau)

B. separandus Vogt, 1909 (part) 
- Face with at least a very few long pale hairs and/or some short branched pale hairs at the base of the antenna, T3 more often with pale hairs laterally and often posteriorly, leg bases more often predominantly pale with few or no black hairs, T4-5 either uniformly orange-red or posteriorly with distinctly paler fringes (western Himalaya, west Qinghai-Tibetan Plateau)

B. keriensis (part)

27. Clypeus in its ventral half with many scattered medium-sized punctures; side of the thorax with yellow hair reaching scarcely more than half of the distance ventrally to the leg bases and the more ventral part entirely black, leg bases entirely black, face entirely black, T3 entirely black (central and southeast Qinghai-Tibetan Plateau)

B. tibeticus sp. nov.

- Clypeus in its ventral half (excluding the depressions adjacent to the labrum) with at most only scattered small punctures; side of the thorax with yellow hair reaching ventrally nearly to the leg bases at least as a very few scattered yellow hairs, leg bases with or without yellow hairs, face black or with a few yellow hairs, T3 either with or without scattered yellow hairs laterally and sometimes posteriorly

28. Hair of the thoracic dorsum with the black band between the wing bases narrower than the yellow bands and often with yellow hairs intermixed above the wing bases and narrowly near the midline (northeast Qinghai-Tibetan Plateau)

B. qilianensis sp. nov.

- Hair of the thoracic dorsum with the black band between the wing bases broader than the yellow bands and without yellow hairs intermixed above the wing bases or narrowly near the midline .. 29

29. Hair of the face usually with at least a very few long pale hairs and/or some short branched pale hairs at the base of the antenna, leg bases with some pale hairs, T3 more often with yellow hairs laterally and sometimes posteriorly, thoracic dorsum pale bands sometimes with a few black hairs intermixed, T4-5 either uniformly orange-red or posteriorly with distinctly paler fringes (western Himalaya, west Qinghai-Tibetan Plateau)

B. keriensis (part)

- Hair of the face entirely black, leg bases either with very few yellow hairs or without pale hairs, T3 often without yellow hairs, thoracic dorsum pale bands without black hairs intermixed, T4-5 uniformly orange-red (Mongolia, Russia, northwest Qinghai-Tibetan Plateau)

B. separandus (part)

30. Hair on the side of the thorax black, or if white in part then the hair on the metasoma is short and T2 is black or anteriorly yellow and the thoracic dorsum has the pale posterior band broad and bright with few black hairs

- Hair on the side of the thorax predominantly either yellow or cream, or if black or white in part then the hair on the metasoma is long and T2 is usually with some white or cream (rarely yellow) and the thoracic dorsum has the pale posterior band often obscured by many black hairs 33

31. Hair of T3 posteriorly red

- Hair of T3 entirely black B. richardsiellus (Tkalců, 1968)

32. Large individuals (body length $>18 \mathrm{~mm}$ : queens) with the hair on $\mathrm{T} 2$ usually with at least a few scattered yellow hairs intermixed in the anterior lateral corners, small individuals (body length $<18 \mathrm{~mm}$ : workers) with T2 predominantly yellow with only a very narrow posterior black fringe, thoracic dorsum with anterior and posterior pale bands bright grey with a minority of black hairs intermixed (western Himalaya eastwards to Nepal)

B. rufofasciatus Smith, 1852

- Large individuals (body length $>18 \mathrm{~mm}$ : queens) with the hair of T2 entirely black, at most with some grey hairs intermixed near the anterior median edge, small individuals (body length $<18 \mathrm{~mm}$ : workers) with $\mathrm{T} 2$ in the anterior half yellow and in much of the posterior half black, thoracic dorsum with anterior and posterior pale bands dull grey, especially posteriorly often obscure with many black hairs intermixed (Qinghai-Tibetan Plateau, Gansu, Sichuan, Yunnan) ... B. prshewalskyi Morawitz, 1880 
33. Hair of the thoracic dorsum with the black band between the wing bases without any pale hairs intermixed next to the wing bases, the hair of the face black B. ladakhensis Richards, 1928

- Hair of the thoracic dorsum with the black band between the wing bases with pale hairs intermixed next to the wing bases, the hair of the face with black and pale hairs intermixed

34. Hair of the thoracic dorsum with the dark band between the wing bases predominantly black with few pale hairs intermixed, the pale bands of the thorax and T1 either brownish-yellow, goldenyellow, or pale greenish-yellow (western Himalaya eastwards to Nepal)

B. eurythorax Wang, 1982

- Hair of the thoracic dorsum with the dark band between the wing bases with nearly equal numbers of black and pale hairs intermixed, the pale bands of the thorax and T1 either cream or grey-white (Sikkim, Bhutan, Arunachal Pradesh)

B. miniatus Bingham, 1897

\section{Key to species for males of the subgenus Melanobombus}

(males of B. tanguticus remain unknown, see the species account for further detail)

1. Hair of the thoracic dorsum uniformly either black or orange-brown or black with short grey hairs intermixed; genitalia with penis-valve head with the recurved inner hook nearly as broad as long ..

- Hair of the thoracic dorsum in part either yellow or white, often with a band of black between the wing bases; genitalia with penis-valve head with the recurved inner hook either much longer than broad or rarely the recurved part fused to the shaft (B. ladakhensis)

2. Hair of the thoracic dorsum uniformly orange-brown; genitalia with penis-valve head with outer distal outer flange narrower than the length of the recurved inner hook B. festivus Smith, 1861

- Hair of the thoracic dorsum either uniformly black or black with short grey hairs intermixed; genitalia with penis-valve head with distal outer flange broader than the length of the recurved inner hook

3. Wings bright yellow with wing veins orange; long hair of the face with short pale brown hair intermixed

B. eximius Smith, 1852

- Wings nearly black with wing veins black; hair of the face entirely black

B. rufipes Lepeletier, 1835

4. Genitalia with gonostylus posteriorly reduced and transverse, $<0.5 \times$ as long as broad, the volsella projecting beyond the gonostylus by $>2 \times$ as long as gonostylus (Asian mountains) ..................... 5

- Genitalia with gonostylus rounded and disc-like, nearly $1 \times$ as long as broad, the volsella projecting beyond the gonostylus by $<1 \times$ as long as gonostylus (widespread) ............................................ 13

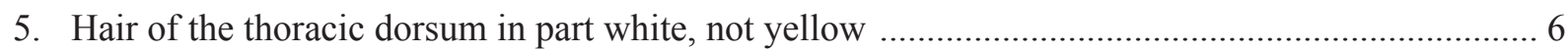

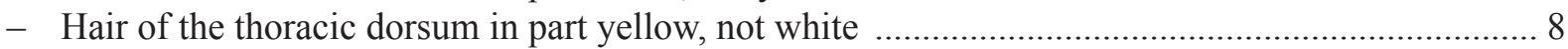

6. Hair of the thoracic dorsum entirely white .............................................. s. simillimus Smith, 1852

- Hair of the thoracic dorsum with a band of black at least intermixed between the wing bases ....... 7

7. Hair of $\mathrm{T} 2$ bright yellow with only a very narrow band with few black hairs along the posterior margin (western Himalaya east to Nepal)

B. rufofasciatus Smith, 1852

- Hair of T2 dull yellow with either at least a few black hairs intermixed or often with many black hairs intermixed and with a broad black band in the posterior quarter that often extends medially towards the anterior (eastern Himalaya from Arunachal Pradesh to the interior of the QinghaiTibetan Plateau, Gansu, Sichuan, Yunnan)

B. prshewalskyi Morawitz, 1880 
8. Genitalia with gonostylus with the posterior interior process reduced to a single narrow spine ..... 9

- Genitalia with gonostylus with the posterior interior process broad with two distal corners ..........11

9. Gonostylus inner basal process narrow with the distal angle $<45^{\circ}$; hair of $\mathrm{T} 3$ sometimes partly black but with at least the posterior margin fringed with yellow

- Gonostylus inner basal process broad with the distal angle nearly $90^{\circ}$; hair of T3 predominantly black

B. richardsiellus (Tkalců, 1968)

10. Hair of T3-5 orange-red with at least a narrow band of yellow along the posterior margin, sometimes entirely yellow (western Himalaya east to Nepal)

B. eurythorax Wang, 1982

- Hair of T3-5 orange-red sometimes with a few black hairs along the posterior margin (Sikkim, Bhutan, Tibet, Arunachal Pradesh)

B. miniatus Bingham, 1897

11. Genitalia with gonostylus with the posterior interior process with the two inner corners projecting with the same length; hair of T2 yellow with very few black hairs (North China)

B. pyrosoma Morawitz, 1890

- Genitalia with gonostylus with the posterior interior process with the dorsal inner corner projecting inwards further than the ventral inner corner; hair of T2 yellow with many black hairs posteriorly .

12. Hair of T4 orange-red with few or no black hairs (Xizang, Qinghai, Yunnan, Sichuan, Guizhou) .... B. friseanus Skorikov, 1933

- Hair of T4 orange-red with many black hairs especially laterally (Taiwan)

B. formosellus (Frison, 1934)

13. Genitalia with penis-valve head with the recurved inner hook extensively fused for 0.75 of its length with the adjacent penis-valve shaft; hair of T6-7 orange-red at the base and white distally

B. ladakhensis Richards, 1928

- Genitalia with penis-valve head with the recurved inner hook not fused for $\leq 0.5$ of its length with the adjacent penis-valve shaft; hair of T6-7 orange-red at the base and usually orange distally ... 14

14. Hair of the thoracic dorsum in part either white or cream 15

- Hair of the thoracic dorsum either in part yellow or entirely black 19

15. Eyes distinctly enlarged relative to eyes of the females; hair of the face, ventral half of the side of the thorax, and anterior half of the scutellum black with few white hairs intermixed (Mongolia) ....

B. incertoides Vogt, 1911

- Eyes similar in relative size to eyes of the females; hair of the face, ventral half of the side of the thorax, and anterior half of the scutellum either white or with few black hairs intermixed ........... 16

16. Hair of $\mathrm{T} 2$ posteriorly without a narrow fringe of black hairs and entirely pale ............................ 17

- Hair of T2 posteriorly with a narrow fringe of black hairs .....B. sichelii Radoszkowski, 1859 (part)

17. From Afghanistan or eastwards to Mongolia ................................... separandus Vogt, 1909 (part)

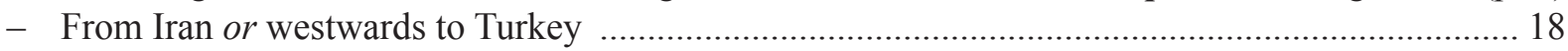

18. Hair of the pale bands white, black band between the wing bases narrower than the anterior white band, scutellum anterior margin with few black hairs, T4-5 red ........... B. incertus Morawitz, 1881

- Hair of the pale bands either white or cream, black band between the wing bases broader than the anterior pale band, scutellum anterior margin with a narrow band of many black hairs, T4-5 orangered

B. alagesianus Reinig, 1930 (part) 
19. Eyes distinctly enlarged relative to eyes of the females; hair of the face predominantly black with a few yellow hairs intermixed B. semenovianus (Skorikov, 1914)

- Eyes similar in relative size to eyes of the females; hair of the face predominantly yellow 20

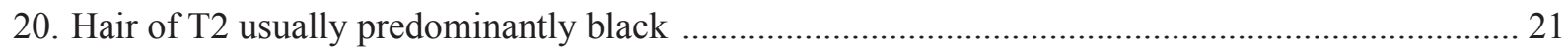

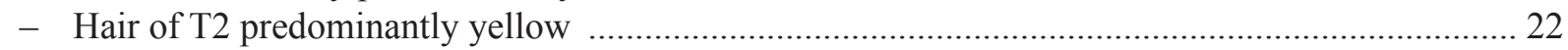

21. Hair of the thoracic dorsum either extensively or entirely black, hair of T1 often yellow (Europe, Turkey)

B. lapidarius (Linnaeus, 1758)

- Hair of the thoracic dorsum either entirely yellow or if there is a narrow black band between the wing bases then $\mathrm{T} 1$ is entirely black (Turkey, Caucasus)

B. eriophorus Klug, 1807

22. Hair of $\mathrm{T} 2$ posteriorly with a broad fringe of black hairs

B. sichelii (part)

- Hair of T2 posteriorly either entirely yellow or with a very few black hairs posteriorly restricted to the middle

23. From Iran or westwards

B. alagesianus (part)

- From Afghanistan or eastwards

24. From Mongolia or Russia

B. separandus (part)

- From the Qinghai-Tibetan Plateau

25. Hair of T3 entirely black

B. tibeticus sp. nov.

- Hair of T3 black with yellow hairs laterally 26

26. Hair of T2 entirely yellow (eastern Qinghai-Tibetan Plateau)

B. qilianensis sp. nov.

- Hair of T2 yellow with a very few black hairs posteriorly in the middle (western Qinghai-Tibetan Plateau)

B. keriensis Morawitz, 1887

\section{Review of the species}

Accounts of the 25 species accepted after integrated assessment follow below. Square brackets [Bombus $x u s]$ are used to indicate transliterations, translations, and interpretations.

\section{Bombus eximius Smith, 1852}

Figs 1, 12, 25-34, 181

Bombus eximius Smith, 1852a: 47.

Bombus latissimus Friese, 1910: 404.

Bombus rufipes var. [subsp.] tonkinensis Friese, 1914: 11.

Bombus latissimus var. [subsp.] detritus Friese, 1916: 109.

Bombus latissimus var. [subsp.] segmentarius Friese, 1916: 109.

Bombus latissimus var. [subsp.] tricoloratus Friese, 1916: 109.

Bombus rufipes var. [subsp.] lutescens Friese, 1918: 517 (non Pérez, 1890: 154 = B. flavidus Eversmann).

Bombus discrepans Pendlebury, 1923: 64.

Bombus geei subsp. nigribasis Cockerell, 1931: 5.

Bombus eximius var. [subsp.] fulvobrunneus Chiu, 1948: 65.

Bombus eximius var. [subsp.] pallidus Chiu, 1948: 66 (non Cresson, 1863: $92=$ B. pensylvanicus (DeGeer)).

Bombus rufipes var. tonkininsis - Friese 1918: 527, incorrect subsequent spelling.

Bombus latiszimus - Friese 1931: 304, incorrect subsequent spelling. 

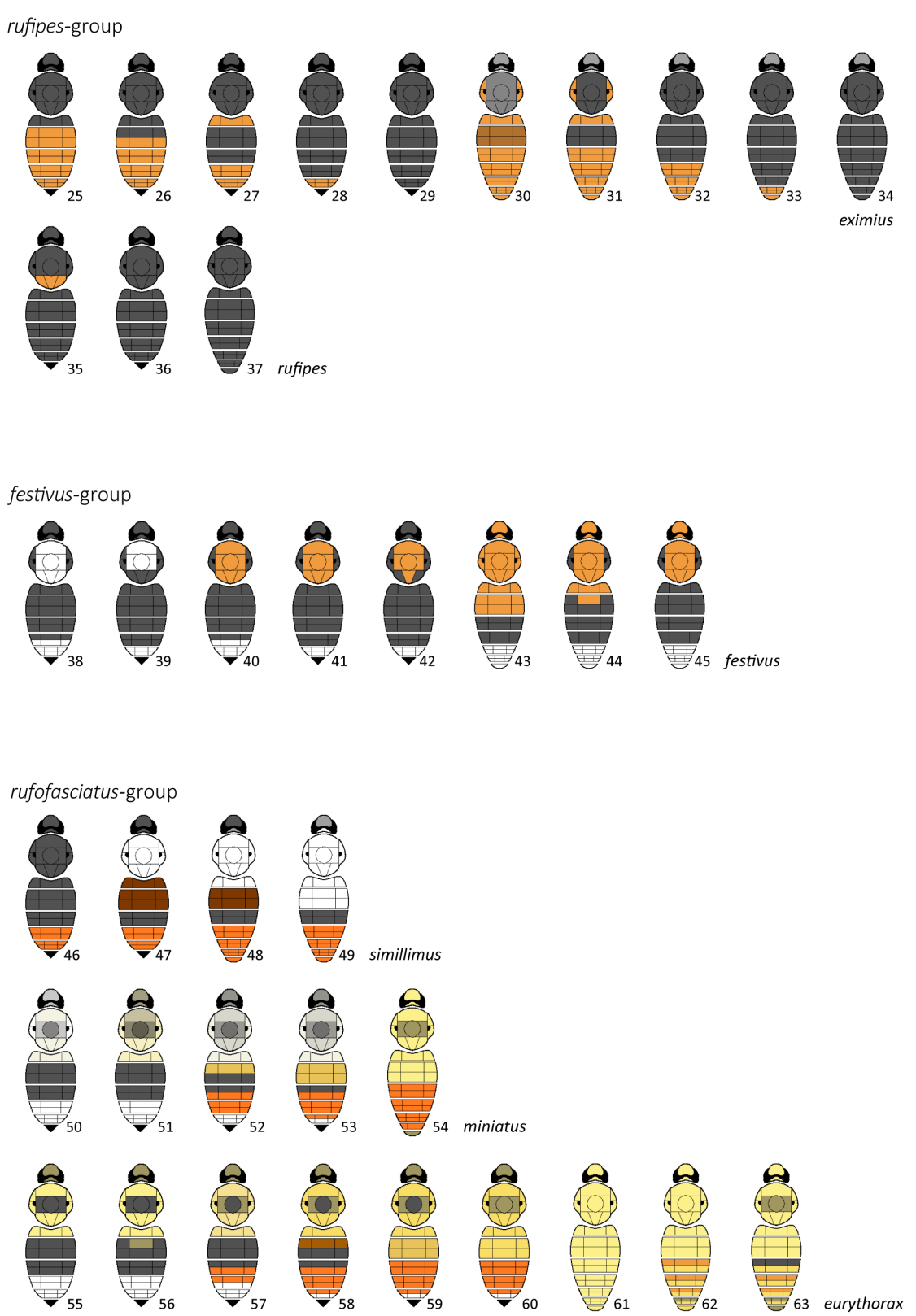

Figs 25-63. Simplified diagrams for the colour patterns of the hair on the dorsum for the species from the integrative analysis. The dorsum is divided into regions, each of which shows only the predominant or most apparent colour for that region using a simplified colour palette, with olive indicating a mixture of black and yellow hair, and grey indicating a mixture of black and white hair. The rufipes-group. 25. Queen, China-Taiwan. 26. Queen, China-Guangdong. 27. Worker, China-Sichuan. 28. Worker, Thailand. 29. Queen, Nepal. 30. Male, China-Sichuan. 31. Male, China-Sichuan. 32. Male, Thailand. 33. Male, Nepal. 34. Male, Nepal. 35. Queen, Indonesia-Sumatra. 36. Queen, Indonesia-Java. 37. Male, Indonesia-Java. The festivus-group. 38. Queen, Nepal. 39. Queen, China-Sichuan. 40. Worker, ChinaSichuan. 41. Worker, China-Xizang. 42. Worker, China-Yunnan. 43. Male, Nepal. 44. Male, ChinaYunnan. 45. Male, China-Yunnan. The rufofasciatus-group. 46. Queen, India-Kashmir. 47. Worker, India-Kashmir. 48. Male, India-Kashmir. 49. Male, India-Kashmir. 50. Queen, India-Arunachal Pradesh. 51. Queen, Bhutan. 52. Worker, Bhutan. 53. Worker, Bhutan. 54. Male, Bhutan. 55. Queen, India-Kashmir. 56. Queen, India-Kashmir. 57. Worker, India-Kashmir. 58. Worker, India-Kashmir. 59. Worker, IndiaKashmir. 60. Worker, Pakistan. 61. Male, India-Kashmir. 62. Male, India-Kashmir. 63. Male, Nepal. 


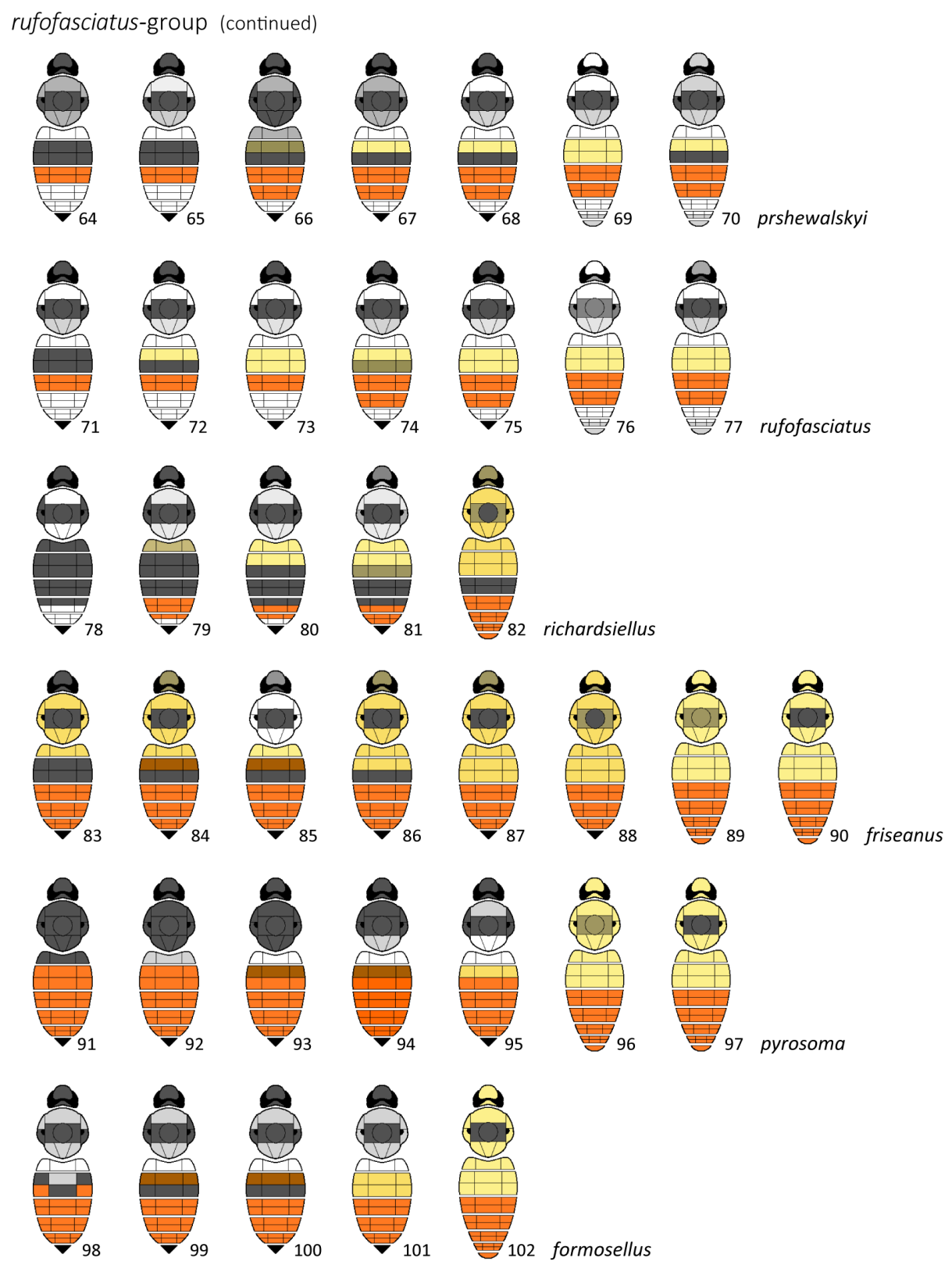

Figs 64-102. Simplified diagrams for the colour patterns of the hair on the dorsum for the species from the integrative analysis. The dorsum is divided into regions, each of which shows only the predominant or most apparent colour for that region using a simplified colour palette, with olive indicating a mixture of black and yellow hair, and grey indicating a mixture of black and white hair. The rufofasciatus-group. 64. Queen, China-Yunnan. 65. Queen, China-Sichuan. 66. Worker, China-Xizang. 67. Worker, ChinaXizang. 68. Worker, China-Gansu. 69. Male, China-Yunnan. 70. Male, China-Xizang. 71. Queen, IndiaKashmir. 72. Queen, India-Kashmir. 73. Queen, Pakistan. 74. Worker, India-Kashmir. 75. Worker, IndiaKashmir. 76. Male, Pakistan. 77. Male, India-Kashmir. 78. Queen, Burma. 79. Worker, Burma. 80. Worker, China-Xizang. 81. Worker, China-Xizang. 82. Male, Burma. 83. Queen, China-Sichuan. 84. Worker, China-Sichuan. 85. Worker, China-Sichuan. 86. Worker, China-Sichuan. 87. Worker, China-Sichuan. 88. Worker, China-Xizang. 89. Male, China-Sichuan. 90. Male, China-Sichuan. 91. Queen, China-Beijing. 92. Queen, China-Beijing. 93. Worker, China-Shanxi. 94. Worker, China-Beijing. 95. Worker, ChinaBeijing. 96. Male, China-Beijing. 97. Male, China-Beijing. 98. Queen, China-Taiwan. 99. Worker, ChinaTaiwan. 100. Worker, China-Taiwan. 101. Worker, China-Taiwan. 102. Male, China-Taiwan. 

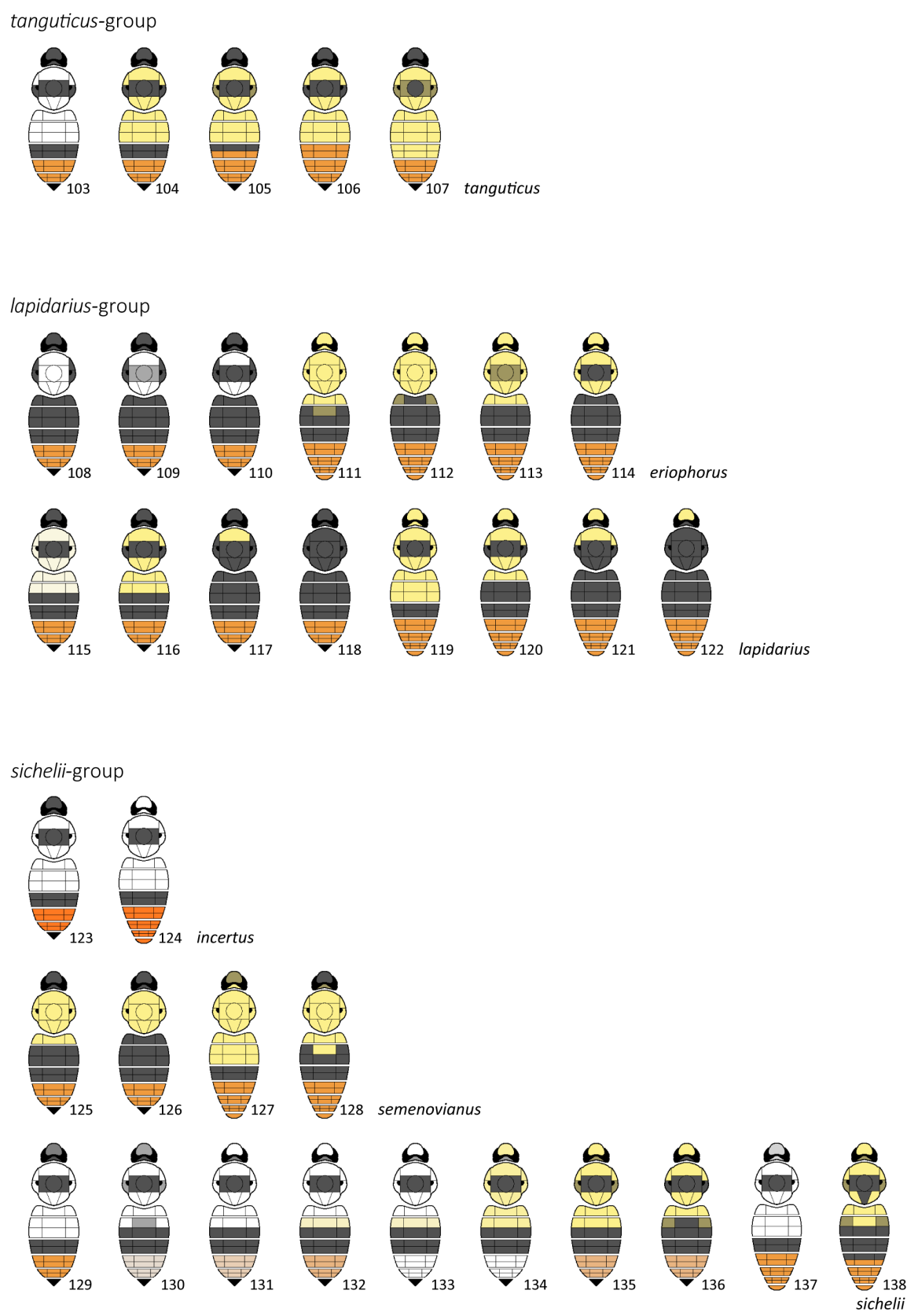

Figs 103-138. Simplified diagrams for the colour patterns of the hair on the dorsum for the species from the integrative analysis. The dorsum is divided into regions, each of which shows only the predominant or most apparent colour for that region using a simplified colour palette, with olive indicating a mixture of black and yellow hair, and grey indicating a mixture of black and white hair. The tanguticus-group. 103. Worker, China-Qinghai. 104. Worker, China-Qinghai. 105. Queen, China-Qinghai. 106. Queen, China-Xizang. 107. Queen, India-Kashmir. The lapidarius-group. 108. Queen, Russia-North Ossetia. 109. Worker, Azerbaijan. 110. Queen, Georgia. 111. Male, Russia-North Ossetia. 112. Male, Russia-North Ossetia. 113. Male, Russia-North Ossetia. 114. Male, Turkey. 115. Queen, Morocco. 116. Queen, Spain. 117. Queen, Spain. 118. Queen, UK. 119. Male, Spain. 120. Male, Spain. 121. Male, UK. 122. Male, UK. The sichelii-group. 123. Queen, Iran. 124. Male, Iran. 125. Queen, India-Kashmir. 126. Queen, IndiaKashmir. 127. Male, India-Kashmir. 128. Male, India-Kashmir. 129. Queen, Iran. 130. Queen, RussiaSakha. 131. Queen, China-Sichuan. 132. Worker, China-Sichuan. 133. Queen, Mongolia. 134. Worker, Mongolia. 135. Queen, Spain. 136. Worker, Austria. 137. Male, Turkey. 138. Male, Mongolia. 


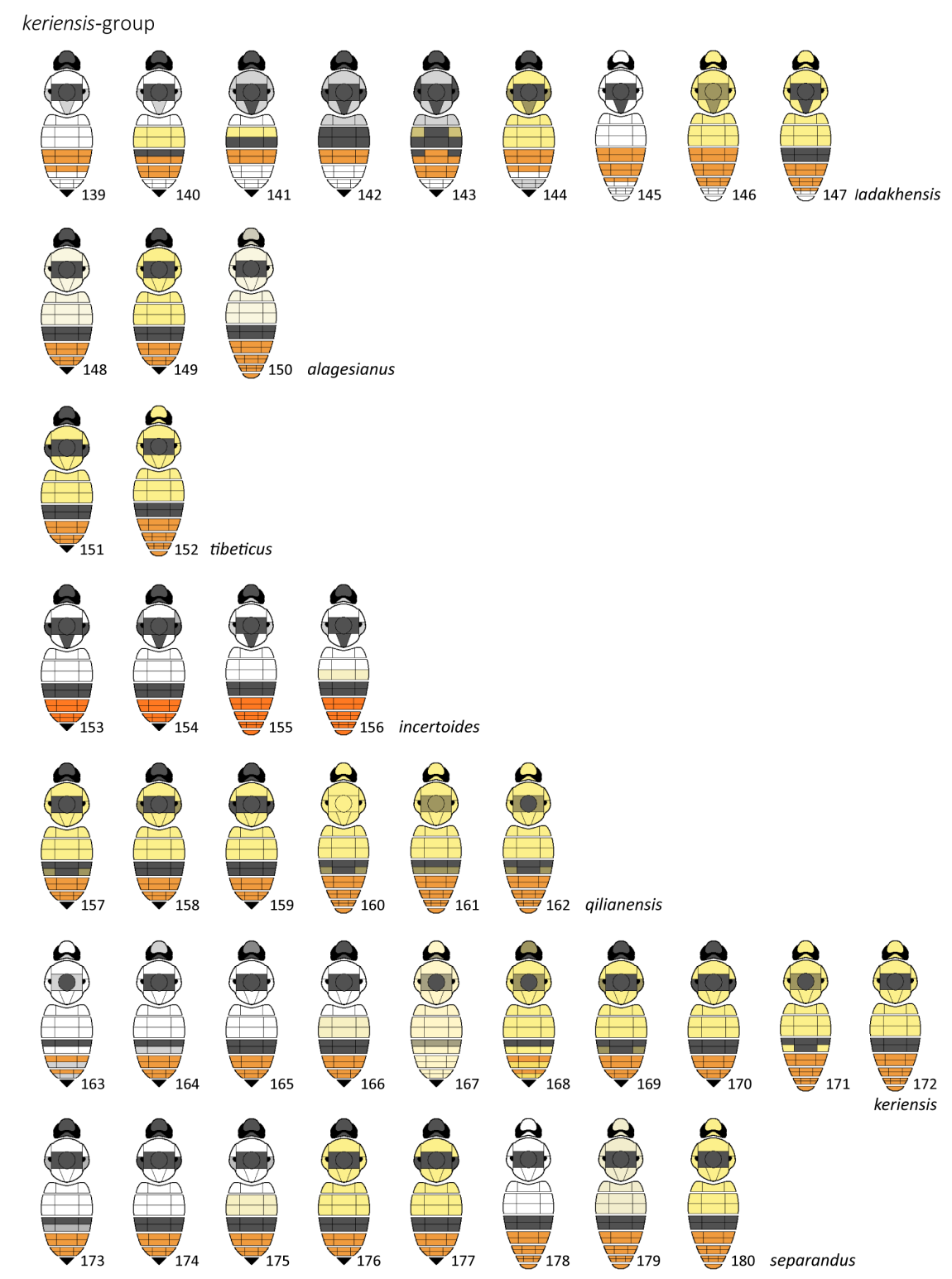

Figs 139-180. Simplified diagrams for the colour patterns of the hair on the dorsum for the species from the integrative analysis. The dorsum is divided into regions, each of which shows only the predominant or most apparent colour for that region using a simplified colour palette, with olive indicating a mixture of black and yellow hair, and grey indicating a mixture of black and white hair. The keriensis-group. 139. Queen, China-Sichuan. 140. Worker, China-Sichuan. 141. Queen, China-Sichuan. 142. Queen, China-Sichuan. 143. Worker, China-Xizang. 144. Queen, India-Kashmir. 145. Male, China-Qinghai. 146. Male, India-Kashmir. 147. Male, China-Gansu. 148. Queen, Armenia. 149. Queen, Iran. 150. Male, Georgia. 151. Worker, China-Qinghai. 152. Male, China-Qinghai. 153. Queen, Mongolia. 154. Worker, Mongolia. 155. Male, Mongolia. 156. Male, Mongolia. 157. Queen, China-Sichuan. 158. Worker, China-Qinghai. 159. Worker, China-Qinghai. 160. Male, China-Qinghai. 161. Male, China-Qinghai. 162. Male, China-Qinghai. 163. Queen, Pakistan. 164. Queen, Pakistan. 165. Queen, Pakistan. 166. Queen, Pakistan. 167. Queen, Afghanistan. 168. Queen, Pakistan. 169. Queen, Pakistan. 170. Queen, India-Kashmir. 171. Male, India-Kashmir. 172. Male, India-Kashmir. 173. Queen, ChinaXinjiang. 174. Queen, Kyrgyzstan. 175. Queen, Kyrgyzstan. 176. Queen, Mongolia. 177. Queen, IndiaKashmir. 178. Male, Kazakhstan. 179. Male, China-Xinjiang. 180. Male, Mongolia. 


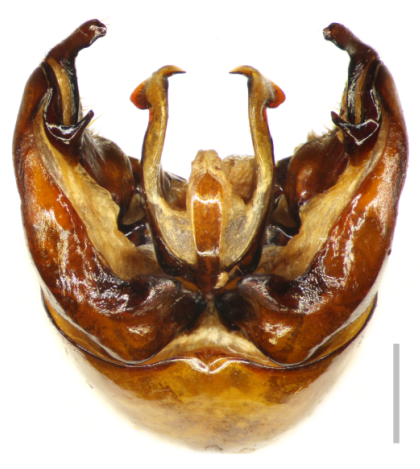

181 eximius

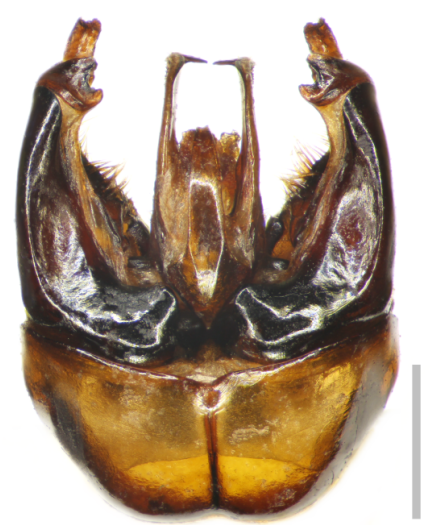

184 simillimus

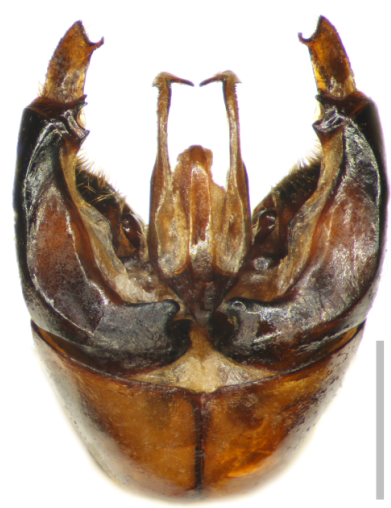

187 prshewalskyi

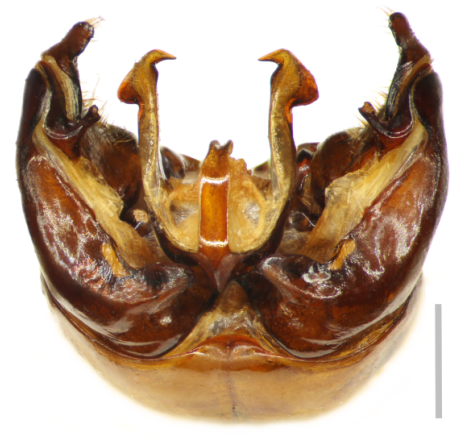

182 rufipes

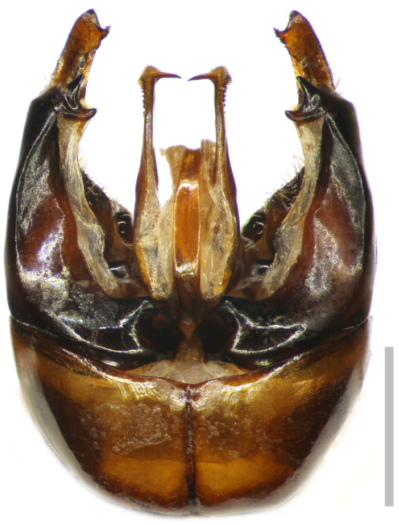

185 miniatus

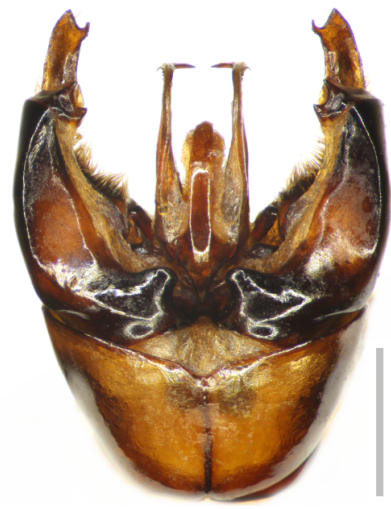

188 rufofasciatus

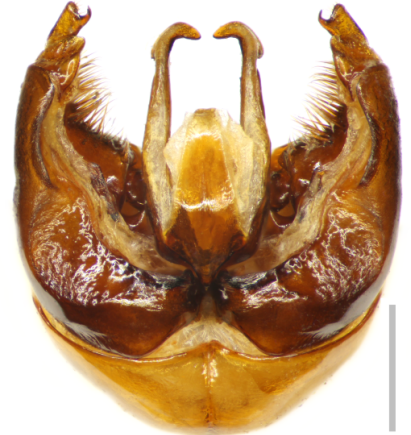

183 festivus

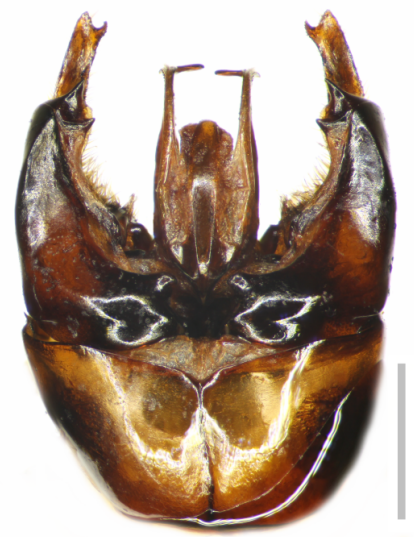

186 eurythorax

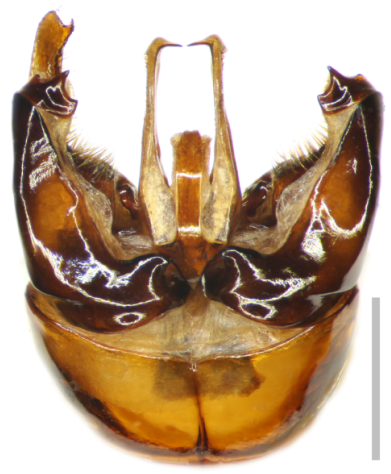

189 richardsiellus

Figs 181-189. Morphology of the male genitalia for species of the subgenus Melanobombus von Dalla Torre, 1880 from the dorsal aspect, anterior at the bottom of the image, posterior at the top. 181. Bombus eximius Smith, 1852, China-Guangxi. 182. B. rufipes Lepeletier, 1835, IndonesiaJava. 183. B. festivus Smith, 1861, Nepal. 184. B. simillimus Smith, 1852, India-Himachal Pradesh. 185. B. miniatus Bingham, 1897, Bhutan. 186. B. eurythorax Wang, 1982 stat. rev., India-Kashmir. 187. B. prshewalskyi Morawitz, 1880 stat. rev., China-Sichuan. 188. B. rufofasciatus Smith, 1852, IndiaKashmir. 189. B. richardsiellus (Tkalců, 1968), Burma (left volsella distal part missing). Scale bars $=$ $1 \mathrm{~mm}$. 


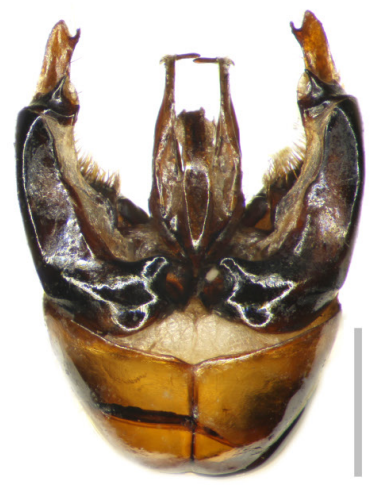

190 friseanus

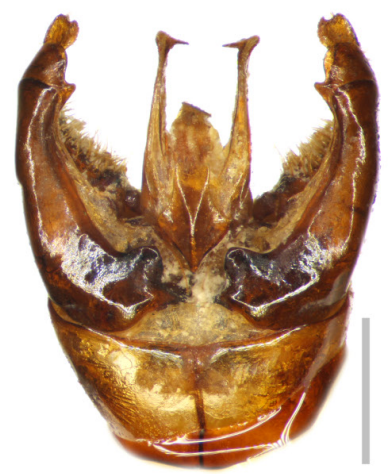

193

eriophorus

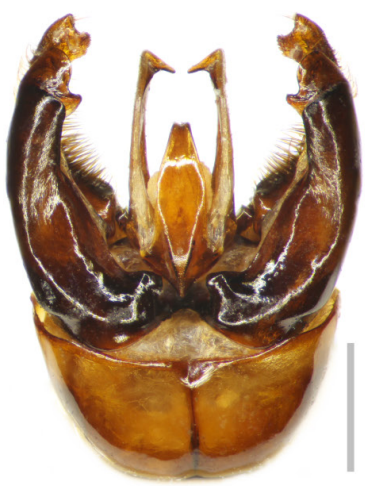

196 semenovianus

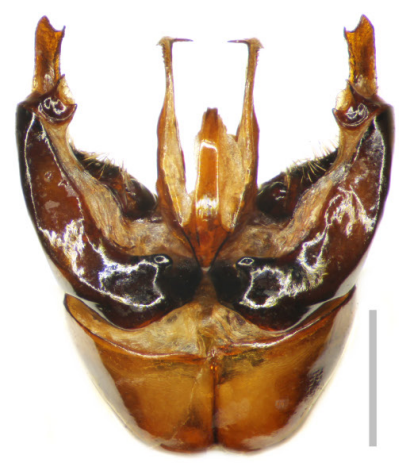

191 pyrosoma

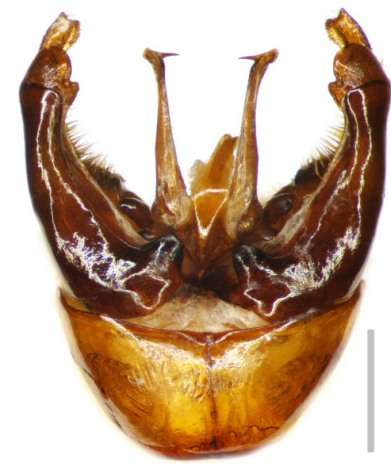

194 lapidarius

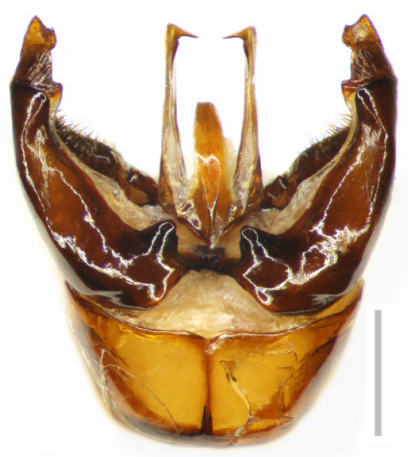

197 sichelii

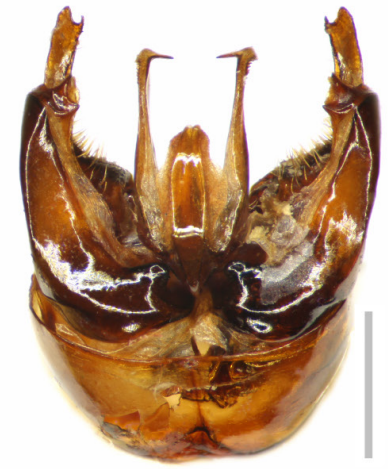

192 formosellus

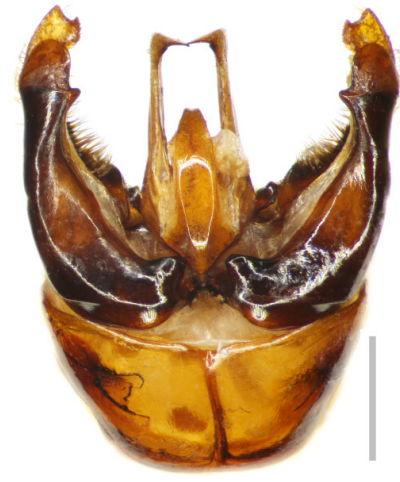

195 incertus

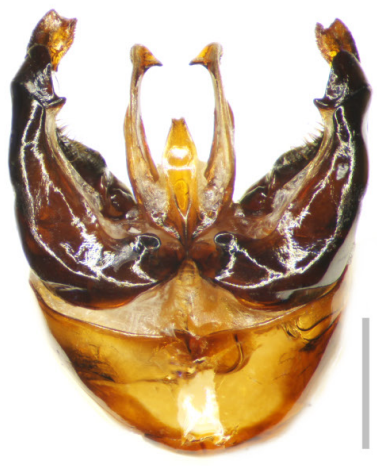

198 ladakhensis

Figs 190-198. Morphology of the male genitalia for species of the subgenus Melanobombus von Dalla Torre, 1880 from the dorsal aspect, anterior at the bottom of the image, posterior at the top. 190. Bombus friseanus Skorikov, 1933, China-Yunnan. 191. B pyrosoma Morawitz, 1890, ChinaBeijing. 192. B. formosellus (Frison, 1934), China-Taiwan. 193. B. eriophorus Klug, 1807, RussiaNorth Ossetia. 194. B. lapidarius (Linnaeus, 1758), UK. 195. B. incertus Morawitz, 1881, Turkey. 196. B. semenoviaus (Skorikov, 1914), India-Kashmir. 197. B. sichelii Radoszkowski, 1859, Austria. 198. B. ladakhensis Richards, 1928 , China-Sichuan. Scale bars $=1 \mathrm{~mm}$. 
Bombus eximius and B. rufipes have a distinctive morphology and previously were placed in a separate subgenus, Rufipedibombus (Skorikov 1923). A close relationship with other species of the subgenus Melanobombus was supported by an analysis of five genes by Cameron et al. (2007) and these subgenera were then synonymised by Williams et al. (2008).

Our PTP analysis (Fig. 10) of coalescents in the COI gene within the rufipes-group supports two species $B$. eximius and B. rufipes, corroborated by differences in morphology. It supports as conspecific within B. eximius s. lat. the individuals from Taiwan that may have much of the hair of T2-6 orange (taxon latissimus), the individuals from southern China and Southeast Asia that often have T2-3 predominantly black and T4 -6 orange, and the individuals from the Himalaya that have T2-4 black and T5-6 either orange or black (taxon eximius s. str.).

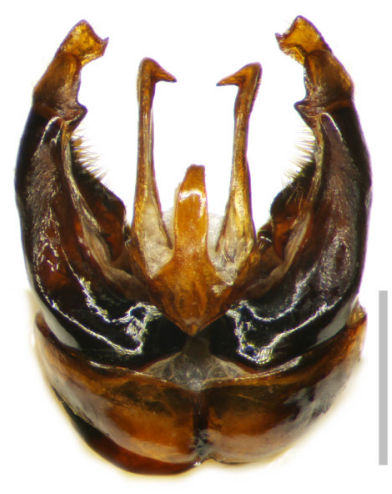

199 alagesianus

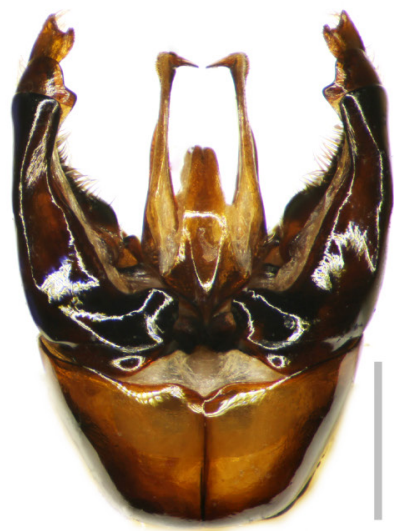

202

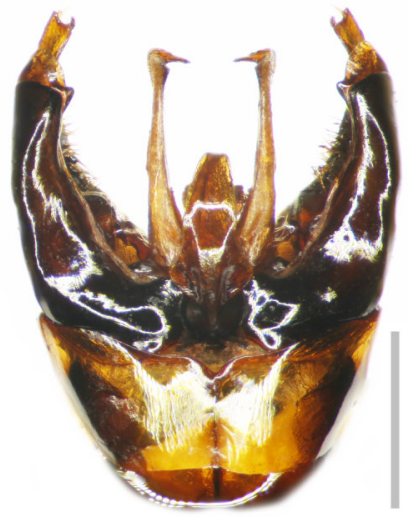

200 tibeticus

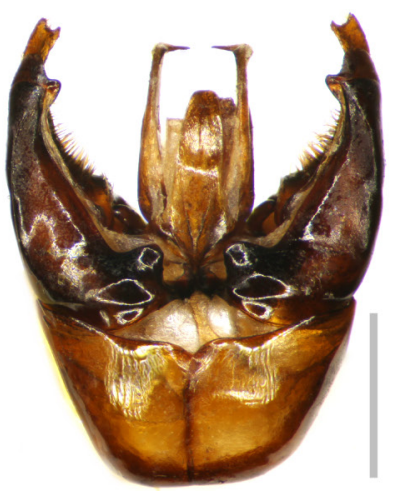

203 keriensis

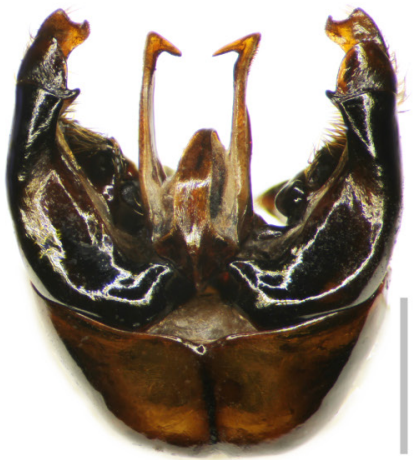

201 incertoides

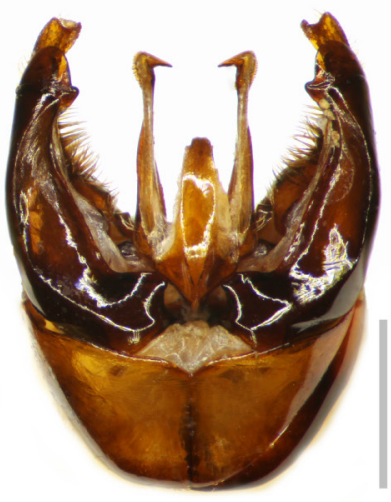

204 separandus

Figs 199-204. Morphology of the male genitalia for species of the subgenus Melanobombus von Dalla Torre, 1880 from the dorsal aspect, anterior at the bottom of the image, posterior at the top. 199. Bombus alagesianus Reinig, 1930 stat. rev., Georgia. 200. B. tibeticus sp. nov., China-Qinghai. 201. B. incertoides Vogt, 1911 stat. rev., Mongolia. 202. B. qilianensis sp. nov., China-Qinghai. 203. B. keriensis Morawitz, 1887, India-Kashmir. 204. B. separandus Vogt, 1909 stat. rev., Kyrgyzstan. Scale bars $=1 \mathrm{~mm}$. 


\section{Diagnosis}

Females (Fig. 1)

Queens very large body length $23-30 \mathrm{~mm}$, workers $13-20 \mathrm{~mm}$. Can be distinguished by their combination of wings yellow with the veins orange (cf. B. rufipes), the hair and integument of mid and hind tibiae and of all barsitarsi orange (cf. some $B$. rufipes). The labral lamella has the anterior edge broad and nearly straight (cf. B. (Pyrobombus) flavescens Smith, 1852, B. (Alpigenobombus) genalis Friese, 1918).

\section{Males}

Body length 16-19 mm. Can be distinguished by their combination of wings yellow with the veins orange (cf. B. rufipes), similarly coloured to the worker but with the hair of the face black intermixed with grey (cf. B. rufipes) and the thoracic dorsum black or sometimes intermixed with grey (cf. B. festivus). Genitalia (Fig. 181) with the gonostylus reduced to a transverse 'S'-shaped band (cf. non-rufipes-group), the proximal inner projection not broadened distally and simple (cf. B. rufipes); volsella projecting beyond the gonostylus by ca $6 \times$ its breadth at its midpoint (cf. B. rufipes), and without an obvious inner distal process or hook (cf. non-rufipes-group); penis valve head with the outer flange greatly expanded as a triangular projection (cf. non-rufipes-group); eye unenlarged relative to female eye.

\section{Material examined}

\section{Holotype}

BANGLADESH • + (queen), holotype of Bombus eximius Smith, 1852 by monotypy (Williams et al. 2009); "Silhet" [= Sylhet]; NHMUK (examined PW).

Material sequenced (7 specimens)

THAILAND • 1 q (worker); Chiang Mai, Doi Inthanon; $18.553^{\circ}$ N, $98.48^{\circ}$ E; 2 Feb. 2007; Y. Areeluck leg.; BOLD seq: 3773E10; PCYU: ML180 • 1 q (worker); same collection data as for preceding; 16 Feb. 2007; Y. Areeluck leg.; BOLD seq: 3773E11; PCYU: ML195 • 1 ㅇ (worker); Chaiyaphum, Tat Tone NP; $15.988^{\circ} \mathrm{N}, 102.041^{\circ} \mathrm{E}$; 12 Oct. 2006; Y. Areeluck leg.; BOLD seq: 3261H06; PCYU: ML196.

CHINA 11 q (queen); Guangdong; $22.2933^{\circ} \mathrm{N}, 111.2061^{\circ} \mathrm{E}$; 16 Jan. 2013; BOLD seq: 1555A07; PW: ML178 • 1 o (worker); Chongqing; 30.13 $\mathrm{N}, 108.1018^{\circ} \mathrm{E}$; Aug. 2010; BOLD seq: 1555A08; PW: ML179.

TAIWAN • 1 q (queen); Taichung, Dashuishan road; $24.2561^{\circ}$ N, $121.0108^{\circ}$ E; 18 Jun. 2004; C. Dietrich leg.; BOLD seq: 1555A06; PW: ML177.

BURMA • 1 क (worker); Chin, Natmataung; $21.2198^{\circ}$ N, $93.9401^{\circ}$ E; 2 Jun. 2010; D. Zimmermann leg.; BOLD seq: 6880E04; NHMW: ML502.

\section{Global distribution}

(Himalayan, south Chinese and southeast Asian mountain species including some of the northern islands) East Asia: CHINA: Xizang, Sichuan, Yunnan, Chongqing, Jiangxi, Guizhou, Fujian, Guangdong, Guangxi, Taiwan. - Himalaya: INDIA: Sikkim, Darjiling Bengal, Arunachal Pradesh, Meghalaya; NEPAL, BHUTAN. - Southeast Asia: BANGLADESH, BURMA, THAILAND, VIETNAM. (IAR, IOZ, KIZ, NHMUK, NHMW, NME, PCYU, PW, RMNH, SEHU, SMNS, USNM, ZMHB, ZMUM.) The species is widely distributed but not common in collections.

\section{Behaviour}

Expected to be food-plant generalists (Kjellsson et al. 1985). 
Bombus rufipes Lepeletier, 1835

Figs 12, 35-37, 182

Bombus rufipes Lepeletier de Saint-Fargeau, [1835]: 473.

Bombus flavipes Handlirsch, 1888: 225.

Bombus rufipes var. [subsp.] obscuripes Friese, 1914: 10.

Bombus rufipes var. [subsp.] intermissus Friese, 1918: 516.

Bremus rufipes var. [subsp.] richardsi Frison, 1930: 6.

Bombus rufipes and B. eximius are now considered parts of the subgenus Melanobombus (see the comments on B. eximius).

Our PTP analysis (Fig. 10) of coalescents in the COI gene within the rufipes-group supports two species B. eximius and B. rufipes, corroborated by differences in morphology.

From morphology, the black wings, black hair of the male face, and the matching form of the male genital volsella and gonostylus support as conspecific the individuals from Sumatra, which usually (not always) have the mid and hind tibiae orange (taxon obscuripes), together with the individuals from Java, which more usually have the mid and hind tibiae predominantly black (taxon rufipes s. str.). The gonostylus interior proximal process is less strongly bifid for the male from Sumatra. For the male labelled Borneo, the black wings, black facial hair, and form of the volsella and gonostylus all match B. rufipes. For this male, the hair of the mid and hind basitarsi is orange, although the hair of the mid tibia is black and the hair of the hind tibia is orange at the base and black at the tips. A few individuals from Sumatra and Peninsular Malaysia have the hair of the scutellum brown or orange (taxon richardsi). A queen of 'ostindischen' origin is described as having T5-6 orange-red (taxon flavipes, not seen).

\section{Diagnosis}

\section{Females}

Queens large body length 24-26 mm, workers 14-18 $\mathrm{mm}$. Can be distinguished by their combination of the hair of the metasoma entirely black with the wings nearly black with the veins black (cf. B. eximius), the hair and integument of mid and hind tibiae and of all barsitarsi either orange or black. The labral lamella has the anterior edge broad and nearly straight (cf. B. (Megabombus) senex Vollenhoven, 1873, B. (Megabombus) melanopoda Cockerell, 1910, from Sumatra).

\section{Males}

Body length 15-18 mm. Can be distinguished by their combination of the hair of the face black with the metasoma entirely black with the wings nearly black with the veins black (cf. B. eximius), and the thoracic dorsum anteriorly black (cf. B. festivus). Genitalia (Fig. 182) with the gonostylus reduced to a transverse ' $S$ '-shaped band (cf. non-rufipes-group), the proximal inner projection broadened distally and bifid (cf. B. eximius); volsella projecting beyond gonostylus by ca $5 \times$ its breadth at its midpoint (cf. B. eximius), without an obvious inner distal process or hook (cf. non-rufipes-group); penis valve head with the outer flange greatly expanded as a triangular projection (cf. non-rufipes-group); eye unenlarged relative to female eye.

\section{Material examined}

Holotype

INDONESIA $\bullet+$ (worker), holotype of Bombus rufipes Lepeletier, 1835 by monotypy; Java; OUMNH (examined PW from photographs). The original description refers to a single worker with no evidence that the author had additional specimens in front of him, so this worker can be recognised as the holotype 
by monotypy. Recognising this specimen as the holotype invalidates the neotype designation by Frison (1930: 11).

Material sequenced ( 2 specimens)

INDONESIA • 2 ô $^{\wedge}$; East Java, Mt Argopuro; $7.9756^{\circ} \mathrm{S}, 113.5193^{\circ} \mathrm{E} ; 5$ Mar. 2010; BOLD seq: 1555E01, 1555E02; SK: ML249, ML250.

\section{Global distribution}

(Southeast Asian mountain species primarily in the southern islands) Southeast Asia: MALAYSIA: Peninsular Malaysia, INDONESIA: Sumatra, Java, ?Kalimantan, ?Sulawesi. (NHMUK, NHMW, PW, OUMNH, SK.)

It was reported previously (by Williams in Starr 1989) that there is a male labelled "Bandjar/Borneo" (= Banjar?) in the NHMUK collection (examined PW). The only other bumblebee species recorded apparently from Borneo is the holotype of B. folsomi (Frison, 1923), which is labelled "Kina Bala/N. Borneo" (= Gunung Kinabalu, Sabah). However, the latter specimen appears to be a mislabelled queen of B. (Pyrobombus) ephippiatus Say, 1837, probably originating from Costa Rica or Panama (Starr 1989; Williams 1998, examined PW).

The NHMUK "Bandjar/Borneo" specimen of B. rufipes reached this collection from B. Pittioni's collection that was assembled in Austria (the specimen carries a det. label from F. Maidl, who was at Vienna's NHMW museum, and a label "Pittioni Coll./ Turner Bequest/B.M. 1954-79"). The NHMW collection has a further three workers and two males with the same locality data in the same handwriting and with the same identification labels. Of nine localities named 'Bandjar' identified in Malaysia and Indonesia from US military gazetteers (USBGN 1968, 1970), one is in Borneo and six are in Java. Frison (1930) interpreted 'Bandjar' as referring to Java for a queen, two workers, and the seven males of B. rufipes loaned to him from the 'Zoological Museum, Buitenzorg, Java' (= Bogor) collection. Two further workers of $B$. rufipes without locality labels are listed by Frison that were loaned to him by Maidl from the NHMW. Handlirsch (1891) wrote that all but one of the B. rufipes then in the NHMW collection were from eastern Java (for the other, see below). The occurrence of B. rufipes on Borneo, perhaps on the higher Maratus mountains of south-eastern Kalimantan near Banjar (across the Java Sea from Java and Sumatra), remains possible, but would need to be confirmed.

Two other records appear to extend the known range. One is a queen in the NHMUK from "Selangor/Bukit Kutu" (Peninsular Malaysia, examined). There is no obvious reason to doubt this record.

Another is a queen in the NHMW collection labelled "N. Celebes / 1908" (= northern Sulawesi, examined $\mathrm{PW}$ ). The occurrence of $B$. rufipes in northern Sulawesi would need to be confirmed because it is ca $2000 \mathrm{~km}$ from the nearest sites with confirmed records for B. rufipes on Java (see the Discussion). The species is widely distributed but not common in collections.

\section{Behaviour}

Some aspects of the behaviour of this species have been described (Michener \& Amir 1977; Kato et al. 1992).

Bombus festivus Smith, 1861

Figs 12, 38-45, 183

Bombus festivus Smith, 1861: 152. 
Bombus atrocinctus Smith, 1870: 193.

Bombus terminalis Smith, 1870: 193.

Bombus melaleucus subsp. discolor Friese, 1905: 514.

Bombus handel-mazettii Pittioni, 1939a: 260.

Bombus calidiformis Pittioni, 1939a: 262.

Bombus festivus has a distinctive morphology and has been placed in a separate subgenus, Festivobombus (Tkalců 1972) or Atrocinctobombus (Skorikov 1933a: name published without description). A close relationship with other species of the subgenus Melanobombus was supported by an analysis of five genes by Cameron et al. (2007) and these subgenera were synonymised by Williams et al. (2008).

Our PTP analysis (Fig. 10) of coalescents in the COI gene within the festivus-group supports a single species B. festivus, corroborated by differences in morphology (see the Diagnosis).

Females show pronounced size-dependent dimorphism in the colour pattern of the hair: large queens have the thoracic dorsum black with a large white patch in the middle (taxon festivus s. str.); whereas workers (which are smaller) and males have the thoracic dorsum extensively orange-brown (taxa atrocinctus and terminalis). That these castes and sexes are conspecific has been confirmed from examining variation within a colony in Nepal (Ito et al. 1984).

\section{Diagnosis}

\section{Females}

Queens large body length 22-26 mm, workers $12-17 \mathrm{~mm}$. Can be distinguished by the hair of the thoracic dorsum either black with a large central white spot (queen) or extensively brown (worker), the wings dark brown, and both castes have the hind tibia with the distal posterior corner produced as a short spine (cf. B. hypnorum (Linnaeus, 1758), B. abnormis (Tkalců, 1968)).

\section{Males}

Body length 13-16 mm. Can be distinguished by the hair of the thoracic dorsum extensively brown, similarly coloured to the worker. Genitalia (Fig. 183) with the gonostylus relatively undifferentiated, although the proximal inner projection is only weakly projecting towards the body midline and more strongly extending ventrally and distally beneath and parallel to the inner edge of the main body of the gonostylus as a shelf (similar to some Pyrobombus but more distinctly pronounced, cf. B. hypnorum, B. abnormis); volsella with a pronounced inner distal corner forming a narrow hook (cf. rufipes-group, lapidarius-group, sichelii-group, keriensis-group); penis valve head with the outer flange only weakly expanded (cf. non-festivus-group); eye unenlarged relative to female eye.

\section{Material examined}

\section{Lectotype}

INDIA - + (queen), lectotype of Bombus festivus Smith, 1861 by designation of Tkalců (1974a); "N.[orth] W.[est]"; NHMUK (examined PW).

\section{Material sequenced (18 specimens)}

NEPAL • 1 q (worker); Bheri, Dilikot; $29.029^{\circ}$ N, $81.749^{\circ}$ E; 28 May 1995; M. Hartmann leg.; BOLD seq: 1551H10; NME: ML198・ 1 q (worker); no data; BOLD seq: 6876H08; PW: ML197.

BHUTAN • 1 q (queen); Thimphu, Lungtenphu; 27.4574 N, 89.6655 E; 17 Mar. 1996; H. Feijen leg.; BOLD seq: 6880H01; RMNH: ML505 • 1 đo; Wangli, Pele-La; $27.5498^{\circ} \mathrm{N}, 90.2157^{\circ}$ E; 16 Sep. 1994; G. Schulten leg.; BOLD seq: 6880H03; RMNH: ML507 • 1 q (queen); Thimphu, Phajoding Gompa; $27.479^{\circ}$ N, $89.595^{\circ}$ E; 25 Apr. 2018; J. Smit leg.; RMNH seq: 1092453; RMNH: ML570 1 q (queen); 
same collection data as for preceding; RMNH seq: 1092451; RMNH: ML572 • 1 q (queen); Wangdue Phodrang, Sephu; $27.53^{\circ}$ N, 90.245 E; 3 May 2018; J. Smit leg.; RMNH seq: 1092504; RMNH: ML571.

CHINA - Yunnan Province • 1 o $^{\top}$; Dali; $25.75^{\circ} \mathrm{N}, 100.1^{\circ} \mathrm{E}$; 8 Jul. 1996; C. Hauser leg.; BOLD seq: 1552A01; SMNS: ML181 • 1 q (worker); Lijiang; $27.0020^{\circ}$ N, $100.182^{\circ}$ E; 13 Jul. 2017; A. Moss leg.;

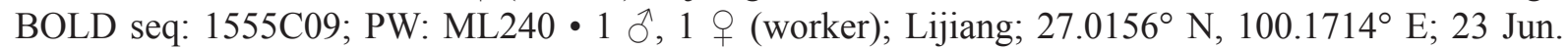
2017; H. Liang leg.; KIB seq: 15; KIB: ML360 • 1 ऊ; same collection data as for preceding; 11 Aug. 2016; KIB seq:16; KIB: ML361 1 त; same collection data as for preceding; 1 Aug. 2016; KIB seq: 17; KIB: ML362 - 1 ; ; same collection data as for preceding; 11 Aug. 2016; KIB seq:18; KIB: ML363

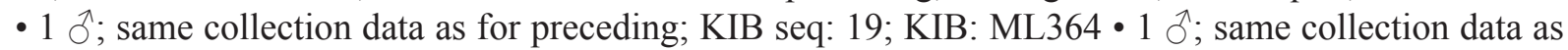
for preceding; 19 Jul. 2017; H. Liang leg.; KIB seq: 20; KIB: ML365 • 1 क; Baima Snow Mountain; 28.3373 ${ }^{\circ}$ N, $99.0771^{\circ} \mathrm{E}$; 14 Aug. 2019; M. Orr leg.; IOZ seq: 14F5; IOZ: ML583. - Sichuan Province - 1 ○ं; Luojishan; $27.5811^{\circ} \mathrm{N}, 102.4028^{\circ} \mathrm{E}$; 11 Aug. 2005; P. Williams leg.; BOLD seq: 1555E06; PW: ML254 1 i (worker); same collection data as for preceding; BOLD seq: 1555E07; PW: ML255.

\section{Global distribution}

(Himalayan, Hengduan, and west Chinese mountain species) East Asia: CHINA: Xizang, Gansu, Sichuan, Yunnan, Shaanxi, Chongqing, Hubei, Guizhou, Guangxi. - Himalaya: INDIA: Himachal Pradesh, Uttaranchal, Sikkim, Darjiling Bengal, Arunachal Pradesh; NEPAL, BHUTAN. - Southeast Asia: BURMA, VIETNAM. (AMNH, IAR, INHS, IOZ, KIB, KIZ, NHMUK, NME, NMS, PW, RMNH, SC, SEHU, SMNS, USNM, ZMUM.) The species is widely distributed and often abundant.

\section{Behaviour}

A colony of this species has been described from Nepal (Ito et al. 1984). Food-plant generalists (Williams et al. 2009; An et al. 2014). The male mate-searching behaviour is expected to resemble the patrolling of $B$. keriensis.

\section{Bombus simillimus Smith, 1852}

Figs 2, 13, 46-49, 184

Bombus simillimis Smith, 1852a: 48.

Bremus oculatus Frison, 1933: 335.

Sibiricobombus tonsus Skorikov, 1933a: 248 (Skorikov 1923, 1931: published without description).

Bombus oculatus var. [subsp.] haemorrhous Richards, 1934: 87.

Bombus similis - Smith 1854: 403, incorrect subsequent spelling.

Bombus simillimus - von Dalla Torre 1896: 548, justified emendation.

Our PTP analysis (Fig. 10) of coalescents in the COI gene within the rufofasciatus-group supports nine species including $B$. simillimus, corroborated by differences in morphology (see the Diagnosis).

Females show pronounced size-dependent dimorphism in the colour pattern of the hair: large queens have the thorax and T1-2 black (taxon simillimus s. str.); whereas workers (which are smaller) have the thorax grey-white and T1-2 dark chocolate brown (Fig. 2: taxon haemorrhous). Males have the thoracic dorsum and often T1-2 grey-white (taxon oculatus). Unsurprisingly, the queens, workers, and males were first described as separate species. That these castes and sexes are conspecific has been confirmed from examining variation within one colony excavated in Kashmir (Williams 1991). The male is distinctive for its unusually large eyes (Frison 1933; Williams 1991). 


\section{Diagnosis}

\section{Females}

Queens large body length $25-27 \mathrm{~mm}$, workers $12-17 \mathrm{~mm}$. Can be distinguished by the combination of the hair of the thoracic dorsum either entirely black (queen) or entirely white (worker: Fig. 2) with the wings dark brown (cf. B. lapidarius, B. eriophorus, B. pyrosoma).

\section{Males}

Body length 16-18 mm. Can be distinguished by the combination of the hair of the thoracic dorsum entirely white with the wings dark brown, similarly coloured to the worker, but the hair of T1 and usually T2 is white; hair of T3 almost entirely black and without a yellow posterior fringe (cf. other rufofasciatus-group species except B. richardsiellus). Genitalia (Fig. 184) with the gonostylus robust, about half as long on its outer side as broad, with the distal edge concave and the inner distal corner and the inner proximal corner both broad and nearly $90^{\circ}$ (cf. all other Melanobombus); volsella with the inner distal corner broadly rounded and without a narrow hook (cf. festivus-group, other rufofasciatusgroup); antenna short and eye strongly enlarged relative to female eye.

\section{Material examined}

\section{Lectotype}

INDIA - + (queen), lectotype Bombus simillimus Smith, 1852 by designation of Williams (1991); "N.[orth]"; NHMUK (examined PW).

Material sequenced ( 5 specimens)

INDIA • 4 q 9 (workers); Kashmir; $34.16^{\circ}$ N, $74.90^{\circ}$ E; Sep. 1980; P. Williams leg.; NHMUK seq: NHMPW17 to NHMPW20; PW: ML182, ML314 to ML316 1 o ; Himachal Pradesh, Jalori pass; 31.5370 N, 77.3729 E; 10 Sep. 2004; R. Raina leg.; BOLD seq: 6877B09; RR: ML384.

\section{Global distribution}

(West Himalayan mountain species) Himalaya: PAKISTAN, INDIA: Kashmir, Himachal Pradesh, Uttaranchal. (IOZ, NHMUK, PW, ZIN, ZMHB.) The species is narrowly distributed but locally common and not rare in collections.

\section{Behaviour}

A colony of this species has been described from underground in a deciduous forest at $1700 \mathrm{~m}$ a.s.l. in Kashmir (Williams 1991). Food-plant generalists (Williams 1991). The male mate-searching behaviour is expected to resemble the territoriality of B. rufofasciatus (Williams 1991).

\section{Bombus miniatus Bingham, 1897}

Figs 13, 50-54, 185

Bombus flavothoracicus Bingham, 1897: 552 (non Hoffer, 1889: 49 = B. campestris (Panzer)).

Bombus miniatus Bingham, 1897: 553.

Bombus stenothorax S.-F. Wang, 1982: 439.

Bombus pyrosoma (part) - Williams 1991: 101 (non Morawitz, 1890: 349).

Bombus miniatus s. lat. was treated as a widespread Himalayan species by Williams (1998), to include the taxon eurythorax. Here, B. miniatus s. str. is recognised as a narrowly distributed east Himalayan species, separate from the west Himalayan species B. eurythorax, because of their unique and strongly divergent species coalescents in the COI gene (Fig. 10), corroborated by differences in morphology. 
The morphological differences are subtle, but do appear to support the two as separate species within a morphologically more distinctive complex of miniatus s. str. + eurythorax.

Our PTP analysis (Fig. 10) supports relatively strongly two coalescents in the COI gene for the west Himalayan B. eurythorax, and the east Himalayan B. miniatus s. str. (sequenced here only from Bhutan). The two coalescent groups differ in COI barcode sequences for at least 21 diagnostic nucleotide positions (3.1\% of the barcode region, although some sequences are incomplete). These nucleotide differences are all synonymous, making no difference to the amino acid sequences at translation.

From morphology, B. miniatus $\mathrm{s}$. str. has a paler colour pattern than B. eurythorax for the females (larger workers and queens). The pale hair is also more extensively intermixed in the dark band between the wing bases for B. miniatus s. str. All of the larger females (queens and workers) of B. miniatus s. str. have the yellow bands on the thorax and T1 grey or cream-white (see Streinzer et al. 2019: their supplementary fig. 2B) rather than yellow or brown as for B. eurythorax. Bombus miniatus $\mathrm{s}$. str. queens have T2 often with few pale hairs anteriorly. Males from Lungtenphu in Bhutan and from Sikkim (sequences unavailable) show no obvious morphological differences from B. eurythorax other than less yellow hair on T3-7.

Available samples of $B$. miniatus s. str. are small and mostly old, so the status of the two candidate species remains uncertain. Current restrictions on collecting and sequencing in the areas where the two candidate species are most likely to occur in proximity (Fig. 13) make clarifying their status difficult. However, more evidence is needed to increase confidence in any interpretation of the status of the candidate species miniatus s. str. and eurythorax and it remains possible with more sampling from the Himalaya that the two taxa could still prove to be parts of a single broader species, $B$. miniatus s. lat. Speciation between B. eurythorax and B. miniatus s. str. may have arisen through vicariance between populations of the western and eastern Himalaya caused by a period of altered climate (cf. B. prshewalskyi/B. rufofasciatus).

Females of B. miniatus s. str. show pronounced size-dependent dimorphism in the colour pattern of the hair: large queens have T2 black and T4 white (taxon flavothoracicus); whereas workers (which are smaller) have T2 brown-yellow and T4 red. Males have the thoracic dorsum and T1-2 extensively yellow and T3-5 extensively orange-red (taxon miniatus s. str.). Consequently, the queens and males were first described as two separate species by Bingham (1897).

\section{Diagnosis}

\section{Females}

Queens large body length 21-28 mm, workers 11-16 $\mathrm{mm}$. Can be distinguished by the combination of the hair of the thoracic dorsum with some grey or cream-white with T5 at least posteriorly white (cf. B. eurythorax, B. rufofasciatus, B. friseanus, B. keriensis, B. richardsiellus).

\section{Males}

Body length $17 \mathrm{~mm}$. Can be distinguished reliably at present only by their COI sequence, but hair of T3-7 bright orange without posterior yellow fringes (cf. B. eurythorax). As well as the holotype male from Sikkim, there is another unsequenced male (ML513) from Lungtenphu in Bhutan presumed to be of this species, although this cannot be confirmed without a barcode sequence. Genitalia (Fig. 185) with the gonostylus much reduced, less than a quarter as long on its outer side as broad, with the distal edge concave and the inner distal process broadly square-ended or weakly bidentate, the inner basal process acutely produced (cf. other rufofasciatus-group species except $B$. eurythorax); volsella with the inner distal corner produced as a narrow curved hook (cf. rufipes-group, B. simillimus, lapidarius-group, sichelii-group, keriensis-group) eye unenlarged relative to female eye. 


\section{Material examined}

Holotype

INDIA $-\widehat{T}$, holotype of Bombus miniatus Bingham, 1897 by original designation; Sikkim, Lintu; May 1894; C. Bingham leg.; NHMUK (examined PW).

\section{Material sequenced (6 specimens)}

BHUTAN • 1 q (worker); Thimphu, Lungtenphu; 27.4574 N, 89.6655 E; Jul. 1995; H. Feijen leg.; BOLD seq: 6880H04; RMNH: ML508 1 क (worker); same collection data as for preceding; 7 Jun. 1996; BOLD seq: 6880H05; RMNH ML509 • 1 o (worker); Paro, Chele-La; $27.3699^{\circ} \mathrm{N}, 89.3466^{\circ} \mathrm{E}$; 11 Sep. 1994; G. Schulten leg.; BOLD seq: 6880H08; RMNH: ML512 • 1 q (queen); Lhuntse, Sengor; $27.3893^{\circ}$ N, $90.9822^{\circ}$ E; 10 Jun. 2017; W. Klein leg.; NBC seq: 10115; RMNH: ML567 • 1 q (queen); same collection data as for preceding; NBC seq: 10113; RMNH: ML568 • 1 q (queen); Thimphu, Phajoding Gompa; $27.479^{\circ}$ N, $89.595^{\circ}$ E; 25 Apr. 2018; W. Klein leg.; RMNH seq: 1092464; RMNH: ML569.

\section{Global distribution}

(East Himalayan mountain species) East Asia: CHINA: Xizang (southern margin only). - Himalaya: INDIA: Sikkim, Arunachal Pradesh; BHUTAN. (IOZ, NHMUK, RMNH.) The species is narrowly restricted to the eastern Himalaya but appears to be abundant locally.

\section{Behaviour}

Food-plant choice expected to be generalist but no records. The male mate-searching behaviour is expected to resemble the patrolling of $B$. eurythorax.

Bombus eurythorax Wang, 1982 stat. rev.

Figs 13, 55-63, 186

Bombus eurythorax Wang, 1982: 439.

Bombus pyrosoma (part) - Williams 1991: 101. - Saini et al. 2015: 116, 211 (non Morawitz, 1890: 349). Bombus miniatus (part) - Williams 1998: 133 (non Bingham, 1897: 552).

Bombus avinoviellus - Saini et al. 2015: 240 (non Skorikov, 1914a: 126).

Bombus eurythorax was described originally by Wang (1982) on the basis of supposed slight differences in the colour pattern of the hair from B. flavothoracicus (=B. miniatus s. lat.): in particular it was suggested that the queen $B$. eurythorax has the 'thorax with [a] black interalar band, where intermixed with some hoary-yellow fine hairs' (even though these are often less pronounced than in B. miniatus s. str., see below). Bombus miniatus s. lat. was subsequently treated as a widespread Himalayan species by Williams (1998), to include the taxon B. eurythorax. Here, B. eurythorax is recognised as a west Himalayan species separate from the east Himalayan B. miniatus s. str., because of their unique and strongly divergent species coalescents in the COI gene (Fig. 10), corroborated by dfferences in morphology. The morphological differences are subtle, but do appear to support the two as separate species within a morphologically more distinctive complex of miniatus s. str. + eurythorax.

Our PTP analysis (Fig. 10) supports relatively strongly two coalescents in the COI gene for the west Himalayan B. eurythorax and the east Himalayan B. miniatus s. str. (sequenced here only from Bhutan). The two coalescent groups differ in COI barcode sequences for at least 21 diagnostic nucleotide positions (3.1\% of the barcode region, although some sequences are incomplete). These nucleotide differences are all synonymous, making no difference to the amino acid sequences at translation. 
From morphology, B. eurythorax usually has a darker colour pattern of the hair than B. miniatus s. str. for the females (larger workers and queens). The pale hair is also less extensively intermixed in the dark band between the wing bases for B. eurythorax (despite the original description of that taxon, see above). All of the larger females (queens and workers) of B. eurythorax have the yellow bands on the thorax and $\mathrm{T} 1$ brownish or yellow rather than grey or cream-white as for B. miniatus $\mathrm{s}$. str. There are a few individuals from the Kishanganga Valley in Pakistan that show a paler hue of the pale bands on the thorax and pale hairs intermixed between the wing bases more similar to B. miniatus s. str. Bombus eurythorax queens usually have T2 anteriorly with a distinct patch of yellow hair that is usually lacking in B. miniatus s. str.

Available samples of the candidate species miniatus are small and mostly old, so the status of the two candidate species remains uncertain. Current restrictions on collecting and sequencing in the areas where these two candidate species are most likely to occur in proximity (Fig. 13) make clarifying their status difficult. However, more evidence is needed to increase confidence in any interpretation of the status of the candidate species miniatus s. str. and eurythorax. Speciation between B. eurythorax and B. miniatus s. str. may have arisen through vicariance between populations of the western and eastern Himalaya caused by a period of altered climate (cf. B. prshewalskyi/ B. rufofasciatus).

Females of B. eurythorax show pronounced size-dependent dimorphism in the colour pattern of the hair: large queens have T2 predominantly black and T4 white; whereas the smaller workers have T2 light chocolate brown and T4 red. Males have the thoracic dorsum and T1-2 extensively yellow and T3-5 extensively yellow or orange-red, often with posterior fringes yellow. That these castes and sexes are conspecific has been confirmed from variation examined within one colony excavated in Kashmir (Williams 1991).

\section{Diagnosis}

\section{Females}

Queens large body length 21-24 mm, workers 10-16 mm. Can be distinguished by the combination of the thoracic dorsum with some distinctly yellow hair and T5 at least posteriorly white (cf. B. miniatus, B. rufofasciatus, B. friseanus, B. keriensis, B. richardsiellus).

\section{Males}

Body length $15-16 \mathrm{~mm}$. Can be distinguished reliably at present only by their COI sequence, but hair of T3-7 often orange in part with at least posterior yellow fringes (cf. B. miniatus). Genitalia (Fig. 186) with the gonostylus much reduced, less than a quarter as long on its outer side as broad, with the distal edge concave and the inner distal corner with a single pronounced spine, the inner basal process acutely produced (cf. other rufofasciatus-group species except $B$. miniatus); volsella with the inner distal corner produced as a narrow curved hook (cf. rufipes-group, B. simillimus, lapidarius-group, sichelii-group, keriensis-group); eye unenlarged relative to female eye.

\section{Material examined}

\section{Holotype}

CHINA - + (queen), holotype of Bombus eurythorax Wang, 1982 by original designation; Xizang, Nyalam; 13 May 1974; X.-Z. Zhang leg.; IOZ (examined PW).

\section{Material sequenced (6 specimens)}

INDIA $・ 1$ đ ; Kashmir, Gulmarg; $34.0546^{\circ}$ N, $74.3856^{\circ}$ E; 1 Aug. 1985; P. Williams leg.; BOLD seq: 3262F04; PW: ML4 • 1 `̊; Kashmir, Gulmarg; $34.0548^{\circ}$ N, $74.3856^{\circ}$ E; 1 Aug. 1985; P. Williams leg.;

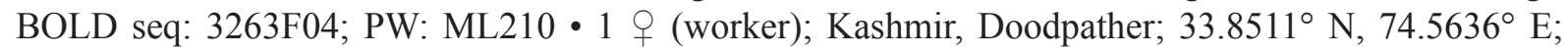


4 Jun. 2012; R. Raina leg.; BOLD seq: 1555G05; RR: ML295 • 1 ô; Himachal Pradesh, Jalori pass; 31.5370 N, 77.3729 E; 11 Sep. 2004; R. Raina leg.; BOLD seq: 6877G10; RR: ML415.

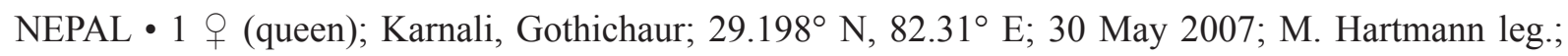
BOLD seq: 1550B11; NME: ML183.

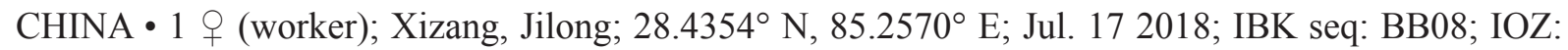
ML580.

\section{Global distribution}

(West Himalayan mountain species) East Asia: CHINA: Xizang (southern margin only). - Himalaya: PAKISTAN, INDIA: Kashmir, Himachal Pradesh, Uttaranchal; NEPAL. (IOZ, NHMUK, NME, PW, RMNH, SEHU, SMNS.) The species is widely distributed in the western Himalaya and often abundant.

\section{Behaviour}

A colony of this species has been described from underground in a coniferous forest at $2500 \mathrm{~m}$ a.s.1. in Kashmir (Williams 1991). Food-plant generalists and male mate-searching behaviour is patrolling (Williams 1991).

Bombus prshewalskyi Morawitz, 1880 stat. rev.

Figs 3, 13, 64-70, 187

Bombus Prshewalskyi Morawitz, 1880: 342.

Bombus rufocinctus Morawitz, 1880: 343 (non Cresson, 1863: 106 = B. rufocinctus Cresson). syn. nov. Bombus chinensis von Dalla Torre, 1890 [Jun. 25]: 139 (non Morawitz, 1890 [April 30]: 352), replacement name for rufocinctus Morawitz, 1880: 343. syn. nov.

Bombus prshewalskii - von Dalla Torre 1896: 548, incorrect subsequent spelling.

Bombus przewalskii - Friese 1918: 84, incorrect subsequent spelling.

Kozlovibombus przewilskii - Skorikov 1933a: 245, incorrect subsequent spelling.

Bombus rufofasciatus (part) - Williams 1991: 105; 1998: 133 (non Smith, 1852a: 48).

Bombus prshewalskyi was described by Morawitz (1880) without reference to Smith's (1852a) closely related taxon rufofasciatus, apparently without knowledge of it. Bombus prshewalskyi is listed as a species (as Kozlovibombus przewalskii) separate from B. rufofasciatus by Skorikov (1923), although the latter was listed by him as "Bombi incertae sedis". The two were synonymised by Richards (1930). Here, B. prshewalskyi is revised as an eastern species separate from the western B. rufofasciatus $\mathrm{s}$. str. because of their unique and strongly divergent species coalescents in the COI gene (Fig. 10), corroborated by morphology. These morphological differences between the two are subtle, but do appear to support that the two taxa are separate species within a morphologically more distinctive complex of rufofasciatus s. str. + prshewalskyi.

Our PTP analysis (Fig. 10) supports relatively strongly two coalescents in the COI gene for the west Himalayan B. rufofasciatus s. str. and B. prshewalskyi of the eastern QTP. The two coalescent groups differ in COI barcode sequences for at least 22 diagnostic nucleotide positions $(3.3 \%$ of the barcode region, although some sequences are incomplete). These differences are all synonymous, making no difference to the amino acid sequences at translation. In contrast, examination of sequences for the slower-evolving PEPCK gene (although it also includes faster-evolving intron regions) shows no diagnostic nucleotide changes. 
From morphology, B. prshewalskyi has a slightly darker colour pattern of the hair than B. rufofasciatus s. str. for the females (larger workers and queens), with the white bands appearing dark greyish because of many black hairs intermixed, especially on the scutellum, and with black hair more extensive on the body generally. T2 has yellow hair conspicuously replaced by black posteriorly.

Current restrictions on collecting and sequencing in the areas where the two candidate species are most likely to occur in proximity (Fig. 13) make clarifying their status difficult. However, more evidence is needed to increase confidence in any interpretation of the status of the candidate species rufofasciatus s. str. and prshewalskyi and it remains possible that with more sampling from the Himalaya the two taxa could still prove to be parts of a single broader species, B. rufofasciatus s. lat. Speciation between $B$. rufofasciatus s. str. and $B$. prshewalskyi may have arisen through vicariance between populations of the western and eastern Himalaya caused by a period of altered climate (cf. B. miniatus / B. eurythorax).

Females show size-dependent dimorphism in the colour pattern of the hair: large queens have T2 predominantly black and T4 white; whereas the workers (which are smaller) have T2 extensively yellow and T4 red. Males have a similar colour pattern to the workers.

\section{Diagnosis}

Females (Fig. 3)

Queens medium-sized body length $19-23 \mathrm{~mm}$, workers $10-15 \mathrm{~mm}$. Can be distinguished by their combination of the hair of T5 white and the hair on the side of the thorax white only in the dorsal half (cf. B. ladakhensis), closely similar to B. rufofasciatus but tending to have T2 with less yellow hair and the scutellum with more black hair.

\section{Males}

Body length 13-17 mm. Can be distinguished reliably at present only by their COI sequence, but tending to have T2 with less yellow hair and the scutellum with more black hair (cf. B. rufofasciatus). Genitalia (Fig. 187) with the gonostylus much reduced, less than a quarter as long on its outer side as broad, with the distal edge concave and the inner distal corner with two almost equally pronounced adjacent acute teeth (cf. other rufofasciatus-group species with the exceptions of some B. friseanus, B. pyrosoma); volsella with the inner distal corner produced as a narrow curved hook (cf. rufipes-group, B. simillimus, lapidarius-group, sichelii-group, keriensis-group); antenna short and eye enlarged relative to female eye.

\section{Material examined}

\section{Syntypes}

CHINA 1 1 (worker, not a queen), 1 (Williams 1991:10), syntypes of Bombus prshewalskyi Morawitz, 1880; "Gan-su" [= Gansu in a much broader sense than currently: the specimen is probably from modern Qinghai]; N. Przhevalsky leg.; ZIN (not seen but identity not in doubt).

\section{Material sequenced (57 specimens)}

CHINA - Gansu Province 1 1 (worker); Gahai; $34.1743^{\circ}$ N, $102.5577^{\circ}$ E; 28 Aug. 2009; P. Williams leg.; BOLD seq: 6876H09; PW: ML1 • 1 ○ं; Hezuo; $34.9027^{\circ}$ N, $102.8445^{\circ}$ E; 27 Aug. 2009; P. Williams leg.; BOLD seq: 1555E03; PW: ML251. - Sichuan Province - 4 specs; Hongyuan; $32.3282^{\circ}$ N, 102.4543 ${ }^{\circ}$ E; 2017; YD seq: DYX9.1, DYX56.2, DYX22.2, DYX32.2; YD: ML424 to ML427 • 1 ㅇ (worker); Hailuogou; $29.89546^{\circ} \mathrm{N}, 102.01324^{\circ} \mathrm{E}$; 7 Aug. 2018; Z. Ren leg.; KIB seq: GGSM102001; KIB: ML555 • 1 q (worker); Que'er shan; $31.89688^{\circ}$ N, $99.14853^{\circ}$ E; 4 Aug. 2018; Z. Ren leg.; KIB seq: QESM202003; KIB: ML560. - Yunnan Province • 1 क (worker); Lijiang; $27.0156^{\circ} \mathrm{N}, 100.1714^{\circ} \mathrm{E}$; 27 Aug. 2012; Y. Zhao leg.; KIB seq: 402646105; KIB: ML366 • 1 o; same collection data as for preceding; 21 Sep. 2012; Y. Zhao leg.; KIB seq: 402648064; KIB: ML367 • 1 q (worker); Baima Snow Mountain; $28.34827^{\circ}$ N, $99.05771^{\circ}$ E; 17 Jul. 2018; Z. Ren leg.; KIB seq: BMXSM102034; 
KIB: ML548 1 ㅇ (worker); Baima Snow Mountain; 28.37252 ${ }^{\circ}$ N, $98.99982^{\circ}$ E; 16 Jul. 2018; Z. Ren

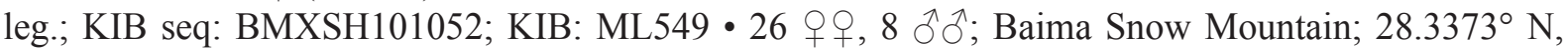
99.0771 ${ }^{\circ} \mathrm{E}$; $14-17$ Aug. 2019; M. Orr leg.; IOZ seq: 14F2 to 14F7, 14F9, $14 \mathrm{~F} 11$ to $14 \mathrm{~F} 16,14 \mathrm{~F} 18,14 \mathrm{M} 1$ to $14 \mathrm{M} 5,16 \mathrm{~F} 1,16 \mathrm{M} 1,16 \mathrm{M} 2,16 \mathrm{M} 4,17 \mathrm{~F} 1$ to $17 \mathrm{~F} 4,17 \mathrm{M} 1$, OR4, OR6 to OR8, OR14, OR16, OR19, OR21, OR25; IOZ: ML599 to ML632. - Xizang Province • 1 o (worker); Anjiulashan; 29.6509 N, 96.71712 ${ }^{\circ}$ E; 23 Jul. 2018; Z. Ren leg.; KIB seq: AJLSM103002; KIB: ML550 • 1 đ̊; Galonglashan; 29.78346 N, 95.69765 E; 24 Jul. 2018; Z. Ren leg.; KIB seq: GLLSM201092; KIB: ML551 • 1 ○; same collection data as for preceding; KIB seq: GLLSM201104; KIB: ML552 • 1 q (queen); same collection data as for preceding; KIB seq: GLLSM101006; KIB ML553 • 1 q (queen); Milashan; $29.85301^{\circ}$ N, $92.33378^{\circ}$ E; 27 Jul. 2018; Z. Ren leg.; KIB seq: MLSH101029; KIB: ML554 • 1 ㅇ (worker); Honglashan; $29.92411^{\circ} \mathrm{N}, 92.77629^{\circ} \mathrm{E}$; 19 Jul. 2018; Z. Ren leg.; KIB seq: HLSM101103;

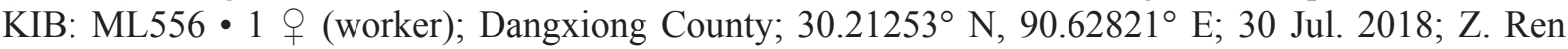
leg.; KIB seq: DXH101006; KIB: ML557 • 1 q (worker); Zhujiaolashan; $31.10878^{\circ} \mathrm{N}, 96.88469^{\circ} \mathrm{E} ; 2$ Aug. 2018; Z. Ren leg.; KIB seq: ZJLSM101045; KIB: ML558; 1 ( (worker); Ailashan; $31.61421^{\circ} \mathrm{N}$, 98.48028 E; 1 Aug. 2018, Z. Ren leg.; KIB-ALSM102002 (KIB ML559) • 1 + (worker); Milashan; 29.8530 ${ }^{\circ}$ N, 92.3338 E 27 Jul. 2018; Z. Ren leg.; KIB seq: MLSH109001; KIB: ML578 • 1 ㅇ (worker); Galongashan; 29.7669 N, 95.6991 E; 24 Jul. 2018; Z. Ren leg.; KIB seq: GLLSM104005; KIB: ML579.

\section{Global distribution}

(Qinghai-Tibetan-Plateau and East Himalayan species) Himalaya: INDIA: Sikkim, Arunachal Pradesh. East Asia: CHINA: Xizang, Qinghai, Gansu, Sichuan, Yunnan. - Southeast Asia: BURMA. (AMNH, IAR, IOZ, KIB, KIZ, MNHN, NHMUK, NME, NMS, PW, SEHU, UAP, YD, ZIN.) The species is widely distributed within its range and often abundant.

\section{Behaviour}

A colony of this species has been found underground in a meadow at $3900 \mathrm{~m}$ a.s.l. in Yunnan (ZR unpublished). Food-plant generalists (Williams et al. 2009; An et al. 2014). Male mate-searching behaviour appears to resemble the true territoriality of B. rufofasciatus with collisions between males in flight and replacement in perch occupancy (PW pers. obs.).

\section{Bombus rufofasciatus Smith, 1852}

Figs 13, 71-77, 188

Bombus rufo-fasciatus Smith, 1852a: 48.

Bombus rufofasciatus var. [subsp.] championi Richards, 1928a: 107.

Bombus waterstoni Richards, 1934: 88.

Bombus rufofasciatus s. str. is revised here as a western species separate from the eastern B. prshewalskyi because of their unique and strongly divergent species coalescents in the COI gene (Fig. 10), corroborated by differences in morphology. The morphological differences are subtle, but do appear to corroborate that the two are separate species within a morphologically more distinctive complex of rufofasciatus s. str. + prshewalskyi.

Our PTP analysis (Fig. 10) supports relatively strongly two coalescents in the COI gene for sister candidate species within a rufofasciatus-complex: the west Himalayan B. rufofasciatus s. str. and B. prshewalskyi of the eastern QTP. The two coalescent groups differ in COI barcode sequences for at least 22 diagnostic nucleotide positions (3.3\% of the barcode region, although some sequences are incomplete). These differences are all synonymous, making no difference to the amino acid sequences 
at translation. In contrast, examination of sequences for the slower-evolving PEPCK gene (even though it also includes faster-evolving intron regions) shows no diagnostic nucleotide changes.

From morphology, B. rufofasciatus s. str. has a slightly lighter colour pattern of the hair than B. prshewalskyi for the females (larger workers and queens), with the white bands often appearing bright white. T2 of workers (and sometimes in the far west, also of queens) is often predominantly yellow.

Current restrictions on collecting and sequencing in the areas where these two candidate species are most likely to occur in proximity (Fig. 13) make clarifying their status difficult. However, more evidence is needed to increase confidence in any interpretation of the status of these candidate species rufofasciatus s. str. and prshewalskyi and it remains possible with more sampling from the Himalaya that the two taxa could still prove to be parts of a single species B. rufofasciatus s. lat. Speciation between B. rufofasciatus s. str. and $B$. prshewalskyi may have arisen through vicariance between populations of the western and eastern Himalaya caused by a period of altered climate (cf. B. miniatus / B. eurythorax).

Females show size-dependent dimorphism in the colour pattern of the hair: large queens vary from having T2 black with a few yellow hairs (in the east) to having T2 predominantly yellow (in the far west in Pakistan) and T4 is white; whereas the smaller workers have T2 extensively yellow and T4 red. Males have a similar colour pattern to the workers. That the castes and sexes are conspecific has been confirmed from examining variation within one colony from Kashmir (Williams 1991).

\section{Diagnosis}

\section{Females}

Queens medium-sized body length 20-23 mm, workers 10-15 mm. Can be distinguished by their combination of the hair of T5 white and the hair on the side of the thorax white only in the dorsal half (cf. B. ladakhensis), closely similar to B. prshewalskyi but tending to have T2 with more yellow hair and the scutellum with less black hair.

\section{Males}

Body length $14-16 \mathrm{~mm}$. Can be distinguished reliably at present only by their COI sequence, but tending to have T2 with more yellow hair and the scutellum with less black hair (cf. B. prshewalskyi). Genitalia (Fig. 188) with the gonostylus much reduced, less than a quarter as long on its outer side as broad, with the distal edge concave and the inner distal corner with two pronounced adjacent acute teeth, the proximal tooth often slightly shorter than the distal tooth (cf. other rufofasciatus-group species); volsella with the inner distal corner produced as a narrow curved hook (cf. rufipes-group, B. simillimus, lapidarius-group, sichelii-group, keriensis-group); antenna short and eye enlarged relative to female eye.

\section{Material examined}

\section{Lectotype}

INDIA • \& (queen), lectotype of Bombus rufofasciatus Smith, 1852 by designation of Tkalců (1974a); "N.[orth]"; NHMUK (examined PW).

Material sequenced (6 specimens)

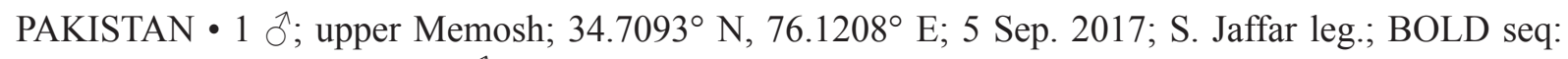
1555E08; UAP: ML256 • 1 त; same collection data as for preceding; BOLD seq: 1555E09; UAP: ML257 • 1 đ̊; same collection data as for preceding; BOLD seq: 6877H05; UAP: ML421.

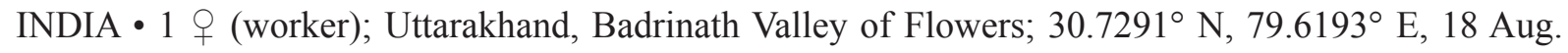
1990; S. Cameron leg.; BOLD seq: 6877E07; PW: ML389. 
NEPAL • $q$ (queen); Karnali, Churta; $29.4667^{\circ}$ N, $82.1^{\circ}$ E; 2 Jun. 2007; F. Creutzburg leg.; BOLD seq: 1551H08; NME: ML213 • O (queen); Karnali, Gothichaur; $29.1972^{\circ}$ N, 82.3083 E; 7 Jun. 2007; F. Creutzburg leg.; BOLD seq: 1551H07; NME ML214.

\section{Global distribution}

(West Himalayan mountain species) Himalaya: PAKISTAN, INDIA: Kashmir, Himachal Pradesh, Uttaranchal; NEPAL. (NHMUK, NME, NMS, PW, SEHU, UAP.) The species is widely distributed within its range and often abundant.

\section{Behaviour}

A colony of this species has been found underground (under large rocks) in a subalpine meadow at $3000 \mathrm{~m}$ a.s.1. in Kashmir (Williams 1991). Food-plant generalists and the male mate-searching behaviour is truly territorial with collisions between males in flight and replacement in perch occupancy (Williams 1991).

Bombus richardsiellus (Tkalců, 1968)

Figs 13, 78-82, 189, 205

Pyrobombus richardsiellus Tkalců, 1968: 42.

Our PTP analysis (Fig. 10) of coalescents in the COI gene within the rufofasciatus-group supports nine species including B. richardsiellus, corroborated by differences in morphology (see the Diagnosis).

Females show size-dependent dimorphism in the colour pattern of the hair: large queens have metasomal T1-3 black, T4 anteriorly black and posteriorly white, and T5 white; whereas large workers (which are smaller) have T1 with some yellow hair, T2 anteriorly with at least a few yellow hairs, T4 orange-red, and T5 anteriorly orange-red, T5 posteriorly and T6 (in part) white; and small workers have white hairs intermixed on the face and on the side of the thorax, T1-2 predominantly yellow, and T5 almost entirely orange. Males have the thoracic bands and T1-2 yellow, T3 black, and T4-5 orange-red.

\section{Diagnosis}

\section{Females}

Queens medium-sized body length 20-21 mm, workers 10-15 mm. Can be distinguished in the Hengduan region by their combination of the hair of the thoracic dorsum with white bands, T1 black or yellow, and T5 posteriorly white (cf. B. rufofasciatus, B. prshewalskyi, B. miniatus, B. friseanus, B. pyrosoma).

\section{Males}

Body length $12 \mathrm{~mm}$. Can be distinguished by their combination of the thorax with yellow bands with the hair of T3 almost entirely black and without a yellow posterior fringe (cf. other rufofasciatus-group species). Genitalia (Fig. 189) with the gonostylus much reduced, less than a quarter as long on its outer side as broad, with the distal edge concave, the inner distal corner with a single- or double-pointed projection, the inner proximal corner broad and nearly $90^{\circ}$ (cf. B. miniatus, B. eurythorax, B. pyrosoma, $B$. formosellus); volsella with the inner distal corner produced as a narrow curved hook. The single examined male specimen (NHMUK) is missing its head, but according to Tkalcu (1968) this male had eyes unenlarged relative to the female.

\section{Material examined}

Holotype

BURMA • + (queen), holotype of Pyrobombus richardsiellus Tkalců, 1968 by original designation; Adung Valley; 8 Jul. 1931; Lord Cranbrook (= J. Gathorne-Hardy) leg.; NHMUK (examined PW). 
Material sequenced (3 specimens)

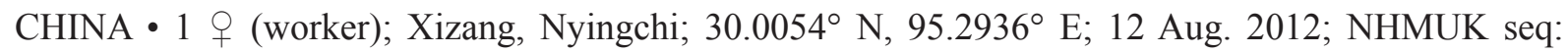
NHMCT1 (sequence data from Williams 2018); PW: ML2 • 1 ㅇ (worker); Xizang, Galonglashan; $29.8266^{\circ}$ N, $95.71532^{\circ}$ E; 25 Jul. 2018; Z. Ren leg.; KIB seq: GLLSL203007; KIB: ML563 • 1 ㅇ (worker); Xizang, Sangjiu; 28.8089 N, 97.6056 E; 31 Aug. 2014; IBK seq: BB09; IOZ: ML581.

\section{Global distribution}

(Hengduan mountain species) East Asia: CHINA: Xizang. - Southeast Asia: BURMA (north). (IAR, IOZ, KIB, NHMUK, PW.) Until recently, the species was known from only five specimens (two queens, two workers, and one male), most from the Adung Valley, Burma, with one queen from Zayul, Xizang (NHMUK, examined PW). Knowledge of this species has increased substantially recently with the collection of a queen and 14 workers from Sanjiu in Xizang in 2014 (IOZ, examined PW) and a collection of 64 workers from Galonglashan in Xizang in 2018 (KIB, examined PW), which brings the total known number of available specimens to 83 . From this information, among bumblebee species with continental distributions, this species remains apparently unusually narrowly distributed (Fig. 205).

\section{Behaviour}

Food-plant choice generalist (ZR unpublished).

Bombus friseanus Skorikov, 1933

Figs 13, 83-90, 190

Bombus friseanus Skorikov, 1933b: 62.

Lapidariobombus pyrrhosoma subsp. hönei Bischoff, 1936: 10.

Bombus pyrosoma (part) - Williams 1991: 101 (non Morawitz, 1890: 349).

Our PTP analysis (Fig. 10) of coalescents in the COI gene within the rufofasciatus-group supports nine species including B. friseanus, corroborated by differences in morphology (see the Diagnosis).

Females show size-dependent dimorphism in the colour pattern of the hair: large queens have T2 predominantly black; whereas workers (which are smaller) have T2 yellow or light chocolate brown. Males have the thoracic dorsum and T1-2 extensively yellow and T3-5 extensively orange-red. This species is widespread and abundant, but despite variation in COI barcodes shows little geographical variation in colour pattern. Individuals from near Qianggang in Xizang $\left(29.998^{\circ} \mathrm{N}, 91.939^{\circ} \mathrm{E}\right)$ have less black hair. One worker (ML5) from Maoshan in Sichuan (31.685 $\left.{ }^{\circ} \mathrm{N}, 103.899^{\circ} \mathrm{E}\right)$ with white bands has been confirmed as this species from a COI sequence. The males have the eye unenlarged relative to the female eye (Williams et al. 2009).

\section{Diagnosis}

\section{Females}

Queens medium-sized body length 19-22 mm, workers 10-16 mm. Can usually be distinguished in the Hengduan region by their combination of the hair of the thoracic dorsum with yellow bands, side of the thorax yellow, and T3-5 red (cf. B. tibeticus, B. qilianensis, B. miniatus, B. pyrosoma, B. tanguticus). From other often similar co-occurring species they can be distinguished by their combination of the hind tibia with the distal hairs entirely black (cf. B. (Pyrobombus) lepidus Skorikov, 1912) with the mid basitarsus with the distal posterior corner broadly rounded (cf. B. (Thoracobombus) impetuosus Smith, 1871). 

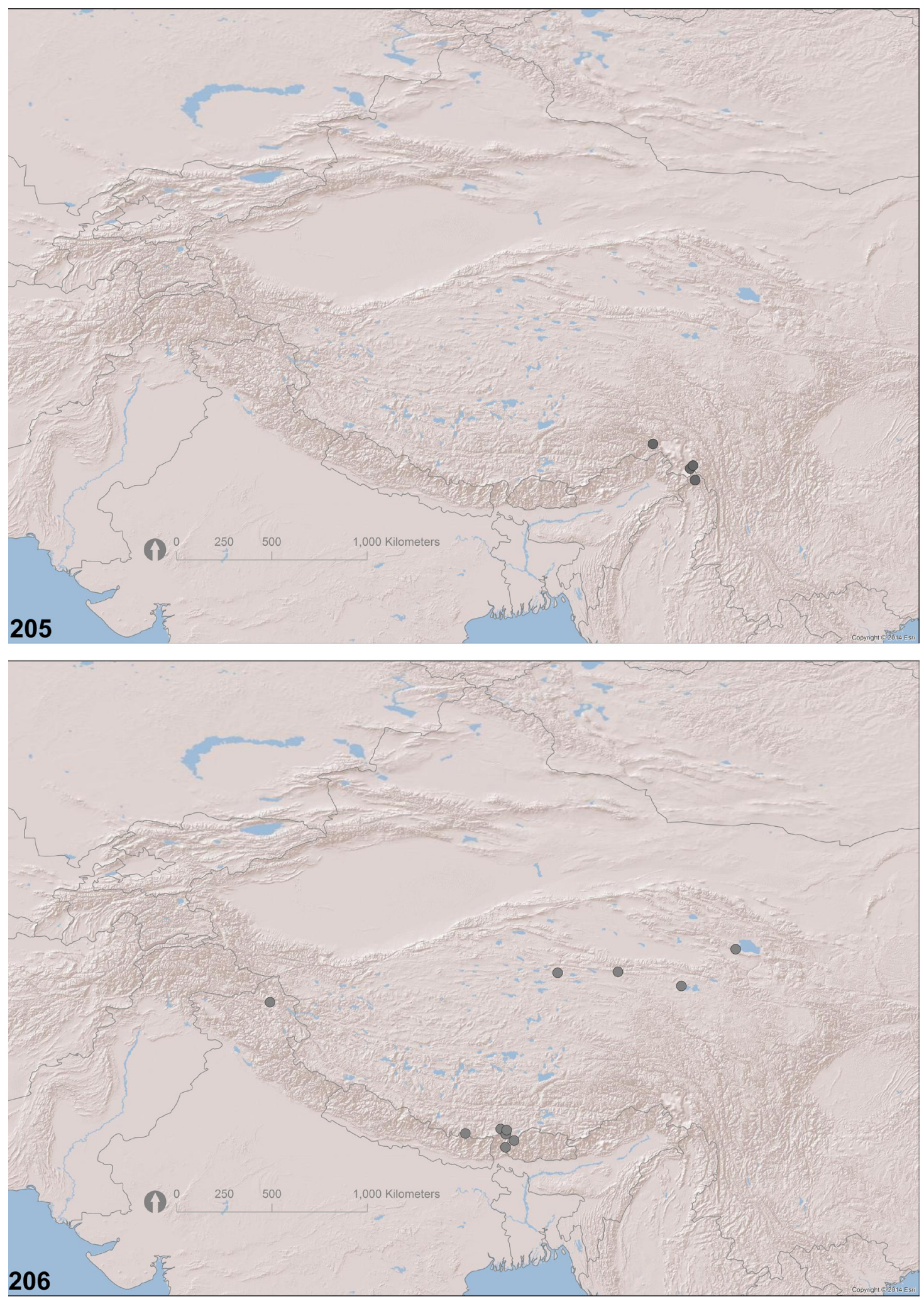

Figs 205-206. Maps of all available global records with all of the specimens examined and confirmed here. 205. Bombus richardsiellus (Tkalců, 1968). 206. B. tanguticus Morawitz, 1887. Relief map with hill shading for the region centred on Tibet with (grey lines) borders to national administration as in UN maps. Image created in ArcGIS using World_Shaded_Relief basemap ${ }^{\circledR} 2014$ Esri. 


\section{Males}

Body length 13-15 mm. Can usually be distinguished in the Hengduan region by their combination of the hair of the thoracic dorsum with yellow bands, side of the thorax yellow, and T3-7 red. Genitalia (Fig. 190) with the gonostylus much reduced, less than a quarter as long on its outer side as broad, with the distal edge concave and the inner distal corner with two almost equally pronounced adjacent acute teeth (cf. other rufofasciatus-group species with the possible exceptions of B. prshewalskyi, B. pyrosoma); volsella with the inner distal corner produced as a narrow curved hook (cf. rufipes-group, B. simillimus, lapidarius-group, sichelii-group, keriensis-group); eye unenlarged relative to female eye.

\section{Material examined}

\section{Holotype}

CHINA - O (queen), holotype of Bombus friseanus Skorikov, 1933 by monotypy (Williams 1991); Sichuan, Songpan; [18]94; M. Berezovsky leg.; ZIN (examined PW).

\section{Material sequenced (65 specimens)}

CHINA-Sichuan Province 1 \& (worker); Maoxian; $31.6853^{\circ}$ N, $103.8994^{\circ}$ E; 10 Aug. 2002; P. Williams leg.; BOLD seq: 1550E09; PW: ML5 1 q (worker); same collection data as for preceding; BOLD seq: 3262F02; PW: ML7 1 1 (worker); same collection data as for preceding; BOLD seq: 3263F02; PW: ML199 1 q (worker); Hongyuan; $32.6403^{\circ} \mathrm{N}, 102.3286^{\circ} \mathrm{E}$; 4 Aug. 2002; P. Williams leg.; BOLD seq: 3262F01; PW: ML8 • 1 क (worker); Haikou; $27.3271^{\circ}$ N, $102.4651^{\circ}$ E; 19 Aug. 2005; P. Williams leg.; BOLD seq: 1555G07; PW: ML297 • 10 specs; Hongyuan; $32.3282^{\circ} \mathrm{N}, 102.4543^{\circ} \mathrm{E} ; 2017$; YD seq: DYX48.2, DYX16.1, DYX40.2, DYX7.2, DYX20.1, DYX6.1, DYX7.4, DYX43.1, DYX6.2, DYX7.1; YD: ML428 to ML437 • 1 क (worker); Ganzi county; $31.62916^{\circ} \mathrm{N}, 100.22675^{\circ}$ E; 5 Aug. 2018; Z.

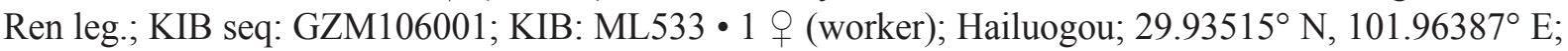
7 Aug. 2018; Z. Ren leg.; KIB seq: GGSL101019; KIB: ML534 • 1 q (worker); Xinduqiao; $30.06679^{\circ} \mathrm{N}$, 101.76088 E; 7 Aug. 2018; Z. Ren leg.; KIB seq: XDQM101028; KIB: ML535 • 1 \% (worker); Daofu county; $30.78966^{\circ} \mathrm{N}, 101.30716^{\circ}$ E; 5 Aug. 2018; Z. Ren leg.; KIB seq: DFM101018; KIB: ML537• 1 q (worker); Ganzi county; $31.62916^{\circ}$ N, $100.22675^{\circ}$ E; 5 Aug. 2018; Z. Ren leg.; KIB seq: GZM102003; KIB: ML540 • 1 ( worker); same collection data as for preceding; KIB seq: GZM101002; KIB: ML541.

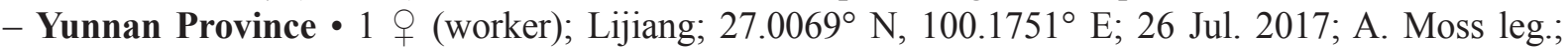
BOLD seq: 1555C10; PW: ML241 1 放; same collection data as for preceding; BOLD seq: 1555G06; PW: ML296• 1 q (queen); Lijiang; 27.0156 ${ }^{\circ} \mathrm{N}, 100.1714^{\circ} \mathrm{E}$; 1 Aug. 2016; H. Liang leg.; KIB seq: 24; KIB: ML368 1 के; same collection data as for preceding; 6 Sep. 2016; H. Liang leg.; KIB seq: 40; KIB: ML369 • 1 क (worker); same collection data as for preceding; 1 Aug. 2016; H. Liang leg.; KIB seq: 52; KIB: ML370 • 1 q (queen); same collection data as for preceding; 14 Jun. 2012; Y. Zhao leg.; KIB seq: 304432147; KIB: ML371 • 1 क (worker); same collection data as for preceding; 26 May 2012; Y. Zhao leg.; KIB seq: 40241082; KIB: ML372 • 1 q (worker); same collection data as for preceding; 2 Aug. 2016; H. Liang leg.; KIB seq:42; KIB ML373 • 1 q (worker); same collection data as for preceding; 26 Jul. 2015; Z. Ren leg.; KIB seq: 2018045; KIB: ML374 • 1 क (worker); same collection data as for preceding; 22 Aug. 2016; H. Liang leg.; KIB seq: 2018071; KIB: ML375 • 1 q (worker); same collection data as for preceding; 15 Jul. 2016; H. Liang leg.; KIB seq: 2018038; KIB: ML376• 1 q (worker); same collection data as for preceding; 19 Jul. 2016; H. Liang leg.; KIB seq: 53; KIB: ML377 • 1 §; same collection data as for preceding; 5 Sep. 2016; H. Liang leg.; KIB seq: 84; KIB: ML378 • 1 ㅇ (worker); same collection data as for preceding; 1 Sep. 2016; H. Liang leg.; KIB seq: 107; KIB: ML379 • 1 q (worker); Cangshan; 25.88991 ${ }^{\circ}$ N, $100.02974^{\circ}$ E; 14 Jul. 2018; Z. Ren leg.; KIB seq: CSL201011; KIB: ML514 • 1 q (worker); Cangshan; $25.88001^{\circ} \mathrm{N}, 100.02691^{\circ} \mathrm{E}$; 14 Jul. 2018; Z. Ren leg.; KIB seq: CSL301005; KIB: ML515 - 1 ( ) (worker); same collection data as for preceding; KIB seq: CSL301016; KIB: ML516 - 1 q (worker); Cangshan; 25.89461 ${ }^{\circ}$ N, $100.02125^{\circ}$ E; 14 Jul. 2018; Z. Ren leg.; KIB seq: CSL101008; KIB: ML517 • 1 q (worker); Baima Snow Mountain; 28.39838 N, 98.99286 E; 18 Jul. 2018; Z. Ren 
leg.; KIB seq: BMXSM301021; KIB: ML518 • 1 q (worker); same collection data as for preceding; KIB seq: BMXSM301049; KIB: ML519 • 6 qo+; Baima Snow Mountain; $28.3373^{\circ} \mathrm{N}, 99.0771^{\circ} \mathrm{E}$; 14-19 Aug. 2019; M. Orr leg.; IOZ seq: 14F2, 14F4, 14F19, OR20, OR24, OR27; IOZ: ML584 to ML589. - Xizang Autonomous Region • 1 o (worker); Milashan; 29.85301 N, 92.33378 ${ }^{\circ}$ E; $27 \mathrm{Jul}$. 2018; Z. Ren leg.; KIB seq: MLSM101027; KIB: ML520 • 1 ㅇ (worker); same collection data as for preceding; KIB seq: MLSM101002; KIB: ML521・1 $\odot$ (worker); same collection data as for preceding; KIB seq: MLSM101034; KIB: ML522 • 1 o (worker); Ranwu Lake; 29.4849 N, 96.64252 ${ }^{\circ}$ E; 23 Jul. 2018; Z. Ren leg.; KIB seq: RWM101017; KIB: ML523 • 1 q (worker); same collection data as for preceding; KIB seq: RWM101057; KIB: ML524 • 1 क (worker); same collection data as for preceding; KIB seq: RWM101001; KIB: ML525 • 1 क (worker); Dongdashan; 29.57184 N, 98.18467 E; 20 Jul. 2018; Z. Ren leg.; KIB seq: DDSM303001; KIB: ML526 • 1 q (worker); Dongdashan; $29.62259^{\circ} \mathrm{N}$, 97.89246 E; 20 Jul. 2018; Z. Ren leg.; KIB seq: DDSM203003; KIB: ML527 • 1 ㅇ (worker); Sejilashan; 29.64141 ${ }^{\circ}$ N, 94.69818 E; 26 Jul. 2018; Z. Ren leg.; KIB seq: SJLSM101009; KIB: ML528 • 1 o (worker); Dongdashan; $29.69073^{\circ}$ N, 98.11641 ${ }^{\circ}$ E; 20 Jul. 2018; Z. Ren leg.; KIB seq: DDSH301056;

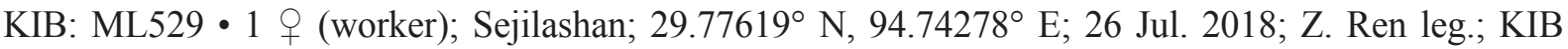
seq: SJLSL301011; KIB: ML530 • 1 q (worker); Galonglashan; 29.78346 N, 95.69765 E; 24 Jul. 2018; Z. Ren leg.; KIB seq: GLLSM103018; KIB: ML531 • 1 + (worker); Anjiulashan; $29.9229^{\circ} \mathrm{N}$, 96.67203ํㅡ; 23 Jul. 2018; Z. Ren leg.; KIB seq: AJLSM101004; KIB: ML532 • 1 q (queen); Yelashan; 30.16394 $\mathrm{N}$, 97.2860 E; 22 Jul. 2018; Z. Ren leg.; KIB seq: YLSH101083; KIB: ML536 • 1 q (worker); Zhujiaolashan; $31.11821^{\circ}$ N, $97.01749^{\circ}$ E; 2 Aug. 2018; Z. Ren leg.; KIB seq: ZJLSM101015; KIB: ML538 • 1 q (queen); Zonglashan; $31.2922^{\circ}$ N, 97.59554 E; 3 Aug. 2018; Z. Ren leg.; KIB seq:

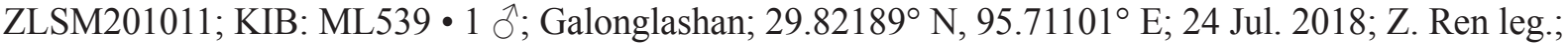
KIB seq: GLLSL301020; KIB: ML542 • 1 q (worker); Xizang; $29.5032^{\circ}$ N, $95.8980^{\circ}$ E; 8 Aug. 2015; IBK seq: BB12; IOZ: ML582.

\section{Global distribution}

(Hengduan mountain species) East Asia: CHINA: Xizang, Qinghai, Sichuan, Yunnan, Guizhou. (AMNH, IAR, IOZ, KIB, KIZ, NHMUK, PW, SAC, USNM, YD, ZIN, ZMHB, ZMUM.) The species is widely distributed within the Hengduan region and often one of the most abundant.

\section{Behaviour}

A colony of this species has been found underground in a coniferous forest at $3300 \mathrm{~m}$ in Yunnan (ZR unpublished). Food-plant generalists (Williams et al. 2009). Male mate-searching behaviour appears to resemble patrolling of $B$. eurythorax (PW pers. obs.).

\section{Bombus pyrosoma Morawitz, 1890}

Figs 13, 91-97, 191

Bombus pyrosoma Morawitz, 1890: 349.

Bombus rufus Friese, 1905: 511 (non Villers, 1789: 328 = B. pascuorum (Scopoli)).

Pyrobombus wutaishanensis Tkalců, 1968: 39.

Bombus pyrrhosoma - von Dalla Torre 1896: 544, unjustified emendation.

Our PTP analysis (Fig. 10) supports relatively strongly two coalescents in the COI gene for sister species within a pyrosoma-complex: the north Chinese B. pyrosoma s. str. and the Taiwan endemic $B$. formosellus. The two coalescent groups differ in COI barcode sequences for at least 12 diagnostic nucleotide positions (1.8\% of the barcode region). These nucleotide differences are all synonymous, making no difference to the amino acid sequences at translation. 
From morphology, B. pyrosoma s. str. has a more extensively black colour pattern than B. formosellus for the females on the thoracic dorsum and T1 (larger workers and queens).

Females show size-dependent dimorphism in the colour pattern of the hair: large queens have the thorax and T1 black and T2-5 orange-red; whereas workers (which are smaller) have the anterior and posterior thoracic bands and T1 white, T2 chocolate brown, and T3-5 orange-red. Males have the anterior and posterior thoracic bands and T1-2 yellow and T3-5 orange-red.

\section{Diagnosis}

\section{Females}

Queens medium-sized body length 20-23 mm, workers 12-15 mm. Can be distinguished in North China by their combination of the hair of the thoracic dorsum and T1 either black or with white bands with T3-5 red (cf. B. sichelii).

\section{Males}

Body length 13-17 mm. Can usually be distinguished in North China by their combination of the hair of the thoracic dorsum with yellow bands, side of the thorax yellow, and T3-7 red. Genitalia (Fig. 191) with the gonostylus much reduced, less than a quarter as long on its outer side as broad, with the distal edge concave and the inner distal corner with two almost equally pronounced adjacent acute teeth (cf. other rufofasciatus-group species with the possible exceptions of B. prshewalskyi, B. friseanus); volsella with the inner distal corner produced as a narrow curved hook (cf. rufipes-group, B. simillimus, lapidarius-group, sichelii-group, keriensis-group); eye unenlarged relative to female eye.

\section{Material examined}

\section{Syntype}

CHINA - + (queen), syntype of Bombus pyrosoma Morawitz, 1890 (Williams 1991); "Kan-ssu" (= Gansu); Jun. 1884; G. Potanin leg.; ZIN (examined PW). The specimen bears a label "Schanji/M. Utai", which could be a corruption of Mt Wutai in the province of Shanxi, where this species does occur (PW pers. obs.).

\section{Material sequenced (10 specimens)}

CHINA - Qinghai Province • 1 q (worker); Ping'an; 36.3594 N $102.1173^{\circ}$ E; 19 Aug. 2013; P. Williams leg.; BOLD seq: 1555C04; PW: ML235. - Gansu Province - 1 q (worker); Xiahe; 35.3644 ${ }^{\circ}$ N, $102.881^{\circ}$ E; 27 Aug. 2009; P. Williams leg.; BOLD seq: 1555G08; PW: ML298 • 1 ㅇ (worker); Diebu; $34.2401^{\circ}$ N, 103.1547 E; 29 Aug. 2009; P. Williams leg.; BOLD seq: 1555G09; PW: ML299. - Beijing Municipality $1 \mathrm{O}^{\text {乃 }}$; Lingshan; $39.9755^{\circ} \mathrm{N}, 115.4803^{\circ} \mathrm{E} ; 20$ Apr. 2007; reared from a queen; BOLD seq: 3262E11; PW: ML3 - 1 त; same collection data as for preceding; BOLD seq: 3262E12; PW: ML6 • 1 q (queen); Beijing; same collection data as for preceding; BOLD seq: 3263E11; PW: ML211 1 q (queen); same collection data as for preceding; BOLD seq: 3263E12; PW: ML212. - Neimenggu Province • 1 क (worker); Majiazi; $43.2176^{\circ}$ N, $117.3153^{\circ}$ E; 10 Sep. 2007; P. Williams leg.; BOLD seq: 1555C03; PW: ML234. - Ningxia Autonomous Region • 1 q (worker); Liupanshan; 35.77438 ${ }^{\circ}$ N, $106.18371^{\circ}$ E; 27 Jul. 2018; K. Li leg.; KIB seq: NX03; KIB: ML561 • 1 ㅇ (worker); same collection data as for preceding; KIB seq: NX04; KIB: ML562.

\section{Global distribution}

(North Chinese mountain species) East Asia: CHINA: Qinghai, Sichuan, Chongqing, Hubei, Henan, Shandong, Gansu, Neimenggu, Ningxia, Shaanxi, Shanxi, Hebei, Beijing, Tianjin, Liaoning. (IAR, IOZ, NHMUK, PW, ZIN, ZMHB.) The species is widely distributed in North China and often one of the most abundant. 


\section{Behaviour}

Food-plant generalists (An et al. 2014). Male mate-searching behaviour appears to resemble patrolling of B. eurythorax (PW pers. obs.).

Bombus formosellus (Frison, 1934)

Figs 13, 98-102, 192

Bremus formosellus Frison, 1934: 163.

Bremus formosellus var. [subsp.] derivatus Frison, 1934: 166.

Bremus formosellus var. [subsp.] gradatus Frison, 1934: 167.

Bombus pyrosoma (part) - Williams 1991: 102 (non Morawitz, 1890: 349).

Bombus formosellus is known only from Taiwan (Frison 1934; Chiu 1948; Starr 1992). Bombus pyrosoma s. lat. has been treated as a widespread Asian species by Williams (1998), to include the taxon formosellus. Here, B. formosellus is recognised as separate from the north Chinese B. pyrosoma s. str. because of their unique and strongly divergent species coalescents in the COI gene (Fig. 10), corroborated by differences in morphology (see the Diagnosis). The morphological differences are subtle, but do appear to support the two as separate species within a morphologically more distinctive complex of pyrosoma s. str. + formosellus.

Our PTP analysis (Fig. 10) supports relatively strongly two coalescents in the COI gene for the north Chinese B. pyrosoma s. str., and the Taiwanese B. formosellus. The two coalescent groups differ in COI barcode sequences for at least 12 diagnostic nucleotide positions (1.8\% of the barcode region). These nucleotide differences are all synonymous, making no difference to the amino acid sequences at translation.

From morphology, B. formosellus has a paler colour pattern of the hair than B. pyrosoma s. str. for the females and especially for the queens. The queen of $B$. formosellus (below) has the hair of the thoracic dorsum with broad anterior and posterior bands strongly dominated by white, whereas for $B$. pyrosoma s. str. these areas are black or usually with a small minority of white hairs intermixed. The male gonostylus inner process is also not clearly divided into two teeth as it is in B. pyrosoma s. str.

Queens of this species have not previously been described. However, S. Lu located a female (ML503) in the TFRI collection that appears to be large enough (body length $20 \mathrm{~mm}$ ) and collected early enough in the year (July 14, by I. Sung) to be a queen. This individual has lost much of its hair so the colour pattern is not clear, but females appear to show weak size-dependent dimorphism in the colour pattern of the hair: the queen has the remaining hair of $\mathrm{T} 2$ extensively black but with white hair narrowly anteriorly and medially and with orange hair narrowly posteriorly, especially in the lateral corners (Fig. 98); whereas workers (which are smaller) either have T2 chocolate-coloured anteriorly and black posteriorly or have T2 extensively dull yellow (Figs 99-101). Recently queens of this species have been reared in laboratory colonies, from which this colour pattern is confirmed (I. Sung in litt.). Males have the thoracic bands and T1-2 yellow (Fig. 102).

\section{Diagnosis}

\section{Females}

Queens medium-sized body length $20 \mathrm{~mm}$, workers $10-15 \mathrm{~mm}$. Can be distinguished within Taiwan by the hair of the thoracic dorsum with white bands (cf. B. eximius). 


\section{Males}

Body length 13-14 mm. Can be distinguished within Taiwan by their combination of the hair of the thoracic dorsum with yellow bands, side of the thorax yellow, and T3-7 red. Genitalia (Fig. 192) with the gonostylus much reduced, less than a quarter as long on its outer side as broad, with the distal edge concave and the inner distal corner with two indistinct adjacent teeth, the proximal tooth slightly shorter than the distal tooth and the two not clearly separated by an indentation (emargination) (cf. pyrosoma s. str.); volsella with the inner distal corner produced as a narrow curved hook (cf. rufipes-group, B. simillimus, lapidarius-group, sichelii-group, keriensis-group); eye unenlarged relative to female eye.

\section{Material examined}

\section{Holotype}

CHINA - $\hat{~}$, holotype of Bremus formosellus Frison, 1934 by original designation; Taiwan, Roeichi; 15 Sep. 1924; T. Shiraki and J. Sonan leg.; INHS (examined PW).

\section{Material sequenced (5 specimens)}

CHINA - Taiwan • 1 q (worker); Tayuling; $23.9767^{\circ}$ N, 121.5206 E; 5 Aug. 1991; C. Starr leg.; NHMUK seq: NHMPW07; PW: ML317 • 1 q (worker); Tahsuehshan; $24.3428^{\circ} \mathrm{N}, 121.1243^{\circ} \mathrm{E}$; M. Kuo leg.; NHMUK seq: NHMPW09; PW: ML318 • 1 spec.; Taiwan; $24.1806^{\circ} \mathrm{N}, 121.3101^{\circ} \mathrm{E}$; GenBank seq: AF279522; SEHU: ML184 2 우 (workers); Taiwan; 15 Jun. 2019; I. Sung leg.; TFRI seq: L11 LL12; TFRI: ML573 ML574.

\section{Global distribution}

(Taiwanese mountain species) East Asia: CHINA: Taiwan. (INHS, NHMUK, PW, TFRI.) The species is narrowly distributed but not rare in collections.

\section{Behaviour}

Expected to be food-plant generalists. Male mate-searching behaviour is expected to resemble the patrolling of B. eurythorax.

Bombus tanguticus Morawitz, 1887

Figs 13, 103-107, 206

Bombus tanguticus Morawitz, 1887: 200.

Our PTP analysis (Fig. 10) of coalescents in the COI gene supports a single species B. tanguticus within the tanguticus-group as identified in the four gene species tree (Figs 21-22), corroborated by differences in morphology.

Bombus tanguticus has a distinctive morphology and has been placed in a separate subgenus, Tanguticobombus (Pittioni 1939b), although this was synonymised with the subgenus Melanobombus by Richards (1968). A close relationship with other species of the subgenus Melanobombus is supported by an analysis of COI barcodes by Williams (2018), which like the tree for the COI gene here (Fig. 10), placed this species in the lapidarius-group. In contrast, when the species tree was estimated from four gene trees that include slower-evolving nuclear genes that can provide more reliable support for older relationships, B. tanguticus is placed in its own tanguticus-group next to the lapidarius-group (Fig. 21). Female morphology is inconclusive, because the labrum has a very narrow median groove and the posterior ocello-ocular areas are relatively unpunctured, which support grouping B. tanguticus with $B$. lapidarius. In contrast, the more densely hairy hind corbiculum and elongate hind basitarsus (as well as large queen body size) support a closer relationship of $B$. tanguticus with $B$. simillimus. Resolving this 
question might be possible with information from other genes, but it is very likely that the morphology of the male genitalia, once the male is described, will be diagnostic among the two species groups. This is one of the few bumblebee species world-wide for which the male still remains unknown (Williams 2018).

The typical colour pattern of this species is yellow banded, but a worker from Qinghai (ML219) has a white-banded colour pattern, as confirmed from their identical COI barcode sequences (Fig. 9).

\section{Diagnosis}

\section{Females}

Queens very large body length 22-28 mm, workers $12-13 \mathrm{~mm}$. Can be distinguished in the QTP by their combination of labral lateral tubercles medially narrowing and projecting as small pointed pyramids, the median longitudinal furrow between them deep and unusually narrow, $0.2 \times$ as broad as the labrum, forming a triangular notch (broader for co-occurring B. tibeticus, B. (Sibiricobombus) semenovi Morawitz, 1887, B. (Sibiricobombus) asiaticus Morawitz, 1875 s. lat.); mandible lacking a distinct sulcus obliquus, the posterior notch (incisura) anterior to the posterior tooth very weak or absent; clypeus with many large punctures especially in the dorsal half, the apical impressions unusually deep; antennal segment 3 (A3) short, nearly equal in length to A5, and only $1.5 \times$ as long as A4 (substantially longer for co-occurring B. tibeticus, B. semenovi, B. asiaticus s. lat.); the mid basitarsus with the posterior distal corner acute; hind tibia with the outer (corbicular) surface weakly reticulate and shining, for the queens uniformly covered (even in the centre) with dense short black fine branched hairs (these can become abraded for older queens and are few or absent in workers); hind basitarsus long and narrow, nearly $4 \times$ as long as its greatest breadth, the posterior edge almost straight in its distal $4 / 5$, the posterior distal corner acutely produced (basitarsus shorter and broader for co-occurring B. tibeticus, B. semenovi, $B$. asiaticus s. lat.), the outer surface with the short hair black with only short side branches so that some of the shining outer surface is visible between them (cf. dense overlapping pale hair for B. tibeticus); T6 posteriorly with a subapical rounded (nearly circular) boss, the apex for workers truncated or for queens deeply and narrowly divided medially (T6 undivided for queens of co-occurring B. tibeticus, B. semenovi, B. asiaticus s. lat.).

\section{Males}

Unknown.

\section{Material examined}

\section{Lectotype}

CHINA • + (queen), lectotype of Bombus tanguticus Morawitz, 1887 by designation of Williams (2018); Qinghai, "Bassin des gelb.[en] Flusses" (= source area of the Huang He, probably near Zhaling Hu: Williams 2018); [1884]; [N. Przhevalsky leg.]; ZIN (examined PW).

\section{Material sequenced (3 specimens)}

CHINA - Qinghai Province 1 \& (worker); Xiangpishan; 36.7589 ${ }^{\circ}$ N, 99.6041 ${ }^{\circ}$ E; 30 Aug. 2010; P. Williams leg.; BOLD seq: 6875A06; PW: ML9 • 1 क (worker); Kunlun Pass; $35.7258^{\circ}$ N, $94.1626^{\circ} \mathrm{E}$; 13 Aug. 2013; P. Williams leg.; NHMUK seq: NHMRC2; PW: ML219. - Xizang Province - 1 ㅇ (queen); Kamba county (Z715 $80 \mathrm{~km}) ; 28.2193^{\circ} \mathrm{N}, 88.7942^{\circ}$ E; $10 \mathrm{Jul}$. 2018; Q.-T. Wu leg.; IOZ seq: BB11; IOZ: ML566.

\section{Global distribution}

(Qinghai-Tibetan-Plateau species) East Asia: CHINA: Xizang, Qinghai. - Himalaya: INDIA: Kashmir, Sikkim. (IAR, IOZ, NHMUK, PW, ZIN.) This is one of the highest recorded bumblebees in 
the world, from an elevation of ca $5640 \mathrm{~m}$ a.s.1. (Williams 2018: along with B. tibeticus). The species is widely distributed but generally very rare (Fig. 206). There are data available for only 12 queens and 2 workers, including the two recent queens from Kamba county, Xizang, collected in 2018 (IOZ, examined PW).

\section{Behaviour}

Expected to be food-plant generalists but very few records known (Williams 2018). Males of B. tanguticus are expected to be flying during mid to late August, either visiting flowers or searching for mates in semi-arid habitats at elevations above $4500 \mathrm{~m}$ a.s.l. (Williams 2018). Males of the mountain species $B$. keriensis have been found patrolling near high ridges towards the upper end of the species' elevational range (above 4000 m a.s.1.) in Kashmir (Williams 1991). Similar 'hill-topping' near high mountain ridges towards the upper end of its elevational range in the QTP is likely for B. tanguticus.

Bombus eriophorus Klug, 1807

Figs 4, 14, 108-114, 193

Bombus eriophorus Klug, 1807: 265.

Bombus caucasicus Radoszkowski, 1860: 482.

Bombus caucasicus var. geogr. [subsp.] tenuicinctus Vogt, 1911: 59.

Bombus caucasicus var. geogr. [subsp.] mixtocinctus Vogt, 1911: 59.

Bombus lapidarius (part) - Reinig 1935: 334. - Williams 1998: 134 (non Linnaeus, 1758: 579).

Vogt (1909: 41, 49) considered the taxon eriophorus s. str. (thoracic dorsum uniformly white) and the taxon caucasicus (thoracic dorsum white with a black band between the wing bases) to be parts of $B$. lapidarius s. lat. (thorax black or often with anterior and sometimes posterior yellow bands). Subsequently, Vogt (1911: 69) regarded B. caucasicus as a species separate from B. lapidarius and listed the taxon eriophorus s. str. as part of B. caucasicus (even though eriophorus s. lat. is the oldest available name for the species). Reinig (1935: text-fig. 4) considered the taxon eriophorus s. str. and the taxon caucasicus to be parts of B. lapidarius s. lat., showing colour-pattern diagrams with apparently intermediate colour patterns as part of his evidence.

Lecocq et al. (2015) considered that B. caucasicus is likely to be a species separate from B. lapidarius from evidence of COI-coalescent analysis and from differences in composition of cephalic labial gland secretions (CLGS, believed to include sex pheromones). They had no samples of B. eriophorus s. str. but considered it likely to be conspecific with B. caucasicus.

In contrast to Reinig (1935), we agree with Lecocq et al. (2015) that B. eriophorus $\mathrm{s}$. lat. and B. lapidarius s. lat. are separate species from evidence of COI coalescents (Fig. 10), corroborated by morphology.

Our PTP analysis (Fig. 10) of coalescents in the COI gene supports three coalescents for candidate species within the lapidarius-group as identified in the four gene species tree (Figs 21-22): a Caucasusregion candidate species, caucasicus, supported strongly, and two more widespread candidate species within the European taxon lapidarius s. lat., supported relatively weakly. We have been unable to secure fresh samples of the taxon eriophorus s. str. - recent collections in the Caucasus mountains made by three different collectors of bumblebees have been unable to find this taxon.

From morphology, B. eriophorus s. lat. has a colour pattern distinct from B. lapidarius s. lat. for the females with a white-banded thorax. A worker from Azerbaijan in the NHMUK has the black hair of the band between the wing bases much intermixed with white hair, representing a state intermediate between 
that typical for the taxon eriophorus s. str. and that for the taxon caucasicus. This is slightly darker than the infrasubspecific taxon atava illustrated in Reinig (1935: text-fig. 4-iv). However, both the NHMUK worker and Reinig's taxon atava with their mixtures of black and white hairs between the wing bases appear to be intermediate in colour pattern between the white unbanded taxon eriophorus $\mathrm{s}$. str. and the white-banded taxon caucasicus, so these two taxa are interpreted provisionally as conspecific as parts of B. eriophorus s. lat.

\section{Diagnosis}

Females (Fig. 4)

Queens medium-sized body length 17-21 mm, workers 11-15 mm. Can be distinguished in West Asia by their combination of the thoracic dorsum with some pure white hair and the hair of the face and T1-2 black (cf. B. lapidarius, B. sichelii, B. incertus, B. alagesianus). Workers can be distinguished (cf. $B$. simillimus) by the combination of the pale hair of the thoracic dorsum white with T1-2 black and the wings clear.

\section{Males}

Body length 12-14 mm. Can be distinguished in West Asia by their combination of thoracic dorsum with extensive yellow hair and T2 usually predominantly black. Genitalia (Fig. 193) with the gonostylus as long as broad, reduced as a rounded flat scale with the inner basal process reduced to a tooth (cf. rufipesgroup, festivus-group, rufofasciatus-group); volsella with the inner distal corner broadly produced but without a narrow hook (cf. rufipes-group, festivus-group, rufofasciatus-group); penis valve head with the recurved inner hook just broader than the narrowest part of the adjacent penis valve shaft (cf. B. lapidarius); eye unenlarged relative to female eye.

\section{Material examined}

Holotype

?RUSSIA • $q$; "monte Caucaso"; "D. Marshall de Biberstein" leg.; type of Bombus eriophorus Klug, 1807 not found (ZIN, ZMHB, ZMUM; possibly lost in a fire with other ZMUM material following the Napoleonic invasion in 1812, A. Antropov pers. com.), but identity not in doubt.

Material sequenced (3 specimens)

GEORGIA • 1 q (queen); Calka; 41.5891ํ N, 44.1330 E; 27 May 2011; G. Japoshvili leg.; BOLD seq: 1555A04; AUG: ML175.

TURKEY • 1 $\left(\right.$ worker); Artvin; $41.0641^{\circ} \mathrm{N}, 42.2749^{\circ} \mathrm{E}$; H. Hines leg.; BOLD seq: 6877H04; SC: ML420.

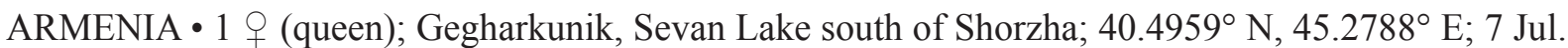
2006; Louda leg.; BOLD seq: 6880A03; MM: ML478.

\section{Global distribution}

(West Asian mountain species) West Asia: TURKEY, GEORGIA, ARMENIA, AZERBAIJAN, RUSSIA: Krasnodar, Stavropol. (AUG, MM, NHMUK, SC.) The species is not known to be common anywhere.

\section{Behaviour}

Food-plant choice expected to be generalist but no records. The male mate-searching behaviour is expected to resemble the patrolling of B. lapidarius. 
Bombus lapidarius (Linnaeus, 1758)

Figs 14, 115-122, 194

Apis Lapidaria Linnaeus, 1758: 579.

Apis Audens Harris, 1776: 130.

Apis Strenuus Harris, 1776: 131.

Apis Opis Harris, 1776: 137.

Apis Pertristis Harris, 1776: 137.

Apis arbuftorum Fabricius, 1776: 246.

Apis coronata Geoffroy in Fourcroy, 1785: 449.

Bremus truncorum Panzer, 1805: 85.

Bremus regelationis Panzer, 1805: 56.

Bombus albicans Schmiedeknecht, 1878: 405.

Bombus lapidarius var. [subsp.] carpatiens Radoszkowski, 1884: 63.

Bombus lapidarius var. [subsp.] decipiens Pérez, 1890: 152.

Bombus luctuosus Ball, 1920: 32 (non Schmiedeknecht, 1878: 388 = B. pratorum (Linnaeus)).

Bombus lapidarius st. [subsp.] atlanticus Benoist, 1928: 212.

Bombus flavescens Knechtel, 1963: 712, 714 (non Smith, 1852a: 45 = B. flavescens Smith).

Bombus bisiculus Lecocq, Biella, Martinet \& Rasmont, 2019: 7. syn. nov.

Bombus lapidarius var. carpaticus - Friese 1905: 518, incorrect subsequent spelling.

Bombus lapidarium - Berezin, Beiko \& Berezina 1996: 118, incorrect subsequent spelling.

Vogt $(1909,1911)$, Reinig (1935), and Lecocq et al. $(2015,2019)$ considered the taxon decipiens (thoracic dorsum with yellow bands) to be conspecific with the taxon lapidarius $\mathrm{s}$. str. (thoracic dorsum black) as divergent regional colour patterns within a polytypic species.

Lecocq et al. $(2015,2019)$ considered B. caucasicus as likely to be a species separate from B. lapidarius from evidence of COI-coalescent analysis and from differences in the composition of male cephalic labial gland secretions (CLGS, believed to be sex pheromones).

Lecocq et al. $(2013,2015,2019)$ also discovered divergence in CLGS between B. lapidarius from most of Europe and the yellow-banded bees in samples from southern Italy and they found this difference to coincide with a divergence in COI. They suggested that this ('decipiens-like' taxon) might represent an 'incipient' species (Lecocq et al. 2013) or a 'recently diverged' species (Lecocq et al. 2019). Subsequently they published the name B. bisiculus for this taxon (Lecocq et al. 2019).

Our PTP analysis (Fig. 10) of coalescents in the COI gene supports three coalescents for candidate species within the lapidarius-group as identified in the four gene species tree (Figs 21-22): a Caucasusregion candidate species, caucasicus, supported strongly, and two more widespread candidate species within the European taxon lapidarius s. lat. (a lapidarius-complex), supported relatively weakly. Our PTP results agree that the taxon decipiens and the taxon lapidarius s. str. are likely to be conspecific as parts of B. lapidarius s. lat. But our PTP results also show that there is a third candidate species (Fig. 10) that is divergent in COI from B. lapidarius s. str. However, this candidate species does not correspond to (i.e., is not congruent or co-terminous with) Lecocq et al.'s $(2015,2019)$ south Italian taxon bisiculus (which is included in Figs 9-10). Our candidate species includes not only some of the yellow-banded samples from southern Italy described as the taxon bisiculus by Lecocq et al., but also (from the same data) some unbanded bees from Slovakia, the Czech Republic, Serbia, Bulgaria, and Hungary (Figs 9-10) that Lecocq et al. identify as the taxon lapidarius s. str. At present, our south-eastern candidate species is not supported as a separate species by integrative analysis because (1) not only is it much more broadly distributed than Lecocq et al.'s divergent south-Italian CGLS taxon bisiculus, but (2) so far 
we have been unable to find any diagnostic morphological characters, even in the colour pattern. Our south-eastern candidate species may represent the descendants of an isolated refugial population from the glacial period (Reinig 1935; Lecocq et al. 2015), which appears now to be surrounded to the west and north by a second weakly divergent lineage, and to the east in Turkey by possibly a third weakly divergent lineage (Figs 9-10). So far this broader south-east European (but not Turkish) population can be identified only from COI sequences, so evidence would be needed from another character source to corroborate its current evolutionary independence before it could be accepted as a separate species. As well as showing only weak divergence among them in their COI barcodes, all of these lineages show very little variation within them, which corroborates them being relatively recent.

More work is needed to assess the variation within the lapidarius-complex in south-eastern Europe, but until further evidence is available from other character sources to corroborate consistent groups as separate species, we regard these bees tentatively as conspecific, as parts of a single widespread species, B. lapidarius s. lat.

\section{Diagnosis}

\section{Females}

Queens medium-sized body length $18-21 \mathrm{~mm}$, workers $11-16 \mathrm{~mm}$. Can be distinguished in Europe and West Asia by their combination of the hair on the face black with the hair on the thoracic dorsum either black or with some cream or yellow but not with pure white and not entirely yellow (cf. B. sichelii, B. eriophorus, B. incertus, B. alagesianus, B. semenovianus). Queens can be distinguished (cf. $B$. simillimus) by the combination of the hair of the thoracic dorsum black with the wings clear.

\section{Males}

Body length 11-16 mm. Can be distinguished in Europe and West Asia by their combination of the hair posteriorly on the thoracic dorsum and on T2 usually predominantly black and T4-7 bright red. Genitalia (Fig. 194) with the gonostylus as long as broad, reduced as a rounded flat scale with the inner basal process reduced to a tooth (cf. rufipes-group, festivus-group, rufofasciatus-group); volsella with the inner distal corner broadly produced but without a narrow hook (cf. rufipes-group, festivus-group, rufofasciatus-group); penis valve head with the recurved inner hook just narrower than the narrowest part of the adjacent penis valve shaft (cf. B. eriophorus); eye unenlarged relative to female eye.

\section{Material examined}

\section{Holotype}

SWEDEN • $q$ (queen), holotype of Apis lapidaria Linnaeus, 1758 (Day 1979); Uppland; C. Linnaeus leg.; LSL (examined PW).

Material sequenced (29 specimens, includes some sequences from Lecocq et al. 2015)

FRANCE 11 ( worker); Aquitaine, Le Fontanaud; $45.314^{\circ}$ N, 0.346 E; 14 Aug. 2007; C. Ratti leg.; BOLD seq: 3771B12; PCYU: ML329 • 1 spec.; Eyne; 42.3024 N, $2.0106^{\circ}$ E; M. Terzo leg.; GenBank seq: KC915850; UMONS: ML284.

SWITZERLAND • 1 ㅇ (worker); Valais, St Luc; 46.2210 N, 7.6202 E; 22 Jul. 1999; P. Williams leg.; NHMUK seq: PW25; PW: ML186.

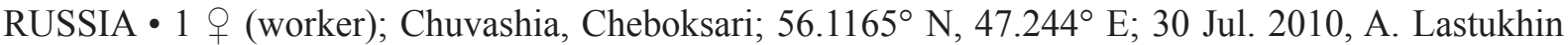
leg.; BOLD seq: SHMEL-E10; CSPU: ML330.

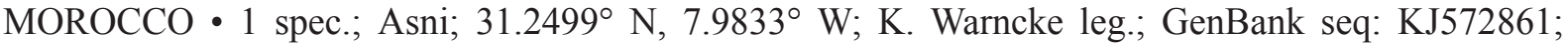
UMONS: ML193. 
SPAIN • 1 spec.; $39.4208^{\circ}$ N, $0.8158^{\circ}$ W; T. Lecocq leg.; GenBank seq: KC915889; UMONS: ML192 - 1 spec.; Camprodón; 42.3136 N, $2.3719^{\circ}$ E; D. Michez leg.; GenBank seq: KC915724; UMONS: ML274 • 1 spec.; Buñol; 39.4208 N $0.8158^{\circ}$ W; T. Lecocq leg.; GenBank seq: KC915826; UMONS:

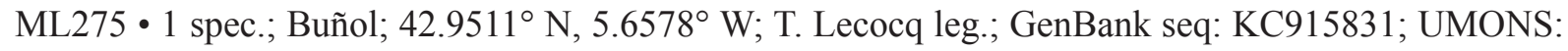
ML276.

IRELAND • 1 spec.; Dublin; 53.3414 N, 6.2769 W; R. Moermans leg.; GenBank seq: KC915738; UMONS: ML282.

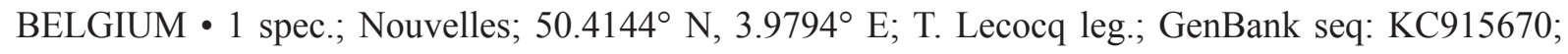
UMONS: ML278.

FINLAND • 1 spec.; Nåtö; 60.0464 N, $19.9731^{\circ}$ E; B. Cederberg leg.; GenBank seq: KC915660; UMONS: ML277.

AUSTRIA • 1 spec.; Mühl; 47.5014N N $10.7361^{\circ}$ E; D. Michez leg.; GenBank seq: KC915689; UMONS: ML279.

ITALY • 1 spec.; S. Margherita; 44.7158 N $9.2087^{\circ}$ E; M. Cornalba leg.; GenBank seq: KC915719; UMONS: ML281 • 1 spec.; Salcito; $41.7447^{\circ}$ N, $14.5147^{\circ}$ E; T. Lecocq leg.; GenBank seq: KC915714;

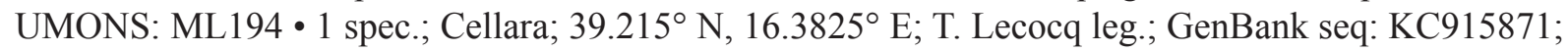
UMONS: ML271 • 1 spec.; Villadoro; $37.6814^{\circ} \mathrm{N}, 14.3047^{\circ} \mathrm{E}$; T. Lecocq leg.; GenBank seq: KC915876; UMONS: ML272 • 1 spec.; Piano Provenzana; $37.7994^{\circ}$ N, $15.0647^{\circ}$ E; T. Lecocq leg.; GenBank seq: KC915881; UMONS: ML273.

SLOVENIA • 1 spec.; Studenčice; $46.3722^{\circ}$ N, $14.1575^{\circ}$ E; T. Lecocq leg.; GenBank seq: KC915710; UMONS: ML386.

UKRAINE • 1 spec.; Lastiosti; $48.7172^{\circ} \mathrm{N}, 24.525^{\circ}$ E; D. Michez leg.; GenBank seq: KC915844; UMONS: ML283.

TURKEY • 1 q (worker); Erzingan, Yeniyol-Ahmitli; 39.8926 N, $39.3676^{\circ}$ E; 5 Aug. 2002; H. Hines leg.; BOLD seq: 6877H02; SC: ML418 • 1 q (worker); Erzingan, Yeniyol-Ahmitli; $39.8926^{\circ} \mathrm{N}$, 39.3676 E; 5 Aug. 2002; H. Hines leg.; BOLD seq: 6877H03; SC: ML419.

SERBIA • 1 spec.; Belgrade; $44.7872^{\circ}$ N, $20.4517^{\circ}$ E; A. Cetkovic leg.; GenBank seq: KC915752; UMONS: ML387.

CZECH REPUBLIC • 1 spec.; Praha; 50.105 N, $14.4167^{\circ}$ E; T. Lecocq leg.; GenBank seq: KC915695; UMONS: ML408.

SLOVAKIA • 1 spec.; Nitra; $48.3036^{\circ}$ N, $18.1539^{\circ}$ E; T. Lecocq leg.; GenBank seq: KC915797; UMONS: ML410.

HUNGARY • 1 spec.; Szentendre; $47.6633^{\circ}$ N, $19.0719^{\circ}$ E; T. Lecocq leg.; GenBank seq: KC915700; UMONS: ML409 • 1 spec.; Gárdony; $47.2011^{\circ} \mathrm{N}, 18.6442^{\circ}$ E; T. Lecocq leg.; GenBank seq: KC915800; UMONS: ML411.

BULGARIA • 1 spec.; Beklemeto; $42.7789^{\circ}$ N, $24.6142^{\circ}$ E; T. Lecocq leg.; GenBank seq: KC915704; UMONS: ML280 • 1 spec.; same collection data as for preceding; GenBank seq: KC915802; UMONS: ML407. 


\section{Global distribution}

(European widespread grassland, often lowland, species extending into the margins of North Africa and West Asia) North Africa: MOROCCO. - Europe: SPAIN, UK, IRELAND, FRANCE, BELGIUM, NETHERLANDS, DENMARK, GERMANY, POLAND, SWEDEN, FINLAND, SWITZERLAND, AUSTRIA, CZECH REPUBLIC, SLOVAKIA, ITALY, HUNGARY, ROMANIA, BULGARIA, SLOVENIA, SERBIA, ALBANIA, MONTENEGRO, MACEDONIA, GREECE, UKRAINE, RUSSIA: European Russia, Crimea, Ural. - West Asia: TURKEY. (NHMUK, PW, ZMHB.) The species is widespread and often abundant.

The distribution of this species is known to extend eastwards into Russia as far as Arkaim Nature Reserve, Chelyabinsk Oblast (AB: $52.65^{\circ} \mathrm{N}, 59.60^{\circ} \mathrm{E}$ ).

\section{Behaviour}

Colonies of this species have been described (Alford 1975; Benton 2006; Goulson 2010). Food-plant generalists (Alford 1975; Rasmont 1988; Benton 2006; Goulson 2010). Male mate-searching behaviour is patrolling (Alford 1975; Benton 2006; Goulson 2010).

\section{Bombus incertus Morawitz, 1881}

Figs 15, 123-124, 195

Bombus incertus Morawitz, 1881: 229.

Bombus insertus - Esmaili \& Rastegar 1974: 25, incorrect subsequent spelling.

Bombus erzurumensis - Lecocq et al. 2015: supplementary table s1 (non Özbek, 1990: 209).

Vogt (1909: 49) initially considered the taxon incertus to be part (a 'Form') of the species B. lapidarius s. lat. although subsequently (Vogt 1909: 52, 1911: 68) he regarded $B$. incertus as a species separate from B. lapidarius s. lat. Reinig (1935) also considered B. incertus to be a separate species.

Our PTP analysis (Fig. 10) of coalescents in the COI gene supports three coalescents for candidate species within the sichelii-group as identified in the four gene species tree (Figs 21-22): a west Asian $B$. incertus, which is strongly supported, and a widespread Eurasian $B$. sichelii s. lat., which is more weakly supported, and the Himalayan B. semenovianus. This is corroborated by differences in morphology that support the three as separate species (see the Diagnosis). The colour pattern of $B$. incertus appears to be particularly invariant.

\section{Diagnosis}

\section{Females}

Queens medium-sized body length 18-21 mm, workers 10-15 mm. Can be distinguished in West Asia by their combination of the hair of the face black, the hair of T2 posteriorly entirely bright white, the hindleg corbicular fringes predominantly black, and the red of T4-5 being a deep almost purplered rather than orange-red (cf. B. lapidarius, B. eriophorus, B. sichelii, B. alagesianus). Queens of $B$. incertus are also larger than similarly coloured queens of $B$. sichelii from Iran and eastern Turkey, and can be distinguished by the complete absence of black hairs from T2 posteriorly and by the hindleg corbicular fringes without extensively orange hairs.

\section{Males}

Body length 12-15 mm. Can be distinguished in West Asia by their combination of the black band between the wing bases narrower than the anterior white band, the scutellum anterior margin with a few 
black hairs, T2 posteriorly entirely bright white, and the red of T4-7 being a deep almost purple-red rather than orange-red. Genitalia (Fig. 195) with the gonostylus as long as broad, reduced as a rounded flat scale with the inner basal process reduced to a tooth (cf. rufipes-group, festivus-group, rufofasciatusgroup); volsella with the inner distal corner broadly produced but without a narrow hook (cf. rufipesgroup, festivus-group, rufofasciatus-group); eye unenlarged relative to female eye.

\section{Material examined}

\section{Holotype}

?RUSSIA - + (queen), holotype of Bombus incertus Morawitz, 1881 by monotypy; "Caucasien"; F. Morawitz leg.; not found (searched both ZIN and ZMUM), but identity as a species widespread in Turkey not in doubt.

\section{Material sequenced ( 8 specimens)}

TURKEY • 1 q (queen); Lake Van; $38.4842^{\circ}$ N, $42.2978^{\circ}$ E; 18 Jun. 1988; K. Guichard leg.; BOLD seq: 1555C08; NHMUK: ML239.

IRAN • 1 q (worker); Tehran, Kamarbon; 36.2162 N, 52.2928 E; 14 Aug. 2010; P. Abdoli leg.; NHMUK seq: IRANPW015; PW: ML11 • 1 q (worker); Tehran, Kamarbon; $36.2161^{\circ} \mathrm{N}, 52.2928^{\circ} \mathrm{E}$; 14 Aug. 2010; P. Abdoli leg.; NHMUK: IRANPW016; PW: ML12 • 1 \& (worker); Kasra; $38.3444^{\circ} \mathrm{N}$, 47.6711 ${ }^{\circ}$ E; 6 Aug. 2009; A. Monfared leg.; NHMUK seq: IRANPW003; PW: ML13 • 1 q (worker); Shahkuh, Gorgan; $37.3698^{\circ}$ N, $55.9065^{\circ}$ E; 25 Sep. 2012; E. Spo leg.; NHMUK seq: NHMRC1; PW: ML14 • 1 q (queen); Mazandaran, Ileka; $36.2077^{\circ}$ N, $51.4088^{\circ}$ E; 9 May 2006; A. Taghavi leg.;

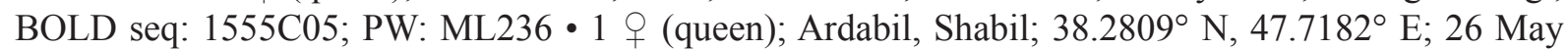
2006; A. Monfared leg.; BOLD seq: 1555C06; PW: ML237 • 1 \% (worker); Meshkinshahr, Walazir; $38.3151^{\circ}$ N, $47.7595^{\circ}$ E; 4 Aug. 2005; A. Monfared leg.; BOLD seq: 1555C07; PW: ML238.

\section{Global distribution}

(West Asian mountain species) West Asia: TURKEY, IRAN. (NHMUK, PW, YUY.) Contrary to some recent claims (S.-F. Wang 1985; S.-F. Wang \& Yao 1996; Niu et al. 2018), this species does not occur in China. Examination of specimens in the IOZ collection labelled $B$. incertus shows these to be mostly misidentified B. separandus with a few B. keriensis from Xinjiang (examined PW). Bombus incertus is locally common.

\section{Behaviour}

Food-plant generalists (Rasmont \& Flagothier 1996). The male mate-searching behaviour is expected to resemble the patrolling of $B$. lapidarius.

Bombus semenovianus (Skorikov, 1914)

Figs 5, 15, 125-128, 196

Lapidariobombus semenovianus Skorikov, 1914a: 127.

Bombus lapidarius subsp. problematicus Bischoff, 1935: 255.

Our PTP analysis (Fig. 10) of coalescents in the COI gene supports three coalescents for candidate species within the sichelii-group as identified in the four gene species tree (Figs 21-22): B. incertus, B. sichelii s. lat., and the Himalayan B. semenovianus.

From morphology, B. semenovianus is supported by its distinctive colour pattern with the thoracic dorsum entirely yellow (known otherwise only for some males of B. eriophorus from the Caucasus), 
by its distinctive form of the male genitalia (see the Diagnosis), and by its slightly enlarged male eye relative to the female eye (Williams, 1991).

\section{Diagnosis}

Females (Fig. 5)

Queens medium-sized body length 17-21 mm, workers $11-15 \mathrm{~mm}$. Can be distinguished by the hair on the thoracic dorsum being uniformly bright yellow (cf. B. keriensis, B. separandus, etc.).

\section{Males}

Body length 12-16 mm. Can be distinguished by the unique combination of having the eyes slightly enlarged relative to female eye and the hair of the thoracic dorsum being uniformly bright yellow (cf. B. eriophorus, B. qilianensis). Genitalia (Fig. 196) with the gonostylus as long as broad, reduced as a rounded flat scale with the inner basal process reduced to a tooth (cf. rufipes-group, festivus-group, rufofasciatus-group); volsella with the inner distal corner broadly produced but without a narrow hook (cf. rufipes-group, festivus-group, rufofasciatus-group); eye slightly enlarged relative to female eye.

\section{Material examined}

\section{Syntype}

INDIA - $q$ (queen), syntype of Lapidariobombus semenovianus Skorikov, 1914 (Williams 1991); Kashmir, Ladakh, Stakmo pass; 13 Jul. 1912; G. Jakobson leg.; ZIN (examined PW).

\section{Material sequenced (5 specimens)}

PAKISTAN • 1 q (worker); Karakorum, Holshal; $36.1962^{\circ}$ N, $74.9496^{\circ}$ E; BOLD seq: 1552 E07; SEHU:

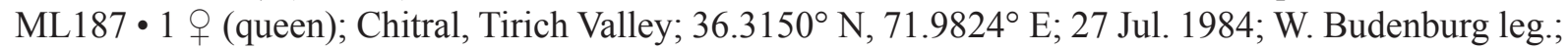
BOLD seq: 6877G11; PW: ML416 • 1 సं; Ganokh; $34.7552^{\circ}$ N, $76.2808^{\circ}$ E; 4 Sep. 2017; S. Jaffar leg.; BOLD seq: 1555E10; UAP: ML258 1 ơ; upper Memosh; $34.7093^{\circ}$ N, $76.1208^{\circ}$ E; 5 Sep. 2017;

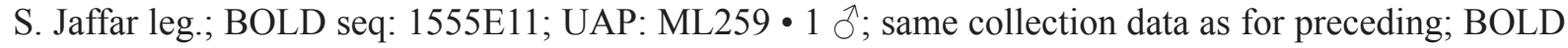
seq: 6877H06; UAP: ML422.

\section{Global distribution}

(West Himalayan mountain species) Himalaya: AFGHANISTAN, PAKISTAN, INDIA: Kashmir. (NHMUK, PW, SEHU, UAP, ZIN, ZSM.) The species is locally common.

\section{Behaviour}

Food-plant generalists (Williams 1991). Male mate-searching behaviour is poorly known (Williams 1991).

\section{Bombus sichelii Radoszkowski, 1860}

Figs 15, 129-138, 197, 211

Bombus SICHELII Radoszkowski, 1860: 481.

Bombus alticola Kriechbaumer, 1873: 339.

Bombus lapidarius subsp. nigritulus Friese, 1905: 518.

Bombus lapidarius subsp. albidulus Friese, 1905: 518.

Bombus sicheli Form [subsp.] uniens Vogt, 1909: 62.

Bombus noster Skorikov, 1910b: 578.

Bombus sicheli var. geogr. [subsp.] czerskiae Vogt, 1911: 59.

Bombus sicheli var. geogr. [subsp.] rehbinderianus Vogt, 1911: 60.

Bombus sicheli var. geogr. [subsp.] cazurroi Vogt, 1911: 60. 
Lapidariobombus verticiflavus Skorikov, 1931: 225.

Bombus sicheli f.g. [subsp.] daghestanicus Reinig, 1935: 345 (non Radoszkowski, 1877: vii = B. sylvarum (Linnaeus)).

Bombus jeholensis Yasumatsu, 1935: 45.

Bombus sicheli subsp. chinganicus Reinig, 1936: 6.

Pyrobombus sicheli subsp. flavissimus Tkalců, 1975: 177, replacement name for latofasciatus Vogt, 1909: 49.

Pyrobombus erzurumensis Özbek, 1990: 209.

Bombus Sicheli - Radoszkowski 1877: 213, incorrect subsequent spelling.

Since Vogt (1909), B. sichelii s. lat. has generally been considered as a species separate from B. lapidarius s. lat. Vogt (1909: 46) stated that his "Formen" are subpopulations, which could be considered equivalent to subspecies. Reinig (1935: 333) stated explicitly that his "f.g." (forma geographica) are equivalent to subspecies. These taxa are considered here to be parts of a sichelii-complex.

The taxon erzurumensis was described more recently as a separate species from north-eastern Turkey, although we have seen it also from Iran. Within the sichelii-complex it has an especially narrow band of black hair posteriorly on T2. It was first recognised as likely to be conspecific with B. sichelii s. lat. by Williams (1998).

Our PTP analysis (Fig. 10) supports two coalescents in the COI gene, for a west Asian B. incertus, which is strongly supported, and a widespread Eurasian $B$. sichelii s. lat. Although the support for a COI coalescent for $B$. sichelii s. lat. is relatively weak, it is the best supported in this part of the tree, so no alternative interpretation of the member taxa is better supported as species. Corroboration from a positive divergence-with-distance relationship both within (Fig. 17) and among (Fig. 18) the component lineages (Fig. 9) is accepted as additional support for B. sichelii s. lat. as a single broadly distributed species in its long accepted sense.

From morphology, B. sichelii s. lat. has a colour pattern of the hair of T2 with black hairs posteriorly that is consistently distinct from $B$. incertus.

\section{Diagnosis}

Females

Queens medium-sized body length 17-20 mm, workers 9-13 mm, Can be distinguished by usually having at least some pale hair on the face at the base of the antenna (cf. B. separandus, B. incertus), T2 posteriorly usually has at least a narrow line of black hair (cf. B. keriensis, B. separandus, $B$. alagesianus, $B$. incertus etc.), and the hindleg corbicular fringes have some extensively orange hairs. Some individuals from eastern Turkey and Iran (the taxon erzurumensis) resemble $B$. incertus closely because they have very few black hairs posteriorly on T2 and few or no pale hair on the face, but the queens of $B$. sichelii are smaller than $B$. incertus, the red of T4-5 is more orange-red, and the hindleg corbicular fringes have some extensively orange hairs.

\section{Males}

Body length 11-15 mm. Can be distinguished in Europe and West Asia by their combination of yellow or white hair posteriorly on the thoracic dorsum, T2 with yellow or white but posteriorly with some black, and T4-7 a pale red. Genitalia (Fig. 197) with the gonostylus as long as broad, reduced as a rounded flat scale with the inner basal process reduced to a tooth (cf. rufipes-group, festivus-group, rufofasciatus-group); volsella with the inner distal corner broadly produced but without a narrow hook (cf. rufipes-group, festivus-group, rufofasciatus-group); eye unenlarged relative to female eye. 


\section{Material examined}

\section{Lectotype}

RUSSIA - $q$ (queen), lectotype of Bombus sichelii Radoszkowski, 1860 by designation of Tkalců (1974b); Kamchatka; Dittmar leg.; ZMHB (examined PW).

Material sequenced (46 specimens, includes some sequences from Lecocq et al. 2015)

SPAIN • 1 J ; Catalonia, Cerbi; $42.646^{\circ}$ N, $1.152^{\circ}$ E; 16 Sep. 1993; C. Schmid-Egger leg.; BOLD seq: BCZSMHYM02963; ZSM: ML327 • 1 §; same collection data as for preceding; BOLD seq: BCZSMHYM02964; ZSM: ML328.

SWITZERLAND • 1 ( (worker); 46.2210 N, 7.6203 E; 22 Jul. 1999; P. Williams leg.; BOLD seq: 1555H11; PW: ML313 • 1 क (worker); Ticino, Lago Sambuco; 46.466 N, 8.648 E; 28 Jul. 1993; C. Schmid-Egger leg.; BOLD seq: BCZSMHYM02961; ZSM: ML326.

AUSTRIA • 1 spec.; Mühl; 47.5014 N, 10.7361 E; D. Michez leg.; GenBank seq: KM458067; UMONS: ML285.

FRANCE • 1 spec.; Col d'Allos; $44.1733^{\circ}$ N, 6.3544 E; O. Poncheau leg.; GenBank seq: KM458070; UMONS: ML288 • 1 spec.; Gavarnie; $42.7119^{\circ}$ N, $0.0075^{\circ}$ W; D. Michez leg.; GenBank seq: KM458072; UMONS: ML289.

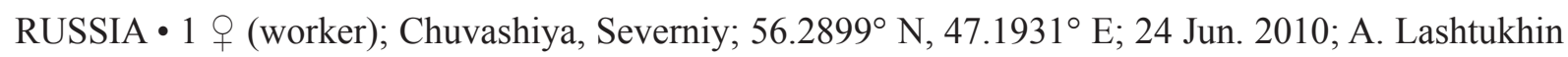
leg.; BOLD seq: SHMEL-E11; SDM ML331 • 1 spec.; Buryatia, Mondy; $51.4103^{\circ} \mathrm{N}, 100.5936^{\circ} \mathrm{E}$; T. DeMeulemeester leg.; GenBank seq: KC915894; UMONS: ML290 • 1 spec.; same collection data as for preceding; GenBank seq: KC915896; UMONS: ML291 • 1 q (worker); Tuva, $31 \mathrm{~km}$ Erzin; $50.0366^{\circ} \mathrm{N}, 95.4348^{\circ} \mathrm{E} ; 18$ Jul. 2014; A. Lelej leg.; BOLD seq: 1555F11; NSUN: ML268 • 1 ㅇ (worker); Sakhalin, south Schmidta Peninsula; 53.8874 ${ }^{\circ}$ N, $142.7429^{\circ}$ E; 13 Aug. 2003; J. Jobe leg.; BOLD seq: 1552F06; SEMC: ML189 • 1 q (queen); Kamchatka; $53.7887^{\circ} \mathrm{N}, 159.3172^{\circ}$ E; BOLD seq: 6879D08; FSCV: ML217.

TURKEY • 1 ( (worker); $41.2008^{\circ} \mathrm{N}, 42.5283^{\circ} \mathrm{E}$; BOLD seq: 6879A04; PW: ML188 • 1 spec.; Zigana Geçidi; $40.6353^{\circ}$ N, $39.4044^{\circ}$ E; P. Rasmont leg.; GenBank seq: KM458068; UMONS: ML286• 1 spec.; same collection data as for preceding; GenBank seq: KM458069; UMONS: ML287.

IRAN • 1 (queen); 38.2974 ${ }^{\circ} \mathrm{N}, 48.0360^{\circ} \mathrm{E}$; 26 May 2006; NHMUK seq: IRANPW022; PW: ML15

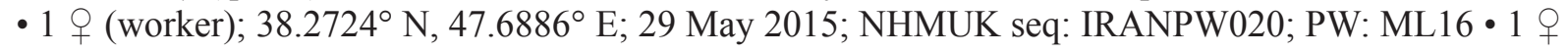
(worker); $38.2717^{\circ} \mathrm{N}, 47.8515^{\circ} \mathrm{E}$; 31 May 2014; NHMUK seq: IRANPW023; PW: ML17.

KYRGYZSTAN • 1 ㅇ (queen); Santash; 42.7389 N, $79^{\circ}$ E; 28 Jun. 2016; R. DeJonghe leg.; BOLD seq: 1555F03; RDJ: ML260.

MONGOLIA 11 (worker); Ovorhangay, Karakorum; 47.1667 N, 102.8333 E; 13-16 Aug. 1990; C. Cockell leg.; BOLD seq: 6874D04; PW: ML18 • 1 (worker); Hovsgol, Tsagaan Nur; $50.601^{\circ} \mathrm{N}$, $101.523^{\circ}$ E; 16 Jul. 2005; J. Gelhaus leg.; BOLD seq: 1550G02; SEMC: ML215 • 1 q (worker); Dalbay; 51.025ํ N, $100.766^{\circ}$ E; 20 Jul. 2007; D. Song leg.; BOLD seq: 9808C12; PCYU: ML332 • 1 (worker); Dalbay; 51.0279 ${ }^{\circ}$, $100.7667^{\circ}$ E; 4 Aug. 2007; D. Song leg.; BOLD seq: 9808E01; PW: ML218 1 q (worker); Khovsgol Nuur; 51.0628 ${ }^{\circ}$ N, $100.7322^{\circ}$ E; 21 Jul. 2004; D. Sheppard leg.; NHMUK seq: PW28; PW: ML324.

CHINA - Neimenggu Province 1 1 (worker); Moerdaga; 51.3349 ${ }^{\circ}$ N, $120.6784^{\circ}$ E; 18 Aug. 2009; P. Williams leg.; NHMUK seq: CT465; PW: ML465 • 1 क (worker); nr. Huanggangliang; $43.5423^{\circ} \mathrm{N}$, 117.6233ํ E; 24 Aug. 2010; P. Williams leg.; BOLD seq: 1555B12; PW: ML231. - Shanxi Province 
- 1 ㅇ (worker); Yingxian; $39.4008^{\circ} \mathrm{N}, 113.4167^{\circ} \mathrm{E}$; 8 Sep. 2007; P. Williams leg.; BOLD seq: 1555C01; PW: ML232. - Gansu Province - 1 (worker); Pinnan; 34.3281 ${ }^{\circ}$ N, $105.6278^{\circ}$ E; 30 Aug. 2009; P. Williams leg.; BOLD seq: 1555H01; PW: ML303. - Sichuan Province • 1 q (worker); Hongyuan; $32.6403^{\circ} \mathrm{N}, 102.3286^{\circ} \mathrm{E}$; 4 Aug. 2002; P. Williams leg.; BOLD seq: 1555H02; PW: ML304 • 16 specs; Hongyuan; $32.3282^{\circ} \mathrm{N}, 102.4543^{\circ} \mathrm{E}$; Y. Dong leg.; YD seq: DYX53.1, DYX53.2, DYY17, DYX61.1, DYX1.1, DYX18.1, DYX30.2, DYX34.1, DYX11.2, DYZX2, DYX64, DYX1.3, DYX13.1, DYX27.1, DYX13.2, DYX69.1; YD: ML443 to ML458.

\section{Global distribution}

(Widespread Palaearctic species, in steppes in the north and in mountains in the south) Europe: SPAIN, FRANCE, SWITZERLAND, AUSTRIA. - West Asia: TURKEY, IRAN. - North Asia: KYRGYZSTAN, MONGOLIA, RUSSIA: European Russia, North Caucasus, Ural, West Siberia, Altai Mountains, East Siberia, Far East. - East Asia: CHINA: Xizang, Sichuan, Gansu, Ningxia, Shanxi, Hebei, Neimenggu, Liaoning, Jilin, Heilongjiang; N KOREA, S. KOREA. (FSCV, IAR, IOZ, NHMUK, PW, SC, SEMC, YUY, ZMHB.) The species is widespread (Fig. 210) and often abundant.

\section{Behaviour}

Food-plant generalists (Rasmont 1988; Neumayer \& Paulus 1999; Williams et al. 2009; An et al. 2014). The male mate-searching behaviour is expected to resemble the patrolling of B. lapidarius.

\section{Bombus ladakhensis Richards, 1928}

Figs 6, 16, 139-147, 198

Bombus rufofasciatus var. [not subsp.] ladakhensis Richards, 1928b: 336, but not infrasubspecific after Tkalců (1974a): 335 (ICZN 1999: Art. 45.6.4.1).

Bombus rufofasciatus var. [not subsp.] phariensis Richards, 1930: 642, but not infrasubspecific after Tkalců (1974a): 336 (ICZN 1999: Art. 45.6.4.1).

Bombus variopictus Skorikov, 1933a: 248.

Bombus variopictus subsp. bianchii Skorikov, 1933a: 248.

Bombus reticulatus Bischoff, 1936: 7.

The name Bombus variopictus was first published without description by Skorikov (1923) and the taxon was not described with a name available at the time until Skorikov (1933a).

Williams (1991) regarded the yellow-banded taxon ladakhensis s. str. and the white-banded taxon phariensis as parts of the same species based on similarity in morphology. There is also a tendency for some individuals from Yunnan to have much more extensive black hair.

Our PTP analysis (Fig. 10) of coalescents in the COI gene supports a single candidate species that includes both the taxon ladakhensis s. str. and the taxon phariensis, corroborated by differences in morphology.

From morphology, there is only the difference in colour pattern (pale bands yellow or white) between the taxon ladakhensis s. str. and the taxon phariensis. These taxa share the uniquely fused reflexed head of the male penis valve. They are considered parts of the single species, B. ladakhensis s. lat.

\section{Diagnosis}

\section{Females}

Queens medium-sized body length 16-19 mm, workers 9-13 mm. Can be distinguished on the QTP by their combination of the hair on the side of the thorax predominantly yellow or white extending 
ventrally as far as the leg bases (cf. B. rufofasciatus, B. prshewalskyi) with the hair of T5 white (or at least extensively white tipped).

Males (Fig. 6)

Body length 11-13 mm. Can be distinguished on the QTP by their combination of either T1 yellow or T2 white (cf. B. rufofasciatus, B. prshewalskyi) with the hair of T6-7 white or at least extensively white tipped. Genitalia (Fig. 198) with the gonostylus as long as broad, reduced as a rounded flat scale with the inner basal process reduced to a tooth (cf. rufipes-group, festivus-group, rufofasciatus-group); volsella with the inner distal corner broadly produced but without a narrow hook (cf. rufipes-group, festivus-group, rufofasciatus-group); penis valve with the recurved hook of the head fused throughout most of its length to the adjacent penis-vale shaft (cf. all other Melanobombus); eye unenlarged relative to female eye.

\section{Material examined}

\section{Holotype}

INDIA - (queen, not a worker), holotype of Bombus rufofasciatus var. ladakhensis Richards, 1928 by monotypy (Williams 1991); Kashmir, Ladakh, Chushal; Jun. 1925; R. Meinertzhagen leg.; NHMUK (examined PW).

\section{Material sequenced (24 specimens)}

CHINA - Qinghai Province 1 \& (worker); Xiangpishan; 36.7589 ${ }^{\circ}$ N, 99.6041 ${ }^{\circ}$ E; 30 Aug. 2010; P. Williams leg.; BOLD seq: 6876H04; PW: ML19 • 1 ( (worker); same collection data as for preceding; BOLD seq: 6876H05; PW: ML20 • 1 क (worker); Kunlun Shan; $35.6920^{\circ}$ N, $94.052^{\circ}$ E; 13 Aug. 2013; P. Williams leg.; NHMUK seq: NHM2; PW: ML22 - 1 q (worker); Burhan Budai Shan, Qushiang; 35.8304 N, 98.0816 ${ }^{\circ}$ E; 16 Aug. 2013; P. Williams leg.; BOLD seq: 1555C02; PW: ML233. - Xizang Province • 1 q (queen); Tanggula Shan; 32.8614 ${ }^{\circ}$ N, 91.9174 E; 29 May 1999; K. Huber leg.; BOLD

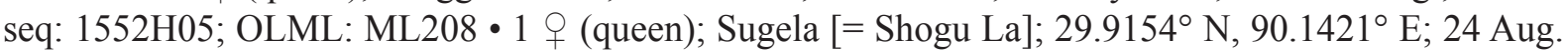
1999; K. Huber leg.; BOLD seq: 1552H04; OLML: ML209 • 1 q (queen); Mt Kailas; $30^{\circ} \mathrm{N}, 82^{\circ}$ E; 16 Jul. 2004; T. Bardell leg.; BOLD seq: 1555G10; PW: ML300 • 1 q (worker); Sejilashan; $29.64141^{\circ} \mathrm{N}$, 94.69818 ${ }^{\circ}$ E; 26 Jul. 2018; Z. Ren leg.; KIB seq: SJLSM102012; KIB: ML544 • 1 o (worker); Milashan; 29.85301 ${ }^{\circ}$ N, $92.33378^{\circ}$ E; 27 Jul. 2018; Z. Ren leg.; KIB seq: MLSH103002; KIB: ML545 • 1 ㅇ (worker); Yelashan; $30.16394^{\circ}$ N, $97.2860^{\circ}$ E; 22 Jul. 2018; Z. Ren leg.; KIB seq: YLSH202002; KIB: ML546. - Sichuan Province • 1 ( (worker); Hongyuan; $32.3282^{\circ}$ N, $102.4543^{\circ}$ E; 3 Aug. 2002; P. Williams leg.; BOLD seq: 1555G12; PW: ML302 • 2 specs; Hongyuan; $32.3282^{\circ} \mathrm{N}, 102.4543^{\circ} \mathrm{E}$; Y. Dong leg.; YD seq: DYX24.1, DYY28; YD: ML438, ML439 • 1 \& (worker); Que'er shan; $31.94192^{\circ} \mathrm{N}$, 98.93244 E; 4 Aug. 2018; Z. Ren leg.; KIB seq: QESH304003; KIB: ML547. - Yunnan Province • 1 ( (worker); Baima Snow Mountain; 28.37252 ${ }^{\circ}$ N, 98.99982 ${ }^{\circ}$ E; 16 Jul. 2018; Z. Ren leg.; KIB seq: BMXSH102017; KIB: ML543 • 9 우; Baima Snow Mountain; $28.3373^{\circ} \mathrm{N}, 99.0771^{\circ} \mathrm{E}$; $14-18$ Aug. 2019; M. Orr leg.; IOZ seq: 14F5 to 14F8, 14F10, OR15, OR17, OR22, OR26; IOZ: ML590 to ML598.

\section{Global distribution}

(Qinghai-Tibetan-Plateau species) East Asia: CHINA: Xizang, Qinghai, Gansu, Sichuan, Yunnan. Himalaya: INDIA: Kashmir, Uttaranchal, Sikkim; NEPAL. (IAR, INHS, IOZ, NHMUK, NMS, OLML, PW, SC, USNM, YD, ZIN, ZMHB.) The species is usually not common.

\section{Behaviour}

Food-plant generalists (Williams 1991; Williams et al. 2009; An et al. 2014). The male mate-searching behaviour is expected to resemble the patrolling of B. keriensis. 
Bombus alagesianus Reinig, 1930 stat. rev.

Figs 16, 148-150, 199, 212

Bombus alagesianus Reinig, 1930: 89.

Lapidariobombus alagesianus subsp. kubanensis Skorikov, 1931: 226.

Bombus keriensis (part) - Reinig 1935: 341. — Williams 1998: 134 (non Morawitz, 1887: 199).

The name Lapidariobombus alagesianus was first published by Skorikov (1923: 152) for a species, but without any description of characters and without a statement to indicate clearly the intention to publish the name of a new species (on page 145 there is also a list that includes "Lapidariobombus alagesianus [and] subsp. cubanensis", but with no further reference or description). It is possible that a manuscript appendix describing this and other new species was written but not included in the publication for some reason. The distribution of L. alagesianus was given on page 152 as Caucasus and Central Asia. Because this name was published with a locality but without a character description it is unavailable (ICZN 1999: Article 12.1, 12.3).

The name B. alagesianus was later published by Reinig (1930) for a species from the Transcaucasus alone, together with a short character description. It is quite possible that Reinig was referring to Skorikov's 1923 name alagesianus, but from Reinig's 1930 text there is no indication directly and explicitly connecting the name alagesianus with Skorikov. Furthermore, Reinig (1935: 340) refers to a taxon "f.g. alagesianus Reinig, 1930" of B. keriensis, so he appears to have believed at that time that he had been the first to describe the taxon alagesianus. Reinig's 1930 description acknowledges that $B$. alagesianus matches $B$. separandus in a couple of colour-pattern characters (that differ from $B$. sichelii) and also distinguishes $B$. alagesianus from $B$. separandus by describing $B$. alagesianus as occurring in "Transkaukasien" rather than in the "Boro-Choro-Gebirge" (Xinjiang, Central Asia) as for $B$. separandus (higher on the same page). This minimal character description for B. alagesianus Reinig is considered sufficient (and combined with the locality is actually fully diagnostic), so the name B. alagesianus is available (ICZN 1999: Article 12.1). Therefore L. alagesianus Skorikov (1923) is an unavailable name and B. alagesianus Reinig (1930) is the oldest name to meet the requirements for availability and is the valid name for the species.

The taxon alagesianus was treated as a part of B. keriensis s. lat. by Reinig (1935) and by Williams (1998). It was listed as a species separate from B. keriensis by Rasmont (1983) and by Lecocq et al. (2015), although neither of these publications gives reasons to justify the change in interpretation.

Our PTP analysis (Fig. 10) of coalescents in the COI gene within the keriensis-complex supports six species including $B$. alagesianus, corroborated by differences in morphology. These species are also supported by the absence of a positive divergence-with-distance relationship among them (Fig. 20) (see Divergence and geographical distance, page 12).

From morphology, B. alagesianus has a more extensively pale colour pattern in the hair on the side of the thorax than most keriensis s. str. for the females (larger workers and queens). This revision is the first time that white-banded individuals have been recognised to be part of B. alagesianus. Bombus alagesianus has often been confused with other species of the subgenus Melanobombus, especially because it is uncommon and occurs with both yellow-banded and white-banded colour patterns.

\section{Diagnosis}

Females

Queens medium-sized body length 17-20 mm, workers 9-14 $\mathrm{mm}$. Can be distinguished in West Asia by their combination of hair on the face black, hair on T2 yellow or nearly white without any black hairs 
posteriorly, and the hindleg corbicular fringes with some extensively orange hairs (cf. B. lapidarius, B. sichelii, B. eriophorus, B. incertus).

\section{Males}

Body length 9-11 mm. Can be distinguished in West Asia by hair on T2 pale without any black hairs posteriorly. Genitalia (Fig. 199) with the gonostylus as long as broad, its inner basal projection reduced to a short stub (cf. rufipes-group, festivus-group, rufofasciatus-group); volsella with the inner distal corner broadly produced but without a narrow hook (cf. rufipes-group, festivus-group, rufofasciatusgroup); eye unenlarged relative to female eye.

\section{Material examined}

The specimen detailed below from the RMNH collection is possibly a syntype of $B$. alagesianus Reinig (1930), which would then be eligible for designation as a lectotype. According to A. de Boer (in litt.), Reinig worked for O. Vogt within the Kaiser Wilhelm Institute for Brain Research in Berlin until the early 1930s, where Reinig might have seen this specimen in Vogt's collection. Vogt's collection was donated to the Zoological Museum of Amsterdam in 1960 and this collection was recently transferred to the RMNH. However, there is no definite evidence either from the specimen labels or from Reinig's (1930) text to show that this specimen was one of those examined and described by Reinig (1930) and most of Reinig's pre-war types are known to have been destroyed (P. Rasmont in litt.). In view of the uncertainty in the status of this specimen as a syntype and the uncertainty in the identity of the species, it is considered preferable to designate this specimen as a neotype.

\section{Neotype designation}

We believe that there is an exceptional need to designate a neotype (ICZN 1999: Article 75.3.1) to clarify the taxonomic status of B. alagesianus Reinig (1930) because there are no definite extant types and because this species is difficult to distinguish from and easily confused with other species of the subgenus Melanobombus.

Reinig (1930) differentiated B. alagesianus from other similar species (ICZN 1999: Article 75.3.2) of the subgenus Melanobombus in West Asia by the hair on T2 pale without any black hairs, in having hair of similar length to B. separandus, and in having the red hair of the metasoma similar in hue to B. separandus.

The neotype can be recognised uniquely (ICZN 1999: Article 75.3.3) as a yellow-banded queen bumblebee in the RMNH collection that agrees with the original description and carries six labels: (1) handwritten faded white label "Alagez, Trans-/kaukasien/9.VII.09" (= Mt Alagyaz = Mt Aragats); (2) handwritten faded white label "B. lapidarius subsp./alagesianus Skorikov/A. Skorikov det"; (3) handwritten pink label "Cotype"; (4) red label printed in black "Bombus / separandus? alagesianus / Reinig, 1930 / ZMAN type HYME.0003.1"; (5) white label printed in black "ZMA.INS.956675 [barcode]"; (6) red label printed in black "NEOTYPE $q$ / Bombus / alagesianus/Reinig, 1930/det. PH Williams 2018".

We believe that the name-bearing types of B. alagesianus Reinig (1930) may have all been destroyed (ICZN 1999: Article 75.3.4). Reinig's description of B. alagesianus does not specify a holotype or a number of syntypes. According to P. Rasmont (in litt.), any of Reinig's pre-war types not in the collection of the Instituut voor Taxonomische Zoölogie in Amsterdam (now transferred to the RMNH) must be considered to have been destroyed by soldiers during the winter of 1945 . The RMNH collection contains a single queen labelled B. lapidarius subsp. alagesianus Skorikov by Skorikov, although there is no evidence from the specimen labels or from Reinig's (1930) text that this specimen was examined and described by Reinig (1930). 
The neotype matches the original description (ICZN 1999: Article 75.3.5) of B. alagesianus Reinig's (1930) in having no black hair on metasomal T2, in having hair of similar length to $B$. separandus, and in having the red hair of the metasoma similar in hue to $B$. separandus. In addition, if Reinig were referring to Skorikov's (1923) Lapidariobombus alagesianus, then this specimen was labelled as B. lapidarius subsp. alagesianus by Skorikov and carries the label "Cotype".

The neotype comes from the original type locality (ICZN 1999: Article 75.3.6) because B. alagesianus is eponymous for the locality given on its label: "Alagez, Trans- / kaukasien" and given by Reinig (1930) in the original description as "Transkaukasien".

The neotype is the property of and housed in the collection of (ICZN 1999: Article 75.3.7) the National Museum of Natural History, Leiden, Netherlands (RMNH: ZMA.INS.956675).

\section{Material sequenced (15 specimens)}

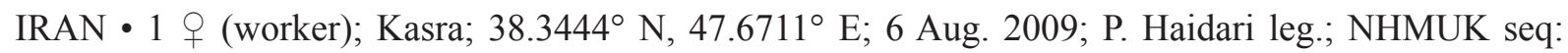
IRANPW019; PW: ML24 • 1 q (worker); same collection data as for preceding; A. Monfared leg.; NHMUK seq: IRANPW017; PW: ML25・1 9 (worker); same collection data as for preceding; NHMUK seq: IRANPW018; PW: ML26.

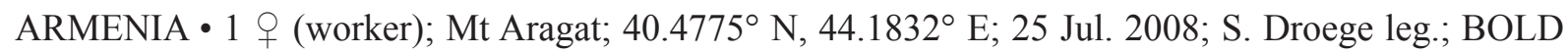
seq: $6876 \mathrm{H} 11$; PW: ML27 1 \& (worker); same collection data as for preceding; BOLD seq: $6876 \mathrm{H} 10$; PW: ML28 • 1 (queen); same collection data as for preceding; NHMUK seq: PW22; PW: ML190 • 1 q (worker); same collection data as for preceding; BOLD seq: 1555H06; PW: ML308 1 q (worker); same collection data as for preceding; BOLD seq: 1555H07; PW: ML309• 1 q (worker); same collection data as for preceding; BOLD seq: 1555H08; PW: ML310.

TURKEY • 1 q (worker); Artvin, Çam Geçidi; $41.2143^{\circ}$ N, $42.3000^{\circ}$ E; 12 Aug. 2011; BOLD seq: 6879A02; PW: ML200 • 1 \& (worker); Artvin, Çam Geçidi; $41.2052^{\circ} \mathrm{N}, 42.5012^{\circ}$ E; 12 Aug. 2011; BOLD seq: 6879A03; PW: ML201.

GEORGIA 1 1 (queen); Lagodekhi; $41.9^{\circ} \mathrm{N}, 46.3333^{\circ}$ E; 22 Jun. 2015; G. Japoshvili leg.; BOLD seq: 1555A03; GJ: ML176 • 1 \& (queen); Javakheti, Bugdasheni lake; $41.1989^{\circ} \mathrm{N}, 43.6902^{\circ} \mathrm{E} ; 14$ May 2013; R. DeJonghe leg.; BOLD seq: 6880C01; RDJ: ML498 • 1 \& (worker); same collection data as for preceding; R. DeJonghe leg.; reared from BOLD seq: 6880C01; BOLD seq: 6880C02; RDJ: ML499 • 1 ; ; same collection data as for preceding; R. DeJonghe leg.; reared from BOLD seq: 6880C01; BOLD seq: 6880C03; RDJ: ML500.

\section{Global distribution}

(West Asian mountain species) West Asia: TURKEY, GEORGIA, ARMENIA, IRAN. (GJ, NHMUK, RDJ, RMNH, PW.) This species is not common (Fig. 212).

\section{Behaviour}

Expected to be food-plant generalists but no records. The male mate-searching behaviour is expected to resemble the patrolling behaviour of $B$. keriensis s. str.

Bombus tibeticus Williams sp. nov. urn:1sid:zoobank.org:act:200860A6-7E80-47AA-A5B0-BE9C95AE977A

Figs 16, 151-152, 200, 207, 212

Bombus keriensis (part) - Reinig 1935: 341. — Williams 1998: 134 (non Morawitz, 1887: 199). 
This species was treated (implicitly from specimens from its unique known range) as a part of $B$. keriensis s. lat. (the keriensis-complex) by Reinig (1935) and by Williams (1998).

Our PTP analysis (Fig. 10) of coalescents in the COI gene within the keriensis-complex supports six species including B. tibeticus sp. nov., corroborated by differences in morphology and by the absence of a positive divergence-with-distance relationship among them (Fig. 20) (see Divergence and geographical distance, page 12). This is the first time that $B$. tibeticus sp. nov. is recognised as a separate species.

Bombus tibeticus sp. nov. co-occurs locally with the closely similar B. qilianensis sp. nov. in the eastern Kunlun mountains of the QTP (PW pers. obs.).

\section{Diagnosis}

Within the keriensis-group: female with the clypeus in its central area with scattered large, medium, and small punctures; hair in the black band between the wing bases without yellow hairs intermixed; hair on the side of the thorax with the yellow extending half of the distance from the wing base to the mid leg base; T1-2 yellow, T3 entirely black, T4-6 orange-red.

Male with hair on the head black except for yellow in a tuft on the face ventral to the antennal base and on the vertex; thoracic dorsum with the black band between the wing bases without yellow hairs intermixed; side of the thorax yellow anterior to the wing base; legs with the long hairs intermixed black and pale; T1-2 yellow, T3 entirely black, T4-7 orange-red; eye unenlarged relative to female eye.

\section{Etymology}

Named after the region where it occurs, Tibet, but with an unusual latinisation in order to avoid homonymy with the more usual forms Bombus tibetanus (Morawitz, 1887), Bombus tibethinus Gribodo, 1892, and Bombus tibetensis S.-F. Wang, 1982, as well as with the form Bombus xizangensis S.-F. Wang, 1979. Of these, only B. (Psithyrus) tibetanus (Morawitz) is currently the accepted valid name of a bumblebee species, but in the distantly-related subgenus of parasitic bumblebees, Psithyrus Lepeletier, 1832. The form tibeticus has been used previously for another bee species, Colletes tibeticus Kuhlmann (2002). Although there are other similar published names, this name is a particularly good description of this species, which is widespread on the southern and eastern QTP. The species epithet is to be treated as a simple adjective.

\section{Material examined}

\section{Holotype designation}

CHINA - o (worker) pinned (the right front leg is missing); four labels: (1) white printed in black "CHINA: Qinghai/Kunlun Shan/Alpine edge 3973m 19/35.80313N, 94.34232E/13.viii.2013 PH Williams"; (2) green printed in black "Melanobombus /ML\# 228. det. PHW"; (3) green printed in black "BOLD\# BBWP/PHW/CCDB-1555-B09"; (4) red printed in black "HOLOTYPE $q$ (w)/ Bombus / tibeticus/Williams, 2019/det. PH Williams 2019”; IOZ (Fig. 207) .

\section{Material sequenced (16 specimens)}

CHINA - Qinghai Province • $1 \partial^{\top}$; Xiangpishan; $36.7589^{\circ}$ N, $99.6041^{\circ}$ E; 30 Aug. 2010; P. Williams leg.; BOLD seq: 1555B05; PW: ML224 - 1 त; same collection data as for preceding; BOLD seq: 1555B06; PW: ML225 • 1 के; same collection data as for preceding; BOLD seq: 1555E04; PW: ML252 • 1 \% ; same collection data as for preceding; BOLD seq: 6880A12; PW: ML484 1 \& (worker); Nanshan pass; $36.7628^{\circ} \mathrm{N}, 99.6071^{\circ} \mathrm{E}$; 17 Aug. 2013; P. Williams leg.; BOLD seq: 1555B10; PW: ML229 • 1 q (worker); Burhan Budai Shan; 36.0556 ${ }^{\circ}$ N, 98.1170 E; 16 Aug. 2013; P. Williams leg.; BOLD seq: 1555B11; PW: ML230 • 1 (worker); Kunlun Shan; $35.6920^{\circ}$ N, $94.052^{\circ}$ E; 13 Aug. 2013; P. Williams 
leg.; BOLD seq: 6877F09; PW: ML402 • 1 今ో; Nuogancha; 37.0982 N, $98.8706^{\circ}$ E; 31 Aug. 2010; P. Williams leg.; BOLD seq: 6877F11; PW: ML404 • 1 त; same collection data as for preceding; BOLD seq: 6880B03; PW: ML487 • 1 q (worker); same collection data as for preceding; BOLD seq: 6876H07; PW: ML23. - Xizang Province • 1 q (queen); Sugela [Shogu La]; 29.9154 N, 90.1421 ${ }^{\circ}$ E; 24 Jun. 1999; K. Huber leg.; BOLD seq: 1552A09; OLML: ML202 • 1 o (worker); Milashan; 29.85301 N, 92.33378 E; 27 Jul. 2018; Z. Ren leg.; KIB seq: MLSM101022; KIB: ML564 • 1 q (worker); Yelashan; 30.16394 N, 97.2860 E; 22 Jul. 2018; Z. Ren leg.; KIB seq: YLSH101083; KIB: ML565 • 1 o (worker); Xizang; Z. Ren leg.; KIB seq: CLiBE035; KIB: ML575 1 q (worker); Yelashan; $30.1639^{\circ} \mathrm{N}$, 97.2860 E; 22 Jul. 2018; Z. Ren leg.; KIB: YLSH101083; KIB: ML576 • 1 ㅇ (worker); Anjiulashan; 29.9229 N, 96.67203ํ E; 23 Jul. 2018; Z. Ren leg.; KIB seq: AJLSM101016; KIB: ML577.

\section{Description}

Female (holotype worker)

Habitus illustrated in Fig. 207. Body size medium (body length of queens 17-20 mm, workers 10-14 mm), hair (pubescence) moderately short and even, wings clear. Mandible with the distal notch anterior to the posterior tooth (incisura) very shallow and hardly marked. Oculo-malar area ('cheek' sensu Williams et al. 2014; not the gena) of medium length, $1.05 \times$ as long as (length measured between the ventral edge of the compound eye and the edge of the malar area at the articulation of the mandible midway between the mandibular condyles) the breadth of the mandible at its base (breadth between and including the mandibular condyles). Clypeus weakly swollen, its raised area nearly flat, the central area with scattered large, medium and small punctures, few punctures medially and ventrally adjacent to the labrum. The area between the inner edge of the compound eye and the outer edge of the lateral ocellus occupied in just more than its outer half by a broad band of mostly large punctures, many spaced by more than their own widths, the smaller punctures between the larger punctures more abundant laterally near the eye margin. Mid basitarsus with the distal posterior corner broadly rounded; hind tibia outer surface with a corbicula, the surface sculpturing weakly reticulate so that the surface appears slightly matt; hind basitarsus in the distal three quarters densely covered with short branched decumbent and overlapping hairs with golden reflections; T6 posteriorly truncate and very shallowly divided medially. Colour pattern of the hair of the body predominantly black. Head entirely black except for orange hairs anteriorly on the labrum. Thoracic dorsum with broad anterior and posterior yellow bands of nearly equal breadth, about equal in breadth to the black band between the wing bases and without black hairs intermixed, the black band between the wing bases without yellow hairs intermixed; side of the thorax (mesepisternum) predominantly black, in its dorsal half yellow. T1-2 yellow without any black hairs; T3 entirely black; T4-6 entirely orange-red.

\section{Male (ML225)}

Body size medium (body length $12-15 \mathrm{~mm}$ ), hair (pubescence) moderately short and even, wings clear. Colour pattern of the hair of the body predominantly black. Head black except for yellow in a tuft on the face ventral to the antennal base, on the vertex, and posteriorly around the base of the proboscis. Thoracic dorsum with broad anterior and posterior yellow bands of nearly equal breadth and without black hairs intermixed, the black band between the wing bases without yellow hairs intermixed; side of the thorax (mesepisternum) yellow anterior to the wing base; legs with the long hairs intermixed black and pale. T1-2 yellow without any black hairs; T3 entirely black; T4-7 entirely orange-red. Genitalia (Fig. 200) with the gonostylus shorter than broad, its inner basal projection reduced to a short stub; volsella with the inner distal corner broadly produced but without a narrow hook.

\section{Global distribution}

(Qinghai-Tibetan-Plateau species) East Asia: CHINA: Xizang, Qinghai. (IAR, IOZ, NHMUK, OLML, PW.) This species is often common relative to other bumblebees (Fig. 212). 


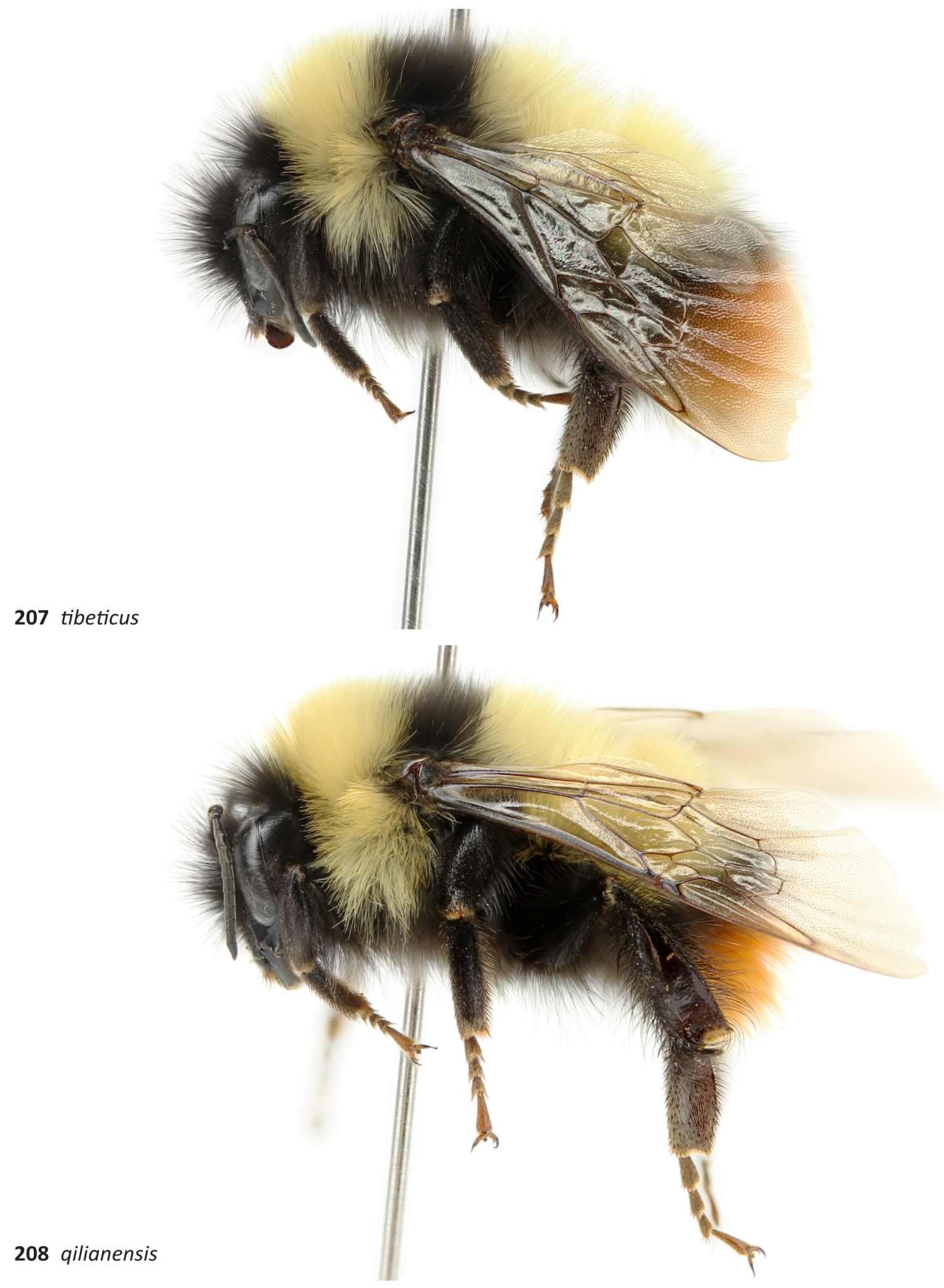

Figs 207-208. Images of holotype workers of two new cryptic species from around the eastern QinghaiTibetan plateau. 207. Bombus tibeticus sp. nov. from near the Kunlun pass ( 3970 m a.s.l.) in the Kunlun mountains (ML228). 208. B. qilianensis sp. nov. from Qushiang (3370 m a.s.1.) in the Burhan Budai mountains (ML306). Viewed from the left lateral aspect. 
This is one of the highest recorded bumblebees in the world, at an elevation of ca $5640 \mathrm{~m}$ a.s.l. (Williams 2018: along with B. tanguticus). Specimens in the NHMUK collection labelled "Sikkim" are actually from Xizang ("Kampa Dzong” = Gampa Dzong, 28.271 N, 88.513² E).

\section{Behaviour}

Food-plant generalists (PW, ZR unpublished records). The male mate-searching behaviour is expected to resemble the patrolling behaviour of $B$. keriensis $\mathrm{s}$. str.

Bombus incertoides Vogt, 1911 stat. rev.

Figs 16, 153-156, 201, 212

Bombus separandus [subsp.] incertoïdes Vogt, 1911: 58 by indication of Vogt (1909): 61, not infrasubspecific after Skorikov 1923: 153 (ICZN 1999: Art. 45.6.4.1).

Bombus keriensis (part) - Reinig 1935: 341. — Williams 1991: 96 (non Morawitz, 1887: 199).

Bombus incertoides was first treated as a separate species by Skorikov (1923), without explanation, but has since been treated as a part of $B$. keriensis s. lat. (the keriensis-complex) by Reinig (1935) and by Williams (1998).

Our PTP analysis (Fig. 10) of coalescents in the COI gene within the keriensis-complex supports six species including $B$. incertoides, corroborated by differences in morphology. These species are also supported by the absence of a positive divergence-with-distance relationship among them (Fig. 20) (see Divergence and geographical distance, page 12).

From morphology, B. incertoides has enlarged male eyes and has a bright white banding pattern in the hair with (most strongly for the keriensis-complex) the thoracic dorsum with the posterior white band particularly narrowed by black hair anteriorly on the scutellum.

Bombus incertoides can co-occur locally with the closely similar (but locally yellow-banded) B. separandus, at least in the Altai mountains of Mongolia.

\section{Diagnosis}

\section{Females}

Queens medium-sized body length 18-21 mm, workers 10-12 mm. Can be distinguished within Mongolia by the hair of the face black, the pale hair anteriorly on the thoracic dorsum pure white, the hair on the side of the thorax in its lower half black, the anterior half of the scutellum black, and by the hair of T4-5 red (cf. B. sichelii, B. separandus).

\section{Males}

Body length $12-15 \mathrm{~mm}$. Can be distinguished within Mongolia by the hair of the face black. Genitalia (Fig. 201) heavily sclerotised and dark, with the gonostylus longer than broad, its inner basal projection reduced to a stub (cf. rufipes-group, festivus-group, rufofasciatus-group); volsella with the inner distal corner broadly produced but without a narrow hook (cf. rufipes-group, festivus-group, rufofasciatusgroup); antenna short and eye slightly enlarged relative to female eye.

\section{Material examined}

Holotype

MONGOLIA - $q$ (queen), holotype of Bombus separandus incertoides Vogt, 1911 by monotypy (Williams, 1991); "N.[orth]" (Leder's material from northern Mongolia is likely to have come from 
a site between Kyakhta and Ulaanbaatar: Williams et al. 2012a); “[18]92”; H. Leder leg.; RMNH (examined PW).

Material sequenced ( 9 specimens)

MONGOLIA • 1 q (queen); Tov, Tuul river; $47.8118^{\circ} \mathrm{N}, 106.6139^{\circ} \mathrm{E} ; 24$ Jun. 2005; D. Altanchimeg leg.; NHMUK seq: NHMSR2; DA: ML148 • 1 ○ं; Khovd, Monkhkhairkhan; $46.9676^{\circ} \mathrm{N}, 91.6496^{\circ} \mathrm{E}$; 9 Aug. 2014; D. Altanchimeg leg.; NHMUK seq: NHMSR6; DA: ML173 • 1 क (queen); Arkhangai, Bat-olziit; $46.7974^{\circ} \mathrm{N}, 101.7551^{\circ} \mathrm{E}$; 18 Jun. 2014; R. DeJonghe leg.; BOLD seq: 6880B06; RDJ:

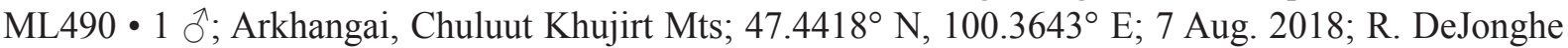
leg.; BOLD seq: 6880B07; RDJ: ML491 - 1 ; ; same collection data as for preceding; BOLD seq:

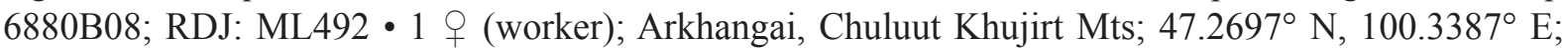
8 Aug. 2018; R. DeJonghe leg.; BOLD seq: 6880B09; RDJ: ML493 • 1 §’; Arkhangai, Chuluut Khujirt Mts; 47.2700 N, $100.3387^{\circ}$ E; 9 Aug. 2018; R. DeJonghe leg.; BOLD seq: 6880B10; RDJ: ML494 • $1 \mathrm{O}^{\top}$; same collection data as for preceding; BOLD seq: 6880B11; RDJ: ML495 1 q (queen); Khovsgol, Khatgal; $50.4815^{\circ} \mathrm{N}, 100.2170^{\circ} \mathrm{E} ; 7$ Jun. 2015; R. DeJonghe leg.; BOLD seq: 6880C04; RDJ: ML501.

\section{Global distribution}

(Mongolian mountain species) North Asia: MONGOLIA. (DA, NHMUK, RMNH, PW, RDJ.) This species is widespread but not common (Fig. 212).

\section{Behaviour}

Expected to be food-plant generalists but no records. The male mate-searching behaviour is unknown.

Bombus qilianensis Williams sp. nov. urn:1sid:zoobank.org:act:66DA4BFF-1258-4B95-9FEC-EE6EE291E317

Figs 16, 157-162, 202, 208, 212

Bombus keriensis (part) - Reinig 1935: 341. — Williams 1998: 134 (non Morawitz, 1887: 199).

This species was treated (implicitly from specimens from its unique known range) as a part of $B$. keriensis s. lat. (the keriensis-complex) by Reinig (1935), Williams (1991, 1998), and by Williams et al. (2009).

Our PTP analysis (Fig. 10) of coalescents in the COI gene within the keriensis-complex supports six species including $B$. qilianensis sp. nov., corroborated by differences in morphology and by the absence of a positive divergence-with-distance relationship among them (Fig. 20) (see Divergence and geographical distance, page 12). This is the first time that $B$. qilianensis sp. nov. is recognised as a separate species.

Bombus qilianensis sp. nov. co-occurs locally with the closely similar B. tibeticus $\mathrm{sp}$. nov. in the eastern Kunlun mountains of the QTP (PW, pers. obs.).

\section{Diagnosis}

Within the keriensis-group: female with the clypeus in its central area smooth and shining, with only scattered small punctures; hair in the black band between the wing bases with a few yellow hairs intermixed especially anteriorly near the midline of the scutum and laterally above the tegula; hair on the side of the thorax with the yellow extending usually two thirds of the distance from the wing base to the mid leg base usually with scattered yellow hairs in the lower third; T1-2 yellow, T3 predominantly black, T4-6 orange. 
Male with hair on the head yellow except for black on the mandibles and narrowly around the eyes; thoracic dorsum with the narrow black band between the wing bases with many yellow hairs intermixed; side of the thorax predominantly yellow; legs with the long hairs pale, mostly yellow; T1-2 yellow, T3 anteriorly black and posteriorly yellow, T4-7 orange; eye unenlarged relative to female eye.

\section{Etymology}

Named after a major feature of the region where it occurs, the Qilian Shan (mountains) of the northeastern QTP. The species epithet is to be treated as a noun in the genitive case.

\section{Material examined}

\section{Holotype designation}

CHINA - + (worker) pinned (the right front leg is missing); four labels: (1) white printed in black "CHINA: Qinghai/Burhan Budai Shan/Qushiang 3373m 22/36.0577N, 98.11624E/16.viii.2013 PH Williams"; (2) green printed in black "Melanobombus/ML\# 306. det. PHW"; (3) green printed in black "BOLD\# BBWP/PHW/CCDB-1555-H04"; (4) red printed in black "HOLOTYPE (w)/ Bombus /qilianensis/Williams, 2019/det. PH Williams 2019"; IOZ (Fig. 208).

\section{Material sequenced (13 specimens)}

CHINA - Gansu Province • 1 q (worker); Gaxiu; $34.3986^{\circ}$ N, $102.2971^{\circ}$ E; 28 Aug. 2009; P. Williams leg.; BOLD seq: 1555B04; PW: ML223 • 1 q (queen); Gansu; $37.8703^{\circ} \mathrm{N}, 101.6696^{\circ} \mathrm{E} ; 13 \mathrm{Jul}$. 2015; BOLD seq: 1555D04; PW: ML247 • 1 क (worker); Labrang; $35.1937^{\circ} \mathrm{N}, 102.5069^{\circ} \mathrm{E}$; P. Williams leg.; BOLD seq: 1555H04; PW: ML306. - Qinghai Province • 1 क (worker); Xingfucun; $35.8877^{\circ} \mathrm{N}$, 97.8785 E; 10 Aug. 2013; P. Williams leg.; BOLD seq: 1555H05; PW: ML307• 1 q (worker); Qushiang; 36.0556 ${ }^{\circ}$ N, 98.1170 E; 16 Aug. 2013; P. Williams leg.; BOLD seq: 1555B07; PW: ML226 • 1 ㅇ (worker); Kunlun Shan; 35.6920 ${ }^{\circ}$ N, 94.052 ${ }^{\circ}$ E; 13 Aug. 2013; P. Williams leg.; BOLD seq: 1555B08;

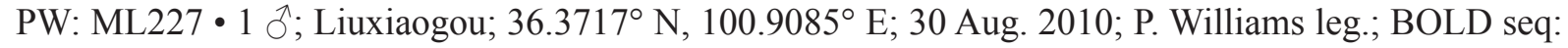
1555E05; PW: ML253 • 1 ố; Nuogancha; $37.0982^{\circ}$ N, 98.8706 E E; 31 Aug. 2010; P. Williams leg.; BOLD seq: 6877F10; PW: ML403 - 1 ; ; same collection data as for preceding; BOLD seq: 6880B02; PW: ML486 • 1 đ; Qushiang; 35.8304 N, 98.0816 E; 16 Aug. 2013; P. Williams leg.; BOLD seq: 6880B01; PW: ML485 • 1 đ̊; Ping'an; $36.3594^{\circ}$ N, $102.1173^{\circ}$ E; 19 Aug. 2013; P. Williams leg.; BOLD seq: 6880B04; PW: ML488. - Sichuan Pronvince • 3 specs; Hongyuan; $32.3282^{\circ} \mathrm{N}, 102.4543^{\circ} \mathrm{E}$; Y. Dong leg.; YD seq: DYX16.2, DYX5.4, DYX8.1; YD: ML440 to ML442.

\section{Description}

Female (holotype worker)

Habitus illustrated in Fig. 208. Body size medium (body length of queens 18-22 mm, workers 11-14 mm), hair (pubescence) moderately short and even, wings clear. Mandible with the distal notch anterior to the posterior tooth (incisura) very shallow and hardly marked. Oculo-malar area ('cheek' sensu Williams et al. 2014; not the gena) of medium length, $1.11 \times$ as long as (length measured between the ventral edge of the compound eye and the edge of the malar area at the articulation of the mandible midway between the mandibular condyles) the breadth of the mandible at its base (breadth between and including the mandibular condyles). Clypeus weakly swollen, its raised area nearly flat, the central area with only scattered small punctures, few punctures medially and ventrally adjacent to the labrum. The area between the inner edge of the compound eye and the outer edge of the lateral ocellus occupied in just more than its outer half by a broad band of mostly large punctures, many spaced by more than their own widths, the smaller punctures between the larger punctures more abundant laterally near the eye margin. Mid basitarsus with the distal posterior corner broadly rounded; hind tibia outer surface with a corbicula, the surface sculpturing weakly reticulate so that the surface appears slightly matt; hind basitarsus in the distal three quarters densely covered with short branched decumbent and overlapping hairs with golden 
reflections; T6 posteriorly truncate and very shallowly divided medially. Colour pattern of the hair of the body predominantly black. Head entirely black except for orange hairs anteriorly on the labrum and some yellow hairs posteriorly on the vertex. Thoracic dorsum with broad anterior and posterior yellow bands of nearly equal breadth, broader than the black band between the wing bases, and without black hairs intermixed, the black band between the wing bases with a few yellow hairs intermixed especially anteriorly near the midline of the scutum and laterally above the tegula; side of the thorax (mesepisternum) in its ventral third black with scattered yellow hairs, in its dorsal two thirds yellow. T1-2 yellow without any black hairs; T3 black with very few isolated yellow hairs laterally; T4-6 entirely orange-red.

Male (ML253)

Body size medium (body length $12-14 \mathrm{~mm}$ ), hair (pubescence) moderately short and even, wings clear. Colour pattern of the hair of the body predominantly black. Head yellow except for black on the mandibles and narrowly around the eyes. Thoracic dorsum with broad anterior and posterior yellow bands of nearly equal breadth and without black hairs intermixed, the narrow black band between the wing bases with many yellow hairs intermixed; side of the thorax (mesepisternum) predominantly yellow; legs with the long hairs pale, mostly yellow. T1-2 yellow without any black hairs; T3 anteriorly black, posteriorly yellow; T4-7 entirely orange. Genitalia (Fig. 202) with the gonostylus shorter than broad, its inner basal projection reduced to a short stub; volsella with the inner distal corner broadly produced but without a narrow hook.

\section{Global distribution}

(Northeast Qinghai-Tibetan-Plateau species) East Asia: CHINA: Qinghai, Gansu, Sichuan. (IAR, IOZ, NHMUK, PW, YD.) The species is usually not common (Fig. 212).

\section{Behaviour}

Food-plant generalists (Williams et al. 2009; An et al. 2014). The male mate-searching behaviour is expected to resemble the patrolling of $B$. keriensis s. str.

Bombus keriensis Morawitz, 1887

Figs 16, 163-172, 203, 209, 212

Bombus keriensis Morawitz, 1887: 199.

Lapidariobombus separandus subsp. meridialis Skorikov, 1914a: 127.

Bombus trilineatus S.-F. Wang, 1982: 441.

Pyrobombus keriensis subsp. karakorumensis Tkalců, 1989: 57.

The taxonomic limits of the species B. keriensis have been a particular long-standing or persistent taxonomic problem.

Vogt (1909: 41, 62) treated B. keriensis s. str. as a species separate from his taxon separandus. Vogt (1911: 58) characterised and distinguished $B$. keriensis $\mathrm{s}$. str. from $B$. separandus by having from a few yellow hairs on the face to having the hair of the face entirely pale.

Skorikov (1931) listed B. keriensis s. str. and B. separandus as two species but discussed them together under a joint heading, "Lapidariobombus keriensis (F. Mor.) 1886 und Lapidariobombus separandus (Vogt) 1909". While he mentioned the difference in face colour, he described B. keriensis s. str. and B. separandus as hardly distinguishable (his Lapidariobombus anargumentosus Skorikov, 1931, on the same page is recognised here from the pattern of punctures on the ocello-ocular area of the head of the syntypes in the ZIN as conspecific with B. (Pyrobombus) biroi Vogt, 1911, syn. nov., and is not a species of the subgenus Melanobombus). 
Reinig (1935) included the taxon keriensis s. str. as a part of a broad species B. keriensis s. lat. that also included the taxa separandus + incertoides + alagesianus. This interpretation was followed by Williams $(1991,1998)$.

Wang (1982) described her taxon trilineatus without reference to B. keriensis, comparing it instead to the more distantly related "B. occulatus var. haemorrhous Richards" [sic] (= B. simillimus) for colour pattern and details of morphology.

Our PTP analysis (Fig. 10) of coalescents in the COI gene within the keriensis-complex supports six species including $B$. keriensis s. str., corroborated by differences in morphology. These species are also supported by the absence of a positive divergence-with-distance relationship among them (Fig. 20) (see Divergence and geographical distance, page 12).

From morphology, after examining $>1000$ specimens of the keriensis-group from across Asia and after comparing the distribution of states of several characters as part of this study (PW), Vogt's character state of at least a few yellow hairs on the face does appear to remain one of the most consistently diagnostic character states for $B$. keriensis $\mathrm{s}$. str. (by comparison with COI sequences), at least for queens in most parts of the species' range (but see the comments on $B$. separandus regarding the Mongolian taxon kozlovi). Several aspects of the colour pattern vary strongly within the species: (1) B. keriensis s. str. includes both yellow-banded and white-banded colour patterns; (2) the extent of pale hair on the face varies; (3) the extent of the black hair between the wing bases varies; (4) the extent of the pale hair on the side and ventral area (leg bases) of the thorax varies; (5) the extent of the pale hair posteriorly on T3 varies (the 'ciliation' described by authors); (6) the contrast of the pale posterior fringes on T4-5 varies. Many of these characters might appear to show a continuum of variation that is also continuous with the variation within B. separandus (Williams 1991), which might then appear consistent with the two taxa being parts of the same species (Reinig 1935). However, evidence from COI barcodes shows that the two gene-coalescent groups differ most consistently in the presence of pale hairs on the face of B. keriensis s. str., supporting Vogt's characterisation of the species, and providing integrated morphological support for its status as a separate species. The overlapping colour variation of B. separandus but only in Mongolia (where B. keriensis $\mathrm{s}$. str. does not occur) does not negate the fact that $B$. keriensis s. str. is recognisable by morphological characters throughout its geographical range.

There are some yellow-banded queens from the Pir Panjal and Great Himalaya ranges (part of B. keriensis s. str. according our COI coalescent results, Fig. 10) that have very few pale hairs on the face, although these specimens still have a few yellow hairs on the leg bases and have a few black hairs in the pale bands of the thoracic dorsum. Many of the available specimens have failed repeated attempts at sequencing, so the species' diagnosis remains tentative. Particularly influential in the interpretation of these individuals is one sequenced yellow-banded queen with very few pale hairs on the face, on the underside of the thorax, and on T3, from the Pir Panjal range (PW: ML405, Figs 170, 209) that groups with B. keriensis s. str. (Fig. 10) rather than with B. separandus (diagnostic base positions 267T, 286T, 301T, 306C, 339C, 363T, 423C, 498T, 529A, 540C, 541T, 556T). This is one of the specimens that most closely resembles some yellow-banded B. separandus also from Kashmir (Figs 177, 210) (the difference in the breadth of the black band between the wings is not diagnostic for these species).

\section{Diagnosis}

\section{Females}

Queens medium-sized body length 17-21 mm, workers 9-14 mm. Can be distinguished in Central Asia by the combination of hair of the face usually with some pale hairs, the leg bases usually with some pale hairs, T2 posteriorly entirely pale without black hairs, with T3 laterally usually with some pale hairs (cf. B. sichelii, B. separandus). 


\section{Males}

Body length 11-15 mm. Can be distinguished reliably at present only by their COI sequence, although in the western Himalaya they may be distinguished by yellow hair between the wing bases and on T3 posterio-laterally. Genitalia (Fig. 203) with the gonostylus shorter than broad, its inner basal projection reduced to a short stub (cf. rufipes-group, festivus-group, rufofasciatus-group); volsella with the inner distal corner broadly produced but without a narrow hook (cf. rufipes-group, festivus-group, rufofasciatus-group); eye unenlarged relative to female eye.

\section{Material examined}

\section{Lectotype designation}

CHINA • + (queen), lectotype of Bombus keriensis Morawitz, 1887; Keria Mts; $9000 \mathrm{ft} \mathrm{a.s.1.;} \mathrm{Przewalsky}$ leg.; ZIN.

Morawitz's original description of several females of B. keriensis gives the type locality as "Keria" [= Keriya/Yutian, east of Hotan/Hetian/Khotan], presumably not in the low-lying town but higher in the neighbouring Karakax Shan (of the western Kunlun Shan [shan = mountains], southern Xinjiang, and probably near the village of Polu/Pulu/Pulucun [cun = village], $36.1850^{\circ} \mathrm{N}, 81.4827^{\circ} \mathrm{E}$. This village was visited by N. Prshewalsky while searching for a pass southwards into Ladakh during his fourth (and final) Central Asian expedition in the summer of 1885 (Rayfield 1976). If the "9000" on the syntype specimen label (below) were an elevation in feet then this is substantially higher than the elevation of Keriya (ca 4500 feet), so a collecting site near Pulu is highly likely. These mountains are very arid, so likely sites with a reliable water supply and food plants every summer sufficient to support bumblebee colonies are restricted (Williams et al. 2015a).

The ZIN collection contains a queen that agrees with the original description and carries seven labels: (1) gold disc; (2)handwritten white label "Keria/ Gebirg. / 9000" reverse "2/10/[illegible]"; (3) handwritten white label "Przewalsky"; (4) handwritten white label "Bombus/keriensis +. .F. Morawitz."; (5) printed white label in Cyrillic "[K. F. Morawitz]"; (6) red label partly printed in black "Lectotypus Bombus/keriensis F. Morawitz/design. Podbolotsk." (unpublished); (7) red label printed in black "LECTOTYPE $+/ B o m b u s / k e r i e n s i s / M o r a w i t z, 1887 /$ det. PH Williams 2017". This specimen, which is complete, is recognised as one of Morawitz's syntypes and is designated here as the lectotype in order to reduce uncertainty in the identity and application of the name.

Material sequenced (7 specimens)

INDIA - Kashmir • 1 q (queen); Gulmarg, Mt Apharwat; $34.0548^{\circ}$ N, $74.3856^{\circ}$ E; Aug. 1985; P. Williams leg.; BOLD seq: 6877G02; PW: ML405 • 1 q (queen); Gulmarg, Mt Apharwat; $34.0212^{\circ} \mathrm{N}$, 74.3208 ${ }^{\circ}$ E; 21 Jul. 2009; BOLD seq: 1552D08; RR: ML204 • 1 q (queen); Zanskar, Padum; $33.4746^{\circ} \mathrm{N}$, 76.8871 ${ }^{\circ} \mathrm{E}$; $30 \mathrm{Jul}$. 2007; BOLD seq: 1552D11; RR: ML203 1 1 (worker); same collection data as for preceding; 31 Jul. 2011; R. Raina leg.; BOLD seq: 1555C12; RR: ML243 • 1 + (worker); Razdaan pass; $34.5390^{\circ} \mathrm{N}, 74.6377^{\circ} \mathrm{E}$; 23 Jul. 2012; R. Raina leg.; BOLD seq: 1555D01; RR: ML244 • 1 q (worker);

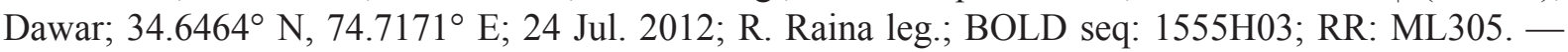
Himachal Pradesh • 1 \& (worker); Saichu Nulla; $31.6^{\circ}$ N, 78.267 E; 8 Sep. 1986; A. Hutchings leg.; BOLD seq: 6877B05; PW: ML159.

\section{Global distribution}

(West Qinghai-Tibetan-Plateau species) Himalaya: AFGHANISTAN, PAKISTAN, INDIA: Kashmir, Himachal Pradesh. - East Asia: CHINA: Xizang. (IOZ, NHMUK, PW, RR, ZIN, ZSM.) The species is usually not common (Fig. 212). 


\section{Behaviour}

Food-plant generalists (Williams 1991). Male mate-searching patrolling behaviour (Williams 1991).

Bombus separandus Vogt, 1909 stat. rev.

Figs 16, 173-180, 204, 210, 212

Bombus lapidarius Form [subsp.] separandus Vogt, 1909: 61.

Bombus lapidarius Form [subsp.] kohli Vogt, 1909: 61 (non Cockerell, 1906: 75 = B. morio (Swederus)). syn. nov.

Bombus kozlovi Skorikov, 1910a: 413, replacement name for kohli Vogt, 1909: 61. syn. nov.

Bombus lapidarius var. [subsp.] tenellus Friese, 1913: 86. syn. nov.

Bombus tenellus var. [not subsp.] alpivagus Richards, 1930: 639, but not infrasubspecific after Reinig 1935: 333 (ICZN 1999: Art. 45.6.4.1). syn. nov.

Lapidariobombus alagesianus subsp. pamirus Skorikov, 1931: 226 (non Skorikov, 1931:232= B. oberti Morawitz, not B. difficillimus Skorikov as given by Skorikov). syn. nov.

Lapidariobombus alagesianus subsp. mongolicus Skorikov, 1931: 226 (non Friese, 1916: 110 ?= B. diversus Smith). syn. nov.

Bombus keriensis f.g. [subsp.] bucharicus Reinig, 1935: 340. syn. nov.

Bombus keriensis f.g. [subsp.] richardsi Reinig, 1935: 341 (non Frison, 1930: 6= B. rufipes Lepeletier). Bombus tenellus subsp. tibetensis S.-F. Wang, 1982: 439, replacement name for richardsi Reinig, 1935: 341. syn. nov.

Bombus kozlowi - Bischoff, 1936: 9, unjustified emendation.

Bombus keriensis (part) - Reinig 1935: 341. — Williams 1998: 134 (non Morawitz, 1887: 199).

Vogt (1909: 46) stated that his "Formen" are subpopulations, which can be considered equivalent to subspecies. Reinig (1935: 333) stated explicitly that his "f.g." (forma geographica) are equivalent to subspecies. Vogt (1909: 61) described his taxon separandus as having the hair of the face and top of the head ("Gesicht und Stirn") black and the underside of the thorax dark haired. He described his taxon kohli (later renamed kozlovi) as having the face with a few yellow hairs. However, Vogt (1911: 58) then characterised the taxon separandus as differing from the taxon keriensis only in having an absence of pale hairs on the face (he did not include the taxon kohli/kozlovi as part of the taxon separandus but did include the taxon incertoides as part of separandus). The taxon separandus was treated as a part of the species B. keriensis s. lat. by Reinig (1935) and by Williams (1998).

Our PTP analysis (Fig. 10) of coalescents in the COI gene within the keriensis-complex supports six species including $B$. separandus, corroborated by differences in morphology. These species are also supported by the absence of a positive divergence-with-distance relationship among them (Fig. 20) (see Divergence and geographical distance, page 12).

From morphology, after examining $>1000$ specimens of the keriensis-group from across Asia and after comparing the distribution of states of several characters as part of this study (PW), Vogt's character state of exclusively black hair on the face does appear to remain one of the most consistently diagnostic characters (in comparison with COI sequences) for B. separandus in the QTP and Central Asia, at least for queens (but see the comments on $B$. keriensis). Nonetheless, there are some individuals of the yellow-banded taxon kozlovi from Mongolia (part of B. separandus s. lat. according our COI-coalescent results, Fig. 10) that do have a few yellow hairs on the face, so that exclusively black hair on the face is not diagnostic in all parts of the range. Several aspects of the colour pattern vary strongly within the species: (1) B. separandus includes both yellow-banded and white-banded colour patterns; (2) the extent of the black hair between the wing bases varies; (3) the extent of the pale hair on the side and ventral area 


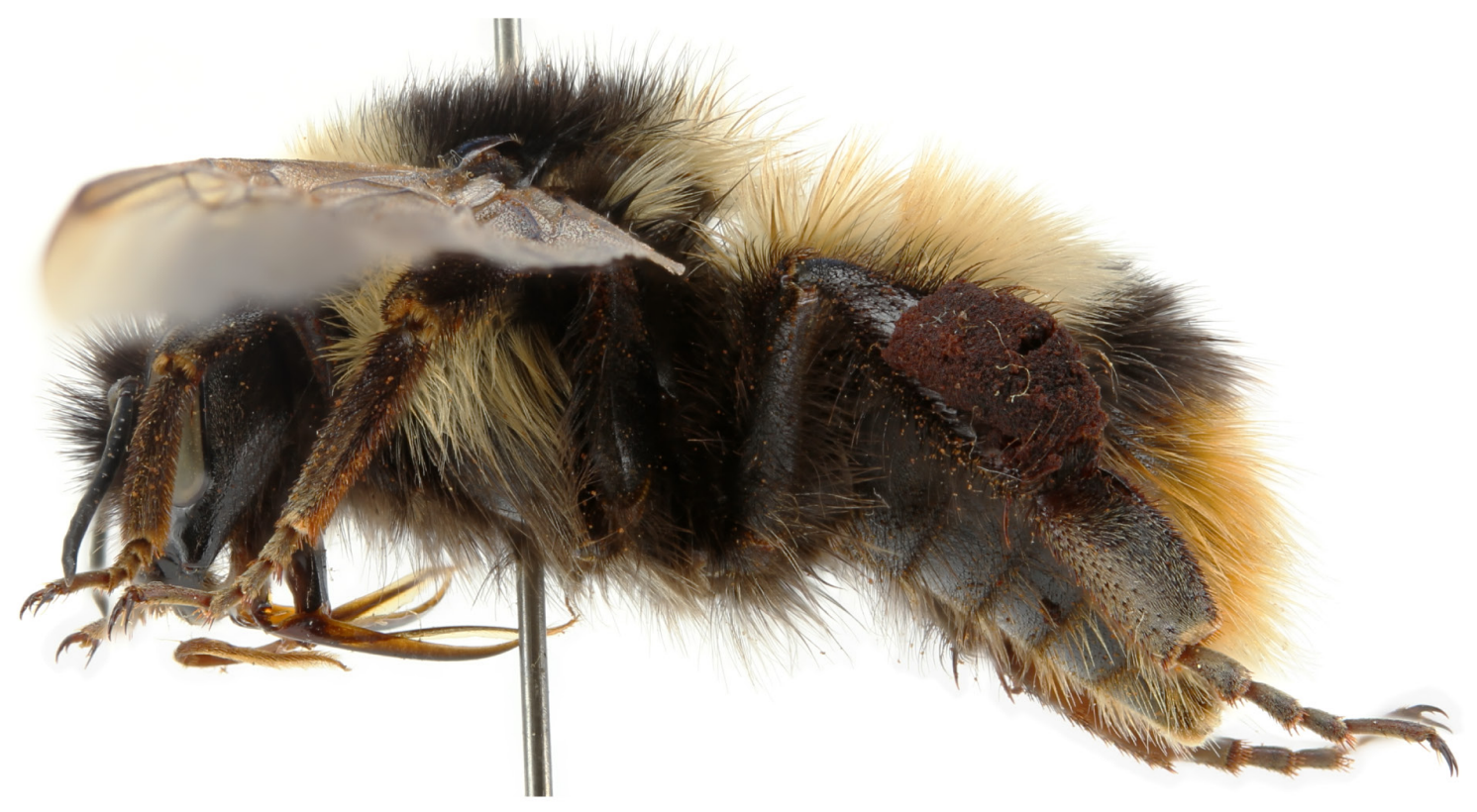

209 keriensis

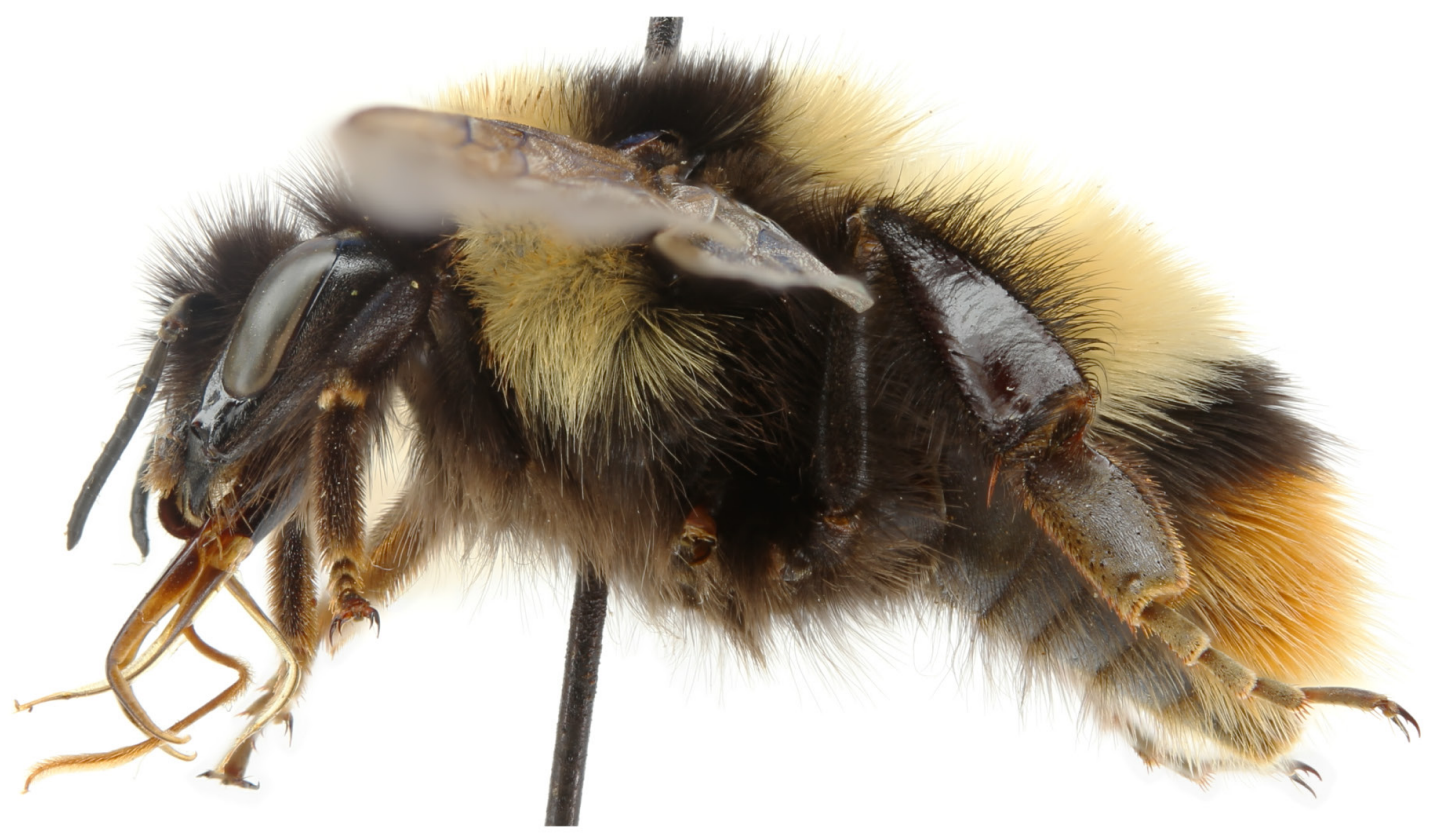

210 separandus

Figs 209-210. Images of queens of two cryptic species from around the western Qinghai-Tibetan plateau. 209. Bombus keriensis Morawitz, 1887 from Mt Apharwat (4000 m a.s.l.) in the Pir Panjal mountains (ML405). 210. B. separandus Vogt, 1909 stat. rev. from Nimaling plain (4800 $\mathrm{m}$ a.s.l.) in the Zanskar mountains (ML311). Viewed from the left lateral aspect. 
(leg bases) of the thorax varies; (4) the extent of the pale hair posteriorly on T3 varies (the 'ciliation' of authors); (5) the contrast of the pale posterior fringes on T4-5 varies. Many of these characters might appear to show a continuum of variation that is also continuous with the variation within $B$. keriensis s. str. (Williams 1991), which might then appear consistent with the two taxa being parts of the same species (Reinig 1935). However, as noted above, evidence from COI barcodes shows that the two genecoalescent groups differ most consistently in the absence of pale hairs on the face for B. separandus, supporting Vogt's characterisation of the species, providing integrated morphological support for its status as a separate species. The overlapping colour variation of $B$. separandus but only in Mongolia (where $B$. keriensis s. str. does not occur) does not negate the fact that $B$. separandus is recognisable by morphological characters throughout its geographical range.

There are some queens of the yellow-banded taxon richardsi (later renamed tibetensis) from the northwestern QTP that have no pale hairs on the face, very few or no yellow hairs on the leg bases, and very few black hairs within the yellow bands of the thoracic dorsum. Many of the available specimens have failed to sequence, so the species' diagnosis remains tentative. Particularly influential in the interpretation of these individuals is one yellow-banded queen with a reduced extent of pale hair on the side of the thorax from the Zanskar range (PW: ML311, Figs 177, 210), which has produced a short sequence (382 bp) that nonetheless shows bases diagnostic for $B$. separandus compared to B. keriensis (base positions 267A, 286C, 301C, 306T, 339T, 363C, 423 T, 498C, 529G, 540T, 541C, 556C). This is one of the specimens that most closely resemble some yellow-banded individuals of the candidate species keriensis $\mathrm{s}$. str. also from Kashmir (Figs 170, 209) (the difference in the breadth of the black band between the wings is not diagnostic for these species).

Bombus separandus co-occurs locally with the similar B. incertoides in the Altai and Khangai mountains of Mongolia. Bombus separandus also co-occurs locally with the similar B. keriensis s. str. in the Zanskar mountains of Kashmir. Examination of specimens in the IOZ collection labelled B. incertus (S.-F. Wang 1985; S.-F. Wang \& Yao 1996; Niu et al. 2018) shows that these are mostly misidentified B. separandus (with a few $B$. keriensis) from Xinjiang.

\section{Diagnosis}

\section{Females}

Queens medium-sized body length 17-20 mm, workers 9-14 mm. Can be distinguished in Central Asia and Mongolia by the combination of hair of the face usually without pale hairs (except in Mongolia where $B$. keriensis does not occur), the leg bases usually without pale hairs, T2 posteriorly entirely pale without black hairs, and T3 laterally usually without pale hairs (cf. B. sichelii, B. keriensis).

\section{Males}

Body length $10-15 \mathrm{~mm}$. Can be distinguished reliably at present only by their COI sequence, although in the western Himalaya they may be distinguished by entirely black hair between the wing bases and hair of T3 entirely black. Genitalia (Fig. 204) with the gonostylus shorter than broad, its inner basal projection reduced to a short stub (cf. rufipes-group, festivus-group, rufofasciatus-group); volsella with the inner distal corner broadly produced but without a narrow hook (cf. rufipes-group, festivus-group, rufofasciatus-group); eye unenlarged relative to female eye.

\section{Material examined}

\section{Lectotype}

CHINA - O (queen), lectotype of Bombus lapidarius Form separandus Vogt, 1909 by designation of Williams (1991: 97); Xinjiang, Borohoro Shan, Tisilikau; RMNH (examined PW). 
Material sequenced ( 25 specimens)

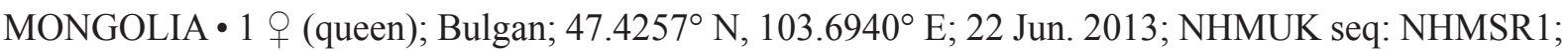
PW: ML147 • 1 क (worker); Bayanolgiy, Bulgan; 46.9333 N, $91.1667^{\circ}$ E; 26 Jul. 1992; Culverwell leg.; BOLD seq: 6877B11; PW: ML151 1 \& (queen); Khenteyn Nuruu, Terelj; $47.9905^{\circ} \mathrm{N}, 107.3719^{\circ} \mathrm{E} ; 16$ Jun. 2015; R. DeJonghe leg.; BOLD seq: 6877A08; RJ: ML333 • 1 q (queen); Khenteyn Nuruu, Terelj; $47.9956^{\circ} \mathrm{N}, 107.3303^{\circ} \mathrm{E} ; 17$ Jun. 2015; R. DeJonghe leg.; BOLD seq: 6880B05; RDJ: ML489 • 1 ㅇ (worker); Arkhangai, Chuluut Khujirt Mts; 47.5750 N, 101.1092 ${ }^{\circ}$ E; 11 Aug. 2018; R. DeJonghe leg.; BOLD seq: 6880B12; RDJ: ML497.

RUSSIA • 1 q (worker); Altai, Ulagansky, $6 \mathrm{~km} \mathrm{NE}$ of Aktash; $50.3158^{\circ} \mathrm{N}, 87.7036^{\circ} \mathrm{E} ; 6$ 6-7 Jul. 2017; S. Knyazev leg.; BOLD seq: 1555F07; PW: ML264 1 q (worker); Altai, Ulagansky, 8 km NE of

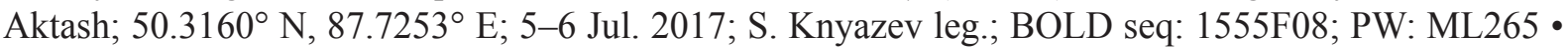
1 q (worker); Tuva, $27 \mathrm{~km} \mathrm{~S}$ of Erzin; 50.0049 ${ }^{\circ}$ N, 95.1719 ${ }^{\circ} \mathrm{E}$; 11-12 Jul. 2014; A. Lelej leg.; BOLD seq: 1555F09; PW: ML266 1 1 (worker); Tuva, $25 \mathrm{~km}$ of Erzin; $50.1611^{\circ} \mathrm{N}, 95.4778^{\circ} \mathrm{E}$; $14-15$ Jul. 2014; A. Lelej leg.; BOLD seq: 1555F10; PW: ML267 • 1 ㅇ (worker); Tuva, 31 km of Erzin; $50.0366^{\circ} \mathrm{N}, 95.4348^{\circ} \mathrm{E} ; 18$ Jul. 2014; A. Lelej leg.; BOLD seq: 1555F12; PW: ML269・ 1 q (worker); same collection data as for preceding; 16 Jul. 2014; A. Lelej leg.; BOLD seq: 1555G01; PW: ML270.

KYRGYZSTAN • 1 q (queen); Jalalabad, Jylamysh; $42.6522^{\circ}$ N, 74.4812 ${ }^{\circ}$ E; 27 May 2009; L. Best leg.; BOLD seq: 1552H03; PW: ML156・1 (queen); Oshakaya, Kyzyl-Suu; $39.4761^{\circ} \mathrm{N}, 71.8933^{\circ} \mathrm{E}$; 18 Jul. 1998; H. Rausch leg.; BOLD seq: 1552A08; OLML: ML191 • 1 q (worker); Chong Aksuu Valley nr Karakol lake; 42.8386 N, 77.3889 E; 26 Jun. 2016; R. DeJonghe leg.; BOLD seq: 1555F04; RJ: ML261 • 1 ㅇ (worker); same collection data as for preceding; BOLD seq: 1555F05; RJ: ML262 • 1 ( (worker); same collection data as for preceding; BOLD seq: 1555F06; RJ: ML263 - 1 q (queen); Kungey Ala-Too, Chong Aksuu nr Karakol lake; $42.8397^{\circ}$ N, $77.37^{\circ}$ E; 25 Jun. 2016; R. DeJonghe leg.; BOLD seq: 6877A09; RJ: ML336 • 1 q (queen); Terskey Ala-Too, Turgon-Aksuu river; $42.4183^{\circ} \mathrm{N}$, 78.9467 E; 2 Jul. 2016; R. DeJonghe leg.; BOLD seq: 6877A11; RJ: ML341 • 1 q (queen); same collection data as for preceding; BOLD seq: 6877A10; RJ: ML342 1 q (queen); Terskey Ala-Too, Turgon-Aksuu river; $42.4019^{\circ} \mathrm{N}, 79.0486^{\circ} \mathrm{E} ; 3 \mathrm{Jul}$. 2016; R. DeJonghe leg.; BOLD seq: 6877A12; RJ:

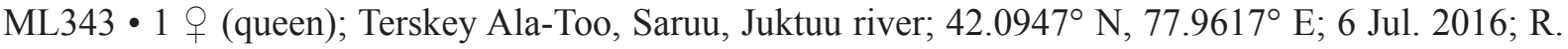
DeJonghe leg.; BOLD seq: 6877B01; RJ: ML348 • 1 q (queen); Santash; $42.7389^{\circ} \mathrm{N}, 79^{\circ} \mathrm{E}$; 29 Jun. 2016; R. DeJonghe leg.; BOLD seq: 6877B02; RJ: ML356 • 1 q (queen); same collection data as for preceding; BOLD seq: 6877B03; RJ: ML357.

PAKISTAN $\bullet 1$ ㅇ (worker); Chitral, Khyber-Pakhtunkhwa, Tirich Valley; $36.3150^{\circ} \mathrm{N}, 71.9824^{\circ} \mathrm{E} ; 8$ Aug. 1984; W. Budenburg leg.; BOLD seq: 6877C02; PW: ML383.

INDIA • 1 q (queen); Kashmir, Zanskar, Nimaling Plain; 33.7927 N, 77.5881 E; 15 Jul. 1980; P. Williams leg.; BOLD seq: 1555H10; PW: ML311.

\section{Global distribution}

(Central Asian and Mongolian mountain species extending into the northwestern corner of the QTP) North Asia: MONGOLIA, RUSSIA: Tuva, Altai Mountains. - Central Asia: KAZAKHSTAN, KYRGYZSTAN, TAJIKISTAN. - East Asia: CHINA: Xinjiang. - Himalaya: PAKISTAN, INDIA: Kashmir. (IAR, IOZ, NHMUK, OLML, PW, RDJ, RMNH, ZIN, ZMHB.). This species is widespread and can be common (Fig. 212).

\section{Behaviour}

Very few food-plant records but expected to be generalists (Caragana versicolor in Williams 1991). The male mate-searching behaviour is expected to resemble the patrolling of B. keriensis s. str. 


\section{Discussion}

This is the first revisionary study of the subgenus Melanobombus that includes information for all known species from genes, morphology, colour pattern, geographical distribution, and provides the first complete keys. While the species we recognise from this study can only be a best current working hypothesis, we have sufficient confidence from the agreement found among the molecular and morphological character sets used here to describe two new species.

\section{Gene coalescents as evidence of species}

Gene-coalescent-based searches to discover species depend on species being monophyletic (Kapli et al. 2017). There is no evidence to challenge this assumption of monophyly for any species of the subgenus Melanobombus in our results (Figs 9-10). Otherwise, any failure to discover all of the genuine species when using gene-coalescent analyses is likely to be caused by three principal factors (Pons et al. 2006):

(1) All samples could belong to the same single species. This is extremely unlikely in this case because our sampling regime is designed to include all of the 17 previously recognised morphological species of the subgenus Melanobombus. Sampling evenly among constituent taxa has been suggested to be unlikely to bias the results (Fujisawa \& Barraclough 2013) and has been suggested as a desirable property of data for PTP analysis (Zhang et al. 2013), although ultimately different species are expected to show different levels of genetic variation requiring different levels ('depths') of sampling (Phillips et al. 2018; see below).

(2) Cases with very recent speciation (Fujisawa \& Barraclough 2013) or with a combination of fast speciation rate and large population sizes could lack gene coalescents or could show incomplete lineage sorting (Pons et al. 2006; Dellicour \& Flot 2015). Our molecular estimates of dates of divergence among the species recognised here within the subgenus Melanobombus are all at least $1 \mathrm{Ma}$ (Fig. 22). This date represents at least one million generations.

(3) Estimating the branching rate within species depends critically on having adequate sample sizes per species. Adequate sample sizes are difficult to estimate (Monaghan et al. 2009; Talavera et al. 2013; Phillips et al. 2018), because at the beginning of a study not only is the number of species unknown but also the degree and distribution of genetic variation within each species is unknown. In any case, larger initial samples (prior to UHF) would always be desirable when available (Fujisawa \& Barraclough 2013). Nonetheless, Talavera et al. (2013) suggest that representation of intermediate haplotypes between the most divergent pair within a species from more thorough sampling can be "basically irrelevant, in the sense that their removal does not produce a split in that species". Instead they emphasised the need to include the most divergent haplotypes, which our sampling across species' entire geographic ranges is more likely to attain (we have no species represented by 'singleton' samples, although there are only two sequences for the inaccessible $B$. rufipes and most species have the rarest haplotypes represented by only a single sequence where ideally this number would be higher: Table 6). However, when subpopulations show little or no gene flow, or when partially isolated subpopulations exist but samples are lacking from the linking subpopulations, then these subpopulations might be falsely recognised as candidate species (Lohse 2009; Fujisawa \& Barraclough 2013; Mason et al. 2020). Limited gene flow is a possibility for bumblebees, because they appear to be poor at long-distance dispersal (Williams et al. 2017b), so that subpopulations isolated by broad barriers of unsuitable habitat (especially in lowlands between mountain subpopulations) are more likely to be genetically isolated. These effects could shift the balance between the measured branching rates within and between subpopulations, changing how many species are recognised, showing again the importance of the context or balance of sampling among species. This is central to the question of how best to discriminate between widespread polytypic species and complexes of local monotypic species and further work is needed. 
Table 6. Sampling of the species as currently recognized from integrative assessment.

\begin{tabular}{|c|c|c|c|c|}
\hline Current species & $\begin{array}{l}\text { Geographical range size as } \\
\text { no. of equal-area grid cells }{ }^{1}\end{array}$ & $\begin{array}{l}\text { No. of COI } \\
\text { sequences }\end{array}$ & $\begin{array}{c}\text { No. of } \\
\text { unique COI } \\
\text { haplotypes }\end{array}$ & $\begin{array}{l}\text { No. of matching } \\
\text { sequences per } \\
\text { rarest haplotype }\end{array}$ \\
\hline sichelii & 46 & 44 & 17 & 1 \\
\hline lapidarius & 28 & 29 & 6 & 1 \\
\hline eximius & 14 & 6 & 1 & 6 \\
\hline separandus & 10 & 25 & 13 & 1 \\
\hline ladakhensis & 10 & 22 & 7 & 1 \\
\hline pyrosoma & 8 & 7 & 3 & 1 \\
\hline friseanus & 7 & 68 & 37 & 1 \\
\hline prshewalskyi & 7 & 57 & 20 & 1 \\
\hline festivus & 7 & 14 & 3 & 1 \\
\hline incertus & 7 & 8 & 4 & 1 \\
\hline rufipes & 7 & 2 & 1 & 2 \\
\hline tibeticus & 6 & 15 & 5 & 1 \\
\hline qilianensis & 4 & 14 & 4 & 1 \\
\hline keriensis & 4 & 6 & 6 & 1 \\
\hline tanguticus & 4 & 3 & 1 & 1 \\
\hline incertoides & 3 & 9 & 5 & 1 \\
\hline rufofasciatus & 3 & 5 & 3 & 1 \\
\hline eurythorax & 3 & 4 & 4 & 1 \\
\hline semenovianus & 2 & 5 & 2 & 1 \\
\hline richardsiellus & 2 & 3 & 3 & 1 \\
\hline alagesianus & 1 & 13 & 5 & 2 \\
\hline miniatus & 1 & 3 & 2 & 1 \\
\hline simillimus & 1 & 5 & 3 & 1 \\
\hline formosellus & 1 & 5 & 5 & 1 \\
\hline eriophorus & 1 & 3 & 2 & 1 \\
\hline
\end{tabular}

${ }^{1}$ Equal-area grid based on intervals of $10^{\circ}$ longitude, which are used to calculate graduated latitudinal intervals to provide equal-area cells (each cell with area approximately $611000 \mathrm{~km}^{2}$ ).

Applying mPTP to the UHF data (UHF is used only for reducing computation time by Kapli et al. 2017) yields similar candidate species to the original PTP procedure but in contrast does not distinguish the morphologically distinct B. eximius from B. rufipes, or B. pyrosoma from B. formosellus, which are distinguished in their COI coalescents by the original PTP. Nonetheless, not only does mPTP support the same inferences as the original PTP for the sichelii-complex and the keriensis-complex, but it also supports separate species status for the morphologically similar B. miniatus and B. eurythorax as well as for B. rufofasciatus and B. prshewalskyi. For data for the subgenus Melanobombus, mPTP is suggested to be too conservative, so that the original PTP yields coalescent candidate species that are closer to morphological candidate species. 


\section{Mitigating 'over-sampling'}

When we apply the UHF procedure to reduce the possible 'over-sampling' of less variable species, our PTP results nontheless increase the number of candidate species recognised in the subgenus Melanobombus from 17 (Williams 1998) to 26 species (Fig. 10: an increase of 53\%). Although using gene-coalescent methods often recognises a similar set of candidate species to a morphological approach, there are usually more candidate species recognised by the gene-coalescent methods (Pons et al. 2006; Talavera et al. 2013). It has been suggested that this may be due partly to incomplete or inconsistent morphological analyses. However in the case of our UHF-PTP results, most of the candidate species are also supported by subtle morphological differences and corroborated by the analyses of genetic divergence-by-distance and analyses of sympatry, so our candidate coalescent species do appear to be consistent with evidence from other sources.

\section{Asymmetries within integrative taxonomy}

Integrative taxonomy has been widely preferred since long before it was given this term, because it draws upon multiple sources of evidence from different sources of characters to corroborate support for species. However, there are caveats that need to be borne in mind.

First, there is a logical asymmetry within the cumulative approach to integrative species assessment: that while multiple character sets might corroborate the support for putatively separate species, in contrast the absence of evidence for separate species from one character set does not necessarily demonstrate the reverse - that candidate species are indeed conspecific (Schlick-Steiner et al. 2010). Crucially, any assessment that stops at this point is incomplete.

Second, when there is an apparent conflict between two different sources of evidence, the necessary next step is to compare the assumptions of the two approaches in order to consider possible alternative evolutionary explanations for the apparent conflict (Schlick-Steiner et al. 2010). The relative strengths of evidence contributed by analyses of apparently conflicting character sets must depend on whether the assumptions made about the evolution of the different character sets are really appropriate for the cases of the particular candidate species.

For example, including data from conservative (slowly evolving) characters is less likely to support the distinction between recently-diverged genuine species (e.g., from the slower-evolving nuclear PEPCK gene compared with COI: Williams et al. 2015b). Similarly, while mate-recognition characters may be expected to diverge rapidly under selection, this can happen only when individuals of the candidate species can meet, either currently or at some time in the past during or since speciation (Williams et al. 2019). In contrast, the gene-coalescent approach when applied to fast-evolving genes might be expected to provide reliable evidence of speciation for recent species even in cases in which individuals of the two species have not co-occurred.

In practice, the gene-coalescent approach could fail to support separate species even with fast genes for a variety of reasons (below), and especially through incomplete lineage sorting. Nonetheless, the gene-coalescent approach has a particular strength in having the potential to discover vicariant allopatric species (those that may never have occurred together), for example when separated on different continents (Williams et al. 2015b). In comparison, mate-recognition characters may provide information for sympatric taxa (e.g., suggested for European species of the subgenus Melanobombus, recognising B. lapidarius, B. sichelii: Lecocq et al. 2013), but may be less reliable for assessing candidate species when their populations are separated on different continents or by consistent geological or climatic barriers (Williams et al. 2019). 
In a related approach, divergent mate-recognition behaviours have been distinguished among some co-occurring west-Himalayan sister species of the rufofasciatus-group (B. rufofasciatus, B. simillimus, and $B$. eurythorax). The different reported mate-searching behaviours are associated with different morphologies among species in cases where the species specialise in habitats with different physical structures (Williams 1991). However, morphology is generally accepted to be slower to evolve compared with some genes, as exemplified in accepted cases of morphologically cryptic species (Rasmont 1984; Bertsch et al. 2005; Williams et al. 2012a), so that examples of morphological characters indicating divergent mate-searching behaviour between recent sister species should not be expected to be universal.

In the present study we concentrate on evidence from gene-coalescents and from morphology. The species we recognise should still be considered as candidate species for further integrative assessment. Ideally future studies to revise the species of the subgenus Melanobombus should endeavour to include a broader range of approaches applied to more character sources (Schlick-Steiner et al. 2010; Carstens et al. 2013). Genomic methods may help clarify some of the complications that may be encountered (e.g., incomplete lineage sorting), but at present a lack of available material and the cost of obtaining data remain prohibitive for representing many samples from each species.

\section{Consequences for Melanobombus taxonomy}

Reinig's (1935) revision of the subgenus Melanobombus from morphological studies across the entire Eurasian region recognised: (1) a "Bombus lapidarius L. Group", consisting of two species, B. lapidarius s. lat. and B. incertus; (2) a "Bombus sicheli [sic] Rad. Group", consisting of a single species, B. sichelii; and (3) a "B. keriensis F. Mor. Group", consisting of a single species, B. keriensis s. lat. (Table 1). Recently, Lecocq et al. (2015) studied only the European and Middle Eastern Melanobombus and suggested a third, new species ('decipiens-like') within Reinig's group (1), which they subsequently named B. bisiculus, and split Reinig's group (2) into two species, the Asian B. sichelii and the European B. alticola.

We can recognise the same three groups as Reinig (1935) on the tree in Fig. 10 (Table 1). In summary, our results agree in supporting few polytypic widespread species for groups (1) and (2) (i.e., 'lumping' taxa within the lapidarius-complex and within the sichelii-complex as the two widespread polytypic species B. lapidarius and B. sichelii respectively, Fig. 211), but contrast strongly in supporting many more, restricted-range species within group (3) (i.e., 'splitting' six of the taxa of the keriensiscomplex, Fig. 212). This contrasting third group differs from the other two relatively more widespread lowland groups in consisting entirely of high mountain species with narrow distributions. The physical heterogeneity of mountains has been suggested previously to promote speciation in bumblebees and this seems to be the case here as well (Williams et al. 2016, 2017a).

\section{Colour patterns of Melanobombus}

It is striking that while some species of the subgenus Melanobombus are quite variable in colour pattern within species (e.g., B. keriensis, B. separandus; Figs 163-180), nevertheless some of those same species do in part share remarkably similar colour patterns (e.g., the yellow-banded and redtailed B. tanguticus, B. lapidarius, B. sichelii, B. tibeticus, B. alagesianus, B. qilianensis, B. keriensis, and B. separandus; Figs 103-180). The yellow-banded or white-banded colour patterns shared locally among many bumblebee species may function in local mimicry (Williams 2007), but the genes in the populations may in some cases be the result of a shared ancestral polymorphism within species, similar to those ancestral polymorphisms inferred for some species of the subgenus Alpinobombus (Williams et al. 2015b). 


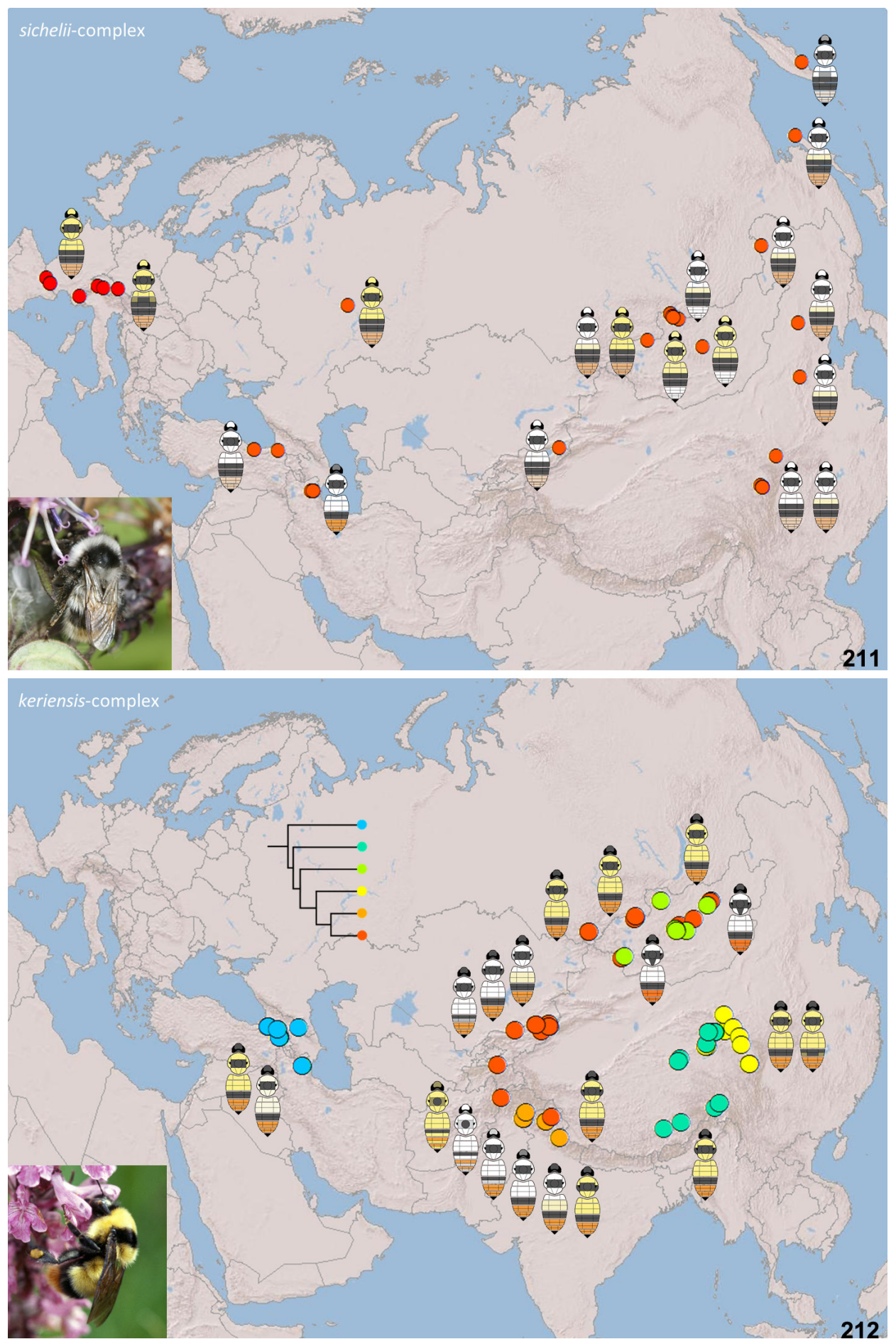

Figs 211-212. Maps of sequenced samples showing the most frequent colour patterns locally. 211. The sichelii-complex, consisting of the single polytypic species B. sichelii Radoszkowski, 1859 (inset: $B$. sichelii worker, China-Neimenggu, photo PW). 212. The keriensis-complex, consisting of B. alagesianus Reinig, 1930 stat. rev. (blue spots), B. tibeticus sp. nov. (dark green spots), B. incertoides Vogt, 1911 stat. rev. (light green spots), B. qilianensis sp. nov. (yellow spots), B. keriensis Morawitz, 1887 (orange spots), and B. separandus Vogt, 1909 stat. rev. (red spots) (inset: B.qilianensis sp. nov. queen, China-Sichuan, photo PW). Maps projected onto a sphere in ArcGIS using World_Shaded_Relief basemap ${ }^{\circ} 2014$ ESRI and showing boundaries between countries as recognised by the UN. 
The species of the rufofasciatus-group are unusual among bumblebees in that the majority are characterised by the females showing size-dependent colour-pattern dimorphism, especially clearly at all elevations in the Himalayan region, with the queens generally darker in colour than the workers (Figs 46-102) (Williams 1991). Any possible adaptive significance, perhaps in relation to the monsoon, remains to be explored.

\section{Phylogeny of Melanobombus}

The topology of the phylogeny estimate in Fig. 22 from four genes agrees closely with earlier results from five genes (Cameron et al. 2007; Williams 2018), although the earlier results were based on some of the same data. This tree is corroborated to some extent by morphology (Reinig 1935; Williams 1991, 2018).

The tree based on COI alone (Fig. 10; Williams 2018) does not support precisely the same relationship for $B$. tanguticus or for $B$. incertus as the four-gene tree in Fig. 10. This may be because COI is faster evolving, so that over-writing of nucleotide changes in COI may obscure evidence for older relationships.

\section{Biogeography of Melanobombus}

The role of colonising new habitats or climatic zones in the mountains around the edge of the QTP may have been important in promoting speciation within the subgenus Melanobombus. This is consistent with an apparent association between age and altitudinal zonation of species in these mountains (ca 16-3 Ma): the early-diverging rufipes-group is primarily subtropical, in low elevation warmer forests; the $B$. festivus and $B$. simillimus are associated especially with the lower warmer forests but also extend to the upper forests; B. miniatus, B. eurythorax, and B. friseanus are associated primarily with the upper forest (with B. pyrosoma in the temperate hills of North China); and B. prshewalskyi and B. rufofasciatus with subalpine and alpine grasslands above the trees (Williams 1991; Williams et al. 2009, 2010). The earlier-diverging Asian groups include the species with most of the largest and the darkest queens (B. rufipes, B. eximius, B. festivus, together with the closely related B. simillimus), which may be advantageous for queens founding colonies in cooler spring seasons in mountains if these are otherwise warm-adapted species. Bombus tanguticus matches these other early-diverging species in the same region in that it has very large queens, but it is more like many of the more recent groups in that it occurs at high elevation and has pale colour patterns.

Further west, the lapidarius-group, sichelii-group, and keriensis-group all have some extant species (ca 8-5 Ma) in the Armenian and Caucasus highlands (Fig. 24). This is consistent with them having dispersed westwards through the Hindu Kush, Alborz, and Armenian mountains, as has been supported for the subgenus Mendacibombus at a similar time (Williams et al. 2017b).

Ancestors of most of the most recently-diverging species of the subgenus Melanobombus are also estimated to have been distributed in the mountains surrounding the QTP (Fig. 24: ca 3-1 Ma). These divergences coincide with the major Pleistocene climate fluctuations (Zachos et al. 2001).

At the coarsest scale, the broad pattern of expansion in distribution for the subgenus Melanobombus represents dispersal from warmer to cooler habitats. Reinig (1935) characterised three largely vicariant groups of species as associated with different habitats: (1) the European lapidarius-group as steppe bees; (2) the North Asian sichelii-group as Taiga-forest bees; and (3) the Central and South Asian keriensisgroup as mountain bees. The especially broad current distributions of B. lapidarius and B. sichelii are extensive vicariously in the lowlands of the western and the eastern Palaearctic Region respectively. These are both likely to be relatively recent re-expansions of their range that probably followed climate warming at the end of the last glaciation (Reinig 1935; Lecocq et al., 2015). 
The keriensis-group is peculiar in appearing to show cycles of dispersal around the major mountain chains of Asia, leaving a succession of species in the eastern QTP (B. tibeticus), Mongolia (B. incertoides), eastern QTP (B. qilianensis), western QTP (B. keriensis), and Tian Shan and Mongolia (B. separandus) in its wake (ca 3-1 Ma; Fig. 212). More detailed study of the evolution and speciation of this group is needed, which would require phylogeographic methods with many more samples for each species.

The full extent of the distribution of B. rufipes in Indonesia remains unclear, possibly obscured in part by its being restricted to low densities in habitats that are not easy to access and which are rarely targeted for sampling bumblebees. Analysis of climatic niches is needed to assess whether the mountains of northern Sulawesi are of sufficiently high elevation for the current climate to provide habitat suitable for this species. This analysis needs to extend deeper into the past, because it is possible that Sulawesi could have been reached by $B$. rufipes when sea levels were lower, connecting China at least as far as Borneo by Sundaland land bridges if the climate were cooler during the ice ages (Bird et al. 2005), possibly connecting these areas with habitat suitable for the spread (short-distance dispersal) of B. rufipes. This raises the question of the probability of colonisation across the Makassar Strait, perhaps between the Maratus mountains of south-eastern Kalimantan and the mountains of Sulawesi. Any occurrence of B. rufipes on Sulawesi is likely to have required its presence on Borneo, at least transiently.

It is planned that the information from this revision will be used to help in the assessment of threats to the conservation of Melanobombus species.

\section{Acknowledgements}

We are especially grateful to A. Antropov (ZMUM), Y. Astafurova (ZIN), J. An and J. Huang (IAR), F. Bakker, W. van Bohemen and V. Kalkman (RMNH), S. Cameron and H. Hines (Illinois), J. Hogan (OUMNH), F. Koch and V. Richter (ZMHB), S. Lu and I. Sung (TFRI), D. Notton (NHMUK), J. Yao and C.-D. Zhu (IOZ), D. Zimmermann (NHMW) for their generous help in accessing collections. Thanks to R. Canty, A. Polaszek, S. Russell, D. Zhang and especially to D. Steinke and the CCDB for help with sequencing. Thanks to Prof. S.-C. Sun and Y. Dong for additional barcodes from Sichuan, and to L. Packer for additional barcodes from Thailand. Thanks to R. Turney (Sackler Lab, NHMUK) for help with imaging specimens. Thanks to V. Blagoderov for help with translation of Russian labels. Thanks to the Chinese SAFEA High-End Foreign Experts Recruitment Program (GDJ20140326002, GDJ20150325001, GDJ2016032602) for funding PW's research in China and to the Strategic Priority Research Program of the Chinese Academy of Sciences (XDB31020000) for funding ZR's research in China. Thanks to L. Bailey, F. Bakker, A. de Boer, P. Rasmont, and I. Sung for discussion and to an anonymous referee for constructive comments.

\section{Contributions of the authors}

Design of the study, PW; collecting specimens specifically for this project, $\mathrm{PW}, \mathrm{RD}, \mathrm{AB}, \mathrm{DA}, \mathrm{SJ}, \mathrm{GJ}$, SK, HL, MM, AM, MO, RR, ZR, CT, YZ; arranging sequencing of specimens, PW, MO, HL, ZR, CT, YZ; identification of specimens, PW; analysis of genetic data and morphological data, and writing of the manuscript and keys, PW; comment and discussion of the manuscript, AB, RD, DA, SJ, GJ, SK, HL, MM, AM, TN, MO, RR, ZR, CT, PW, YZ, CZ.

\section{References}

Alford D.V. 1975. Bumblebees. Davis-Poynter, London.

Almeida E.A.B., Packer L., Melo G.A.R., Danforth B.N., Cardinal S.C., Quinteiro F.B. \& Pie M.R. 2018. The diversification of neopasiphaeine bees during the Cenozoic (Hymenoptera: Colletidae). Zoologica Scripta 48 (2): 226-242. https://doi.org/10.1111/zsc.12333 
An J.-D., Huang J.-X., Shao Y.-Q., Zhang S.-W., Wang B., Liu X.-Y., Wu J. \& Williams P.H. 2014. The bumblebees of North China (Apidae, Bombus Latreille). Zootaxa 3830: 1-89.

https://doi.org/10.11646/zootaxa.3830.1.1

Ball F.J. 1920. Notes supplementaires sur les bourdons de la Belgique. Annales de la Société entomologique de Belgique 60: 31-43.

Barraclough T.G. \& Vogler A.P. 2000. Detecting the geographical pattern of speciation from specieslevel phylogenies. American Naturalist 155: 419-434. https://doi.org/10.1086/303332

Barrowclough G.F. 1982. Geographic variation, predictiveness, and subspecies. The Auk 99: 601-603.

Baum D. \& Smith S. 2012. Tree Thinking: an Introduction to Phylogenetic Biology. Roberts and Company, Greenwood Village, CO, USA.

Benoist R. 1928. Bombus lapidarius L. st. atlanticus R. Ben. Bulletin de la Société des sciences naturelles du Maroc 1927: 212.

Benton T. 2006. Bumblebees, the Natural History \& Identification of the Species Found in Britain. Collins, London.

Berezin M.V., Beiko V.B. \& Berezina N.V. 1996. Analysis of structural changes in the bumblebee (Bombus, Apidae) population of Moscow Oblast over the last forty years. Entomological Review 76: $115-123$

Bertsch A. 2010. A phylogenetic framework for the bumblebee species of the subgenus Bombus sensu stricto based on mitochondrial DNA markers, with a short description of the neglected taxon B. minshanicola Bischoff, 1936 n. status. Beiträge zur Entomologie 60: 471-487.

https://doi.org/10.21248/contrib.entomol.60.2.471-487

Bertsch A., Schweer H. \& Titze A. 2004. Discrimination of the bumblebee species Bombus lucorum, B. cryptarum and B. magnus by morphological characters and male labial gland secretions. Beiträge zur Entomologie 54: 365-386. https://doi.org/10.21248/contrib.entomol.54.2.365-386

Bertsch A., Schweer H., Titze A. \& Tanaka H. 2005. Male labial gland secretions and mitochondrial DNA markers support species status of Bombus cryptarum and B. magnus (Hymenoptera, Apidae). Insectes sociaux 52: 45-54. https://doi.org/10.1007/s00040-004-0761-1

Bertsch A., Habré de Angelis M. \& Przemeck G.K.H. 2010. Phylogenetic relationships of the bumblebees Bombus moderatus, B. albocinctus, B. burjaeticus, B. florilegus and B. cryptarum based on mitochondrial DNA markers: a complex of closely related taxa with circumpolar distribution. Beiträge zur Entomologie 60: 13-32. https://doi.org/10.21248/contrib.entomol.60.1.13-32

Bingham C.T. 1897. The Fauna of British India, including Ceylon and Burma. Hymenoptera. Vol. I. Wasps and Bees. Taylor \& Francis, London.

Bird M.I., Taylor D. \& Hunt C. 2005. Palaeoenvironments of insular Southeast Asia during the Last Glacial Period: a savanna corridor in Sundaland? Quaternary Science Reviews 24: 2228-2242.

https://doi.org/10.1016/j.quascirev.2005.04.004

Bischoff H. 1935. Genus BOMBUS (Apidae, Hymen.). In: Wissenschaftliche Ergebnisse der niederländischen Expedition in den Karakorum und die angrenzenden Gebiete in den Jahren 1922, 1925 und 1929/30: 255-256. C. Visser \& J. Visser-Hooft, Leipzig.

Bischoff H. 1936. Schwedisch-chinesische wissenschaftliche Expedition nach den nordwestlichen Provinzen Chinas, unter Leitung von Dr. Sven Hedin und Prof. Sü Ping-chang. Insekten gesammelt vom schwedischen Arzt der Expedition Dr. David Hummel 1927-1930. 56. Hymenoptera. 10. Bombinae. Arkiv för zoologi 27A: 1-27. 
Bolton B. 2007. How to conduct large-scale taxonomic revisions in Formicidae. In: Snelling R.R., Fisher B.L. \& Ward P.S. (eds) Advances in Ant Systematics (Hymenoptera: Formicidae): Homage to E.O. Wilson - 50 Years of Contributions. Memoirs of the American Entomological Institute 80: 52-71.

Brasero N., Lecocq T., Martinet B., Valterova I., Urbanova K., De Jonghe R. \& Rasmont P. 2017. Variability in sexual pheromones questions their role in bumblebee pre-mating recognition system. Journal of Chemical Ecology 44: 9-17. https://doi.org/10.1007/s10886-017-0910-4

Cameron S.A., Derr J.N., Austin A.D., Wooley J.B. \& Wharton R.A. 1992. The application of nucleotide sequence data to phylogeny of the Hymenoptera: a review. Journal of Hymenoptera Research 1: 63-79.

Cameron S.A., Hines H.M. \& Williams P.H. 2007. A comprehensive phylogeny of the bumble bees (Bombus). Biological Journal of the Linnean Society 91: 161-188.

https://doi.org/10.1111/j.1095-8312.2007.00784.x

Campillo L.C., Barley A.J. \& Thomson R.C. 2020. Model-based species delimitation: are coalescent species reproductively isolated? Systematic Biology 69: 708-721. https://doi.org/10.1093/sysbio/syz072

Cardoso A., Serrano A. \& Vogler A.P. 2009. Morphological and molecular variation in tiger beetles of the Cicindela hybrida complex: is an 'integrative taxonomy' possible? Molecular Ecology 18: 648-664. https://doi.org/10.1111/j.1365-294X.2008.04048.x

Carstens B.C., Pelletier T.A., Reid N.M. \& Satler J.D. 2013. How to fail at species delimitation. Molecular Ecology 22: 4369-4383. https://doi.org/10.1111/mec.12413

Chesser R.T. \& Zink R.M. 1994. Modes of speciation in birds: a test of Lynch's method. Evolution 48: 490-497. https://doi.org/10.1111/j.1558-5646.1994.tb01326.x

Chiu S.C. 1948. Revisional notes on the Formosan bombid-fauna (Hymenoptera). Notes d'entomologie chinoise 12: 57-81.

Cockerell T.D.A. 1906. Descriptions and records of bees. - XII. Annals and Magazine of Natural History Series 7 18: 69-75. https://doi.org/10.1080/00222930608562581

Cockerell T.D.A. 1931. Bees obtained by Professor Claude R. Kellog in the Foochow district, China, with new records of Philippine Bombidae. American Museum Novitates 480: 1-7. Available from http://hdl.handle.net/2246/3030 [accessed 14 Aug. 2020].

Cracraft J. 1989. Speciation and its ontology: the empirical consequences of alternative species concepts for understanding patterns and processes of differentiation. In: Otte D. \& Endler J.A. (eds) Speciation and its Consequences: 28-59. Sinauer Associates, Sunderland.

Cresson E.T. 1863. List of the North American species of Bombus and Apathus. Proceedings of the Entomological Society of Philadelphia 2: 83-116.

Darwin C. 1859. On the Origin of Species by Means of Natural Selection, or the Preservation of Favoured Races in the Struggle for Life. John Murray, London. https://doi.org/10.5962/bhl.title.68064

Day M.C. 1979. The species of Hymenoptera described by Linnaeus in the genera Sphex, Chrysis, Vespa, Apis and Mutilla. Biological Journal of the Linnean Society 12: 45-84.

https://doi.org/10.1111/j.1095-8312.1979.tb00049.x

De Meulemeester T. 2012. Approche intégrative dans la systématique de taxons complexes: bourdons et abeilles fossiles. $\mathrm{PhD}$ thesis, Université de Mons, France.

de Queiroz K. 2007. Species concepts and species delimitation. Systematic Biology 56: 879-886.

https://doi.org/10.1080/10635150701701083 
Dehon M., Engel M.S., Gerard M., Atytekin A.M., Ghisbain G., Williams P.H., Rasmont P. \& Michez D. 2019. Morphometric analysis of fossil bumble bees (Hymenoptera, Apidae, Bombini) reveals their taxonomic affinities. Zookeys 891: 71-118. https://doi.org/10.3897/zookeys.891.36027

Dellicour S. \& Flot J.-F. 2015. Delimiting species-poor data sets using single molecular markers: a case study of barcode gaps, haplowebs and GMYC. Systematic Biology 64 (6): 900-908.

https://doi.org/10.1093/sysbio/syu130

Dias B.S.F., Raw A. \& Imperatri-Fonseca V.L. 1999. International Pollinators Initiative: the São Paulo Declaration on Pollinators. Report on the Recommendations of the Workshop on the Conservation and Sustainable Use of Pollinators in Agriculture with Emphasis on Bees. Brazilian Ministry of the Environment, Brasília. Available from https://www.pollinator.org/international [accessed 3 Sep. 2020].

Dillon R.T. 1984. Geographic distance, environmental difference, and divergence between isolated populations. Systematic Zoology 33: 69-82. https://doi.org/10.1093/sysbio/33.1.69

Dowton M. \& Austin A.D. 1994. Molecular phylogeny of the insect order Hymenoptera: apocritan relationships. Proceedings of the National Academy of Sciences of the United States of America 91: 9911-9915. https://doi.org/10.1073/pnas.91.21.9911

Dray S. \& Dufour A.-B. 2007. The ade4 package: implementing the duality diagram for ecologists. Journal of Statistical Software 22: 1-20. https://doi.org/10.18637/jss.v022.i04

Drummond A.J. \& Bouckaert R.R. 2015. Bayesian Evolutionary Analysis with BEAST. Cambridge University Press, Cambridge, UK. https://doi.org/10.1017/CBO9781139095112

Drummond A.J. \& Rambaut A. 2007. BEAST: Bayesian evolutionary analysis by sampling trees. BioMed Central Evolutionary Biology 7: 214. https://doi.org/10.1186/1471-2148-7-214

Drummond A.J., Rambaut A. \& Bouckaert R.R. 2013. Divergence dating tutorial with BEAST 2.0. https://doi.org/10.1371/journal.pcbi.1003537.s004

Duennes M.A., Petranek C., Díez de Bonilla E.P., Mérida-Rivas J., Martinez-López O., Sagot P., Vandame R. \& Cameron S.A. 2017. Population genetics and geometric morphometrics of the Bombus ephippiatus species complex with implications for its use as a commercial pollinator. Conservation Genetics 18: 553-572. https://doi.org/10.1007/s10592-016-0903-9

Esmaili M. \& Rastegar R. 1974. Identified species of aculeate Hymenoptera of Iran. Journal of the Entomological Society of Iran 2: 43-44 + [41-52].

Fabricius J.C. 1776. Genera Insectorum eorumque characteres naturales secundum numerum, figuram, situm et proportionem omnium partium oris adiecta mantissa specierum nuper detectarum. Bartsch, Kiel [Chilonii]. https://doi.org/10.5962/bhl.title.119827

Fourcroy A.F.d. 1785. Entomologia Parisiensis; sive Catalogus Insectorum quce in agro Parisiensi reperiuntur; secundum methodum Geoffrceanam in sectiones, genera \& species distributus: cui addita sunt nomina trivialia \& fere trecentce novee species. Paris. https://doi.org/10.5962/bhl.title.36528

Friese H. 1905. Neue oder wenig bekannte Hummeln des russischen Reiches (Hymenoptera). Ezhegodnik Zoologicheskago muzeya 9: 507-523.

Friese H. 1910. Neue Bienenarten aus Japan. Verhandlungen der Zoologisch-Botanischen Gesellschaft in Wien 60: 404-410.

Friese H. 1913. Über einige neue Apiden (Hym.). Archiv für Naturgeschichte 78: 85-89.

Friese H. 1914. Die Bienenfauna von Java. Tijdschrift voor Entomologie 57: 1-13.

Friese H. 1916. Über einige neue Hummelformen. Bombus 1916: 107-110. 
Friese H. 1918. Wissenschaftlishe Ergebnisse einer Forschungsreise nach Ostindien, ausgeführt im Auftrage der Kgl. Preuss. Akademie der Wissenschaften zu Berlin von Herrn Prof. Dr. v. Buttel-Reepen. VII. Bienen aus Sumatra, Java, Malakka und Ceylon. Gesammelt von Herrn Prof. Dr. Buttel-Reepen in den Jahren 1911-1912. Zoologische Jahrbücher, Abteilung für Systematik, Geographie und Biologie der Tiere 41: 489-520.

Frison T.H. 1923. Systematic and biological notes on bumblebees (Bremidae; Hymenoptera). Transactions of the American Entomological Society 48: 307-326.

Available from https://www.jstor.org/stable/25077076 [accessed 14 Aug. 2020].

Frison T.H. 1930. The bumblebees of Java, Sumatra and Borneo (Bremidae: Hymenoptera). Treubia 12: $1-22$.

Frison T.H. 1933. Records and descriptions of Bremus and Psithyrus from India (Bremidae: Hymenoptera). Record of the Indian Museum 35: 331-342.

Frison T.H. 1934. Records and descriptions of Bremus and Psithyrus from Formosa and the asiatic mainland. Transactions of the Natural History Society of Formosa 24: 150-185.

Fujisawa T. \& Barraclough T.G. 2013. Delimiting species using single-locus data and the Generalized Mixed Yule Coalescent approach: a revised method and evaluation on simulated data sets. Systematic Biology 62: 707-724. https://doi.org/10.1093/sysbio/syt033

Ghiselin M. 1974. A radical solution to the species problem. Systematic Zoology 23: 536-544.

https://doi.org/10.1093/sysbio/23.4.536

Goulson D. 2010. Bumblebees, Behaviour, Ecology, and Conservation, $2^{\text {nd }}$ Ed. Oxford University Press, Oxford.

Gribodo G. 1892. Contribuzioni imenotterologiche. Sopra alcune specie nuove o poco conosciute di imenotteri antofili (generi Ctenoplectra, Xylocopa, Centris, Psithyrus, Trigona, e Bombus). Bolletino della Società Entomologica Italiana 23: 102-119.

Handlirsch A. 1888. Die Hummelsammlung des k. k. naturhistorischen Hofmuseums. Annalen des Naturhistorischen Museums in Wien 3: 209-250.

Available from https://www.jstor.org/stable/41767613 [accessed 14 Aug. 2020].

Handlirsch A. 1891. Hummelstudien. Annalen des Naturhistorischen Museums in Wien 6: 446-454. Available from https://www.jstor.org/stable/41767691 [accessed 14 Aug. 2020].

Harris M. 1776. An Exposition of English Insects, with Curious Observations and Remarks, wherein each Insect is particularly described; its Parts and Properties considered; the different Sexes distinguished, and the natural History faithfully related. London. https://doi.org/10.5962/bhl.title.122956

Hasegawa M., Kishino H. \& Yano T. 1985. Dating of the human-ape splitting by a molecular clock of mitochondrial DNA. Journal of Molecular Evolution 22: 160-174. https://doi.org/10.1007/BF02101694

Hebert P.D.N., Penton E.H., Burns J.M., Janzen D.H. \& Hallwachs W. 2004. Ten species in one: DNA barcoding reveals cryptic species in the neotropical skipper butterfly Astraptes fulgerator. Proceedings of the National Academy of Sciences of the United States of America 101: 14812-14817.

https://doi.org/10.1073/pnas.0406166101

Hines H.M. 2008. Historical biogeography, divergence times, and diversification patterns of bumble bees (Hymenoptera: Apidae: Bombus). Systematic Biology 57: 58-75.

https://doi.org/10.1080/10635150801898912 
Hines H.M. \& Williams P.H. 2012. Mimetic colour pattern evolution in the highly polymorphic Bombus trifasciatus (Hymenoptera: Apidae) species complex and its comimics. Zoological Journal of the Linnean Society 166: 805-826. https://doi.org/10.1111/j.1096-3642.2012.00861.x

Hoffer E. 1889. Die Schmarotzerhummeln Steiermarks. Lebensgeschichte und Beschreibung derselben. Mitteilungen des Naturwissenschaftlichen Vereins für Steiermark 25: 82-158.

Hull D.L. 1980. Individuality and selection. Annual Review of Ecology and Systematics 11: 311-332. https://doi.org/10.1146/annurev.es.11.110180.001523

Hyde K.D. \& Zhang Y. 2008. Epitypification: should we epitypify? Journal of Zhejiang University SCIENCE B 9: 842-846. https://doi.org/10.1631/jzus.B0860004

ICZN 1999. International Code of Zoological Nomenclature $4^{\text {th }}$ Ed.. International Commission on Zoological Nomenclature, London. Available from

https://www.iczn.org/the-code/the-international-code-of-zoological-nomenclature/the-code-online/ [accessed 14 Aug. 2020].

Ito M., Matsumura T. \& Sakagami S.F. 1984. Anest of the Himalayan bumblebee Bombus (Festivobombus) festivus. Kontyu 52: 537-539.

Jackson J.M., Pimsler M.L., Oyen K.J., Koch-Uhuad J.B., Herndon J.D., Strange J.P., Dillon M.E. \& Lozier J.D. 2018. Distance, elevation and environment as drivers of diversity and divergence in bumble bees across latitude and altitude. Molecular Ecology 27: 2926-2942. https://doi.org/10.1111/mec.14735

Kapli P., Lutteropp S., Zhang J., Kobert K., Pavlidis P., Stamatakis A. \& Flouri T. 2017. Multi-rate Poisson tree processes for single-locus species delimitation under maximum likelihood and Markov chain Monte Carlo. Bioinformatics 33: 1630-1638. https://doi.org/10.1093/bioinformatics/btx025

Kato M., Salmah S. \& Nagamitsu T. 1992. Colony cycle and foraging activity of a tropical-montane bumblebee, Bombus rufipes (Hymenoptera, Apidae) in Southeast Asia. Japanese Journal of Entomology 60: 765-776.

Kjellsson G., Rasmussen F.N. \& Dupuy D. 1985. Pollination of Dendrobium infundibulum, Cymbidium insigne (Orchidaceae) and Rhododendron lyi (Ericaceae) by Bombus eximius (Apidae) in Thailand: a possible case of floral mimicry. Journal of Tropical Ecology 1: 289-302.

https://doi.org/10.1017/S0266467400000389

Klug F. 1807. Species apiariarum familiae novas, descripsit, generumque characteres adjecit. Magazin der Gesellschaft Naturforschender Freunde zu Berlin 1: 263-265.

Knechtel W.K. 1963. Bombine din imprejurimile Lacului Petea (reg. Crisana). Communicarile Academiei Republicii Populare Romine 13: 711-715.

Knowles L.L. \& Carstens B.C. 2007. Delimiting species without monophyletic gene trees. Systematic Biology 56: 887-895. https://doi.org/10.1080/10635150701701091

Kriechbaumer J. 1873. Bemerkungen über einige Hummelarten. Stettiner entomologische Zeitung 34: 335-339.

Kuhlmann M. 2002. Neue Arten der Bienengattung Colletes Latr. aus Südtibet mit Beschreibung der Route der "Deutschen Tibet Expedition Ernst Schäfer 1938/9" (Hymenoptera: Apidae: Colletinae). Linzer biologische Beiträge 34: 1155-1178.

Lamm K.S. \& Redelings B.D. 2009. Reconstructing ancestral ranges in historical biogeography: properties and prospects. Journal of Systematics and Evolution 47: 369-382.

https://doi.org/10.1111/j.1759-6831.2009.00042.x 
Lecocq T., Dellicour S., Michez D., Lhomme P., Vanderplanck M., Valterova I., Rasplus J.-Y. \& Rasmont P. 2013. Scent of a break-up: phylogeography and reproductive trait divergences in the redtailed bumblebee (Bombus lapidarius). BMC Evolutionary Biology 13: 263.

https://doi.org/10.1186/1471-2148-13-263

Lecocq T., Brasero N., DeMeulemeester T., Michez D., Dellicour S., Lhomme P., de Jonghe R., Valterova I., Urbanova K. \& Rasmont P. 2014. An integrative taxonomic approach to assess the status of Corsican bumblebees: implications for conservation. Animal Conservation 18: 236-248.

https://doi.org/10.1111/acv.12164

Lecocq T., Dellicour S., Michez D., Dehon M., Dewulf A., De Meulemeester T., Brasero N., Valterova I., Rasplus J.-Y. \& Rasmont P. 2015. Methods for species delimitation in bumblebees (Hymenoptera, Apidae, Bombus): towards an integrative approach. Zoologica Scripta 44: 281-297.

https://doi.org/10.1111/zsc.12107

Lecocq T., Biella P., Martinet B. \& Rasmont P. 2019. Too strict or too loose? Integrative taxonomic assessment of Bombus lapidarius complex (Hymenoptera: Apidae). Zoologica Scripta 49: 187-196. https://doi.org/10.1111/zsc. 12402

Leliaert F., Verbruggen H., Vanormelingen P., Steen F., Lopez-Bautista J.M., Zuccarello G.C. \& de Clerck O. 2014. DNA-based species delimitation in algae. European Journal of Phycology 49: 179196. https://doi.org/10.1080/09670262.2014.904524

Lepeletier de Saint-Fargeau A.L.M. [1835] 1836. Histoire naturelle des Insectes. Hyménoptères. Vol. 1. Librairie Enciclopédique de Roret, Paris. https://doi.org/10.5962/bhl.title.9005

Linnaeus C. 1758. Systema Naturae per Regna Tria Naturae, Secundum Classes, Ordines, Genera, Species, cum Characteribus, Differentiis, Synonymis, Locis, Editio Decima, Reformata. Laurentii Salvii, Stockholm [Holmiae]. https://doi.org/10.5962/bhl.title.542

Lohse K. 2009. Can mtDNA barcodes be used to delimit species? A response to Pons et al. (2006). Systematic Biology 58: 439-442. https://doi.org/10.1093/sysbio/syp039

Maddison W.P. \& Knowles L.L. 2006. Inferring phylogeny despite incomplete lineage sorting. Systematic Biology 55: 21-30. https://doi.org/10.1080/10635150500354928

Mallet J. 2013. Species, concepts of. In: Encyclopedia of Biodiversity, $2^{\text {nd }}$ Ed: 679-691. Elsevier. https://doi.org/10.1016/B978-0-12-384719-5.00131-3

Mantel N. 1967. The detection of disease clustering and a generalized regression approach. Cancer Research 27: 209-220.

Mardulyn P. \& Cameron S.A. 1999. The major opsin in bees (Insecta: Hymenoptera): a promising nuclear gene for higher level phylogenetics. Molecular Phylogenetics and Evolution 12: 168-176.

https://doi.org/10.1006/mpev.1998.0606

Martinet B., Brasero N., Lecocq T., Biella P., Valterova I., Michez D. \& Rasmont P. 2018a. Adding attractive semio-chemical trait refines the taxonomy of Alpinobombus (Hymenoptera: Apidae). Apidologie 49: 838-851. https://doi.org/10.1007/s13592-018-0611-1

Martinet B., Lecocq T., Brasero N., Biella P., Urbanova K., Valterova I., Cornalba M., Gjershaug J.O., Michez D. \& Rasmont P. 2018b. Following the cold: geographical differentiation between interglacial refugia and speciation in the arcto-alpine species complex Bombus monticola (Hymenoptera: Apidae). Systematic Entomology 43: 200-217. https://doi.org/10.1111/syen.12268

Mason N.A., Fletcher N.K., Gill B.A., Funk W.C. \& Zamudio K.R. 2020. Coalescent-based species delimitation is sensitive to geographic sampling and isolation by distance. Systematics and Biodiversity 18: 269-280. https://doi.org/10.1080/14772000.2020.1730475 
Matzke N.J. 2013. Probabilistic historical biogeography: new models for founder-event speciation, imperfect detection, and fossils allow improved accuracy and model-testing. Frontiers of Biogeography 5: 242-248. https://doi.org/10.21425/F55419694

Mayr E. 1963. Animal Speciation and Evolution. Harvard University Press, Cambridge, MA.

Meier R., Shiyang K., Vaidya G. \& Ng P.K.L. 2006. DNA barcoding and taxonomy in Diptera: a tale of of high intraspecific variability and low identification success. Systematic Biology 55: 715-728.

https://doi.org/10.1080/10635150600969864

Meyer C.P. \& Paulay G. 2005. DNA barcoding: error rates based on comprehensive sampling. PLoS Biology 3: e422. https://doi.org/10.1371/journal.pbio.0030422

Michener C.D. 2000. The Bees of the World. $1^{\text {st }}$ Ed. John Hopkins University Press, Baltimore.

Michener C.D. \& Amir M. 1977. The seasonal cycle and habitat of a tropical bumble bee. Pacific Insects 17: $237-240$.

Monaghan M.T., Balke M., Gregory T.R. \& Vogler A.P. 2005. DNA-based species delineation in tropical beetles using mitochondrial and nuclear markers. Philosophical Transactions of the Royal Society B 360: 1925-1933. https://doi.org/10.1098/rstb.2005.1724

Monaghan M.T., Wild R., Elliot M., Fujisawa T., Balke M., Inward D.J.G., Lees D.C., Ranaivosolo R., Eggleton P., Barraclough T.G. \& Vogler A.P. 2009. Accelerated species inventory on Madagascar using coalescent-based models of species delineation. Systematic Biology 58: 298-311.

https://doi.org/10.1093/sysbio/syp027

Morawitz F.F. 1880. Ein Beitrag zur Bienen-Fauna mittel-Asiens. Izvêstiya Imperatorskoi akademii nauk 26: 337-379.

Morawitz F.F. 1881. Die russischen Bombus-Arten in der Sammlung der Kaiserlichen Akademie der Wissenschaften. Izvêstiya Imperatorskoi akademii nauk 27: 213-265.

Morawitz F.F. 1887. Insecta in itinere cl. N. Przewalskii in Asia centrali novissime lecta. I. Apidae. Trudy Russkago éntomologicheskago obshchestva 20 (1886): 195-229.

Morawitz F.F. 1890. Insecta a cl. G. N. Potanin in China et in Mongolia novissime lecta. XIV. Hymenoptera Aculeata. II). III. Apidae. Trudy Russkago éntomologicheskago obshchestva 24: 349-385.

Neumayer J. \& Paulus H.F. 1999. Ökologie alpiner Hummelgemeinscahften: Blütenbesuch, Ressourcenaufteilung und Energiehaushalt. Untersuchungen in den Ostalpen Österreichs. Stapfia 67: $5-246$.

Niu Z.-Q., Yuan F. \& Zhu C.-D. 2018. Species Catalogue of China. Volume 2 Animals. Insecta (IV). Apoidea (Apidae, Melittidae, Halictidae). Science Press, Beijing.

Özbek H. 1990. A new bumblebee species of Pyrobombus Dalla Torre (Hymenoptera, Apidae, Bombinae) in eastern Anatolia, Turkey. Türkiye entomoloji dergisi 14: 207-214.

Padial J.M., Miralles A., De La Riva I. \& Vences M. 2010. The integrative future of taxonomy. Frontiers in Zoology 7: 16. https://doi.org/10.1186/1742-9994-7-16

Panzer G.W.F. 1805. Faunae Insectorum Germanicae initia oder Deutschlands Insecten gesammelt und herausgegeben. Nürnberg. https://doi.org/10.5962/bhl.title.15007

Papadopoulou A., Bergsten J., Fujisawa T., Monaghan M.T., Barraclough T.G. \& Vogler A.P. 2008. Speciation and DNA barcodes: testing the effects of dispersal on the formation of discrete sequence clusters. Philosophical Transactions of the Royal Society B 363: 2987-2996.

https://doi.org/10.1098/rstb.2008.0066 
Papadopoulou A., Monaghan M.T., Barraclough T.G. \& Vogler A.P. 2009. Sampling error does not invalidate the Yule-coalescent model for species delimitation. A response to Lohse (2009). Systematic Biology 58: 442-444. https://doi.org/10.1093/sysbio/syp038

Paterson H.E.H. 1985. The recognition concept of species. In: Vrba E.S. (ed.) Species and Speciation: 21-29. Pretoria.

Pendlebury H.M. 1923. Four new species of Bombus from the Malay Peninsula. Journal of the Federated Malay States Museums 11: 64-67.

Pérez J. 1890. Catalogue des mellifères du sud-ouest. Actes de la Société linnéenne de Bordeaux 44: $133-200$.

Phillips J.D., Gillis D.J. \& Hanner R.H. 2018. Incomplete estimates of genetic diversity within species: implications for DNA barcoding. Ecology and Evolution 9: 2996-3010.

https://doi.org/10.1002/ece3.4757

Pittioni B. 1939a. Neue und wenig bekannte Hummeln der Paläarktis (Hymenopt., Apidae). Konowia 17: 244-263.

Pittioni B. 1939b. Tanguticobombus subg. nov. (Hymenopt., Apidae). Zoologischer Anzeiger 126: 201205.

Pons J., Barraclough T.G., Gomez-Zurita J., Cardoso A., Duran D.P., Hazell S., Kamoun S., Sumlin W.D. \& Vogler A.P. 2006. Sequence-based species delimitation for the DNA taxonomy of undescribed insects. Systematic Biology 55: 595-609. https://doi.org/10.1080/10635150600852011

Potapov G.S., Kondakov A.V., Spitsyn V.M., Filippov B.Y., Kolosova Y.S., Zubril N.A. \& Bolotov I.N. 2017. An integrative taxonomic approach confirms the valid status of Bombus glacialis, an endemic bumblebee species of the High Arctic. Polar Biology 41: 629-642.

https://doi.org/10.1007/s00300-017-2224-y

Potapov G.S., Kondakov A.V., Filippov B.Y., Gofarov M.Y., Kolosova Y.S., Spitsyn V.M., Tomilova A.A., Zubril N.A. \& Bolotov I.N. 2019. Pollinators on the polar edge of the Ecumene: taxonomy, phylogeography, and ecology of bumble bees from Novaya Zemlya. Zookeys 866: 85-115. https://doi.org/10.3897/zookeys.866.35084

Radoszkowski O. 1860. Sur quelques hyménoptères nouveaux ou peu connus de la collection du Musée de l'Académie des sciences de St. Pétersbourg. Byulleten' Moskovskogo obshchestva ispytatelei prirody 32 (1859): 479-486.

Radoszkowski O. 1877. Séance du 3 (15) Mai 1876 [Preliminary diagnoses of two new species of Bombus]. Trudy Russkago éntomologicheskago obshchestva 13: vii-viii.

Radoszkowski O. 1883. Sur quelques espèces Russes appartenant au genre Bombus. Byulleten' Moskovskogo obshchestva ispytatelei prirody 58: 168-226.

Radoszkowski O. 1884. Révision des armures copulatrices des mâles du genre Bombus. Byulletin' Moskovskogo obshchestva ispytatelei prirody 59: 51-92.

Rasmont P. 1983. Catalogue commenté des bourdons de la région ouest-paléarctique (Hymenoptera, Apoidea, Apidae). Notes fauniques de Gembloux 7: 1-71.

Rasmont P. 1984. Les bourdons du genre Bombus Latreille sensu stricto en Europe occidentale et centrale (Hymenoptera, Apidae). Spixiana 7: 135-160.

Rasmont P. 1988. Monographie écologique et zoogéographique des bourdons de France et de Belgique (Hymenoptera, Apidae, Bombinae). PhD Thesis, Faculté des Sciences agronomiques de l'Etat, Gembloux. 
Rasmont P. \& Flagothier D. 1996. Biogéographie et choix floraux des bourdons (Hymenoptera, Apidae) de la Turquie. Rapport preliminaire 1995-1996. In: NATO-OTAN TU-Pollination Project. Université de Mons-Hainaut, Mons, Belgium.

Ratnasingham S. \& Hebert P.D.N. 2013. A DNA-based registry for all animal species: the barcode index number (BIN) system. PLoS ONE 8: e66213. https://doi.org/10.1371/journal.pone.0066213

Rayfield D. 1976. The Dream of Lhasa. The Life of Nikolay Przhevalsky (1839-88), Explorer of Central Asia. Elek Books, London.

Ree R.H. \& Sanmartín I. 2009. Prospects and challenges for parametric models in historical biogeographical inference. Journal of Biogeography 36: 1211-1220.

https://doi.org/10.1111/j.1365-2699.2008.02068.x

Ree R.H. \& Smith S.A. 2008. Maximum likelihood inference of geographic range evolution by dispersal, local extinction, and cladogenesis. Systematic Biology 57: 4-14.

https://doi.org/10.1080/10635150701883881

Reid N.M. \& Carstens B.C. 2012. Phylogenetic estimation error can decrease the accuracy of species delimitation: a Bayesian implementation of the general mixed Yule-coalescent model. BMC Evolutionary Biology 12: 196. https://doi.org/10.1186/1471-2148-12-196

Reinig W.F. 1930. Untersuchungen zur Kenntnis der Hummelfauna des Pamir-Hochlandes. Zoologische Ergebnisse der deutsch-russischen Alai-Pamir-Expedition der Notgemeinschaft der Deutschen Wissenschaft und der Akademie der Wissenschaften der U.d.S.S.R. Zeitschrift für Morphologie und Ökologie der Tiere 17: 68-123.

Reinig W.F. 1935. On the variation of Bombus lapidarius L. and its cuckoo, Psithyrus rupestris Fabr., with notes on mimetic similarity. Journal of Genetics 30: 321-356. https://doi.org/10.1007/BF02982243

Reinig W.F. 1936. Beiträge zur Kenntnis der Hummelfauna von Mandschukuo (Hym. Apid.). Mitteilungen der Deutschen entomologischen Gesellschaft 7: 2-10.

Reinig W.F. 1939. Die Evolutionsmechanismen, erläutert an den Hummeln. Verhandlungen der Deutschen zoologischen Gesellschaft (Supplement) 12: 170-206.

Richards O.W. 1928a. Bombus and Volucella in the Himalayas. Entomologist's Monthly Magazine 64: 107-108.

Richards O.W. 1928b. On a collection of humble-bees (Hymenoptera, Bombidae) made in Ladakh by Col. R. Meinertzhagen. Annals and Magazine of Natural History Series 10 2: 333-336.

https://doi.org/10.1080/00222932808672888

Richards O.W. 1930. The humble-bees captured on the expeditions to Mt. Everest (Hymenoptera, Bombidae). Annals and Magazine of Natural History Series 10 5: 633-658.

https://doi.org/10.1080/00222933008673177

Richards O.W. 1934. Some new species and varieties of oriental humble-bees (Hym. Bombidae). Stylops 3: 87-90. https://doi.org/10.1111/j.1365-3113.1934.tb01552.x

Richards O.W. 1968. The subgeneric divisions of the genus Bombus Latreille (Hymenoptera: Apidae). Bulletin of the British Museum (Natural History) (Entomology) 22: 209-276. https://doi.org/10.5962/bhl.part.9953

Ronquist F. 1996. DIVA 1.1 User's Manual. Computer program and manual available by anonymous FTP from Uppsala University. Available from ftp.uu.se or ftp.systbot.uu.se [accessed 7 Sep. 2020].

Ronquist F. \& Huelsenbeck J.P. 2003. MrBayes 3: Bayesian phylogenetic inference under mixed models. Bioinformatics 19: 1572-1574. https://doi.org/10.1093/bioinformatics/btg180 
Saini M.S., Raina R.H. \& Ghator H.S. 2015. Indian Bumblebees. B. Singh and M. P. Singh, Dehra Dun, India.

Sandhouse G.A. 1943. The type species of the genera and subgenera of bees. Proceedings of the United States National Museum 92: 519-619. https://doi.org/10.5479/si.00963801.3156.519

Schlick-Steiner B.C., Steiner F.M., Seifert B., Stauffer C., Christian E. \& Crozier R.H. 2010. Integrative taxonomy: a multisource approach to exploring biodiversity. Annual Review of Entomology 55: 421438. https://doi.org/10.1146/annurev-ento-112408-085432

Schluter D. \& Pennell M.W. 2017. Speciation gradients and the distribution of biodiversity. Nature 546: 48-55. https://doi.org/10.1038/nature22897

Schmidt B.C. \& Sperling F.A.H. 2008. Widespread decoupling of mtDNA variation and species integrity in Grammia tiger moths (Lepidoptera: Noctuidae). Systematic Entomology 33: 613-634.

https://doi.org/10.1111/j.1365-3113.2008.00433.x

Schmidt S., Schmid-Egger C., Mornière J., Haszprunar G. \& Hebert P.D.N. 2015. DNA barcoding largely supports 250 years of classical taxonomy: identifications for Central European bees (Hymenoptera, Apoidea partim). Molecular Ecology Resources 15: 985-1000. https://doi.org/10.1111/1755-0998.12363

Schmiedeknecht H.L.O. 1878. Monographie der in Thüringen vorkommenden Arten der HymenopterenGattung Bombus mit einer allgemeinen Einleitung in dieses Genus. Jenaische Zeitschrift für Naturwissenschaft 12: 303-430.

Skorikov A.S. 1910a. [New forms of bumblebees] (Hymenoptera, Bombidae). ([Preliminary diagnoses]). III. Russkoe éntomologicheskoe Obozrênie 9 (1909): 409-413. [In Russian.]

Skorikov A.S. 1910b. Revision der in der Sammlung des weil. Prof. E. A. Eversmann befindlichen Hummeln. Trudy Russkago éntomologicheskago obshchestva 39: 570-584.

Skorikov A.S. 1914a. Les formes nouvelles des bourdons (Hymenoptera, Bombidae). VI. Russkoe éntomologicheskoe Obozrênie 14: 119-129.

Skorikov A.S. 1914b. Subterraneobombus fedtschenkoi (F. Mor.), un bourdon de Turkestan peu connu (Hymenoptera, Bombidae). Russkoe éntomologicheskoe Obozrênie 14: 287-292.

Skorikov A.S. 1923. [Palaearctic bumblebees. Part I. General biology (including zoogeography)]. Izvestiya Severnoi oblastnoi stantsii zashchity rastenii ot vreditelei 4 (1922): 1-160.

Skorikov A.S. 1931. Die Hummelfauna Turkestans und ihre Beziehungen zur zentralasiatischen Fauna (Hymenoptera, Bombidae). In: Lindholm V.A. (ed.) Abhandlungen der Pamir-Expedition 1928: 175247. Academy of Sciences of the USSR, Leningrad.

Skorikov A.S. 1933a. Zur Fauna und Zoogeographie der Hummeln des Himalaya. Doklady Akademii nauk SSSR 1933: 243-248.

Skorikov A.S. 1933b. Zur Hummelfauna Japans und seiner Nachbarländer. Mushi 6: 53-65.

Smith F. 1852a. Descriptions of some hymenopterous insects from northern India. Transactions of the Entomological Society of London 7 (2): 45-48. https://doi.org/10.1111/j.1365-2311.1852.tb02209.x

Smith F. 1852b. Descriptions of some new and apparently undescribed species of hymenopterous insects from north China, collected by Robert Fortune, Esq. Transactions of the Entomological Society of London 7 (2): 33-45. https://doi.org/10.1111/j.1365-2311.1852.tb02208.x

Smith F. 1854. Catalogue of Hymenopterous Insects in the Collection of the British Museum. Part II. Apidae. Trustees of the British Museum, London. https://doi.org/10.5962/bhl.title.20858 
Smith F. 1861. Descriptions of new genera and species of exotic Hymenoptera. Journal of Entomology 1: $146-155$.

Smith F. 1870. [V. Notes on the habits of some hymenopterous insects from the North-west Provinces of India. By Charles Horne, Esq., B.C.S., F.Z.S.] With an appendix, containing descriptions of some new species of Apidae and Vespidae collected by Mr. Horne: by Frederick Smith, of the British Museum. Illustrated by plates from drawings by the author of the notes. Transactions of the Zoological Society of London 7: 161-196. https://doi.org/10.5962/bhl.title.56718

Starr C.K. 1989. Bombus folsomi and the origin of Philippine bumble bees (Hymenoptera: Apidae). Systematic Entomology 14: 411-415. https://doi.org/10.1111/j.1365-3113.1989.tb00294.x

Starr C.K. 1992. The bumble bees (Hymenoptera: Apidae) of Taiwan. Bulletin of the National Museum of Natural Science 3: 139-157.

Streinzer M., Chakravorty J., Neumayer J., Megu K., Narah J., Schmitt T., Bharti H., Spaethe J. \& Brockmann A. 2019. Species composition and elevational distribution of bumble bees (Hymenoptera: Apidae: Bombus) in the East Himalaya, Arunachal Pradesh, India. ZooKeys 851: 71-89.

https://doi.org/10.3897/zookeys.851.32956

Talavera G., Dinca V. \& Vila R. 2013. Factors affecting species delimitations with the GMYC model: insights from a butterfly survey. Methods in Ecology and Evolution 4: 1101-1110.

https://doi.org/10.1111/2041-210X.12107

Tamura K. \& Nei M. 1993. Estimation of the number of nucleotide substitutions in the control region of mitochondrial DNA in humans and chimpanzees. Molecular Biology and Evolution 10: 512-526. https://doi.org/10.1093/oxfordjournals.molbev.a040023

Tamura K., Stecher G., Peterson D., Filipski A. \& Kumar S. 2013. MEGA6: molecular evolutionary genetics analysis version 6.0. Molecular Biology and Evolution 30: 2725-2729.

https://doi.org/10.1093/molbev/mst197

Tkalců B. 1968. Neue Arten der Unterfamilie Bombinae der paläarktischen Region (Hymenoptera, Apoidea). Sborník Entomologického oddeleni Národního musea v Praze 65: 21-51.

Tkalců B. 1972. Arguments contre l'interprétation traditionelle de la phylogénie des abeilles (Hymenoptera, Apoidea). Première partie, introduction et exposés fondamentaux. Bulletin de la Société entomologique de Mulhouse 1972: 17-28.

Tkalců B. 1974a. Eine Hummel-Ausbeute aus dem Nepal-Himalaya (Insecta, Hymenoptera, Apoidea, Bombinae). Senckenbergiana biologica 55: 311-349.

Tkalců B. 1974b. Ergebnisse der 1. und 2. mongolisch-tschechoslowakischen entomologisch-botanischen Expedition in der Mongolei. Nr. 29: Hymenoptera, Apoidea, Bombinae. Sborník faunistickych prací Entomologického oddelení Národního musea v Praze 15: 25-57.

Tkalců B. 1975. Beitrag zur Kenntnis der Hummelfauna der französischen Basses-Alpes (Hymenoptera, Apoidea, Bombinae). Sborník Slovenského Narodného Muzea 20 (1974): 167-186.

Tkalců B. 1989. Neue Taxa asiatischer Hummeln (Hymenoptera, Apoidea). Acta entomologica bohemoslovaca 86: 39-60.

USBGN 1968. Official Standard Names Gazetteer, No. 13. Indonesia and Portuguese Timor. US Army Topographic Command, Washington D.C.

USBGN 1970. Official Standard Names Gazetteer, No. 10. Malaysia, Singapore, and Brunei. US Army Topographic Command, Washington D.C. 
Vieites D.R., Wollenberg K.C., Andreone F., Köhler J., Glaw F. \& Vences M. 2009. Vast underestimation of Madagascar's biodiversity evidenced by an integrative amphibian inventory. Proceedings of the National Academy of Sciences of the United States of America 106: 8267-8272. https://doi.org/10.1073/pnas.0810821106

Villers C.J.d. 1789. Caroli Linnoi Entomologia, Faunce Suecica Descriptionibus Aucta; DD. Scopoli, Geoffroy, de Geer, Fabricii, Schrank, \&c. speciebus vel in systemate non enumeratis, vel nuperrime detectis, vel speciebus Gallice australis locupletata, generum specierumque rariorum iconibus ornata; curante \& augente Carolo de Villers, Acad. Lugd. Maffil. Villa-Fr. Rhotom. necnon geometrice regio professore. Vol. 3. Piestre et Delamolliere, Lyon [Lugduni]. https://doi.org/10.5962/bhl.title.12476

Vogt O. 1909. Studien über das Artproblem. 1. Mitteilung. Über das Variieren der Hummeln. 1. Teil. Sitzungsberichte der Gesellschaft naturforschender Freunde zu Berlin 1909: 28-84.

Vogt O. 1911. Studien über das Artproblem. 2. Mitteilung. Über das Variieren der Hummeln. 2. Teil. (Schluss). Sitzungsberichte der Gesellschaft naturforschender Freunde zu Berlin 1911: 31-74.

von Dalla Torre K.W. 1890. Hymenopterologische Notizen. Wiener entomologische Zeitung 9: 139.

von Dalla Torre K.W. 1896. Catalogus Hymenopterorum hucusque Descriptorum Systematicus et Synonymicus. Volumen X: Apidae (Anthophila). G. Engelmann, Leipzig [Lipsiae].

https://doi.org/10.5962/bhl.title.10348

Wallace A.R. 1865. On the phenomena of variation and geographical distribution as illustrated by the Papilionidae of the Malayan region. Transactions of the Linnean Society of London 25: 1-71.

https://doi.org/10.5962/bhl.title.9531

Wang S.-F. 1979. Three new species of bomble [sic] bees from Tibet. Acta entomologica sinica 22: 188-191.

Wang S.-F. 1982. Hymenoptera: Apidae - Bombus. In: Qinghai-Tibet Plateau Comprehensive Scientific Investigation Team of the Chinese Academy of Sciences (ed.) Insects of Xizang: 427-447. Science Press, Beijing.

Wang S.-F. 1985. Apidae - Bombus. In: [Organisms of the Tumuefeng region of Tianshan]: 160-165.

Wang S.-F. \& Yao J. 1996. Hymenoptera: Apodae [sic] - Bombini. In: Huang F.-S. (ed.) Insects of the Karakorum-Kunlun Mountains: 303-309. Science Press, Beijing.

Wickham H. 2011. GGPLOT2. WIREs Computational Statistics 3: 180-185. https://doi.org/10.1002/wics.147

Williams P.H. 1985. A preliminary cladistic investigation of relationships among the bumble bees (Hymenoptera, Apidae). Systematic Entomology 10: 239-255.

https://doi.org/10.1111/j.1365-3113.1985.tb00529.x

Williams P.H. 1991. The bumble bees of the Kashmir Himalaya (Hymenoptera: Apidae, Bombini). Bulletin of the British Museum (Natural History) (Entomology) 60: 1-204.

Williams P.H. 1998. An annotated checklist of bumble bees with an analysis of patterns of description (Hymenoptera: Apidae, Bombini). Bulletin of The Natural History Museum (Entomology) 67: 79-152. Available and updated from www.nhm.ac.uk/bombus/ [accessed 2019].

Williams P.H. 2007. The distribution of bumblebee colour patterns world-wide: possible significance for thermoregulation, crypsis, and warning mimicry. Biological Journal of the Linnean Society 92: 97-118. https://doi.org/10.1111/j.1095-8312.2007.00878.x

Williams P.H. 2011. Bumblebees collected by the Kyushu University Expeditions to Central Asia (Hymenoptera, Apidae, genus Bombus). Esakia 50: 27-36. 
Williams P.H. 2018. In a group of its own? Rediscovery of one of the world's rarest and highest mountain bumblebees, Bombus tanguticus. Journal of Natural History 52: 305-321.

https://doi.org/10.1080/00222933.2018.1428377

Williams P.H. submitted. Discriminating true from false cryptic species - is quick also dirty? In: Systematics Association biennual Meeting, Bristol.

Williams P.H., Cameron S.A., Hines H.M., Cederberg B. \& Rasmont P. 2008. A simplified subgeneric classification of the bumblebees (genus Bombus). Apidologie 39: 46-74.

https://doi.org/10.1051/apido:2007052

Williams P.H., Tang Y., Yao J. \& Cameron S. 2009. The bumblebees of Sichuan (Hymenoptera: Apidae, Bombini). Systematics and Biodiversity 7: 101-190. https://doi.org/10.1017/S1477200008002843

Williams P.H., Ito M., Matsumura T. \& Kudo I. 2010. The bumblebees of the Nepal Himalaya (Hymenoptera: Apidae). Insecta Matsumurana 66: 115-151.

Williams P.H., An J.-D. \& Huang J.-X. 2011. The bumblebees of the subgenus Subterraneobombus: integrating evidence from morphology and DNA barcodes (Hymenoptera, Apidae, Bombus). Zoological Journal of the Linnean Society 163: 813-862. https://doi.org/10.1111/j.1096-3642.2011.00729.x

Williams P.H., Brown M.J.F., Carolan J.C., An J.-D., Goulson D., Aytekin A.M., Best L.R., Byvaltsev A.M., Cederberg B., Dawson R., Huang J.-X., Ito M., Monfared A., Raina R.H., SchmidHempel P., Sheffield C.S., Sima P. \& Xie Z.-H. 2012a. Unveiling cryptic species of the bumblebee subgenus Bombus s. str. world-wide with COI barcodes (Hymenoptera: Apidae). Systematics and Biodiversity 10: 21-56. https://doi.org/10.1080/14772000.2012.664574

Williams P.H., Byvaltsev A.M., Sheffield C.S. \& Rasmont P. 2012b. Bombus cullumanus - an extinct European bumblebee species? Apidologie 44: 121-132. https://doi.org/10.1007/s13592-012-0161-x

Williams P.H., Thorp R.W., Richardson L.L. \& Colla S.R. 2014. Bumble Bees of North America. An Identification Guide. Princeton University Press, Princeton, NJ.

Williams P.H., Bystriakova N., Huang J.-X., Miao Z.-Y. \& An J.-D. 2015a. Bumblebees, climate and glaciers across the Tibetan plateau (Apidae: Bombus Latreille). Systematics and Biodiversity 13: 164181. https://doi.org/10.1080/14772000.2014.982228

Williams P.H., Byvaltsev A.M., Cederberg B., Berezin M.V., Ødegaard F., Rasmussen C., Richardson L.L., Huang J.-X., Sheffield C.S. \& Williams S.T. 2015b. Genes suggest ancestral colour polymorphisms are shared across morphologically cryptic species in arctic bumblebees. PLoS ONE 10: 1-26.

https://doi.org/10.1371/journal.pone.0144544

Williams P.H., Huang J.-X., Rasmont P. \& An J.-D. 2016. Early-diverging bumblebees from across the roof of the world: the high-mountain subgenus Mendacibombus revised from species' gene coalescents and morphology (Hymenoptera, Apidae). Zootaxa 4204: 1-72.

https://doi.org/10.11646/zootaxa.4204.1.1

Williams P.H., Huang J.-X. \& An J.-D. 2017a. Bear wasps of the Middle Kingdom: a decade of discovering China's bumblebees. Antenna 41: 21-24. Available from http://hdl.handle.net/10141/622626 [accessed 19 Aug. 2020].

Williams P.H., Lobo J.M. \& Meseguer A.S. 2017b. Bumblebees take the high road: climatically integrative biogeography shows that escape from Tibet, not Tibetan uplift, is associated with divergences of present-day Mendacibombus. Ecography 41: 461-477. https://doi.org/10.1111/ecog.03074

Williams P.H., Berezin M.V., Cannings S.G., Cederberg B., Ødegaard F., Rasmussen C., Richardson L.L., Rykken J., Sheffield C.S., Thanoosing C. \& Byvaltsev A.M. 2019. The arctic and alpine bumblebees 
of the subgenus Alpinobombus revised from integrative assessment of species' gene coalescents and morphology (Hymenoptera, Apidae, Bombus). Zootaxa 4625: 1-68.

https://doi.org/10.11646/zootaxa.4625.1.1

Wilson E.O. \& Brown W.L. 1953. The subspecies concept and its taxonomic application. Systematic Zoology 2: 97-111. https://doi.org/10.2307/2411818

Winter K., Adams L., Thorp R.W., Inouye D.W., Day L., Ascher J. \& Buchmann S. 2006. Importation of non-native bumble bees into North America: potential consequences of using Bombus terrestris and other non-native bumble bees for greenhouse crop pollination in Canada, Mexico, and the United States. In: A White Paper of the North American Pollinator Protection Campaign (NAPCC): 33. San Francisco.

Woodard S.H., Lozier J.D., Goulson D., Williams P.H., Strange J. \& Jha S. 2015. Molecular tools and bumble bees: revealing hidden details of ecology, evolution, and behavior in a model system. Molecular Ecology 24: 2916-2936. https://doi.org/10.1111/mec.13198

Yasumatsu K. 1935. Insects of Jehol, VIII. Superfamily Apoidea (Order Hymenoptera, II). Art 67. In: Report of the First Scientific Expedition, Manchuoko, Section 5: 1-47.

Yu Y., Blair C. \& He X.-J. 2019. RASP 4: ancestral state reconstruction tool for multiple genes and characters. Molecular Biology and Evolution 37: 604-606. https://doi.org/10.1093/molbev/msz257

Zachos J.C., Pagani M., Sloan L., Thomas E. \& Billups K. 2001. Trends, rhythms, and aberrations in global climate 65 Ma to Present. Science 292: 686-693. https://doi.org/10.1126/science.1059412

Zayed A. \& Packer L. 2005. Complementary sex determination substantially increases extinction proneness of haplodiploid populations. Proceedings of the National Academy of Sciences of the United States of America 102: 10742-10746. https://doi.org/10.1073/pnas.0502271102

Zhang J.-J., Kapli P., Pavlidis P. \& Stamatakis A. 2013. A general species delimitation method with applications to phylogenetic placements. Bioinformatics 29: 2869-2876.

https://doi.org/10.1093/bioinformatics/btt499

Zink R.M. 2004. The role of subspecies in obscuring avian biological diversity and misleading conservation policy. Proceedings of the Royal Society of London B 271: 561-564.

https://doi.org/10.1098/rspb.2003.2617

Manuscript received: 31 March 2020

Manuscript accepted: 15 July 2020

Published on: 2 October 2020

Topic editor: Nesrine Akkari

Section editor: Gavin Broad

Desk editor: Pepe Fernández

Printed versions of all papers are also deposited in the libraries of the institutes that are members of the EJT consortium: Muséum national d'histoire naturelle, Paris, France; Meise Botanic Garden, Belgium; Royal Museum for Central Africa, Tervuren, Belgium; Royal Belgian Institute of Natural Sciences, Brussels, Belgium; Natural History Museum of Denmark, Copenhagen, Denmark; Naturalis Biodiversity Center, Leiden, the Netherlands; Museo Nacional de Ciencias Naturales-CSIC, Madrid, Spain; Real Jardín Botánico de Madrid CSIC, Spain; Zoological Research Museum Alexander Koenig, Bonn, Germany; National Museum, Prague, Czech Republic. 
Appendix 1. GenBank COI sequences from Lecocq et al. (2015: supplementary table s1) downloaded on 20 January 2018 and identified by searching the BOLD database (http://boldsystems.org/index.php/IDS_OpenIdEngine) and by including the sequences in a PTP analysis with the sequences from Figs 9-10. Abbreviations for subgenera: $M l=$ Melanobombus von Dalla Torre, 1880; $P r=$ Pyrobombus von Dalla Torre, 1880; Bo = Bombus s. str. Latreille, 1802; Th= Thoracobombus von Dalla Torre, 1880.

\begin{tabular}{|c|c|c|c|}
\hline Given taxon name & GenBank numbers & BOLD identification $^{1}$ & PTP identification \\
\hline Ml. alagesianus & $\begin{array}{l}\text { KC915645 } \\
\text { KM458064 }\end{array}$ & $\begin{array}{l}\text { Pr. brodmannicus } \\
\text { Pr. brodmannicus }\end{array}$ & \\
\hline Ml. caucasicus $^{2}$ & $\begin{array}{l}\text { KC915729 } \\
\text { KC915730 } \\
\text { KC915731 } \\
\text { KC915732 }\end{array}$ & $\begin{array}{l}\text { Bo. lucorum } \\
\text { Bo. patagiatus } \\
\text { Bo. lucorum } \\
\text { Bo. lucorum }\end{array}$ & \\
\hline Ml. erzurumensis & $\begin{array}{l}\text { KC915646 } \\
\text { KC915647 } \\
\text { KM458065 } \\
\text { KM458066 }\end{array}$ & $\begin{array}{l}\text { Ml. sichelii } \\
\text { Ml. sichelii } \\
\text { Ml. sichelii } \\
\text { Ml. sichelii }\end{array}$ & $\begin{array}{l}\text { Ml. incertus }{ }^{3} \\
\text { Ml. incertus }{ }^{3} \\
\text { Ml. incertus }{ }^{3} \\
\text { Ml. incertus }\end{array}$ \\
\hline Ml. incertus & KC915649 & Th. pascuorum & \\
\hline
\end{tabular}

${ }^{1}$ BOLD identifications became complicated during 2017 because these GenBank sequences were uploaded into BOLD with names from Lecocq et al. (2013). Sequence identities have been checked using BOLD identification trees for all of the $>8200$ bumblebee sequences in BOLD in January 2018. The sequence names in BOLD are expected to be corrected soon.

${ }^{2}$ GenBank BLAST of a sequence emailed by T. Lecocq for the caucasicus specimen LaC001 also returned highest matches on 18 May 2018 for B. lucorum (Linnaeus, 1761) - the top match was for sequence JQ843494.

${ }^{3}$ Identification of reference sequence material in Figs 9-10 are based on comparison with original descriptions. 
Appendix 2. Computational $\mathrm{C}$ code for approximating Great Circle distances from decimal latitude and longitude coordinates and the mean radius of the Earth of $6371 \mathrm{~km}$ for the WGS84 ellipsoid.

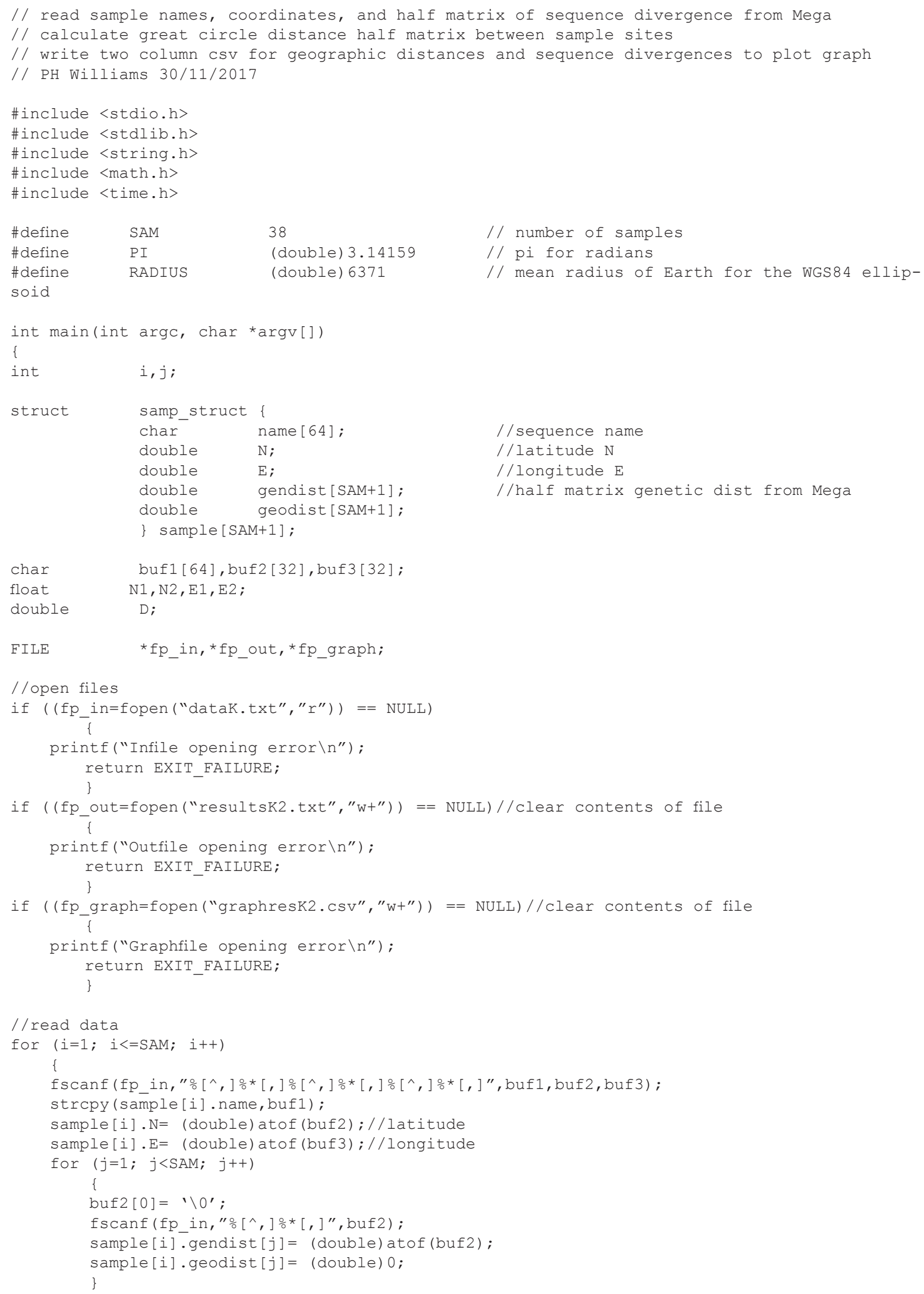




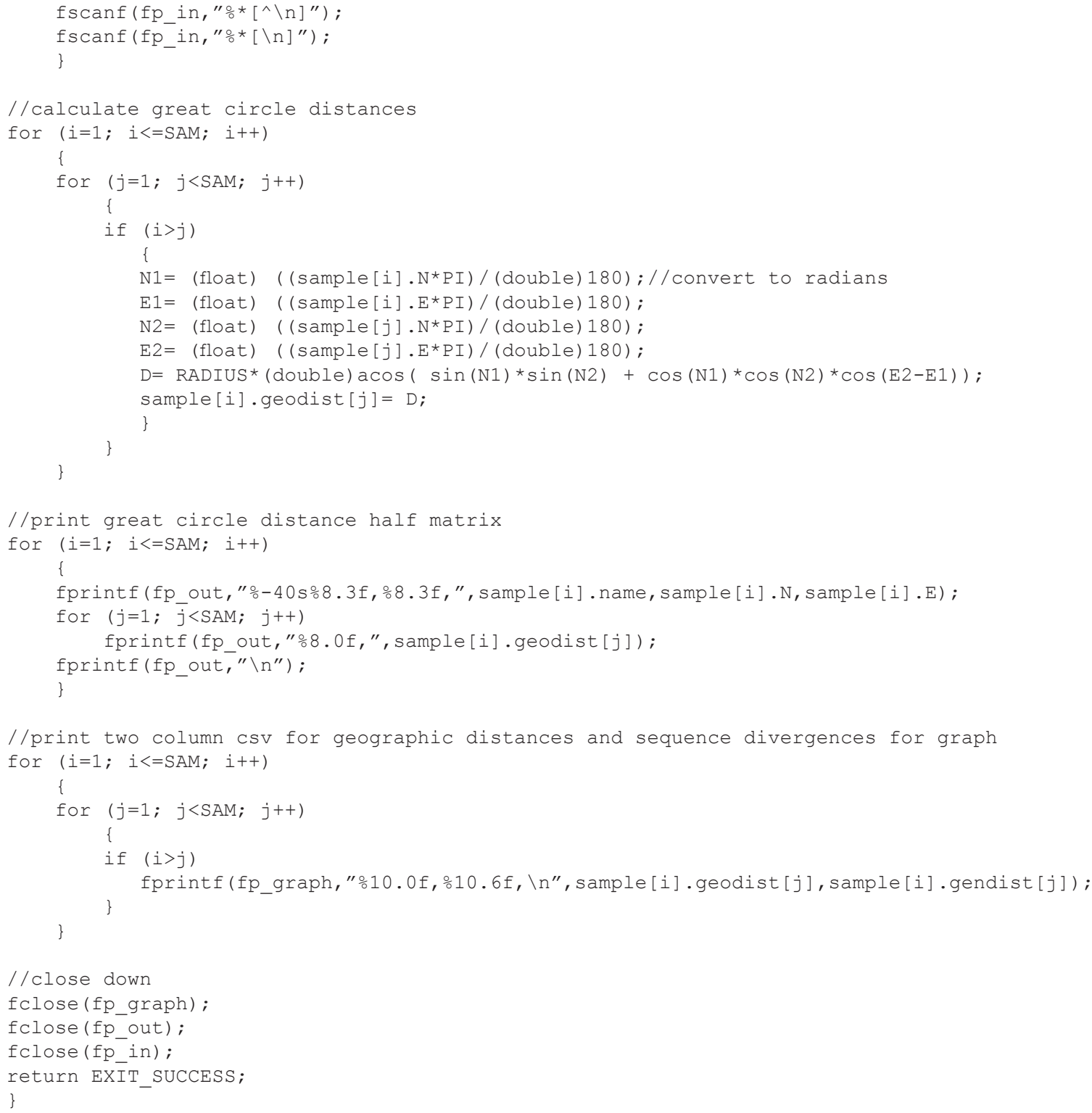

